
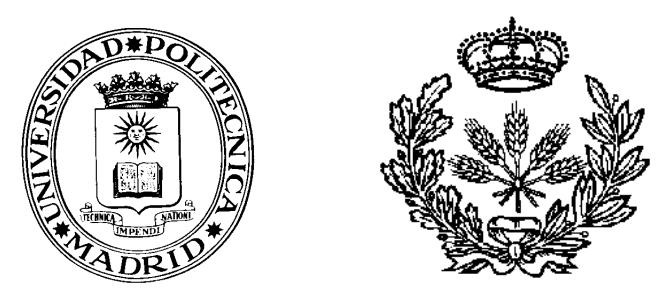

UNIVERSIDAD POLITÉCNICA DE MADRID

ESCUELA TÉCNICA SUPERIOR DE INGENIEROS AGRÓNOMOS

Departamento de Ingeniería Agroforestal

\title{
EVALUACIÓN DE LA PERTINENCIA DE MAESTRÍAS EN INGENIERÍA: APLICACIÓN EN LA UNIVERSIDAD DE PIURA, PERÚ
}

\section{TESIS DOCTORAL}

Erick Miñán Ubillús

Ingeniero Industrial

Director: José María Díaz Puente

Dr. Ingeniero Agrónomo 



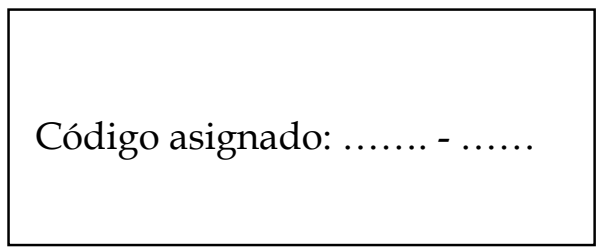

Tribunal designado por el Comité Académico y de Calidad el día... de..........de 2016

Presidente:

Secretario:

Vocal:

Suplente:

Realizado el acto de defensa y lectura de la Tesis el día... de. de $20 \ldots$ en las instalaciones de.

EL PRESIDENTE

EL VOCAL

EL SECRETARIO 

A mis padres Lidia y Reynaldo A mi esposa María Isabel y a mis hijos Victoria y Darío 

Agradecimientos 

Este trabajo ha sido posible gracias al apoyo de muchas personas. Quiero agradecer primero a Dios y a mis padres a quienes debo mi educación y mis valores. Agradecerles por haberme sacado adelante, porque sin su esfuerzo y sin su confianza nada de esto habría sido posible. Agradezco especialmente a mi esposa Isabel y a mis hijos Victoria y Darío, por apoyarme siempre, por sacrificar días y horas de estar juntos para que ahora pueda presentar este trabajo.

A mi Director de Tesis, el Dr. José María Díaz Puente, por la confianza que me brindó en todo momento, porque hizo suya mi lucha y por sus siempre acertados comentarios y sugerencias.

Al Dr. Adolfo Cazorla, catedrático de la Universidad Politécnica de Madrid y Director del Grupo de Investigación Gesplan, un profesional visionario al que admiro por su capacidad para levantar proyectos y porque ayuda a crecer profesionalmente a sus colaboradores. Agradezco su acogida, así como los comentarios y sugerencias que hizo para mejorar mi tesis. A los profesores y miembros de Gesplan: Ignacio de los Ríos, José Luis Yagüe, Pablo Vidueira, Susana Sastre, Victor Luis De Nicolás, Pablo Rodríguez, Ramón Zamorano, Rodrigo Cuenca, Esperanza Echevarría y Fernando Aparicio. Agradezco sus atenciones y su compañía para hacernos sentir como en casa.

A la Universidad de Piura, por la sólida formación que me brindó cuando fui estudiante y por el apoyo brindado ahora que soy uno de sus profesores. Quiero agradecer especialmente al Dr. Dante Guerrero y a la Dra. Susana Vegas, Decano y ex Decana de la Facultad de Ingeniería respectivamente, por su apoyo incondicional y porque siempre me alentaron a culminar con éxito este doctorado. Mi profunda gratitud a ellos y a los profesores de la facultad que siempre me apoyaron cuando tuve que ausentarme para viajar a Madrid, en especial a Hugo Fiestas y a mis compañeros de doctorado Isabel Chiyón y Martín Palma. Muchísimas gracias. 

Motivación 

Estudié Ingeniería Industrial en la Universidad de Piura (Udep). De esta formación surge en mí la convicción de que la educación de calidad y la contribución de la ingeniería son fundamentales para el desarrollo integral de mi país.

Mi experiencia profesional ha pasado por tres etapas: la primera desarrollada en el sector privado (5 años) principalmente como Jefe de Almacenes en empresas privadas importantes del Perú. La segunda desarrollada en el sector público (8 años) en la sede central del Ministerio de Educación en Lima, donde participé en proyectos financiados por el Banco Mundial referidos al fortalecimiento institucional de los órganos descentralizados del sector y la mejora de la educación rural a nivel nacional. Esta experiencia valiosa me permitió conocer la realidad diversa de las 24 regiones de mi país a lo largo de su costa, sierra y selva. Ahora soy profesor a tiempo completo en la Facultad de Ingeniería de la Udep (ya tengo 8 años) donde dicto los cursos de Dirección de Proyectos y Algebra Lineal.

Me interesé en los proyectos de desarrollo porque considero que para salir adelante hay que saber aprovechar los recursos (naturales, humanos, financieros, etc.) de manera eficaz, eficiente atendiendo necesidades reales. Actualmente Perú vive una etapa de crecimiento económico que puede quedar en la historia como la etapa que no se aprovechó para lograr el ansiado desarrollo sostenido. Es aceptado por todos que es importante mejorar la calidad de la educación. Dentro de este complejo sector, considero que la mejora de la formación postgrado en ingeniería es una de las primeras cosas que se debe atacar porque tendría mayor impacto en el corto y mediano plazo. La ingeniería y el postgrado tienen en su esencia, resolver problemas del entorno y atender las necesidades y demandas de la población para mejorar sus condiciones de vida.

Como profesor universitario de ingeniería en una universidad en un país en vías de desarrollo me interesa que la formación que brinda mi universidad sea de calidad y sea pertinente, particularmente en las maestrías. En este Doctorado he aprendido que los proyectos de desarrollo deben ser instrumentos que transformen la realidad y que en su evaluación se debe considerar siempre su impacto en el territorio. He querido aplicar la teoría de evaluación de proyectos y programas en la mejora de la educación superior, específicamente las maestrías, considerando los conceptos, características y tendencias de la educación superior en el presente siglo. 

Resumen 

La formación de postgrado en ingeniería es muy importante para mejorar la competitividad y lograr el desarrollo en los países. Para ello es necesaria una fuerte vinculación de la universidad con su entorno socio económico de modo que los objetivos que se plantea en sus programas formativos sean coherentes con las necesidades reales de los beneficiarios: los estudiantes, la universidad y la comunidad. Es decir, los programas deben ser pertinentes. Y en los países en vías de desarrollo este tema es aún más importante.

Se necesita modelos de evaluación que midan este grado de adecuación entre los objetivos de los programas con las necesidades de los estudiantes y las partes interesadas. Sin embargo, los modelos de evaluación existentes tienen principalmente fines de acreditación y están diseñados para evaluar la eficacia, es decir si los resultados obtenidos están de acuerdo con la misión y los objetivos planteados. Su objetivo no es medir la pertinencia.

Esta investigación tiene como objetivo diseñar un modelo de evaluación de la pertinencia de maestrías en ingeniería y aplicarlo a un caso concreto. Se trata de maestrías que ya están en funcionamiento y son dictadas en una universidad en un país en desarrollo. Para diseñar el modelo se define primero el concepto de pertinencia de una maestría en ingeniería haciendo una revisión bibliográfica y consultando a expertos en los temas de pertinencia de la educación superior y formación en postgrado en ingeniería. Se utiliza una definición operativa que facilita luego la identificación de factores e indicadores de evaluación. Se identifica dos tipos de pertinencia: local y global. La pertinencia global está relacionada con la inserción de la maestría en el sistema global de producción de conocimiento. La pertinencia local tiene tres dimensiones: la personal, relacionada con la satisfacción de necesidades de los estudiantes, la institucional, relacionada con las necesidades e intereses de la universidad que acoge a la maestría y la pertinencia social, ligada a la satisfacción de necesidades y demandas de la comunidad local y nacional.

El modelo diseñado es aplicado en la maestría en Ingeniería Civil con mención en Ingeniería Vial de la Universidad de Piura, Perú lo que permite obtener conclusiones para su aplicación en otras maestrías. 

Summary 

Graduate engineering education is very important to improve competitiveness and achieve development in countries. It is necessary a strong linkage between university and its socio economic environment, so that programs objectives are consistent with the real needs of the students, university and community. That is to say programs must be relevant. And in developing countries this issue is very important.

Evaluation models to measure the degree of adequacy between the programs objectives with the needs of students and stakeholders is needed. However, existing evaluation models have mainly the purpose of accreditation and are designed to evaluate the efficacy. They evaluate if the results are consistent with the mission and objectives. Their goal is not to measure the relevance.

This work aimed to design a model for evaluating the relevance of master's degrees in engineering and applied to a specific case. They must be masters already in operation and are taught at a university in a developing country. In order to build the model, first concept of relevance of a master's degree in engineering was defined. Literature was reviewed and we consulted experts on issues of relevance of higher education and graduate engineering education.

An operational definition is used to facilitate the identification of factors and evaluation indicators. Local and global: two types of relevance were identified. The global relevance is related to the inclusion of Master in the global system of knowledge production. The local relevance has three dimensions: personal, related to meeting students' needs, institutional, related to the needs and interests of university that houses the Master and social relevance, linked to the satisfaction of needs and demands of local and national community.

The designed model is applied to the Master degree in Civil Engineering with a major in Traffic Engineering of Universidad de Piura, Peru which allowed to obtain conclusions for application in other masters. 

Índices 



\section{INDICE GENERAL}

INTRODUCCIÓN

A. Preguntas de investigación 4

B. Objetivos e hipótesis de la investigación 5

C. Metodología general de la investigación 6

$\begin{array}{ll}\text { C.1. Esquema general de la investigación } & 7\end{array}$

$\begin{array}{ll}\text { D. Producción científica asociada a la tesis } & 10\end{array}$

$\begin{array}{ll}\text { E. Bibliografía del capítulo de Introducción } & 12\end{array}$

CAPÍTULO I. LA PERTINENCIA DE LAS MAESTRÍAS EN INGENIERÍA 13

1.1. LA EDUCACIÓN SUPERIOR UNIVERSITARIA Y SU VINCULACIÓN CON EL $\begin{array}{ll}\text { ENTORNO } & 16\end{array}$

1.1.1. La educación superior universitaria en el siglo XXI 16

1.1.2. La pertinencia de la educación superior universitaria 23

1.1.3. Diversos modos de vinculación de la universidad con el entorno $\quad 27$

1.2. DEFINICIÓN OPERATIVA DEL CONCEPTO DE PERTINENCIA 31

1.2.1. La formación de postgrado en ingeniería 31

1.2.2. Definición de pertinencia de una maestría en ingeniería 38

1.2.3. Importancia de la evaluación de la pertinencia de las maestrías en ingeniería

1.3. CONCLUSIONES DEL CAPÍTULO I 44

1.4. BIBLIOGRAFÍA DEL CAPÍTULO I 46 
2.1. CONTEXTO SOCIO ECONÓMICO DE PIURA, PERÚ 54

2.1.1. Contexto socio económico latinoamericano 54

2.1.2. Contexto socio económico peruano 57

2.1.3. Contexto socio económico de Piura 63

2.2. LA EDUCACIÓN SUPERIOR EN PIURA, PERÚ 66

2.2.1. La educación superior en Latinoamérica 66

2.2.2. La educación superior en Perú 75

2.2.3. La Universidad de Piura 82

2.3. CONCLUSIONES DEL CAPÍTULO II 86

2.4. BIBLIOGRAFÍA DEL CAPÍTULO II 89

CAPÍTULO III. LA PERTINENCIA VISTA POR LOS ORGANISMOS DE ACREDITACIÓN

3.1. EVALUACIÓN DE LA PERTINENCIA EN LOS ORGANISMOS DE ACREDITACIÓN INTERNACIONAL 96

3.1.1. La evaluación y la acreditación 96

3.1.2. Modelos de acreditación internacional 101

3.1.2.1. Modelo nacional: ANECA en España 101

3.1.2.2. Modelo regional: ENQA en Europa 103

3.1.2.3. Modelo institucional: CHEA en Estados Unidos 104

3.1.2.4. Modelo internacional: la Red INQAAHE 106

3.1.2.5. Modelo de mercado: OMC 107

3.1.3. Modelos de acreditación de maestrías en ingeniería 108

3.1.3.1. Modelo institucional: ABET en América 108 
3.1.4. Tratamiento de la pertinencia en los organismos de acreditación

3.2.1. Modelos de evaluación de programas de postgrado en Latinoamérica 115

3.2.2. Modelos de evaluación de maestrías en Perú

3.2.3. Evaluación con fines de acreditación en la Universidad de Piura

CAPÍTULO IV. MODELO DE EVALUACIÓN DE LA PERTINENCIA DE MAESTRÍAS EN INGENIERÍA

4.1.1. Principios y características del modelo

4.1.2. Concepto de pertinencia de una maestría en ingeniería

4.1.3. Beneficiarios y partes interesadas en una maestría en ingeniería

4.2.1. Factores de pertinencia

4.2.2. Indicadores y fuentes de verificación

4.3.1. Estructuración

4.3.2. Observación 
4.3.3. Análisis de la información $\quad 161$

4.3.4. Juicio 163

4.4. CONCLUSIONES DEL CAPÍTULO IV 163

4.5. BIBLIOGRAFIA DEL CAPÍTULO IV 166

CAPÍTULO V. APLICACIÓN DEL MODELO DE EVALUACIÓN DE LA PERTINENCIA EN LA UNIVERSIDAD DE PIURA, PERÚ 167

$\begin{array}{ll}\text { 5.1. ESTRUCTURACIÓN } & 169\end{array}$

$\begin{array}{ll}\text { 5.2. OBSERVACIÓN } & 172\end{array}$

$\begin{array}{ll}\text { 5.2.1. Resultados de encuestas } & 172\end{array}$

$\begin{array}{ll}\text { 5.2.2. Resultados de entrevistas } & 188\end{array}$

5.2.3. Resultados del análisis documental 192

5.3. ANÁLISIS DE LA INFORMACIÓN 192

$\begin{array}{lr}\text { 5.4. JUICIO } & 198\end{array}$

5.5. CONCLUSIONES DEL CAPÍTULO V 199

5.6. BIBLIOGRAFIA DEL CAPÍTULO V 201

$\begin{array}{ll}\text { CAPÍTULO VI. CONCLUSIONES } & 203\end{array}$

6.1. CONCLUSIONES 205

6.2. FUTURAS LÍNEAS DE INVESTIGACIÓN 208

$\begin{array}{ll}\text { BIBLIOGRAFÍA GENERAL } & 209\end{array}$

$\begin{array}{ll}\text { ANEXOS } & 219\end{array}$ 
ANEXO 1. Algunos indicadores socio económicos de Latinoamérica, Perú y Piura

ANEXO 2. Algunos indicadores de la educación superior en Latinoamérica y Perú

ANEXO 3. Instrumentos de recogida de información en el modelo propuesto. Encuestas y guías de entrevista

ANEXO 4. Malla curricular - maestría en Ingeniería Civil con mención en Ingeniería Vial, Universidad de Piura 


\section{INDICE DE TABLAS}

Tabla 1.1. Publicaciones, patentes y movilidad estudiantil a nivel global 17

Tabla 1.2. Modelos de universidad según Fischman \& Haas (2011) 18

Tabla 1.3. Características de las universidades de investigación 21

Tabla 1.4. Funciones y competencias de universidades y empresas 28

Tabla 1.5. Razones para iniciar una interrelación entre universidad y empresa 29

Tabla 1.6. Tipos de interacción entre universidad y empresa. 29

Tabla 1.7. Canales de comunicación entre universidad y empresa 30

Tabla 1.8. Características de los dos tipos de maestría identificados por AUIP (2009)33

Tabla 1.9: Diferencias entre las maestrías profesionales y las de investigación 35

Tabla 1.10. Diferencias entre las maestría en ingeniería de las universidades de los países desarrollados y las de los países en desarrollo

Tabla 1.11. Los 12 pilares de la competitividad según World Economic Forum (2012)

Tabla 2.1. Principales proyectos a ejecutarse en Perú en los próximos años.

Tabla 2.2. Mejores universidades de Latinoamérica según el World Universities Ranking

Tabla2.3. Fuentes de presupuesto público para ES universitaria en Perú 2006- 201081

Tabla 2.4. Alumnos de pregrado Universidad de Piura 2014

Tabla 2.5. Alumnos de postgrado Universidad de Piura 2014

Tabla 2.6. Número de docentes Universidad de Piura

Tabla 2.7. Ranking 2013 - Mejores universidades de Perú según América Economía 85

Tabla 2.8. Ranking 2013 - Ingeniería Industrial en Perú según América Economía 84

Tabla 2.9. Alumnos de pregrado en la facultad de ingeniería - Udep 2014

Tabla 2.10. Alumnos de postgrado en la facultad de ingeniería - Udep 2014 
Tabla 3.1. Características de los modelos de acreditación internacional (Eaton, 2007)

Tabla 3.2. Criterios de evaluación de la Agencia Nacional de Evaluación de la Calidad y Acreditación - ANECA, España

Tabla 3.3. Criterios para la garantía interna de calidad en el Espacio Europeo de Educación

Superior - European Association for Quality Assurance - ENQA 103

Tabla 3.4. Criterios de evaluación de los Master Erasmus Mundus 104

Tabla 3.5. Criterios de evaluación del Council for Higher Education Accreditation - CHEA de Estados Unidos

Tabla 3.6. Principios de funcionamiento de las agencias de garantía de la calidad según la Red INQAAHE

Tabla 3.7. Criterios ABET para acreditación de programas de ingeniería 109

Tabla 3.8. Resultados del estudiante ABET

Tabla 3.9. Criterios de evaluación - Proyecto EUR-ACE

Tabla 3.10. Niveles de acreditación de programas de postgrado en México

Tabla 3.11. Criterios de evaluación del postgrado - PNPC, México

Tabla 3.12. Criterios de evaluación de programas de Postgrado - CAPES, Brasil

Tabla 3.13. Dimensiones a evaluar para la acreditación de programas - CINDA

Tabla 3.14. Criterios de evaluación de programas de postgrado - Asociación Universitaria Iberoamericana de postgrado - AUIP

Tabla 3.15. Criterios para la acreditación de programas de maestría CONEAU - Perú

Tabla 3.16. Estándares que evalúan la pertinencia de una maestría en el modelo de

CONEAU - Perú

Tabla 3.17. Criterios de evaluación ICACIT

Tabla 3.18. Modelo de autoevaluación de las maestrías de la PUCP

Tabla 3.19. Estándares que evalúan la pertinencia de una maestría en el modelo de PUCP 
Tabla 4.4. Indicadores y fuentes de verificación para evaluar la pertinencia de maestrías en ingeniería

Tabla 4.5. Preguntas de evaluación - Encuestas

Tabla 4.6. Preguntas de evaluación - Entrevistas

Tabla 4.7. Análisis de la información - Técnica de los Gráficos de Cuadrante

Tabla 5.1. Población de los grupos de interés - Maestría en Ingeniería Vial

Tabla 5.2. Total de personas que respondieron la encuesta

Tabla 5.3. Resultados de la encuesta a ESTUDIANTES - Maestría en Ingeniería Civil con mención en Ingeniería Vial

Tabla 5.4. Resultados de la encuesta a DOCENTES - Maestría en Ingeniería Civil con mención en Ingeniería Vial

Tabla 5.5. Resultados de la encuesta a EGRESADOS - Maestría en Ingeniería Civil con mención en Ingeniería Vial

Tabla 5.6. Resultados de la encuesta a EMPLEADORES - Maestría en Ingeniería Civil con mención en Ingeniería Vial

Tabla 5.7. Maestría en Ingeniería Vial - Número de alumnos matriculados por año. 189

Tabla 5.8. Resultado de encuestas de la maestría en Ingeniería Vial - Suma de "Muy de acuerdo" y "De acuerdo"

Tabla 5.9. Resultados de los indicadores M, X, Y para estudiantes, docentes y egresados de la maestría en Ingeniería Vial

Tabla 5.10. Resultados de los indicadores A, M, P para egresados y empleadores de la maestría en Ingeniería Vial

Tabla 5.11. Resultados de indicadores no triangulados. Docentes de maestría en Ingeniería Vial

Tabla 5.12. Resultados de indicadores no triangulados. Egresados y empleadores de maestría en Ingeniería Vial 


\section{INDICE DE GRÁFICOS}

$\begin{array}{ll}\text { Gráfico a.1. Metodología general de la investigación } & 7\end{array}$

Gráfico a.2. Esquema general de la investigación $\quad 8$

Gráfico 1.1. Metodología para la producción de conocimiento del Grupo GESPLAN

Gráfico 1.2. Relación entre ciencia, tecnología e ingeniería 32

Gráfico 1.3. Dimensiones de la pertinencia de una maestría en ingeniería $\quad 40$

Gráfico 2.1. Actividades de innovación en países seleccionados (porcentajes de sus ventas

Gráfico 2.2. Evolución del PIB per cápita de Perú, Latinoamérica y el mundo

Gráfico 2.3. Evolución de la pobreza y pobreza extrema, periodo 2004 - 2012 en Perú

Gráfico 2.4. Perú. Acceso a servicios de agua, desagüe y alumbrado eléctrico 2004 - 2012

Gráfico 2.5. Ubicación del departamento de Piura, Perú

Gráfico 2.6. Piura. Incidencia de pobreza monetaria total

Gráfico 2.7. Piura. Acceso a servicios de agua, desagüe y alumbrado eléctrico 2001 - 2012

Gráfico 2.8. Perú: Número de universidades, por año censal, según tipo de universidad

Gráfico 2.9. Universidad de Piura - campus Piura

Gráfico 3.1. Organismos de acreditación internacional en los que se analizaron los criterios e indicadores de evaluación

Gráfico 3.2. Organismos de acreditación de programas de ingeniería en los que se analizaron los criterios e indicadores de evaluación 
Gráfico 3.4. Modelos de evaluación de postgrados en Latinoamérica que fueron revisados

Gráfico 3.5. Paradigma del modelo de evaluación de postgrados en México

Gráfico 3.6. Modelos de evaluación de postgrados en Perú que fueron analizados 125

Gráfico 4.1. Factores de pertinencia

Gráfico 4.2. Identificación de indicadores de evaluación

Gráfico 4.3. Estructuración de la evaluación de la pertinencia de maestrías en ingeniería

Gráfico 4.4. Ejemplo de Gráfico de Cuadrante

Gráfico 5.1. Indicador A - Los conocimientos adquiridos en la maestría ayudaron a un mejor desempeño laboral.

Gráfico 5.2. Indicador B - Los temas dictados durante la maestría se relacionan con los temas del trabajo o son de interés del estudiante.

Gráfico 5.3. Indicador C - Funciona un sistema de seguimiento al desempeño de egresados.

Gráfico 5.4. Indicador D - Cursar la maestría ayudó a mejorar la situación laboral del egresado.

Gráfico 5.5. Indicador E - La actualización de los syllabus considera la opinión de estudiantes y egresados.

Gráfico 5.6. Indicador H - Los docentes han publicado algún paper en ISI, Scopus o Scient

Direct utilizando el nombre de la universidad, en los dos últimos años.

Gráfico 5.7. Indicador K - Existe correspondencia entre la misión y objetivos de la maestría con el plan de estudios.

Gráfico 5.8. Indicador M - La maestría aprovecha las oportunidades locales y nacionales para beneficio de sus estudiantes y docentes.

Gráfico 5.9. Indicador O - El plan de estudios ayuda a satisfacer necesidades reales de la localidad y del país. 
Gráfico 5.10. Indicador P - Los proyectos de fin de máster tienen aplicación o resuelven problemas en las empresas.

Gráfico 5.11. Indicador R - La maestría cuenta con un comité consultivo integrado por representantes de los principales grupos de interés.

Gráfico 5.12. Indicador S - Los docentes participan en redes o asociaciones científicas y profesionales.

Gráfico 5.13. Indicador T - Los docentes poseen movilidad académica.

Gráfico 5.14. Indicador U - Los docentes actualizan los syllabus incorporando los resultados de sus investigaciones o los resultados de investigaciones recientes

Gráfico 5.15. Indicador V - La organización de la universidad facilita la investigación multidisciplinaria y centrada en problemas.

Gráfico 5.16. Indicador W - Los docentes participan en proyectos de investigación con financiamiento externo (nacional o internacional).

Gráfico 5.17. Indicador X - Las asignaturas promueven la transdisciplinariedad y la innovación.

Gráfico 5.18. Indicador Y - Se utiliza un enfoque de aprendizaje basado en proyectos.

Gráfico 5.19. Nivel de acuerdo con las declaraciones basadas en los indicadores de pertinencia - Resultados de la encuesta aplicada a estudiantes vs resultados egresados 



\section{Introducción}




\section{INTRODUCCIÓN}

El crecimiento económico de Perú en los últimos años y la demanda de profesionales competentes que genera este crecimiento ha puesto en evidencia una vez más los grandes retos que tiene el sistema educativo peruano. La formación de postgrado en ingeniería es una de las prioridades a atender y mejorar por dos razones. La primera tiene que ver con la razón de ser de la ingeniería: resolver problemas concretos y satisfacer necesidades humanas con carácter inmediato, sin provocar colapsos y degradación de la naturaleza (Cazorla et. al, 2011). La segunda tiene que ver con los objetivos del postgrado: la formación para la especialización, la investigación y la innovación (AUIP, 2009).

La educación superior en el siglo XXI no sólo debe ser de calidad sino también debe ser pertinente y esta pertinencia debe ser evaluada en función de lo que la sociedad espera de las universidades y lo que las universidades hacen (Gibbons, 1998). Es decir, la universidad debe estar vinculada a su entorno socioeconómico y atender sus demandas y necesidades (Cazorla, 2015).

En un sistema global de educación superior regido por lo que hacen las universidades "mundiales" o "de investigación" y donde la guerra que luchan estas universidades no necesariamente es la misma guerra que luchan las universidades de los países en desarrollo, es más importante esta pertinencia, esta vinculación con el entorno, especialmente si las universidades están llamadas a contribuir con el desarrollo del país.

Sin embargo este tema que parece tan importante, la pertinencia, no es muy considerado en los modelos de evaluación de programas formativos existentes porque son modelos de evaluación de la calidad del programa. Lo que se hace es analizar si los resultados obtenidos corresponden a la misión y objetivos planteados, es decir se evalúa la eficacia del programa. Y lo que se quiere es averiguar si los objetivos planteados satisfacen necesidades e intereses reales de los beneficiarios y de las partes interesadas, es decir, evaluar la pertinencia del programa. Este enfoque se obtuvo gracias al Doctorado cuyo trabajo de investigación presento ahora.

El concepto de pertinencia en la educación superior fue tomado de la teoría de programas y proyectos pero el autor de la presente tesis considera que no ha sido bien manejado. Algunos autores incluso hablan de un paradigma de la pertinencia pues desde un enfoque 
economicista se considera que un plan de estudios, una investigación o una institución tiene pertinencia cuando responden a demandas del Mercado, su producción es eficiente en términos de aplicabilidad inmediata, son rentables y permiten obtener financiamiento externo, etc.; (Naidorf et. al, 2007).

En la presente investigación se propone un modelo de evaluación de la pertinencia de maestrías en ingeniería. No se estudia los doctorados porque hay diferencias significativas entre estos dos tipos de postgrado y porque en Perú hay muchas más maestrías que doctorados. Se asume que la maestría ya está en funcionamiento y que es dictada por una universidad, por tanto no aplican las dictadas por empresas o instituciones no universitarias. La maestría puede ser a tiempo completo o tiempo parcial, puede ser de investigación o puede ser una maestría profesional.

\section{A. PREGUNTAS DE INVESTIGACIÓN}

A continuación se enuncian las preguntas de investigación planteadas

1. ¿Cuáles son las características, tendencias, tipos y misiones de la universidad del siglo XXI?

2. ¿Qué se entiende por pertinencia de la educación superior y cómo se vincula la universidad con su entorno?

3. ¿Qué características tiene la formación de postgrado en ingeniería y qué se entiende por pertinencia de una maestría en ingeniería?

4. ¿Cuál es el contexto socio económico de Latinoamérica, de Perú y de Piura en el que se desarrolla la formación de postgrado en ingeniería?

5. ¿Qué modelos de evaluación de programas de postgrado existen en Latinoamérica y en el mundo y cuáles son los criterios e indicadores utilizados?

6. ¿Se considera la evaluación de la pertinencia de los programas en los organismos de acreditación internacional?

7. ¿Es posible diseñar un modelo de evaluación de la pertinencia de maestría en ingeniería?

8. ¿Qué factores e indicadores de evaluación debería contener ese modelo de evaluación y cómo podría aplicarse? 


\section{B. OBJETIVOS E HIPÓTESIS DE LA INVESTIGACIÓN}

Esta investigación presenta el siguiente objetivo general y los siguientes objetivos específicos.

\section{Objetivo general}

Diseñar un modelo de evaluación de la pertinencia de maestrías en ingeniería que considere indicadores de la adecuación de los objetivos de la maestría a las necesidades e intereses de los estudiantes y las partes interesadas, y aplicarlo a un caso concreto.

\section{Objetivos específicos}

1. Analizar el concepto de pertinencia de la educación superior y aplicarlo al caso concreto de maestrías en ingeniería.

2. Describir el contexto socio económico y la educación superior de Latinoamérica, de Perú y de Piura, en el que se desarrolla la formación de postgrado en ingeniería.

3. Analizar los modelos de evaluación de programas de postgrado existen en el mundo, en Latinoamérica y Perú juzgando si existen o no criterios e indicadores de evaluación de la pertinencia.

4. Diseñar un modelo de evaluación de la pertinencia de maestrías en ingeniería planteando factores, indicadores de evaluación y metodología de implementación.

5. Aplicar el modelo de evaluación en un caso concreto: una maestría de la facultad de ingeniería de la Universidad de Piura, Perú.

\section{Hipótesis:}

Las preguntas de investigación planteadas y los objetivos propuestos nos llevan a definir nuestras hipótesis de investigación:

1. Los principales modelos de garantía de la calidad y organismos de acreditación internacional no evalúan la pertinencia de los programas formativos porque se enfocan en la evaluación de la eficacia del programa.

2. Es posible diseñar un modelo de evaluación de la pertinencia de las maestrías en ingeniería que considere indicadores de la adecuación de los objetivos de la maestría a las necesidades e intereses de los estudiantes y las partes interesadas. 
3. Para evaluar esta adecuación de los objetivos a las necesidades se requiere la complementación de métodos cuantitativos y cualitativos, así como de fuentes primarias y secundarias.

4. La aplicación del modelo de evaluación permitirá identificar oportunidades de mejora y sacar conclusiones para superar las debilidades de la maestría en relación a su pertinencia.

\section{METODOLOGÍA GENERAL DE LA INVESTIGACIÓN}

La metodología utilizada en la investigación considera un enfoque mixto inductivo y deductivo, el cual a su vez se basa en la corriente filosófica del pragmatismo y en el proceso de aprendizaje derivado de la experiencia (Cazorla et.al, 2004).

La investigación parte del análisis de una realidad concreta: las maestrías de la facultad de Ingeniería de la Universidad de Piura (1). Sobre esta realidad se generan una serie de preguntas de investigación (2) y unas hipótesis (3) que permiten definir el marco conceptual (4) y proponer un modelo teórico para la evaluación de la pertinencia de las maestrías en ingeniería (5). Este marco conceptual es aplicado a la misma realidad de la que parte (6), permitiendo explicar la realidad y extraer lecciones de experiencia (7). Se trata de una investigación de ciencia aplicada, en donde el propio "laboratorio de aprendizaje" son las maestrías en ingeniería de la Universidad de Piura. 
Gráfico a.1. Metodología general de la investigación

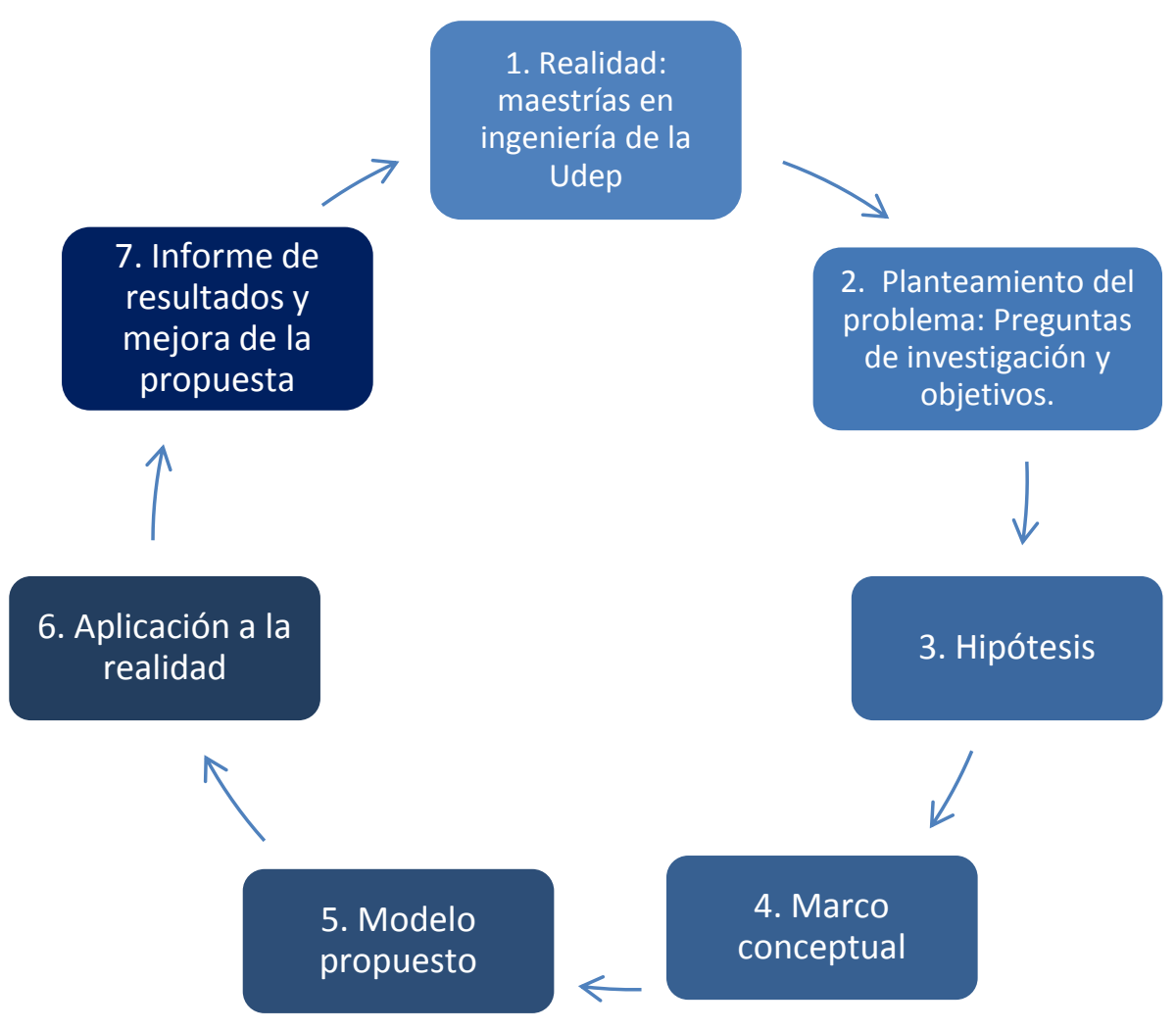

\section{C.1. Esquema general de la investigación}

Para poder responder a las preguntas de investigación, lograr los objetivos planteados y confirmar el cumplimiento o no de las hipótesis, la investigación se organizó en las siguientes etapas:

Etapa 1: Marco teórico y marco contextual.

Etapa 2: Modelo conceptual

Etapa 3: Aplicación del modelo.

Etapa 4: Conclusiones 
Gráfico a.2. Esquema general de la investigación

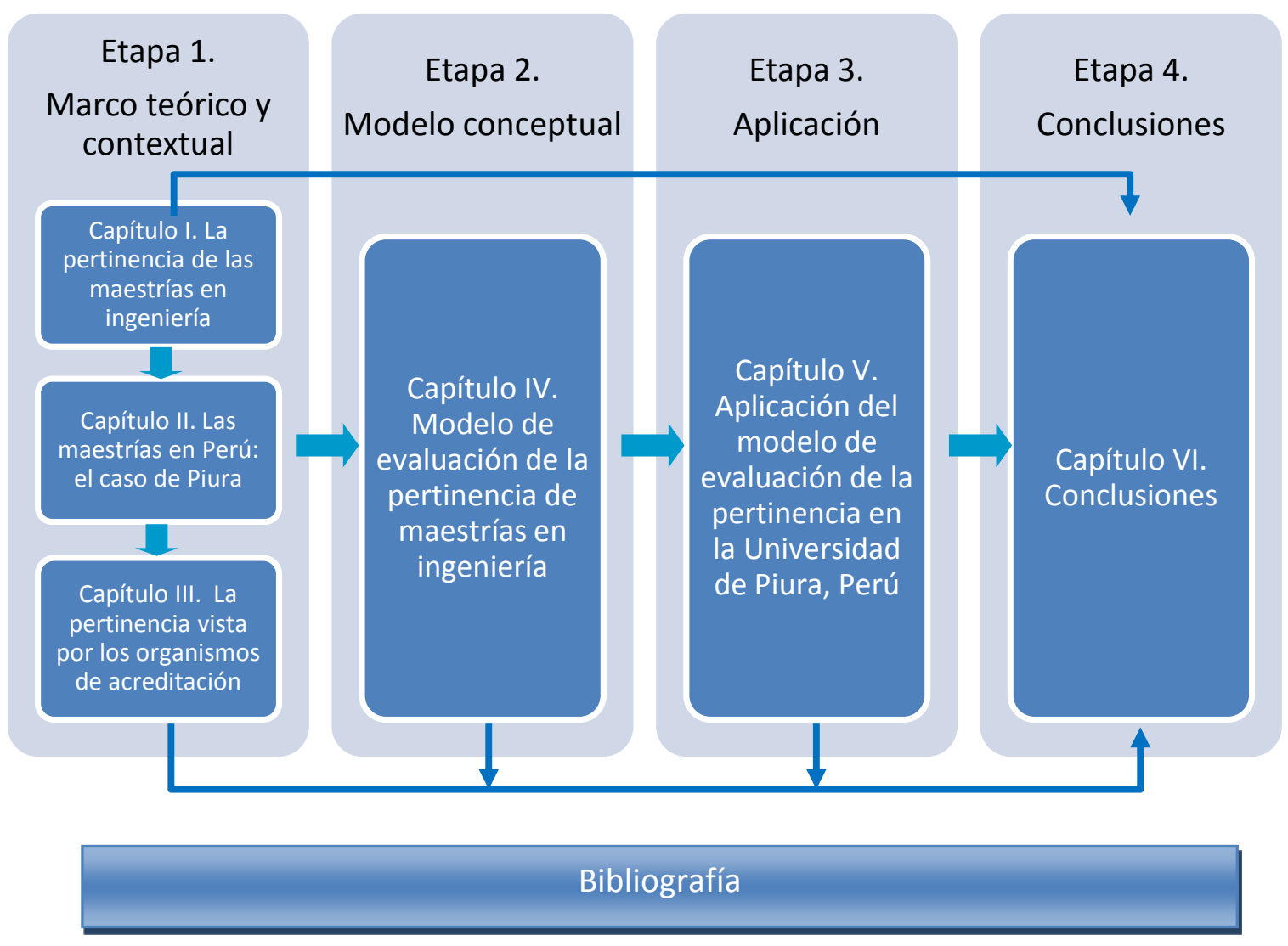

\section{Etapa 1: Marco teórico y marco contextual.}

Esta etapa comprende los capítulos I, II y III de la tesis donde se hace una revisión bibliográfica de los conceptos claves para la investigación.

Capítulo I: La pertinencia de las maestrías en ingeniería. En este capítulo se describe las características más importantes de la educación universitaria, la importancia de la pertinencia de la educación superior y la necesaria vinculación de las universidades con el entorno. Se describe el caso particular de la formación de postgrado en ingeniería, definiendo el concepto de pertinencia de una maestría en ingeniería y sustentando la importancia de su evaluación.

Capítulo II: Las maestrías en Perú: el caso de Piura. Este capítulo tiene como objetivo contextualizar el modelo a proponer poniendo en evidencia que en el contexto socio económico y la situación de la educación superior de Latinoamérica y Perú es imprescindible evaluar la pertinencia. Se describe y analiza esta realidad en tres niveles: Latinoamérica, Perú 
y Piura. Primero se describe el contexto socio económico y luego las características y tendencias en la educación superior.

Capítulo III: La pertinencia vista por los organismos de acreditación. En este capítulo se presentan los modelos de evaluación utilizados por los organismos de acreditación internacional de Europa, Estados Unidos y España y se revisa si se está considerando o no criterios de evaluación de pertinencia en dichos modelos. Asimismo se revisan los modelos de evaluación de los programas de postgrado en Latino América y Perú así como los modelos existentes para maestrías en ingeniería.

\section{Etapa 2: Modelo conceptual.}

Capítulo IV: Modelo de evaluación de la pertinencia de maestrías en ingeniería. El modelo es diseñado a partir de los resultados de los capítulos I, II y III. Primero se presentan los principios y características del modelo. Considerando que es una evaluación que arroja resultados de tipo descriptivo, los métodos cuantitativos se complementan con los cualitativos y las fuentes primarias con las secundaria (Olds et.al, 2005). Se definen los factores de pertinencia de una maestría en ingeniería de manera coherente con el concepto vertido en el capítulo I, es decir se plantean cuatro factores de pertinencia: Pertinencia Personal, Pertinencia Institucional, Pertinencia Social y Pertinencia Global. Para cada factor se define indicadores y fuentes de verificación. Finalmente se establece los pasos a seguir en el proceso de evaluación (estructuración), los instrumentos para la recogida de información (encuestas y entrevistas) y recomendaciones para el análisis de la información y el juicio.

\section{Etapa 3: Aplicación del Modelo.}

Capítulo V: Aplicación del modelo de evaluación de la pertinencia en la Universidad de Piura, Perú. En este capítulo se presenta la aplicación del modelo de evaluación de la pertinencia en la maestría en Ingeniería Civil con mención en Ingeniería Vial de la Universidad de Piura, Perú. El objetivo es extraer lecciones de experiencia de este caso concreto de estudio para su replicación en otras maestrías. Se siguen los pasos establecidos en el capítulo anterior. Se utiliza las encuestas, las guías de entrevista, la técnica para el análisis de la información y las recomendaciones para la elaboración del informe, planteadas en el capítulo IV. El análisis de la información y el juicio es efectuado teniendo como referencia los factores de pertinencia. Se valora si la maestría tiene alta, media o baja pertinencia 
personal, pertinencia institucional, pertinencia social y pertinencia global. Las recomendaciones de mejora se obtienen de los mismos indicadores del modelo de evaluación.

\section{Etapa 4: Conclusiones}

Capítulo V: Conclusiones. En este capítulo se efectúa un análisis de los resultados de la investigación y se extraen conclusiones poniendo énfasis en aspectos transversales a los cuatro capítulos anteriores. Asimismo, de este análisis se identifican futuras líneas de investigación.

\section{PRODUCCIÓN CIENTÍfICA ASOCIADA A LA TESIS}

En este apartado se citan los artículos y comunicaciones asociados a la investigación.

\section{Capítulo I: La pertinencia de las maestrías en ingeniería.}

"Relevance of Higher Education. How to measure it? The case of masters of engineering in Peru". Publicado en la International Journal of Innovative Research in Advanced Engineering, Issue 12, Volumen 2 (diciembre 2015), 100-111. Revista indexada con ISSN $2349-2163$

\section{Capítulo II: Las maestrías en Perú: el caso de Piura.}

"Competencias genéricas en ingeniería: un estudio comparado en el contexto internacional". XV International Congress on Project Engineering, AEIPRO, 6-8 julio de 2011. Huesca, España. Esta comunicación dio lugar al ACCESIT DEL PREMIO de los Colegios oficiales de Ingenieros Agrónomos, Ingenieros de Caminos canales y puertos y de Ingenieros Industriales de Aragón y Rioja. Coautores: Martín Palma, Ignacio de los Ríos. 


\section{Capítulo III: La pertinencia vista por los organismos de acreditación.}

"Local relevance evaluation in the accreditation bodies for engineering master's programs". Publicado en Procedia Social and Behavioral Sciences Journal, número 15, año 2011, 475 479. ISSN: 1877-0428. Indexada en ScienceDirect, Scopus y Thomson Reuters Conference Proceedings Citation Index (ISI Web of Science). Coautores: Isabel Chiyón, José M. DíazPuente.

"Acreditación internacional y evaluación de la pertinencia local de las maestrías en ingeniería de proyectos". XV International Congress on Project Engineering", AEIPRO, 6-8 julio de 2011. Huesca, España. Coautores: Isabel Chiyón, J.M. Díaz Puente.

\section{Capítulo IV: Modelo de evaluación de la pertinencia de maestrías en ingeniería.}

"Relevance evaluation of engineering master's program in Peru”. Publicado en Procedia Social and Behavioral Sciences Journal, año 2012, número 46, 1557 - 1564. ISSN: 1877-0428. Indexada en ScienceDirect, Scopus y Thomson Reuters Conference Proceedings Citation Index (ISI Web of Science). Coautores: José M. Díaz-Puente, Carlos Lavalle.

\section{Capítulo V: Aplicación del modelo de evaluación de la pertinencia en la Universidad de Piura, Perú.}

"Relevance Evaluation of a Master's Degree in Engineering in Peru". 2nd International Conference on Economic, Education and Management (ICEEM 2012), 1- 2 de junio de 2012, Shangai, China. Publicado en ISI web of knowledge, Web of Sciences, ISBN 978-98819750-3-4. Coautor: J.M. Díaz Puente. 


\section{E. BIBLIOGRAFÍA DEL CAPÍTULO DE INTRODUCCIÓN}

AUIP, A. U. (2009). Evaluación de Programas de Postgrado - Guía de Autoevaluación. Recuperado el junio de 2014, de www.auip.org

Cazorla, A., De los Ríos, I., \& Salvo, M. (2004). Modelos de planificación para un desarrollo rural y local. (D. d. Madrid, Ed.) Madrid.

Cazorla, A., De los Ríos, I., \& Yagüe, J. L. (2011). Trabajando con la gente. En J. Olvera, R. mendoza, N. Pérez, \& I. De los Ríos, Modelos para el desarrollo rural con enfoque territorial en México (págs. 9 - 46). México: Colegio de Postgraduados, Campus Puebla.

Cazorla, A. (27 de diciembre de 2015). Una Universidad para la empresa y la sociedad. El Mundo, España.

Gibbons, M. (1998). "Higher Education Relevance in the 21st Century". UNESCO World Conference on Higher Education. Paris.

Naidorf, J., Giordana, P., \& Horn, M. (2007). La pertinencia social de la universidad como categoría equívoca. Nomadas (27), 22-33.

Olds, B., Moskal, B., \& Miller, R. (2005). "Assessment in engineering education: Evolution, approaches and collaborations". Journal of Engineering Education, 94, 1, 13-25. 


\section{Capítulo I}

La pertinencia de las maestrías en ingeniería 
La pertinencia de las maestrías en ingeniería 


\section{Capítulo I}

\section{La pertinencia de las maestrías en ingeniería}

La principal aportación de este capítulo es la definición del concepto de pertinencia de las maestrías en ingeniería. En este capítulo se sustenta también la importancia de la evaluación de la pertinencia, especialmente en países en desarrollo. La definición operativa de la pertinencia constituye el principal insumo para la construcción del modelo de evaluación propuesto en la presente investigación. Este concepto considera que un programa de maestría debe tener pertinencia global y pertinencia local. La pertinencia local incluye tres aspectos: el personal que implica satisfacer las necesidades de los estudiantes, el institucional que implica satisfacer las necesidades e intereses de la institución que acoge la maestría y el aspecto social que implica resolver problemas y atender necesidades del entorno nacional y regional.

El capítulo se ha dividido en dos partes. En la primera parte se describen las características más importantes de la educación universitaria, de la importancia de la pertinencia de la educación superior y su necesaria vinculación con el entorno. En la segunda parte se describe el caso particular de la formación de postgrado en ingeniería, se define el concepto de pertinencia de una maestría en ingeniería y se sustenta la importancia de su evaluación.

En la primera parte se describen las características, tipos y misiones de la universidad del siglo XXI y su necesaria vinculación con el entorno. Se argumenta que la universidad ya no tiene el monopolio de producción y transmisión del conocimiento y que por tanto tiene que ser pertinente. Se muestran también los posibles canales de vinculación de la universidad con su entorno, que se deben tomar en cuenta si se desea que ésta sea pertinente.

En la segunda parte se describe las características particulares de la formación de postgrado en ingeniería, considerando que hay dos tipos de maestrías: las profesionales y las de investigación. Se utiliza el marco teórico revisado para definir un concepto pertinencia que servirá de base luego para revisar en el capítulo II los modelos de evaluación existentes.

La metodología seguida para el desarrollo de este capítulo es la recopilación de información de fuentes secundarias, principalmente bibliografía de bases de datos científicas internacionales así como publicaciones de organismos internacionales relacionados con la evaluación de la calidad de la educación superior. Los resultados de esta revisión bibliográfica

La pertinencia de las maestrías en ingeniería 
se validaron con entrevistas a expertos en el tema y entrevistas a estudiantes, egresados y docentes de maestrías en ingeniería en Madrid y Piura.

\subsection{LA EDUCACIÓN SUPERIOR UNIVERSITARIA Y SU VINCULACIÓN CON EL ENTORNO}

\subsubsection{La educación superior universitaria en el siglo XXI}

En este apartado analizaremos las misiones, los tipos y las características de la universidad así como las tendencias en la educación superior universitaria del presente siglo. Para (Varghese, 2008) la principal misión de la universidad es la formación de personas, la segunda es la investigación científica. Esta segunda misión es clave en la economía del conocimiento que caracteriza al mundo actual, donde el desarrollo tecnológico y la innovación son fundamentales para sostener el crecimiento económico y la competitividad internacional (World Economic Forum, 2012). La tercera misión, conocida como extensión, consiste en actividades de transferencia de tecnología y de conocimiento y se da a través del uso, aplicación y comercialización de los resultados de las investigaciones (Fernández et.al, 2007). Esta tercera misión ha originado por ejemplo, la creación de oficinas de transferencia tecnológica u oficinas de patentes y las empresas “spin-off” para explotar comercialmente algún conocimiento, tecnología o resultado de investigación desarrollado dentro de la universidad.

Estas tres misiones de la universidad tienen matices y estos se acentúan dependiendo de si se trata de países desarrollados o países en desarrollo al ser las necesidades socioeconómicas distintas. Así, en los países en desarrollo, donde las universidades tienen un peso considerable en la ejecución de actividades de investigación y desarrollo, se espera que las universidades investiguen y ayuden a resolver los problemas de su contexto socio económico (CEPAL, 2010); (Eun et.al, 2006).

(Altbach \& Knight, 2007) afirman que el mundo académico global se ha caracterizado siempre por constar de centros y periferias donde el centro está compuesto por las universidades más potentes como las universidades de "clase mundial" o "universidades de investigación”. A la mayoría de las universidades del mundo en desarrollo les resulta muy difícil figurar en el escenario de la educación superior mundial. En la Tabla 1 se muestra que

La pertinencia de las maestrías en ingeniería 
el conjunto de los países de alto ingreso producen el $79 \%$ de las publicaciones internacionalmente registradas y el 99\% de las patentes concedidas por la Oficina de Patentes y Comercio de los Estados Unidos (USPTO); captan 8 de cada 10 alumnos de educación superior internacionalmente móviles y albergan 99 de las 100 primeras universidades, según el ranking de Shanghai.

Tabla 1.1. Publicaciones, patentes y movilidad estudiantil a nivel global

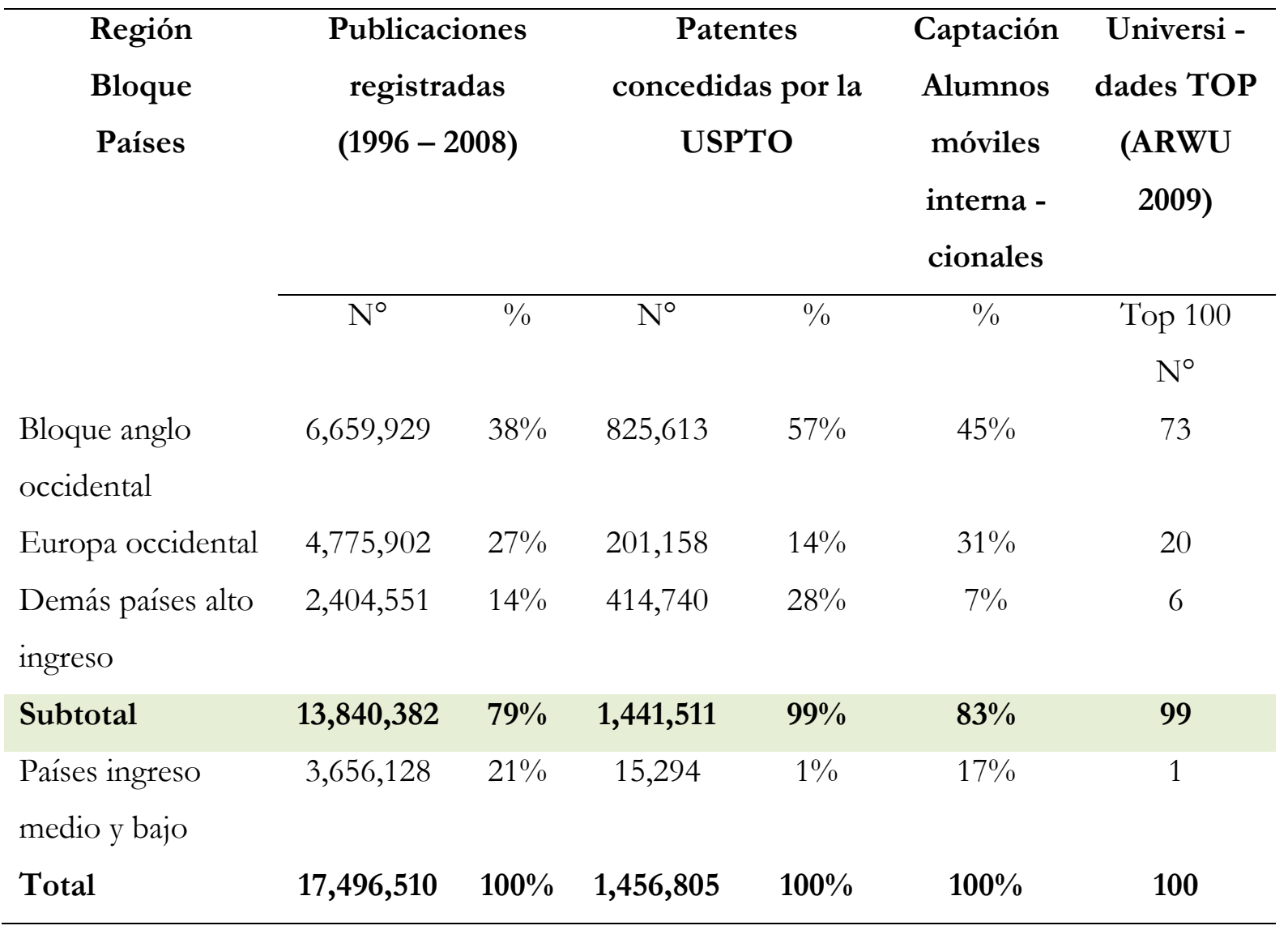

Fuente: Brunner (2010)

Históricamente se han adoptado distintos modelos o concepciones de lo que debe que ser la Universidad: el modelo anglosajón, donde predomina la conservación y la transmisión de conocimientos sobre el progreso de los mismos; el modelo germánico, prototipo de universidad fundamentalmente científica; el modelo progresista de las universidades norteamericanas; el modelo napoleónico, que ha impregnado la vida universitaria española y latinoamericana durante muchos años; y el modelo soviético, en el que la universidad se concibe, fundamentalmente, como un factor de producción (Cazorla, 2013).

La pertinencia de las maestrías en ingeniería 
Fischman \& Haas (2011) identifican tres modelos de universidades en la actualidad. En un estudio se preguntaron cómo han abordado los diarios más influyentes de los Estados Unidos el concepto de "universidad" en los últimos 26 años y concluyen en tres prototipos de universidad: La Nostalgia Académica, El Emprendedorismo Educativo y El Consumismo-Educativo Redentor. Las características de estos tres prototipos se muestran en la Tabla 1.2.

Tabla 1.2. Modelos de universidad según Fischman \& Haas (2011)

\begin{tabular}{|c|c|}
\hline $\begin{array}{l}\text { Modelo de } \\
\text { universidad }\end{array}$ & Características \\
\hline $\begin{array}{l}\text { Nostalgia } \\
\text { Académica }\end{array}$ & $\begin{array}{l}\text { - Tiene como propósitos: 1. La enseñanza y el aprendizaje de las } \\
\text { grandes verdades, universales y atemporales (a través de su } \\
\text { transmisión desde un profesor a un estudiante). } 2 \text {. La } \\
\text { producción de conocimiento de por sí, sin considerar } \\
\text { directamente los beneficios económicos. 3. La mejora de la } \\
\text { sociedad, con énfasis en el surgimiento de líderes comunitarios. } \\
\text { - Esta universidad debe ser sostenida por el Estado y debe ser } \\
\text { una institución autónoma con su propia cultura y procesos. }\end{array}$ \\
\hline $\begin{array}{l}\text { Emprendedorismo } \\
\text { Educativo }\end{array}$ & $\begin{array}{l}\text { - Tiene como propósitos: 1. Entregar conocimiento "objetivo" a } \\
\text { los estudiantes que lo utilizan para mejorar su posición } \\
\text { económica. 2. Producir empresarios calificados, trabajadores y } \\
\text { conocimientos fruto de la investigación. } \\
\text { - Debe ser una institución financieramente autosuficiente } \\
\text { (adoptando un modelo empresarial /de negocios). } \\
\text { - Debe producir conocimiento "objetivo" y luego venderlo } \\
\text { como ventaja económica para sus estudiantes y los potenciales } \\
\text { clientes. } \\
\text { - Debe promover la competencia. }\end{array}$ \\
\hline $\begin{array}{l}\text { Consumismo- } \\
\text { Educativo } \\
\text { Redentor }\end{array}$ & $\begin{array}{l}\text { - Es el punto medio entre los dos extremos anteriores. } \\
\text { - Tiene como propósitos: } 1 \text {. Aumentar su alcance y ser abierta y } \\
\text { accesible a todo tipo de estudiantes meritorios. 2. Perseguir } \\
\text { formas superiores de conocimiento, capacitar a un cuerpo } \\
\text { diverso de estudiantes en una disciplina académica o profesión } \\
\text { bien sólida, pero también fomentar las actitudes } \\
\text { emprendedoras. 3. Mejorar no sólo la sociedad sino también } \\
\text { sus clientes (estudiantes, sus familias, empresas, gobierno). } \\
\text { - La competencia es un proceso clave para mejorar la eficiencia y } \\
\text { la equidad. } \\
\text { - El gobierno debe ser un actor clave del financiamiento de la } \\
\text { universidad a través de subsidios, por lo general mediante } \\
\text { ayuda financiera o estímulos fiscales, pero los presupuestos de } \\
\text { las universidades deben considerar otras fuentes de ingresos. }\end{array}$ \\
\hline
\end{tabular}

Fuente: Fischman \& Haas (2011)

La pertinencia de las maestrías en ingeniería 
La educación superior universitaria en el siglo XXI es masiva. La matrícula ha pasado de 13 millones de estudiantes universitarios en 1960 a 144 millones en el 2006 y 158 millones en el 2008 según el Informe anual del Instituto de Estadísticas de (UNESCO, 2010). El 51\% de la tasa de matrícula es femenina.

La educación se ha vuelto permanente (Rama, 2008). El enfoque tradicional de estudiar de una vez y por todas para obtener un título o para terminar con la educación de postgrado, antes de iniciar la vida laboral está siendo reemplazado por prácticas de educación a lo largo de la vida. En educación permanente se distingue entre formación general, que eleva la productividad del trabajador en cualquier empresa y la formación específica, que aumenta la productividad únicamente en la ocupación actual (Tünnermann, 1998).

La educación superior es transfronteriza, se ha internacionalizado. La globalización ha originado la exigencia de nuevas competencias profesionales en el mercado laboral y esto a su vez ha originado dos cosas: la migración de trabajadores extranjeros que tienen el nivel de calificación exigido y la migración de estudiantes de países en desarrollo hacia los países desarrollados buscando una formación en las competencias profesionales exigidas (IIEP, 2009). Según cifras de la UNESCO ya son más de tres millones de estudiantes internacionales en el mundo. La movilidad académica también se da a nivel de docentes, programas, instituciones, planes de estudio, entre otros.

Si bien la globalización y la internacionalización de la educación superior ofrecen nuevas posibilidades de estudio e investigación, tal tendencia atentaría contra la cultura y la autonomía nacionales, por ello es necesaria la cooperación y los acuerdos internacionales (Altbach \& Knight, 2007), como el Proceso de Bolonia ${ }^{1}$ en Europa que ha pasado a servir de referencia a esfuerzos similares de convergencia en otras partes del mundo.

La educación superior está caracterizada también por el avance del sector privado. Se tiene instituciones privadas de alto nivel en algunos casos y de muy bajo nivel en otros (por absorción de la demanda). La matrícula en las instituciones privadas crece rápidamente -más que en el sector público- contando actualmente con un tercio del total mundial de estudiantes, cifra que en América Latina supera el 50\% (Rama, 2010).

El conocimiento se ha convertido en un bien negociable entre los países. La Organización Mundial del Comercio - OMC, promueve que la educación superior sea considerada como

\footnotetext{
${ }^{1}$ Para mayor información ver en: http://www.ehea.info/.
} 
un servicio más que depende de las fuerzas del mercado, que se intercambia según las reglas del Acuerdo General sobre el Comercio de Servicios - GATS (Brunner, 2010). En contraposición a esto, la UNESCO promueve la inclusión de la educación superior en los países como un servicio público que puede tener financiamiento público o privado.

En este contexto de masificación y diversificación de la oferta de la educación superior se hace cada vez más urgente el aseguramiento de la calidad y la tendencia actual es lograrlo a través de procesos de acreditación (Sanyal \& Martin, 2007).

La educación superior universitaria se caracteriza también por contar con estudiantes de distintos grupos sociales, étnicos, económicos y académicos y con distintas demandas. Se caracteriza por el uso cada vez más frecuente de las tecnologías de información y comunicación TIC en el salón de clases; por la permanente renovación de los conocimientos en todas las disciplinas; por la rendición de cuenta a las instituciones y a la comunidad; por la presión proveniente de los sistemas de aseguramiento de la calidad (Brunner, 2010).

Según Rama (2008) se ha producido un cambio en la economía de la educación superior desde una lógica basada en la oferta, a una lógica basada en la demanda (la educación permanente, la renovación de los conocimientos, la necesidad de formación en conocimientos y habilidades específicas). Para atender a esas demandas, las mejores universidades han tenido que replantear su misión institucional asumiendo la responsabilidad que tienen con su entorno social, redefiniendo su concepto de universidad dedicada casi exclusivamente a la docencia para pensar en formas de vincularse en forma efectiva con su entorno productivo y empresarial. Las universidades han tenido que conectarse a redes de conocimiento y de cooperación académica que le ayuden en su desarrollo académico y científico mejorando su competitividad institucional.

Las universidades consideradas las mejores del mundo, según los ranking globales, son las "universidades de investigación" que de acuerdo con Fernandez Pello (2013) ${ }^{2}$ tienen las características mostradas en la Tabla 1.3.

\footnotetext{
${ }^{2}$ Ex Decano de University of California, Berkeley
} 
Tabla 1.3. Características de las universidades de investigación

\begin{tabular}{cc}
\hline $\mathbf{N}^{\circ}$ & Característica \\
\hline 1. & Tiene programas de postgrado: maestrías de investigación y doctorados. \\
2. & $\begin{array}{l}\text { En el pregrado se enseñan los fundamentos de las ciencias. Enseñanza enfocada } \\
\text { a la investigación (no enseñar un oficio). Prepara individuos para la investigación } \\
\text { en academia, laboratorios e industria (la innovación necesita investigación). }\end{array}$ \\
3 & $\begin{array}{l}\text { Tienen estudiantes de primera línea. Los estudiantes de postgrado participan en } \\
\text { los proyectos de investigación. Los de pregrado pueden participar. }\end{array}$
\end{tabular}

4. El presupuesto de la universidad tiene un alto porcentaje relacionado con la investigación (en Berkeley el 50\% viene de contratos de investigación).

5. Los docentes son contratados principalmente por su récord de investigación.

6. Los docentes aumentan su sueldo con contratos de investigación. La promoción de los docentes depende de la enseñanza, la investigación y el servicio profesional.

7. La universidad contribuye a la sociedad fomentando desarrollo tecnológico y conocimiento. Los docentes desarrollan proyectos de investigación de gran interés social y técnico.

8. Hay creatividad para escribir propuestas competitivas en el mercado de la financiación de la investigación.

9. La infraestructura ayuda a la investigación. La calidad de los despachos y los laboratorios depende de la calidad de la investigación.

10. Hay laboratorios para la enseñanza y otros para la investigación. Los profesores enseñan en el aula y en los laboratorios.

11. Los departamentos académicos están organizados para la enseñanza y para la investigación.

12. Los planes académicos y de investigación de pregrado y de postgrado son revisados anualmente por la administración. Las tecnologías modernas y nacientes son incorporadas a la enseñanza y la investigación. Se identifican tendencias.

13. Los departamentos académicos pueden crecer o desaparecer.

Fuente: Elaboración propia a partir de Fernandez Pello (2013)

La llamada Universidad de investigación se caracteriza, de acuerdo con Cazorla (2015), por tener "una docencia relevante y con gran proporción de alumnos internacionales, sobre todo, en programas de máster; realizar una investigación que se traduce en publicaciones, patentes, etc., de impacto mundial, y tener una relevancia en la sociedad que percibe que, esa institución, contribuye a su desarrollo, concretándose en trabajos de muy diverso tipo, promovidos junto con empresas, gobiernos en sus diversos niveles, instituciones públicas o privadas, etc., que aportan así, además, una importante financiación a la universidad. La Universidad de investigación mantiene el sentido genuino de universidad y su prestigio. Pero

La pertinencia de las maestrías en ingeniería 
para asimilar ese arquetipo hace falta cambiar las estructuras de la universidad, poniéndolas al servicio de la investigación".

Sin embargo, la generación de nuevos conocimientos y la innovación, tan importantes actualmente para lograr competitividad y crecimiento económico en un país, no depende solamente de las universidades o centros de investigación, o de las empresas individuales, sino que depende de redes formadas por organizaciones de distintos tipos que persiguen distintos objetivos. Cada vez es más difícil que una compañía, por sí sola, pueda disponer de todas las capacidades requeridas para competir en un mundo donde el avance de la tecnología es muy rápido y la especialización se profundiza. Tales capacidades solo pueden desarrollarse plenamente en un contexto de redes, en el que la información y la tecnología transferida es tan importante como los bienes transferidos (CEPAL, 2010); (Gibbons, 1998).

Hoy las universidades ya no tienen un papel exclusivo ni en la investigación ni en la enseñanza; han perdido el monopolio de la generación y transmisión de nuevos conocimientos (Gibbons, 1998); (Maffioli, 2003). Las empresas están empezando a liderar el proceso de investigación y la generación de nuevos conocimientos para responder a las necesidades de la competencia y de su propia rentabilidad. Actualmente el tipo de investigación práctico, que busca un resultado económico, está siendo desarrollado por los centros de $\mathrm{I}+\mathrm{D}$ de las grandes empresas o centros públicos especializados mientras que el tipo de investigación intelectual, al que no necesariamente se le asocia un resultado económico está siendo dejada a las universidades. Este problema golpea al concepto mismo de universidad como centro de docencia e investigación en forma integrada (Rama, 2008).

La pertinencia de las maestrías en ingeniería 


\subsubsection{La pertinencia de la educación superior universitaria}

La Conferencia Mundial de Educación Superior de la UNESCO realizada en París en 1998 puso en relieve el tema de la pertinencia de la educación superior. En esta conferencia Gibbons (1998) plantea que la pertinencia debe evaluare en función de la adecuación entre lo que la sociedad espera de las instituciones de educación superior y los que éstas hacen.

El enfoque que se otorgue al tema de la pertinencia depende sin embargo del concepto que se tenga de la educación superior. Hay dos corrientes que se ubican a los extremos: aquella que considera la educación superior como un bien público (UNESCO) y otra que considera la educación superior como un servicio sujeto sólo a las leyes del mercado (OMC) ${ }^{3}$.

Para Dias (2008) la educación es un bien público, derecho de todos, deber del Estado y en tanto bien público, la educación no es un bien negociable, aunque sea impartida también por actores privados. Asimismo afirma que es muy difícil definir satisfactoriamente la palabra "calidad" en educación, pero es inevitable vincularla con: la pertinencia, la equidad, la responsabilidad social, la diversidad cultural y a los contextos específicos en que se desarrolla. Dias (2008) afirma que para los países subdesarrollados, es fundamental fortalecer la identidad nacional. Entonces, si la educación superior es un bien público y su calidad debe estar asociada a la pertinencia, a la equidad y a los objetivos nacionales y regionales, sin perder su perspectiva universal, ella no puede ser un "bien público global”. Esta redefinición, dentro de un plan global, desvincula la educación de sus raíces históricas y de los medios concretos donde se insertan las instituciones y donde se producen los conocimientos.

Para Gibbons (1998), Didriksson (2007), Memon et. al (2009) la educación superior universitaria es pertinente si sus objetivos y resultados atiende problemas y necesidades de su entorno socioeconómico y no sólo busca el conocimiento por el conocimiento en sí, sino que también sirve a la sociedad, mejorando las condiciones de vida de sus ciudadanos.

Cazorla (2015) afirma que: "la universidad debe de transformar la sociedad y para ello el conocimiento no sólo debe ser conocido por ella, sino que debe poder aplicarlo a resolver parte de los problemas o a generar nuevas oportunidades. No acepto la excusa de que ello es

\footnotetext{
${ }^{3}$ Organización Mundial del Comercio
}

La pertinencia de las maestrías en ingeniería 
mercantilizar la universidad. Para que la levadura fermente el pan, debe estar en la masa y no encerrada en un castillo de marfil".

Los conceptos de calidad y pertinencia están muy relacionados. Para Sanyal \& Martin (2007) hay dos enfoques de calidad de la educación superior: Un primer enfoque de la calidad basado en estándares, donde la calidad del programa se juzga por la medida en que éste satisface el conjunto de los estándares mínimos establecidos para los insumos, procesos y resultados. En el segundo enfoque la calidad viene determinada por la pertinencia de la misión/objetivos de un programa educativo (adecuación del objetivo) y por el nivel con que dicho programa los cumple (adecuación para el objetivo). Los autores prefieren el último enfoque pues comprueba si el programa logra el objetivo que se planteó y verifica si el objetivo en sí es aceptable. Concluyen que no es posible evaluar todas las instituciones y programas con los mismos estándares, dado que abastecen a clientelas específicas en un sistema de educación superior muy diversificado. Por tanto la garantía de la calidad (y la acreditación) no se pueden debatir sin tener en cuenta el contexto nacional del sistema de educación superior.

Para Knights \& Scarbrough (2010) la educación superior no sólo tendrá que ser pertinente sino que, además, esa pertinencia será juzgada en términos de productos, de la contribución que haga al desempeño de la economía nacional y, a través de ello, del mejoramiento sostenible de las condiciones de vida de las mayorías. Asimismo, la universidad será más pertinente cuando responda a las demandas del mercado, cuando su producción sea eficiente en términos de aplicabilidad inmediata, cuando sea más rentable y pueda obtener financiamiento externo.

Este concepto de pertinencia de las universidades representa un cambio del concepto de universidad tradicional de Von Humboldt y Newman, por tanto será necesario revisar la organización de las universidades y las relaciones con su entorno (Gibbons, 1998).

La mayoría de las universidades están organizadas según las disciplinas científicas. A este modo de organización Gibbons (1998) le llama Modo 1. En este caso, la investigación y los planes de estudio se organizan alrededor de lo que las disciplinas producen. Sin embargo, según Gibbons, ha surgido una nueva modalidad de producción del conocimiento con características propias que afectan el desempeño de la investigación y la enseñanza en las universidades llamada Modo 2. En el modo 2 se tiene un "sistema distribuido de producción de conocimiento" donde las universidades ya no tienen el monopolio de la producción del conocimiento. En el modo 1, los problemas se plantean y solucionan en el contexto regido

La pertinencia de las maestrías en ingeniería 
por los intereses (principalmente académicos) de una comunidad específica, en cambio en el modo 2, el conocimiento se produce en un contexto de aplicación, cuando se intenta resolver un problema real, dentro de un sistema complejo, en un territorio, en un contexto social, económico, político y ambiental determinado. El modo 1 se refiere a una disciplina y el modo 2 es transdisciplinario. En el modo 2 se tiene mayor responsabilidad social y se requiere intercambiar tecnología y compartir recursos en redes y asociaciones (Hessels \& Van Lente, 2008).

La difusión del modo 1 ha hecho que, por ejemplo, los planes de investigación y planes de estudio dentro de una carrera sean semejantes en todas las universidades del mundo. Como en el modo 1 es necesario el uso de métodos e instrumentos cada vez más avanzados, los planes de investigación científica en todo el mundo los deciden generalmente los países desarrollados. De esta forma los países desarrollados deciden también las formas de evaluar la calidad y la pertinencia de los programas formativos de educación superior. Se deduce entonces que los países en desarrollo se ven obligados a aceptar problemas y prioridades que les interesa poco o nada, sin embargo, si quieren participar en el plano internacional, entonces deben seguir los planes determinados por la comunidad científica internacional (Gibbons, 1998).

La mayoría de las universidades no cuestionan la arraigada creencia de que el modo 1 es la única forma de producir el conocimiento fundamental. Sin embargo el modo 1 no provee conocimientos en un contexto de aplicación, que es precisamente lo que necesitan los países en desarrollo. Estos países necesitan resolver problemas locales en el corto plazo comprendiendo sistemas complejos y no pueden esperar hasta que las estructuras de disciplinas lleguen a ocuparse de sus necesidades específicas. Tampoco pueden esperar a que los gobiernos nacionales incluyan dentro de las políticas de investigación a sus problemas locales, por eso una alternativa es organizarse según el modo 2. Este modo 2 también les permitiría compartir los escasos recursos con los que cuentan las universidades de los países en desarrollo e intercambiar tecnología a través de redes y asociaciones entre universidades, empresas y estado.

La pertinencia de las maestrías en ingeniería 
El modo 2 de Gibbons aterriza con la metodología de producción de conocimiento utilizada por el Grupo GESPLAN de la Universidad Politécnica de Madrid. En esta metodología, los pasos para lograr una producción científica sostenible y de calidad en un departamento académico o grupo de

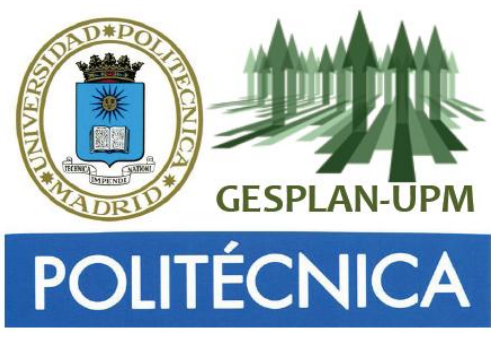
investigación son:

1. Partir de un conocimiento acumulado.

2. Desarrollar trabajos, consultoría y proyectos de investigación.

3. Presentar comunicaciones en congresos internacionales.

4. Publicar artículos en revistas indexadas.

5. Producir proyectos de fin de máster, tesis doctorales, definir líneas de investigación.

6. Desarrollar más publicaciones: libros, estudios, promover premios.

7. Hacer nuevas conexiones: mejorar la oferta de conocimiento acumulado.

8. Empezar de nuevo el ciclo.

Gráfico 1.1. Metodología para la producción de conocimiento del Grupo GESPLAN - UPM

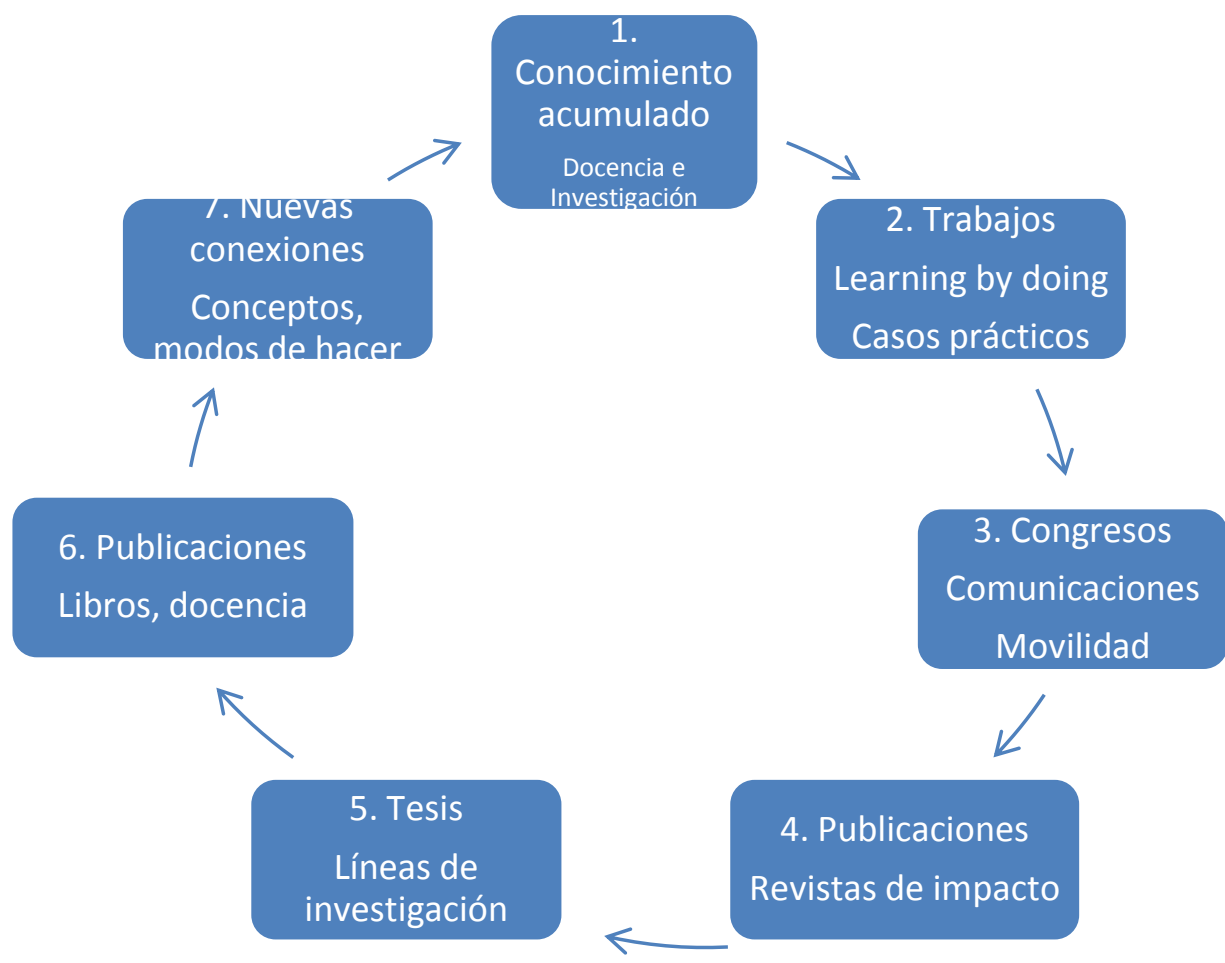

Fuente: Adaptado de Cazorla, 2013

La pertinencia de las maestrías en ingeniería 


\section{Un programa de postgrado garantiza su pertinencia entonces, si se inserta en un sistema como el del Grupo GESPLAN.}

\subsubsection{Diversos modos de vinculación de la universidad con el entorno}

Las universidades cumplen un rol muy importante en el crecimiento económico y desarrollo de un país, lo cual está muy ligados al nivel de investigación, innovación y competitividad. Para desempeñar mejor ese rol, las universidades tienen que estar muy vinculadas con su entorno, es decir con las empresas y el Estado principalmente (D’Este, 2009); (Cortes, 2006). Etzkowitz et. al (2000) se refiere a una triple hélice necesaria para el desarrollo de la innovación en una sociedad. El modelo se centra en el análisis de las relaciones e interacciones mutuas entre las universidades y los entornos científicos como primera pala de la hélice, las empresas e industrias como segunda pala y las administraciones o gobiernos como tercera pala. Asume que la innovación surge de las interacciones mutuas entre ellas.

La cooperación o trabajo en red es muy importante para la innovación ya que facilita la transferencia de conocimientos acumulados en las universidades, empresas, centros de investigación y permite reducir costos y riesgos asociados a las actividades de innovación (Veugelers \& Cassiman, 2005).

CEPAL (2010) en el estudio. "Espacios iberoamericanos: vínculos entre universidades y empresas para el desarrollo tecnológico" distingue cuatro aspectos en la relación de la universidad con el Estado: a) Legislación que promueva la innovación a través del trabajo conjunto entre en universidades y empresas; b) Financiamiento de proyectos de investigación, formación de postgrado; c) Regulación de la propiedad intelectual; d) desarrollo de parques tecnológicos.

Los modos de vinculación de la universidad con las empresas son más abundantes. Es importante para efectos de esta investigación revisar los distintos aspectos que pueden facilitar o entorpecer dicha vinculación. En la Tabla 1.4 se presentan las principales funciones y competencias de las universidades y las empresas que es importante considerar a la hora de evaluar y diseñar mecanismos de cooperación entre ambas instituciones (CEPAL, 2010).

La pertinencia de las maestrías en ingeniería 
Tabla 1.4. Funciones y competencias de universidades y empresas

\begin{tabular}{|c|c|c|}
\hline & Universidades & Empresas \\
\hline Funciones primarias & $\begin{array}{l}\text { Formar capital humano } \\
\text { Realizar investigación }\end{array}$ & $\begin{array}{l}\text { Producir utilidades } \\
\text { Mantenerse en el mercado }\end{array}$ \\
\hline $\begin{array}{l}\text { Motivaciones en la } \\
\text { generación del } \\
\text { conocimiento }\end{array}$ & $\begin{array}{l}\text { Motivaciones académicas } \\
\text { Poner a prueba el paradigma } \\
\text { científico y avanzar en él }\end{array}$ & $\begin{array}{l}\text { Mantener y expandir sus } \\
\text { ventajas competitivas gracias al } \\
\text { desarrollo de nuevos productos } \\
\text { o procesos. }\end{array}$ \\
\hline Uso de los resultados & $\begin{array}{l}\text { Difusión en la sociedad y en la } \\
\text { comunidad científica (mediante } \\
\text { seminarios y artículos de revistas, } \\
\text { entre otros) }\end{array}$ & $\begin{array}{l}\text { Innovación } \\
\text { Apropiabilidad y protección } \\
\text { (mediante mecanismos de } \\
\text { protección de la propiedad } \\
\text { intelectual: patentes, secreto } \\
\text { industrial, entre otros) }\end{array}$ \\
\hline $\begin{array}{l}\text { Criterios de } \\
\text { evaluación de los } \\
\text { resultados }\end{array}$ & $\begin{array}{l}\text { Evaluación por los pares (peer } \\
\text { review) y por la comunidad } \\
\text { cientifica }\end{array}$ & $\begin{array}{l}\text { Aplicabilidad, innovación } \\
\text { Rentabilidad }\end{array}$ \\
\hline $\begin{array}{l}\text { Tipo de coordinación } \\
\text { interna }\end{array}$ & Flexible & Jerárquica \\
\hline $\begin{array}{l}\text { Recursos financieros } \\
\text { para actividades de } \\
\text { investigación y } \\
\text { desarrollo }\end{array}$ & Mayoritariamente públicos & Mayoritariamente privados \\
\hline
\end{tabular}

Fuente: CEPAL (2010)

Las universidades establecen vínculos con las empresas buscando mejoras en la calidad de la formación y la investigación ya que encuentran aplicación práctica a sus investigaciones, se mantienen al tanto de los más recientes desarrollos tecnológicos y tienen acceso a tecnologías productivas, a estudios de casos complejos o aplicaciones tecnológicas que a veces solo pueden lograrse en las empresas (CEPAL, 2010).

Las razones que tendrían las universidades y las empresas para iniciar una interrelación se muestran en la Tabla 1.5 . 
Tabla 1.5. Razones para iniciar una interrelación entre universidad y empresa

\section{Universidad}

Empresa

- Dar solución a problemas específicos.

- Contar con una alternativa económica a las actividades internas de investigación y desarrollo (outsourcing).

- Desarrollar capacidades científicotecnológicas.

- Llevar adelante una estrategia innovadora de largo plazo para el mantenimiento y mejora de la competitividad.

Fuente: CEPAL (2010)

Las formas, la intensidad y los canales de interacción entre las universidades y las empresas son diversos y cambiantes y dependen en gran medida de la institucionalidad de cada país. En la Tabla 1.6 se presenta una clasificación de los canales de interacción entre universidad y empresa más utilizados.

Tabla 1.6. Tipos de interacción entre universidad y empresa.

\begin{tabular}{ll}
\hline \multicolumn{1}{c}{ Tipo de interrelación } & \multicolumn{1}{c}{ Canales } \\
\hline $\begin{array}{l}\text { Flujos de recursos } \\
\text { humanos. }\end{array}$ & $\begin{array}{l}\text { Pasantías. } \\
\text { Formación de estudiantes en las empresas. } \\
\text { Contratación de graduados. }\end{array}$ \\
\hline $\begin{array}{l}\text { Contactos informales entre } \\
\text { profesionales }\end{array}$ & $\begin{array}{l}\text { Redes profesionales } \\
\text { Intercambio de informaciones. }\end{array}$ \\
\hline $\begin{array}{l}\text { Actividades de difusión del } \\
\text { conocimiento }\end{array}$ & $\begin{array}{l}\text { Eventos, seminarios, conferencias, publicaciones, } \\
\text { publicaciones conjuntas. }\end{array}$ \\
\hline Servicios & $\begin{array}{l}\text { Servicios de asesoría, asistencia técnica, consultorías, uso } \\
\text { de equipos. }\end{array}$ \\
\hline Proyectos conjuntos & $\begin{array}{l}\text { Cooperación en investigación y desarrollo, contratos de } \\
\text { investigación, intercambio de investigadores, redes } \\
\text { formales de trabajo, parques científicos y tecnológicos. }\end{array}$ \\
\hline Licenciamiento & Patentes, oficinas de transferencia tecnológica (OTT). \\
\hline $\begin{array}{l}\text { Empresas de base } \\
\text { tecnológica }\end{array}$ & $\begin{array}{l}\text { Spin-offs, incubadoras, actores híbridos } \\
\text { conformados por la empresa y la universidad. }\end{array}$ \\
\hline
\end{tabular}

Fuente: CEPAL (2010)

Hay diversos canales de interacción entre universidad y empresa de acuerdo a su nivel de complejidad. Esta complejidad expresa la intensidad de la relación entre universidad y

La pertinencia de las maestrías en ingeniería 
empresa: cuanto más compleja es la forma de interrelación, más cerrados y fuertes son los vínculos y más sofisticada su gestión. Hay canales de baja complejidad, canales de complejidad media y canales de alta complejidad. En la Tabla 1.7 se muestran estos canales de comunicación con sus respectivas características.

Tabla 1.7. Canales de comunicación entre universidad y empresa

\begin{tabular}{|c|c|c|c|c|}
\hline $\begin{array}{c}\text { Nivel de } \\
\text { complejidad }\end{array}$ & Canal & Dirección & Formalidad & $\begin{array}{c}\text { Plazo } \\
\text { temporal }\end{array}$ \\
\hline \multirow[t]{3}{*}{ Baja } & $\begin{array}{l}\text { Flujo de } \\
\text { recursos } \\
\text { humanos }\end{array}$ & $\begin{array}{l}\text { Unidireccional: desde } \\
\text { la universidad hacia } \\
\text { las empresas. }\end{array}$ & Baja & Corto plazo \\
\hline & $\begin{array}{l}\text { Contactos } \\
\text { informales }\end{array}$ & $\begin{array}{l}\text { Bidireccional: ambas } \\
\text { partes proveen } \\
\text { conocimiento }\end{array}$ & Baja & Corto plazo \\
\hline & $\begin{array}{l}\text { Actividades de } \\
\text { difusión del } \\
\text { conocimiento. }\end{array}$ & $\begin{array}{l}\text { Unidireccional: desde } \\
\text { la universidad hacia la } \\
\text { sociedad }\end{array}$ & Media a baja & Corto plazo \\
\hline \multirow[t]{2}{*}{ Media } & Servicios & $\begin{array}{l}\text { Unidireccional: desde } \\
\text { la universidad hacia } \\
\text { las empresas. }\end{array}$ & Media a alta & $\begin{array}{l}\text { Medio o corto } \\
\text { plazo }\end{array}$ \\
\hline & $\begin{array}{l}\text { Proyectos } \\
\text { específicos }\end{array}$ & $\begin{array}{l}\text { Bidireccional: ambas } \\
\text { partes proveen } \\
\text { conocimiento }\end{array}$ & Alta & $\begin{array}{l}\text { Medio a largo } \\
\text { plazo }\end{array}$ \\
\hline \multirow[t]{2}{*}{ Alta } & Licenciamiento & $\begin{array}{l}\text { Bidireccional: ambas } \\
\text { partes proveen } \\
\text { conocimiento }\end{array}$ & Alta & Largo plazo \\
\hline & $\begin{array}{l}\text { Empresas de } \\
\text { base } \\
\text { tecnológica }\end{array}$ & $\begin{array}{l}\text { Bidireccional: ambas } \\
\text { partes proveen } \\
\text { conocimiento y } \\
\text { recursos }\end{array}$ & Alta & Largo plazo \\
\hline
\end{tabular}

Fuente: Elaboración propia, adaptado de CEPAL (2010) 


\subsection{DEFINICIÓN OPERATIVA DEL CONCEPTO DE PERTINENCIA}

\subsubsection{La formación de postgrado en ingeniería}

Por ingeniería entendemos la actividad humana que aplica conocimientos científicos y técnicos para resolver problemas concretos y satisfacer necesidades humanas con carácter inmediato, sin provocar colapsos y degradación de la naturaleza (Cazorla et. al, 2011). La ingeniería ha surgido principalmente en la búsqueda de soluciones a problemas prácticos (Arias, 1998) y es muy importante en el desarrollo humano, económico, social y cultural (UNESCO, 2010); (Scavarda, 2010). La ingeniería es fundamental para hacer frente a los Objetivos de Desarrollo del Milenio de la ONU, el mundo necesita más que nunca las soluciones que aporta la ingeniería para hacer frente a desafíos importantes que van desde la reducción de la pobreza hasta la atenuación del cambio climático. Sin embargo, según (UNESCO, 2010), en muchos países se está registrando una disminución del número de jóvenes (y sobre todo de mujeres) que estudian ingeniería.

La (UNESCO, 2010) estima que tan sólo en los países del África Subsahariana se necesitarían 2,5 millones de ingenieros y técnicos suplementarios para alcanzar la meta de relativa al acceso al agua potable y los servicios de saneamiento. Estima también que el valor del mercado mundial de la búsqueda de soluciones para atenuar el cambio climático (como fabricación de productos con bajo consumo de combustible fósil y establecimiento de sistemas de energías renovables) alcanzará pronto la suma de un billón de dólares y seguirá aumentando.

Para suscitar un mayor interés y lograr un incremento del número de estudiantes, la ingeniería tiene que innovar y transformarse. Es preciso adoptar nuevos enfoques en la enseñanza y la formación, especialmente en lo que se refiere a la instrucción práctica, al aprendizaje basado en el planteamiento de problemas y el aprendizaje basado en proyectos, que refleja la naturaleza misma de la ingeniería: resolver problemas (Palma et. al, 2011).

La ingeniería conecta las necesidades sociales con la innovación y las aplicaciones comerciales (Marjoram \& Zhong, 2010); (Marischio \& Von Pamel, 2000). El Foro Económico Mundial, en su Reporte de Competitividad Global, en el pilar N ${ }^{\circ} 11$ "Innovación", considera como indicadores de competitividad, la disponibilidad de científicos e ingenieros así como la

La pertinencia de las maestrías en ingeniería 
colaboración entre universidad e industria en I+D (World Economic Forum, 2012). La relación entre ciencia, tecnología e ingeniería se muestra en la Gráfico 1.

Gráfico 1.2. Relación entre ciencia, tecnología e ingeniería

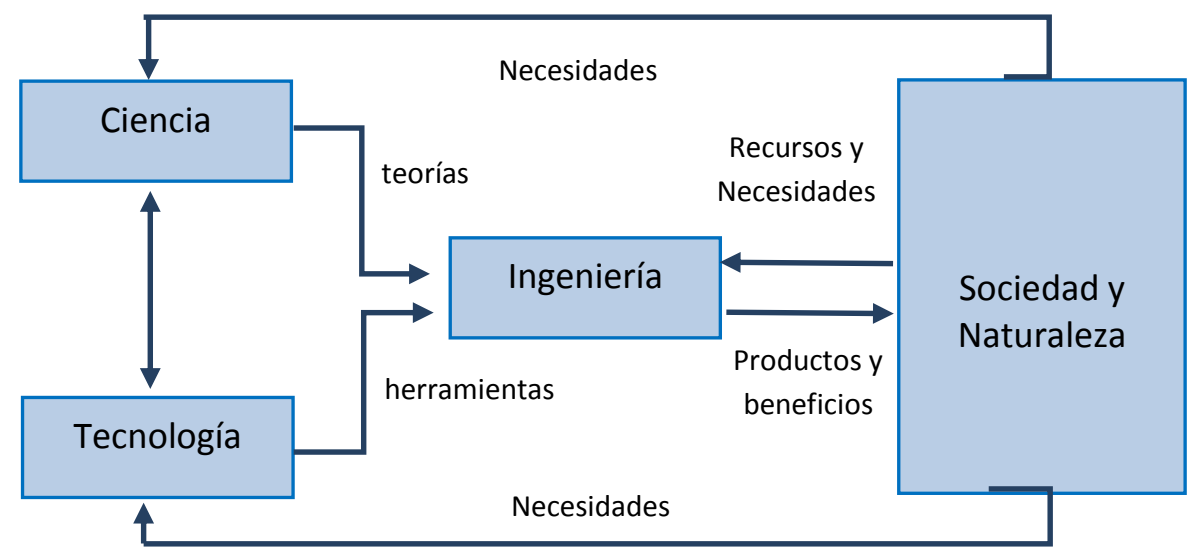

Fuente: UNESCO (2010)

La formación en ingeniería por tanto debe considerar estos aspectos y debe proporcionar capacidad técnica, flexibilidad y comprensión del contexto social en que se encuentra (Augustine \& Vest, 1994). El espacio donde se fortalece el vínculo entre las universidades y su entorno es el postgrado (Mendieta, 2013); (AUIP, 2009); (CONACYT, 2004); (Cruz, 2003). Las maestrías en ingeniería, contribuyen a reforzar dicho vínculo.

Postgrado, para los efectos de esta tesis, es la formación de nivel superior avanzado que se imparte después de una licenciatura o grado, de un título universitario, cuyo propósito fundamental es el ejercicio especializado de una profesión, la preparación para la docencia universitaria, la investigación o la aplicación tecnológica. La investigación y la innovación son características particulares de este nivel de formación. En la actualidad, el postgrado cumple dos funciones diferentes: una, la formación de quienes pretenden continuar su educación en el nivel avanzado y, otra, el reciclaje de profesionales que regresan a las universidades para complementar su formación o desarrollarse en nuevas áreas de conocimiento demandadas por el nuevo contexto económico y social (AUIP, 2009).

De acuerdo con la Asociación Universitaria Iberoamericana de Postgrado - AUIP (r2009) se puede distinguir tres niveles de formación en postgrado: los cursos de especialización, las maestrías y los doctorados. La Especialización es una extensión de la formación profesional y profundiza en un campo del saber específico, responden, por lo general, a demandas de formación del mundo del trabajo. La maestría brinda una formación amplia y profunda en 
un campo del saber académico o profesional, a la vez que proporciona conocimientos avanzados, generalmente, de carácter interdisciplinario. Puede tener como objetivo desarrollar una alta capacidad para la innovación del ejercicio profesional, para el ejercicio de la docencia de alto nivel y para la investigación. El doctorado ofrece preparación para la investigación o para la innovación y genera aportes originales significativos al acervo de conocimientos en un área específica.

En cuanto a las maestrías, hay que distinguir dos tipos: las maestrías "profesionales" que tienen como objetivo desarrollar una alta capacidad para la innovación del ejercicio profesional y las "maestrías de investigación" que tienen como meta la iniciación en la investigación (AUIP, 2009). En la Tabla 1.8 se muestra un cuadro comparativo con las características de cada uno de estos tipos de maestría identificados por AUIP.

Tabla 1.8. Características de los dos tipos de maestría identificados por AUIP (2009)

\begin{tabular}{|c|c|}
\hline Maestría profesional & Maestría de investigación \\
\hline $\begin{array}{l}\text { - Brinda una formación de alto nivel en el } \\
\text { conocimiento avanzado. } \\
\text { críticamente los avances de una } \\
\text { disciplina, con el objetivo de } \\
\text { transferirlos a la práctica, resolviendo } \\
\text { problemas de manera innovadora } \\
\text { - Tiene un enfoque interdisciplinario. } \\
\text { - Favorece la mejora continua del } \\
\text { quehacer profesional. }\end{array}$ & $\begin{array}{l}\text { - Brinda una amplia formación en los } \\
\text { paradigmas del campo de estudio y en } \\
\text { los aspectos teóricos y metodológicos } \\
\text { indispensables para generar nuevo } \\
\text { conocimiento } \\
\text { - Desarrolla la capacidad de hacer } \\
\text { generalizaciones, plantear problemas y } \\
\text { proponer proyectos de investigación, } \\
\text { con rigor metodológico y juicio crítico. } \\
\text { En algunos casos, estos programas son } \\
\text { reconocidos como el primer tramo en la } \\
\text { formación doctoral. }\end{array}$ \\
\hline
\end{tabular}

Fuente: Elaboración propia a partir de AUIP (2009)

En la Clasificación Internacional Normalizada de la Educación (CINE) de la UNESCO (2011), no sólo se consideran maestría profesionales sino también doctorados profesionales. Así el nivel 7 (maestría o equivalente) y el nivel 8 (doctorado o equivalente) están subdivididos 
en programas con orientación académica, programas con orientación profesional y programas con orientación no especificada ${ }^{4}$.

En América Latina y el Caribe existe una mayor oferta de programas de postgrado profesionales o de corte "profesionalizante", especialmente en las áreas de ciencia y tecnología como ingeniería, en desmedro de los programas de postgrado de “investigación” (Sánchez, 2008). La situación se complica cuando no se hace la diferencia y se mezclan propósitos, perfiles (de ingresantes y egresados), tipo de trabajo de grado, entre otros. Sánchez Maríñez propone el marco de referencia mostrado en la Tabla 1.9.

Se debe tener claro el propósito central del programa de maestría (si es profesional o de investigación) porque dependiendo de éste se desarrollan la planificación, el diseño, la evaluación, las acciones de mejora, etc. Si no se tiene claro entonces podría pasar que se imponga como requisito para obtener el grado, la realización de una investigación original en un programa profesionalizante, o que en un programa de tipo académico predominen profesores con un perfil profesional, que pueden ser muy competentes en su ejercicio aplicado, pero muy divorciados de la investigación científica o la producción intelectual propiamente dichas. O puede pasar que se utilicen criterios y estándares de evaluación de un tipo de programa aplicados a un programa del otro tipo (Sánchez, 2008).

La calidad del postgrado y en general la calidad de la educación superior es un concepto con una gran variedad de significados. Es un concepto multidimensional, dinámico que depende en gran medida del marco contextual de un sistema determinado, depende de la misión institucional o de las condiciones o normas dentro de una disciplinada dada (CINDA, 2009)

Para la (AUIP, 2009) la calidad del postgrado está muy ligada a la satisfacción de necesidades del entorno porque el postgrado se caracteriza principalmente por la investigación, la innovación, el estudio y solución de problemas específicos.

\footnotetext{
${ }^{4}$ Para mayor información ver http://unesdoc.unesco.org/images/0021/002116/211619s.pdf.
}

La pertinencia de las maestrías en ingeniería 
Tabla 1.9: Diferencias entre las maestrías profesionales y las de investigación

\begin{tabular}{|c|c|c|}
\hline Aspecto & Profesional & De Investigación \\
\hline Propósito & $\begin{array}{l}\text { Desarrollo de conocimientos } \\
\text { / competencias } \\
\text { profesionales. }\end{array}$ & $\begin{array}{l}\text { Desarrollo de capacidades de } \\
\text { investigación o creación } \\
\text { intelectual. }\end{array}$ \\
\hline Perfil del ingresante & $\begin{array}{l}\text { Profesional, con experiencia, } \\
\text { en busca de especialización o } \\
\text { profundización de } \\
\text { conocimientos aplicados. }\end{array}$ & $\begin{array}{l}\text { Con o sin experiencia } \\
\text { profesional, con intereses en la } \\
\text { investigación. }\end{array}$ \\
\hline Perfil del egresado & Profesional o Consultor & Investigador o Docente \\
\hline Perfil del docente & Profesional / Docente & Investigador / Docente \\
\hline $\begin{array}{l}\text { Nivel de } \\
\text { estructuración de los } \\
\text { aprendizajes }\end{array}$ & $\begin{array}{l}\text { Media a alta, predominio de } \\
\text { cursos, talleres y prácticas } \\
\text { estructuradas. }\end{array}$ & $\begin{array}{l}\text { Media a baja, se valora el estudio } \\
\text { y la producción independiente. }\end{array}$ \\
\hline $\begin{array}{l}\text { Experiencias } \\
\text { formativas }\end{array}$ & Participación en proyectos. & $\begin{array}{l}\text { Participación en actividades de } \\
\text { investigación o producción } \\
\text { intelectual. }\end{array}$ \\
\hline Trabajo de grado & $\begin{array}{l}\text { Proyecto o prototipo. } \\
\text { Tesis: modelos o sistemas de } \\
\text { intervención. }\end{array}$ & $\begin{array}{l}\text { Revisión de la literatura. } \\
\text { Tesis: Investigación }\end{array}$ \\
\hline $\begin{array}{l}\text { Evaluadores del } \\
\text { programa }\end{array}$ & $\begin{array}{l}\text { Expertos profesionales y } \\
\text { empleadores o beneficiarios } \\
\text { de la actividad profesional. }\end{array}$ & Pares académicos \\
\hline
\end{tabular}

Fuente: Adaptado de Sánchez (2008).

Para la Organización Internacional de Normalización ISO la definición de la calidad aplicada a la educación superior podría ser: "especificar objetivos de aprendizaje que merezcan la pena y permitir que los estudiantes los alcancen" (Gola, 2003). Especificar objetivos de aprendizaje que merezcan la pena implicaría articular estándares académicos que cumplan: i) las expectativas de la sociedad; ii) las aspiraciones de los estudiantes; iii) las demandas del gobierno, las empresas y la industria, y iv) las necesidades de las instituciones profesionales.

Para De Miguel (2003) hay dos aproximaciones al concepto de calidad. La primera aproximación indica que la calidad es la búsqueda de la "excelencia académica en la 
transmisión del conocimiento por el conocimiento" donde cada profesor es una autoridad en su materia. La segunda aproximación indica que la calidad es un "problema a negociar" entre las partes interesadas del programa formativo y por tanto debe atender simultáneamente: i) los intereses del Estado si la universidad es pública o los promotores si es privada, ii) los intereses de los de los profesores y iii) las necesidades sociales y del mercado (Clark, 1998); (Green, 1994).

La calidad del postgrado en ingeniería por tanto tiene mucho que ver con atender necesidades del entorno y entonces tan importante como la calidad de la formación de postgrado es su pertinencia. Para (Cruz, 2003) la calidad de los programas de postgrado en los países en desarrollo está relacionada especialmente con dos tipos de necesidades: la de "nivelar por lo alto", es decir, poder compararse con los países más desarrollados y la de contar con una oferta académica adecuada a las necesidades del entorno socio económico local. Se exige a los posgraduados estar preparados no solamente para resolver los problemas del entorno local o nacional sino para operar también en escenarios internacionales.

Es importante indicar que los estudios de pregrado son muy diferentes a los de postgrado. En el postgrado, que puede ser a tiempo completo o parcial, los estudiantes son sujetos activos de su propio aprendizaje y aprenden no solo del docente sino también de sus compañeros, que en número es mucho menor que en pregrado. El aprendizaje se da en un contexto concreto, que puede ser incluso el ámbito laboral del estudiante. Los estudiantes de postgrado saben lo que quieren y necesitan y muy probablemente ellos mismos se pagan los estudios, por tanto son más exigentes. Los docentes de postgrado deben tener experiencia profesional en la especialidad y los planes de estudio son más fáciles de actualizar.

Para Rama (2008) el postgrado requiere procesos de evaluación y acreditación internacionales mientras que el pregrado está asociado a la evaluación y acreditación local. El postgrado se rige principalmente por una regulación internacional y de mercado, y el pregrado se rige principalmente por una regulación nacional académica.

En el postgrado el proceso de enseñanza aprendizaje es tan importante como lo es la investigación, que es un proceso de alto grado de autonomía y creatividad. En las carreras de ingeniería y tecnología la investigación debe principalmente tender a solucionar problemas reales del sector productivo con la participación de grupos interdisciplinarios (Cruz, 2003).

La pertinencia de las maestrías en ingeniería 
Los postgrados globales van más allá de los procesos de Investigación y Desarrollo I+D y están incursionando en los procesos de Investigación, Desarrollo e innovación $\mathrm{I}+\mathrm{D}+\mathrm{i}$. Las universidades de clase mundial están eliminando departamentos y creando institutos multidisciplinares para animar a los académicos e investigadores a ir más allá de sus propias disciplinas, a trabajar en equipo y a intentar ser más creativos, más innovadores y más eficientes en la solución de los problemas de su entorno (AUIP, 2009). Todo esto implica cambios importantes en el enfoque de formación de postgrado y, por supuesto, también cambios en los indicadores de evaluación de la calidad que se han estado utilizando (Abreu et. al, 2009).

De acuerdo con Abreu et. al (2009) es necesario no sólo revisar y ajustar los indicadores de calidad usados hasta ahora (indicadores de primera generación: procesos de selección de alumnos y profesores, plan de estudios, infraestructura, procesos de formación y seguimiento de alumnos, gestión y resultados en términos de productividad científica, número de graduados), sino también definir y validar otros indicadores de segunda generación que pongan énfasis en procesos de $\mathrm{I}+\mathrm{D}+\mathrm{i}$ relevantes y vinculados al entorno.

Para Fernández (2010) uno de los grandes retos que debe asumir el postgrado es la internacionalización de su enseñanza y para ello es necesaria la cooperación entre universidades y centros de investigación nacionales e internacionales. Según Fernández las principales demandas del postgrado serían: la formación continua, la movilidad estudiantil, el aumento de la oferta de formación multidisciplinaria y el uso de metodologías semipresenciales o virtuales. En el caso de ingeniería es importante considerar que la alta velocidad de generación de nuevos conocimientos tecnológicos y científicos está originando dos cosas: una presión por disminuir la duración de los estudios de postgrado y una presión para que la enseñanza deba realizarse en relación cada vez más directa con las empresas y con el sector industrial de bienes y servicios.

Smerdon (2000) señala que en el pasado la mayoría de las titulaciones de postgrado en los EE.UU. se habían dirigido hacia la investigación y el logro académico, educando a los estudiantes de postgrado para llenar puestos de investigación. Sin embargo los profesores universitarios de mañana tienen que mirar el mercado y determinar lo que los clientes (que es más que los estudiantes) quieren.

La pertinencia de las maestrías en ingeniería 


\subsubsection{Definición de pertinencia de una maestría en ingeniería}

Para evaluar la pertinencia de una maestría en ingeniería se necesita una definición operativa de la pertinencia, algo que nos permita luego identificar claramente los factores e indicadores para su evaluación. En la teoría de planificación de proyectos encontramos una definición de pertinencia que es muy útil en nuestros propósitos.

Para la Comisión Europea (1999) pertinencia es la adecuación de los objetivos explícitos de una intervención, con respecto a los problemas socio-económicos que la intervención pretende resolver. La pertinencia es importante sobre todo en la evaluación ex ante de los programa y proyectos, porque la atención se centra en la estrategia elegida o en su justificación. En una evaluación intermedia es necesario comprobar si el contexto socioeconómico se ha desarrollado como se esperaba y si esta evolución pone en cuestión determinados objetivos iniciales (European Comission, 1999).

En consecuencia podemos decir que una maestría en ingeniería es pertinente si los objetivos que se plantea se adecúan a las necesidades de formación de los estudiantes, si se adecúan a los intereses de la universidad y si resuelven problemas del contexto socio-económico contribuyendo al desarrollo de su comunidad.

El contexto socioeconómico de la maestría en el caso de las "universidades de investigación”, en los países desarrollados principalmente, es el contexto global. Sin embargo, para una maestría en ingeniería en un país en desarrollo, que generalmente es a tiempo parcial, es de tipo profesionalizante (no de investigación) y la inversión en actividades de $\mathrm{I}+\mathrm{D}+\mathrm{i}$ es muy poca, ese contexto no necesariamente es el global.

Si bien, en los países en vías de desarrollo, los estudiantes deben actualizarse en los últimos avances de la ciencia, la aplicación de los conocimientos adquiridos en la maestría está generalmente limitada a un espacio geográfico nacional o local. Entonces se tiene que la maestría debería tener Pertinencia Global y Pertinencia Local. Si se quiere que una maestría sea pertinente se debe tener en cuenta estas diferencias (Ver Tabla 1.10).

La pertinencia de las maestrías en ingeniería 
Tabla 1.10. Diferencias entre las maestría en ingeniería de las universidades de los países desarrollados y las de los países en desarrollo

\begin{tabular}{lll}
\multicolumn{1}{c}{$\begin{array}{c}\text { Aspecto de la } \\
\text { maestría }\end{array}$} & \multicolumn{1}{c}{$\begin{array}{c}\text { Universidades de países } \\
\text { desarrollados }\end{array}$} & \multicolumn{1}{c}{$\begin{array}{c}\text { Universidades de países en } \\
\text { desarrollo }\end{array}$} \\
\hline Producción de & Trabaja en la frontera del & Utiliza el conocimiento producido \\
conocimiento & enocimiento los países desarrollados \\
\hline Perfil del & Estudiantes de diferentes & Estudiantes nacionales, mayormente \\
estudiante & partes del mundo & del departamento donde se dicta la \\
& & maestría. \\
\hline Perfil del egresado & Va a desempeñarse & Mayormente va a trabajar en una \\
& profesionalmente o & empresa local o nacional. \\
& investigar en cualquier parte & \\
& del mundo & \\
\hline Investigación & Básica y aplicada & Aplicada cuando la hay (el \\
& & porcentaje de egresados que \\
& & culminan el proyecto de fin de \\
& máster es bajo) \\
\hline Modalidad & Generalmente tiempo & Generalmente tiempo parcial (fines \\
& completo & de semana) \\
\hline
\end{tabular}

Fuente: Elaboración propia a partir de la revisión bibliográfica

Podemos considerar que una maestría tiene Pertinencia Global si cumple con estándares internacionales comúnmente aceptados en los modelos de evaluación con fines de acreditación internacional.

Sobre la Pertinencia Local, hay varios aspectos que nos pueden dar indicios de qué tanta Pertinencia Local tiene una maestría en ingeniería, es decir qué tan vinculada está con su entorno, qué tanto satisface las necesidades de los estudiantes, empleadores y comunidad y qué tanto ayuda a la universidad a cumplir con sus misiones. Ver Gráfico 1.3.

La pertinencia de las maestrías en ingeniería 
Gráfico 1.3. Dimensiones de la pertinencia de una maestría en ingeniería

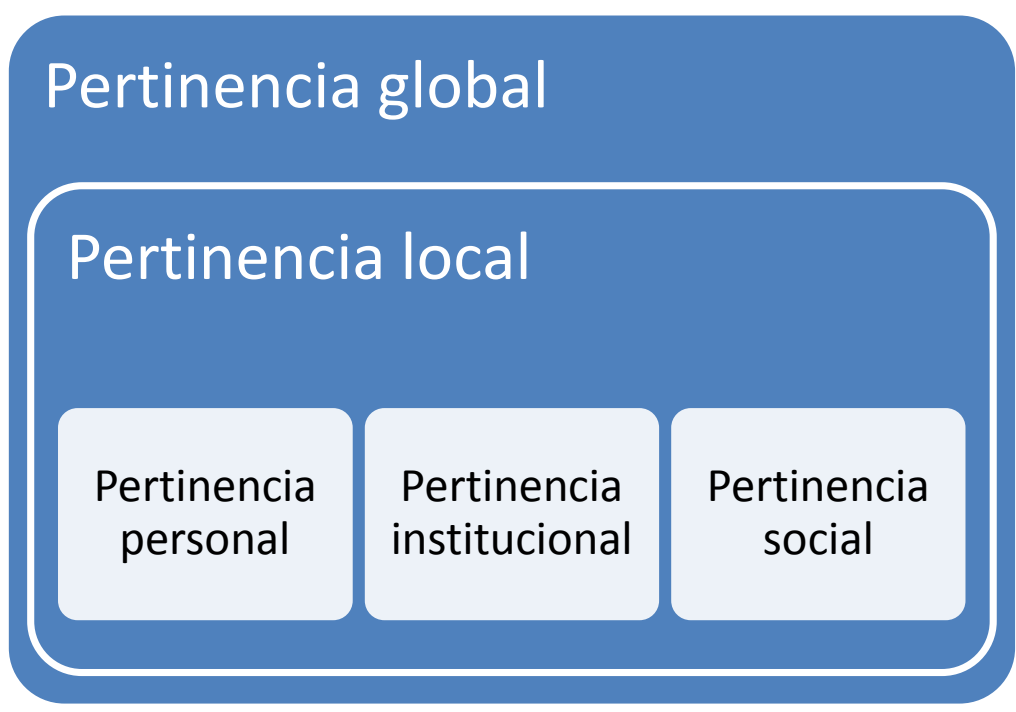

Fuente: Elaboración propia

Hablamos por tanto de tres dimensiones de la Pertinencia Local. La primera es la Pertinencia Personal de la maestría que tiene que ver con la satisfacción personal de estudiantes, egresados y empleadores. Una maestría en ingeniería es pertinente si satisface las necesidades de formación de sus estudiantes, es decir si hay una adecuación de los contenidos (plan de estudios) con las necesidades e intereses de los estudiantes y con las necesidades del mercado laboral. Estos estudiantes son profesionales que laboran en un contexto donde es necesario el conocimiento especializado para la resolución de problemas. Un egresado del programa estará contento si la maestría le ayudó a mejorar su desempeño laboral, a desarrollar las competencias necesarias, a mejorar su situación laboral (remuneración) y si la maestría está en contacto con él después de terminar el programa. Los empleadores a su vez estarán satisfechos si el mejor desempeño laboral de estos estudiantes logrado por la maestría redunda en beneficio de la compañía.

La segunda dimensión de la Pertinencia Local es la Pertinencia Social que tiene que ver con la vinculación de los docentes de la maestría (y la investigación que realizan) con el entorno. De acuerdo con (Hansen \& Lehmann, 2006); (Etzkowitz et. al, 2000) y (Gibbons, 1998), las interacciones entre la universidad, la industria y el estado son la base para el acceso al desarrollo económico. Un programa de maestría es más pertinente si la investigación científica que promueve es multidisciplinaria y centrada en problemas y si los proyectos de fin de máster están orientados hacia la solución de problemas en las empresas o al desarrollo de proyectos de innovación.

La pertinencia de las maestrías en ingeniería 
La tercera dimensión de la Pertinencia Local es la Pertinencia Institucional que tiene que ver con la alineación de los objetivos de la maestría con la misión, objetivos y políticas de la universidad que la imparte. Por ejemplo debe haber correspondencia entre la dirección y administración de la maestría con las políticas y procedimientos de trabajo de la institución que la acoge, ya que finalmente es ésta la que decide el dictado o no de la maestría. Asimismo, la maestría se adecúa más a las necesidades e intereses de la universidad que la acoge si la ayuda a cumplir con su misión de investigación y le da visibilidad, es decir, si sus docentes investigan y publican usando el nombre de dicha universidad.

El modelo de evaluación de la pertinencia que se quiere construir en la presente investigación considera estas dimensiones.

\subsubsection{Importancia de la evaluación de la pertinencia de las maestrías en ingeniería}

La evaluación de la pertinencia de las maestrías en ingeniería es importante por varias razones. La primera tiene que ver con la definición misma y la razón de ser de la ingeniería, que es utilizar los avances de la ciencia y las herramientas que brinda la tecnología para resolver problemas, por tanto un programa de formación en ingeniería debe estar vinculado con el entorno, resolviendo sus problemas o atendiendo sus necesidades. La segunda tiene que ver con las características del postgrado. En este nivel de formación se deben brindar conocimientos especializados, ya sea con el fin de desarrollar capacidades para del desempeño profesional de la carrera de ingeniería (maestría profesional) o como primer paso en el desarrollo de un doctorado (maestría de investigación), en ambos casos debe haber una estrecha vinculación con el entorno.

Es importante evaluar la pertinencia también porque las condiciones originales de diseño de la maestría pueden haber cambiado: las necesidades de capacitación de los estudiantes, los avances tecnológicos, el estado de desarrollo económico del país (crisis o crecimiento), el desarrollo de algunos sectores económicos o aparición de otros, las normas técnicas, leyes, entre otros. Puede haber cambiado también los intereses y políticas de la universidad que acoge a la maestría. En general, la organización del programa de maestría debe estar atenta para adecuar sus procesos y procedimientos a la atención de las cambiantes necesidades e intereses de los estudiantes, la universidad y las partes interesadas.

La pertinencia de las maestrías en ingeniería 
Si bien una universidad puede establecer su misión institucional y los objetivos de una maestría en ingeniería no ligándolos necesariamente a las necesidades e intereses del entorno socio económico local o nacional, sino en relación con algunas necesidades e intereses propios, de todas maneras tiene que conectar con las necesidades e intereses de los estudiantes (cuidando la pertinencia global) si quiere garantizar la calidad y sostenibilidad de dicha maestría.

En el caso de los países en vías de desarrollo es importante garantizar también la pertinencia local de las maestrías en ingeniería, como la hemos definido en el apartado anterior, porque la forma de desarrollar el postgrado en estos países no es la misma que la que tienen los países desarrollados. El postgrado en un país está muy ligado a su nivel de desarrollo económico (World Economic Forum, 2012).

El Foro Económico Mundial, en su Reporte de Competitividad Global ${ }^{5}$, clasifica a los países de acuerdo a su estado o etapa de desarrollo económico. Identifica tres estados de desarrollo o tipos de economía: Las "factor driven economies" (economías impulsadas por aumentos en factores productivos), las "efficiency driven-economies" (economías impulsadas por mejoras de eficiencia) y las "innovation driven economies" (economías impulsadas por la innovación). En la Tabla 1.11 se muestran los 12 pilares de la competitividad de un país agrupados de acuerdo a la importancia de éstos en cada uno de los tres estados de desarrollo económico.

Todos los pilares de competitividad importarán en cierta medida para todas las economías pero afectan de diferentes maneras. La mejor manera que tiene Vietnam para mejorar su competitividad no es la misma que tiene Canadá. Esto se debe a que Vietnam y Canadá se encuentran en diferentes etapas de desarrollo (World Economic Forum, 2012).

Es errado que todos los países pretendan imitar el modelo de crecimiento de Estados Unidos, que desde 1870 viene expandiéndose a una tasa más o menos constante basado en el desarrollo tecnológico. En cambio, los países con abundantes recursos naturales como Perú deberían observar qué han hecho Australia (minerales), Noruega (petróleo) o Canadá

\footnotetext{
${ }^{5}$ El Índice de Competitividad Mundial para este ranking mundial está compuesto por 113 variables sobre 125 países del mundo agrupadas en doce pilares que pretenden sintetizar el conjunto de instituciones, políticas y factores que determinan la productividad de un país. Estos pilares son: Instituciones, infraestructura física, estabilidad macroeconómica, seguridad, capital humano, mercado de bienes eficiente, eficiencia en el mercado del trabajo, eficiencia en el mercado financiero, disponibilidad de tecnología, apertura y tamaño de los mercados, sofisticación de los negocios y la innovación.
}

La pertinencia de las maestrías en ingeniería 
(petróleo), y basar su modelo de desarrollo en sus fortalezas. El factor tecnológico será incorporado con el tiempo y debido a la necesidad del crecimiento (Kuczynski et. al, 2014) ${ }^{6}$; (Krugmann, 2014) $)^{7}$

Tabla 1.11. Los 12 pilares de la competitividad según World Economic Forum (2012)

\begin{tabular}{|c|c|c|}
\hline Tipo & Pilar & Crucial para \\
\hline $\begin{array}{l}\text { Requisitos } \\
\text { básicos }\end{array}$ & $\begin{array}{l}\text { Instituciones } \\
\text { Infraestructura } \\
\text { Macroeconomía } \\
\text { Salud y Educación Primaria }\end{array}$ & $\begin{array}{l}\text { Crucial para economías impulsadas por } \\
\text { factores productivos (recursos } \\
\text { naturales y mano de obra barata). } \\
\text { Bolivia, Vietnam }\end{array}$ \\
\hline $\begin{array}{l}\text { Reforzadores } \\
\text { de Eficiencia }\end{array}$ & $\begin{array}{l}\text { Educación Superior y } \\
\text { Capacitación } \\
\text { Eficiencia del mercado de } \\
\text { bienes } \\
\text { Eficiencia del mercado } \\
\text { laboral } \\
\text { Desarrollo del mercado } \\
\text { financiero } \\
\text { Preparación tecnológica } \\
\text { Tamaño del mercado }\end{array}$ & $\begin{array}{l}\text { Crucial para economías impulsadas por } \\
\text { la eficiencia (Procesos de producción } \\
\text { más eficientes productos con valor } \\
\text { agregado mejores niveles salariales). } \\
\text { Argentina, Brasil, China, Rusia, Perú. }\end{array}$ \\
\hline $\begin{array}{l}\text { Variables de } \\
\text { innovación }\end{array}$ & $\begin{array}{l}\text { Sofisticación empresarial } \\
\text { Innovación }\end{array}$ & $\begin{array}{l}\text { Crucial para las economías impulsadas } \\
\text { por la innovación (Altos niveles } \\
\text { salariales y niveles de vida sostenibles a } \\
\text { través de empresas altamente } \\
\text { competitivas con producción de bienes } \\
\text { y servicios innovadores). Suiza, } \\
\text { EE.UU, Canadá, Alemania, España. }\end{array}$ \\
\hline
\end{tabular}

Fuente: World Economic Forum (2012)

De igual forma sucede en el postgrado. La mejor manera que tienen los países desarrollados para desarrollar su postgrado no es la misma que tienen los países en desarrollo. Por ello es importante la pertinencia de una maestría en ingeniería en los países en desarrollo, porque la vincula con el entorno, porque promueve la investigación y la innovación al ponerla en contacto con los problemas de su contexto socioeconómico. Esto indudablemente contribuye a la mejora de la calidad de la maestría.

Para facilitar la pertinencia de la maestría en ingeniería, la universidad podría organizarse según el esquema del modo 2, es decir formando parte de un sistema distribuido de

\footnotetext{
${ }^{6}$ Kuczynski fue Presidente del Consejo de Ministros de Perú (2004 - 2006), Ministro de Economía y Finanzas (2001) y Ministro de Energía y Minas (1980)

${ }^{7}$ Premio Nóbel de Economía 2008
}

La pertinencia de las maestrías en ingeniería 
producción de conocimiento, conformando redes y asociaciones con empresas y los gobiernos. La investigación debería estar centrada en problemas, aplicada en un contexto determinado, con equipos transdisciplinarios. No se hablaría de investigadores sino principalmente de identificadores, solucionadores e intermediarios de problemas.

\subsection{CONCLUSIONES DEL CAPÍTULO I}

La educación superior universitaria en el siglo XXI es masiva, es transfronteriza, se ha internacionalizado. Existe movilidad de estudiantes y profesores, es cada vez más privada, más virtual y se busca garantizar la calidad a través de procesos de acreditación. Debido que los cambios tecnológicos se producen muy rápidamente hay una gran demanda de formación permanente. En este contexto de cambios permanentes la universidad debe cumplir con sus tres misiones: la enseñanza, la investigación y la extensión. Para lograrlo debe estar muy vinculada a su entorno socio económico.

La economía de la educación superior ha cambiado de una lógica basada en la oferta a una economía basada en la demanda. Para atender esa demanda, las universidades han tenido que desarrollar distintos modos de vinculación con el entorno productivo y empresarial como: desarrollar patentes de manera conjunta, crear empresas de base tecnológica, desarrollar proyectos de innovación conjuntos, brindar servicios de consultoría, pasantías, programas de formación permanente, entre otros. En esta investigación analizaremos los programas de formación permanente como las maestrías teniendo presente que existe una fuerte relación entre este canal de vinculación con los otros descritos en el apartado 1.1.3.

La generación de nuevos conocimientos y la innovación, tan importantes actualmente para lograr competitividad y crecimiento económico de un país, no depende solamente de las universidades o centros de investigación, o de las empresas individuales, sino que depende de redes formadas por organizaciones de distintos tipos que persiguen distintos objetivos. En las universidades existen dos modos de generación y distribución del conocimiento, según (Gibbons, 1998). En el Modo 1 las universidades se organizan de acuerdo a las disciplinas científicas y la investigación se organiza alrededor de éstas disciplinas, los problemas se plantean y solucionan en el contexto regido por intereses principalmente académicos. En el Modo 2 se tiene un "sistema distribuido de producción de conocimiento", los problemas se plantean y solucionan en el contexto de aplicación, dentro de un sistema complejo, en un territorio, en un contexto social, económico, político y ambiental determinado. En el modo

La pertinencia de las maestrías en ingeniería 
2 se tiene mayor responsabilidad social y se requiere intercambiar tecnología y compartir recursos en redes y asociaciones. Este modo 2 le permite a la universidad tener mayor pertinencia.

La educación superior universitaria es pertinente si sus objetivos y resultados se adecúan a los problemas y necesidades de su entorno socioeconómico y no sólo busca el conocimiento por el conocimiento en sí, sino que también sirve a la sociedad, mejorando las condiciones de vida de sus ciudadanos.

El desarrollo de la educación superior en un país, por tanto debe considerar su contexto socio económico. Así el camino que debe seguir un país de altos ingresos para el desarrollo de su postgrado no es el mismo camino que debe seguir un país con bajos ingresos. Depende mucho de las características de su economía y de su competitividad. Aquí empieza a ser importante el concepto de pertinencia.

Una maestría en ingeniería es pertinente si los objetivos que se plantea se adecúan a las necesidades de formación de los estudiantes, si se adecúan a los intereses de la universidad y si resuelven problemas del contexto socio-económico contribuyendo al desarrollo de su comunidad.

Para facilitar la construcción de un modelo de evaluación de la pertinencia de una maestría en ingeniería debemos hablar de dos tipos de pertinencia: la global y la local. La pertinencia global implica desarrollar en los estudiantes competencias de acuerdo a los avances globales de la ciencia y la tecnología utilizando contenidos actualizados. La pertinencia local tiene tres dimensiones: una personal, una institucional y una social. La pertinencia personal debe buscar la mejora del desempeño profesional y del nivel de competitividad de los estudiantes de modo que éstos puedan acceder por ejemplo a mejores salarios y ascensos. La pertinencia institucional significa alinear los objetivos de la maestría a la misión, objetivos estratégicos y políticas de la universidad que la acoge. Y la pertinencia social implica conectar a la maestría con problemas, necesidades y prioridades nacionales y regionales.

Es importante evaluar la pertinencia de una maestría en ingeniería por varias razones. La primera, por la definición misma de "ingeniería" que está ligada a resolver problemas del entorno y satisfacer necesidades. Las características mismas del postgrado obligan también a vincular el programa con el entorno, brindando conocimientos especializados de aplicación inmediata y desarrollando investigación multidisciplinaria centrada en problemas reales, en

La pertinencia de las maestrías en ingeniería 
un contexto determinado (modo 2 de Gibbons). Es importante también como evaluación intermedia pues las condiciones de diseño de la maestría pueden haber cambiado.

Es importante tener en cuenta que principalmente en las carreras ligadas a la ciencia y la tecnología como ingeniería, hay dos tipos de maestría: las maestrías "profesionales" que tienen como objetivo desarrollar una alta capacidad para la innovación del ejercicio profesional y las "maestrías de investigación" que tienen como meta la iniciación en la investigación. Dependiendo del tipo de maestría deben desarrollarse las actividades de planificación, diseño y evaluación.

\subsection{BIBLIOGRAFÍA DEL CAPÍTULO I}

Abreu L.F.; Cruz, V.\& Martos, F. (2009). Introducción. En Asociación Universitaria Iberoamericana de Postgrado AUIP, Evaluación de Programas de Postgrado. En Guía de autoevaluación (págs. pags. 11-13). Salamanca: AUIP.

Altbach, P., \& Knight, J. (2007). The Internationalization of Higher Education: Motivations and Realities. Journal of Studies in International Education, Vol. 11, 3-4, 290-305.

Arias, V. (1998). La enseñanza de Post - Grado en Ingeniería. Rev. Inst. investig. Fac. minas metal cienc. Geogr. Universidad Nacional Mayor de San Marcos (Vols. Vol.1, No.1).

Augustine, N., \& Vest, C. (1994). Engineering Education for a Changing World. Joint Project by the Engineering Deans Council and the Corporate Roundtable of the American Society for Engineering Education, ASEE.

AUIP, A. U. (2009). Recuperado el 20 de 11 de 2010, de http://www.auip.org

Brunner, J. J. (2010). Globalización de la educación superior: crítica de su figura ideológica. Revista Iberoamericana de Educación Superior (RIES), vol. I, núm.2, 75-83.

Cazorla, A. (27 de diciembre de 2015). Una Universidad para la empresa y la sociedad. El Mundo, España.

Cazorla, A. (4 de setiembre de 2013). Conferencia "UPM: hacia una Universidad de investigación, Gesplan". Simposio "De una universidad profesional a una universidad de investigación: Una oportunidad para Latinoamérica". Quito, Ecuador.

Cazorla, A., De los Ríos, I., \& Yagüe, J. L. (2011). Trabajando con la gente. En J. Olvera, R. mendoza, N. Pérez, \& I. De los Ríos, Modelos para el desarrollo rural con enfoque territorial en México (págs. 9 - 46). México: Colegio de Postgraduados, Campus Puebla.

La pertinencia de las maestrías en ingeniería 
CEPAL, C. E. (2010). Espacios iberoamericanos: vínculos entre universidades y empresas para el desarrollo tecnológico.

CINDA, C. I. (2009). Universia. Obtenido de

http://www.cinda.cl/proyecto_alfa/downoad_finales/8MarcodereferenciaparaelProyectos obreAQ.pdf

Clark, B. R. (1998). The Entrepreneurial University: Demand and Response. . Tertiary Education and Management, , 4, 1, 5-16.

CONACY'T, C. N. (2004). Obtenido de

http://www.siicyt.gob.mx/siicyt/docs/contenido/ingenieria.pdf

Cortes, F. (2006). La relación universidad-entorno socioeconómico y la innovación. Ingeniería e Investigación.

Cruz, V. (2003). Calidad de la enseñanza en el postgrado y su acreditación internacional. Santiago de Cali: Universidad del Valle.

D'Este, P. C.-M.-G. (2009). Documento de base para un "Manual de Indicadores de Vinculación de la universidad con el entorno socioeconómico": un marco para la discusión. Ingenio. Instituto de Gestión de la Innovación y del Conocimiento.

De Miguel, M. (2003). Calidad de la enseñanza universitaria y desarrollo profesional del profesorado. Revista de Educación,331, 13-34.

Dias Sobrinho, J. (2008). Calidad, pertinencia y responsabilidad social de la universidad latinoamericana y caribeña. En IESALC-UNESCO, Tendencias de la Educación Superior en América Latina y el Caribe. (pp 87 -112). Caracas.

Didriksson, A. \&. (2007). La nueva responsabilidad social y la pertinencia de las universidades. En Global University Network for Innovation. En La Educación Superior en el mundo 2007: Acreditación para la Garantía de la Calidad, Qué está en juego (págs. XL-XLV). Barcelona: Mundi Prensa Libros SA.

Etzkowitz, H., Webster, A., Gebhardt, C., \& Cantisano Terra, B. R. (2000). The future of the university and the university of the future: evolution of ivory tower to entrepreneurial paradigm. Research Policy, 29, 313-330.

Eun, J-H.; Lee, K.; Wu, G. (2006). "Explaining the "University-run enterprises" in China: A theoretical framework for university-industry relationship in developing countries and its application to China". Research Policy, 35 , 1329-1346.

European Comission. (1999). Evaluating socio-economics programmes, Glosary of 300 concepts and technical terms- Means Collection (Vol. 6). Luxembourg: Office for official publications of the European Communities.

La pertinencia de las maestrías en ingeniería 
Fernández , A. (2010). La formación de postgrado: fortaleza real y potencial de la Universidad. En Instituto Internacional de la Unesco para la Educación Superior en América Latina y el Caribe, La Universidad latinoamericana en discusión. Caracas: UCV - UNESCO-IESALC.

Fernandez Pello, C. (4 de setiembre de 2013). Conferencia: Berkeley: una universidad de investigación. Simposio: De una universidad profesional a una universidad de investigación: Una oportunidad para Latinoamérica. Quito, Ecuador.

Fernández, I., Vega-Jurado, J., \& Huanca-Lopez, R. (2007). “¿La relación universidad empresa en América Latina: apropiación incorrecta de modelos foráneos?”. Journal of Technology Management and Innovation, vol. 2, N².

Fischman, G., \& Haas, E. (18 de 06 de 2011). Nostalgia, emprendedorismo y redención: modelos discursivos sobre la universidad. Revista Iberoamericana de Educación Superior (RIES), 3-34.

Gibbons, M. (1998). "Higher Education Relevance in the 21st Century". UNESCO World Conference on Higher Education. Paris.

Gola, M. (2003). Premises to accreditation. A minimum set of accreditation requirements in accreditation models in higher education experiences and perspectives in ENQA. En Workshops Reports 3, European Network for Quality Assurance in Higher Education, Helsinki (págs. 25-31).

Green, D. . (1994). Wat is Quality in Higher Education? London, SRHE/Open Univetsity Press, 1994.

Hansen, J., \& Lehmann, M. (2006). "Agents of change: universities as development hubs". Journal of Cleaner Production, 14, 820-829.

Hessels, L., \& Van Lente, H. (2008). Re-thinking new knowledge production: A literature review and a research agenda. Research Policy (37), 740 - 760.

IIEP, (. I. (2009). Obtenido de http://www.iiep.unesco.org/es/focus-onhighereducation.html.

Knights, D., \& Scarbrough, H. (2010). "In Search of Relevance: Perspectives on the Contribution of Academic-Practitioner Networks". Organization Studies.

Krugmann, P. (20 de marzo de 2014). Seminario Internacional "Nuevos paradigmas en competitividad". Lima. Recuperado el 24 de mayo de 2014, de http://www.esan.edu.pe/conexion

Kuczynski, P., Carranza, L., \& Araoz, M. (23 de mayo de 2014). Simposio del oro y la plata - La Minería y su Rol en la Economía del Perú. Recuperado el 24 de mayo de 2014, de http://semanaeconomica.com

La pertinencia de las maestrías en ingeniería 
Maffioli, F. \&. (2003). Tuning engineering education into the european higher education orchestra. European Journal of the Engineering Education.

Marischio, S., J., R., \& Von Pamel, O. (2000). "El Trabajo Colaborativo por Proyectos en Ambientes Virtuales como Estrategia Formativa Profesional en Ingeniería", $4^{a}$ Jornadas de Educación a Distancia del Mercosur del CREAD/INTA.

Marjoram, T., \& Zhong, Y. (2010). Engineering: issues, challenges and opportunities for development. What engineering is, what engineers do, 24-26.

Memon, J. A., Demirdögen, R. E., \& Chowdhry, B. S. (2009). Achievements, outcomes and proposal for global accreditation of engineering education in developing countries. Procedia Social and Behavorial Sciences, 1, 2557-2561.

Mendieta, C. (2013). Vinculación del postgrado y la formación continua con el entorno productivo y empresarial en Iberoamérica. Desarrollo Indoamericano.

Palma, M., De los Ríos, I., \& Miñán, E. (2011). "Generic competences in engineering field: a comparative study between Latin America and European Union". Procedia - Social and Behavioral Sciences, 15, 576-585

Rama, C. (2008). El nacimiento de la acreditación internacional. En Primer Congreso Internacional de Evaluación y Acreditación,. Campeche, México.

Rama, C. (21-23 de enero de 2010). Seminario de Doctorado. Doctorado en Ciencias de la educación. Escuela de Comando y Estado Mayor del Ejército de Bolivia, Bolivia.

Sánchez, J. (2008). Una propuesta conceptual para diferenciar los programas de postgrado profesionalizantes y orientados a la investigación. Implicaciones para la regulación, el diseño y la implementación de los programas de postgrado. Ciencia y Sociedad.

Sanyal, B., \& Martin, M. (2007). Garantía de la Calidad y el papel de la Acreditación: Una Visión Global. En Global University Network for Innovation. En La Educación Superior en el mundo 2007: Acreditación para la Garantía de la Calidad, Qué está en juego (págs. 3-17). Barcelona: Mundi Prensa Libros SA.

Scavarda, L. (2010). Engineering for the Sustainable Development. International leadership colloquium on quality insurance, accreditation and assessment in higher education. Madrid.

Smerdon, E. (2000). An Action Agenda for Engineering Curriculum Innovation. En 11th IEEE-USA Biennial Careers Conference. San Jose,California.

Tünnermann, C. (1998). "La educación permanente y su impacto en la educación superior". UNESCO, Nuevos Documentos sobre la educación superior, mimeo. Paris.

UNESCO. (2011). Clasificación Internacional Normalizada de la Educación. Recuperado el 24 de mayo de 2014, de http://www.uis.unesco.org

La pertinencia de las maestrías en ingeniería 
UNESCO. (2010). Engineering: Issues, Challenges and Opportunities for Development. Francia.

UNESCO. (1998). La educación superior en el siglo XXI: Visión y acción. Obtenido de http://www.unesco.org/education/educprog/wche/declaration_spa.htm

Varghese, N. (2008). Globalization of higher education and cross-border student mobility. Research papers IIEP.

Veugelers, R., \& Cassiman, B. (2005). R\&D cooperation between firms and universities, some empirical evidence from Belgian manufacturing. International Journal of Industrial Organization, , 23.

World Economic Forum. (2012). “The Global Competitiveness Report 2011-2012”. 
Capítulo II

Las maestrías en Perú: el caso de Piura 


\section{Capítulo II}

\section{Las maestrías en Perú: el caso de Piura}

En este capítulo se busca contextualizar el modelo a proponer poniendo en evidencia que en el contexto socio económico y la situación de la educación superior de Latinoamérica y Perú es imprescindible evaluar y garantizar la pertinencia.

En la primera parte se muestra un contexto de crecimiento económico sostenido con disminución de la pobreza. Se presentan datos de evolución de PBI, ingresos per cápita, inversión extranjera, inversión en ciencia y tecnología, inversiones futuras, entre otros. Para precisar que todavía falta mucho para lograr un desarrollo inclusivo se muestran también datos de pobreza y de acceso a servicios básicos.

En la segunda parte se describe la historia de la educación superior en Latinoamérica con sus respectivas características para visualizar las tendencias a futuro. Se muestran datos de matrícula, características de estudiantes, docentes, investigación, esfuerzos de integración regional, entre otros. Se menciona especialmente el postgrado y la formación en ingeniería.

En este capítulo se muestra que es necesario mejorar en competitividad e innovación para sostener el crecimiento económico. Para lograrlo es necesaria una formación de postgrado pertinente y muy vinculada con su entorno socio económico nacional y regional. Esto contribuirá a la sostenibilidad del crecimiento económico que vive actualmente Perú y le permitirá permanecer en el camino hacia el desarrollo.

La adecuación del postgrado a las necesidades e intereses de su entorno mejorará el desempeño profesional de los estudiantes, si se trata de una maestría profesional, y permitirá obtener investigaciones más pertinentes y con mayor impacto si se trata de una maestría de investigación.

Queda claro que sea cual sea la misión establecida por una universidad latinoamericana, si desea prevalecer en el tiempo, entonces debe considerar como una prioridad la función de investigación y de producción de conocimiento con visibilidad internacional. En el caso de la formación en ingeniería esta investigación conviene que sea aplicada y centrada en problemas nacionales y regionales. En concreto: investigación en las universidades peruanas sí, pero contextualizada, en temas prioritarios y en asociación con otros centros de investigación o universidades globales. En las maestrías en ingeniería se necesita pertinencia local con visibilidad internacional. 


\subsection{CONTEXTO SOCIO ECONÓMICO DE PIURA, PERÚ}

\subsubsection{Contexto socio económico latinoamericano}

En los últimos diez años Latinoamérica tuvo un crecimiento económico promedio de $4.2 \%$ y 70 millones de personas dejaron la pobreza. En general, la estabilidad macroeconómica, políticas comerciales más abiertas y un clima de inversión favorable apuntalaron y proyectan un sólido crecimiento de cara al futuro. El número de personas de clase media creció en 50 millones entre 2003 y 2009, un aumento de 50\%. Este es un logro notable para una región caracterizada por la desigualdad en la distribución de la riqueza. Aún así, América Latina sigue siendo la región más desigual del mundo (Yong Kim, 2013)․․

En 2013 se registró un crecimiento del PIB del 2.5\% inferior al 3.1\% del año 2012. La región experimentó un tercer año consecutivo de desaceleración del crecimiento económico debido principalmente a que se debilitaron el consumo y la inversión. Hubo diferencias importantes en el ritmo de crecimiento de los países. El bajo crecimiento regional en 2013 responde en parte al escaso dinamismo de las dos mayores economías de América Latina y el Caribe: Brasil (2.3\%) y México (1.1\%). Estas dos economías representan alrededor del 63\% del PIB total de América Latina y el Caribe. Crecieron más del 5\% Paraguay, Panamá, el Estado Plurinacional de Bolivia y Perú, mientras que Chile, Colombia, Guyana, Nicaragua y Uruguay crecieron entre 4\% y 5\%. Por subregiones, América del Sur anotó un crecimiento del 3.0\%, una tasa algo menor que el $4.3 \%$ registrado por Centroamérica (incluyendo a Haití y a República Dominicana), mientras que persistió el bajo crecimiento (1.2\%) del Caribe de habla inglesa y holandesa (CEPAL, 2014).

El crecimiento regional en los últimos años estuvo impulsado principalmente por el dinamismo de la demanda interna (tanto del consumo como de la inversión) y a pesar del aporte negativo de las exportaciones netas en algunos años (recordemos que México no exporta tanto productos primarios). La inversión extranjera directa ha aumentado mucho en los últimos años, especialmente en América del Sur.

En el año 2013 los sectores que mostraron mayor dinamismo fueron: el comercio, la construcción y los servicios financieros y empresariales. El desempeño de la minería y la

\footnotetext{
${ }^{8}$ Presidente del Banco Mundial
} 
actividad industrial fueron modestos, con un bajo crecimiento generalizado al nivel de los países (CEPAL, 2013).

La tasa de inflación regional acumulada en 12 meses a diciembre de 2013, en promedio ponderado, fue de 7.3\% versus el 5.6\% del 2012. La República Bolivariana de Venezuela y Argentina fueron los países de la región que registraron tasas de inflación más altas: 56.2\% y 10.9\% respectivamente. La desaceleración del crecimiento económico desaceleró también la generación de empleo. La tasa de desempleo abierto urbano fue de 6.2\% (CEPAL, 2014).

Para algunos economistas como Hinds (2013) el crecimiento de América Latina ha sido condicionado en gran medida por los precios de los productos primarios (incluyendo la comida preparada además de minerales, combustibles y materias primas agrícolas). El PIB de la región sube cuando suben los precios de estos productos y baja cuando éstos bajan. Del 2003 al 2008 los precios de los productos primarios estuvieron altos y los países que experimentaron mayores crecimientos de sus exportaciones fueron aquellos que tienen mayores proporciones de productos primarios en sus exportaciones totales como Bolivia (100\%), Perú (86\%), Paraguay (89\%), Colombia (82\%) y Ecuador (92\%), mientras que los que menos crecieron fueron los que menos primarios tienen entre sus exportaciones (México, El Salvador, República Dominicana y Costa Rica).

La región tiene activos pero también brechas estructurales. Entre los activos tenemos: mejores indicadores macroeconómicos, caída de la pobreza y abundante dotación de recursos naturales. Entre las brechas y pasivos: persistente desigualdad, estructura productiva basada en ventajas comparativas estáticas, baja productividad y rezagos en innovación, ciencia y tecnología, se recauda poco y mal (CEPAL, 2013b).

Sólo Brasil cuenta con un considerable sector industrial basado en el conocimiento, mientras que el resto de las economías de la región concentra sus actividades manufactureras en sectores no intensivos en tecnología o poco demandantes de conocimiento, privilegiando actividades con alta densidad de recursos naturales, como en el caso de los países sudamericanos, o que requieren mano de obra poco calificada, como en el de la mayoría de los países de Centroamérica (CEPAL, 2010).

Para aumentar la competitividad de los países latinoamericanos hay que promover actividades de innovación en las empresas, que según CEPAL (2010) pueden ser:

- Capacitación 
- Gasto en tecnología desincorporada, que considera la adquisición de tecnología externa en forma de patentes, inventos no patentados, licencias, diseños y otros, con vistas a la implementación de mejoras, innovaciones o ambas en productos y procesos.

- Ingeniería y diseño industrial, que comprende planos y gráficos tendientes a definir procedimientos y especificaciones técnicas, así como características operativas que exige la introducción de innovaciones.

- Investigación y desarrollo, que incluyen el trabajo creativo, cuyo objetivo es ampliar el acervo de conocimientos y su uso para crear nuevas aplicaciones.

- Inversión en "tecnología incorporada", que comprende la compra de maquinaria y equipos (incluidos programas informáticos) destinada a mejorar el desempeño tecnológico de procesos y productos de la empresa.

Al parecer el empresariado latinoamericano no tiene plena conciencia de la importancia de la inversión en investigación y desarrollo y, entre las actividades de innovación, se ha concentrado en la compra de maquinaria y equipos, dedicando menos recursos a la investigación y el desarrollo (CEPAL, 2010). 
Gráfico 2.1. Actividades de innovación en países seleccionados (porcentajes de sus ventas

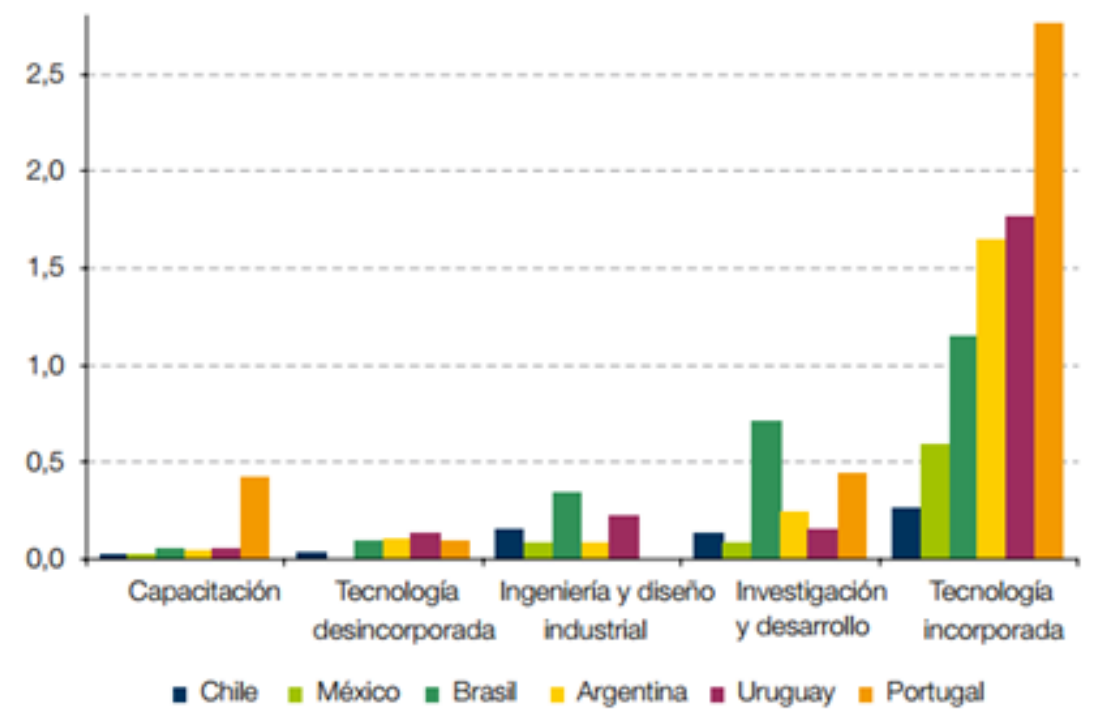

Fuente: CEPAL (2010)

\subsubsection{Contexto socio económico peruano}

La República del Perú está ubicada en la parte central y occidental de América del Sur. Las cifras más importantes son?:

Superficie

Población estimada

Esperanza de vida

Población Económicamente Activa

Cobertura de salud

Hogares con agua potable

Hogares con teléfono móvil

Hogares con internet

PBI per cápita
1’285,215 $\mathrm{Km}^{2}$

30’814,175 habitantes

74.4 años

16’142,100 habitantes

$61.9 \%$

$82.5 \%$

$79.7 \%$

$20.2 \%$

US\$6,376

El crecimiento económico promedio anual de Perú en la última década fue del $6 \%$ en un marco de estabilidad macroeconómica. En términos per cápita, desde el 2000, el PIB peruano

\footnotetext{
${ }^{9}$ Datos del Instituto Nacional de Estadística e Informática www.inei.gob.pe
} 
creció a una tasa promedio anual del 4\%, el doble de lo registrado durante los años noventa, cuando se estabilizó la economía y se hicieron reformas estructurales. Este saneamiento macroeconómico hizo posible que Perú pueda amortiguar los efectos de la crisis financiera del 2008-2009, logre tasas elevadas de crecimiento del ingreso per cápita y reduzca la pobreza.

\section{Gráfico 2.2. Evolución del PIB per cápita de Perú, Latinoamérica y el mundo}
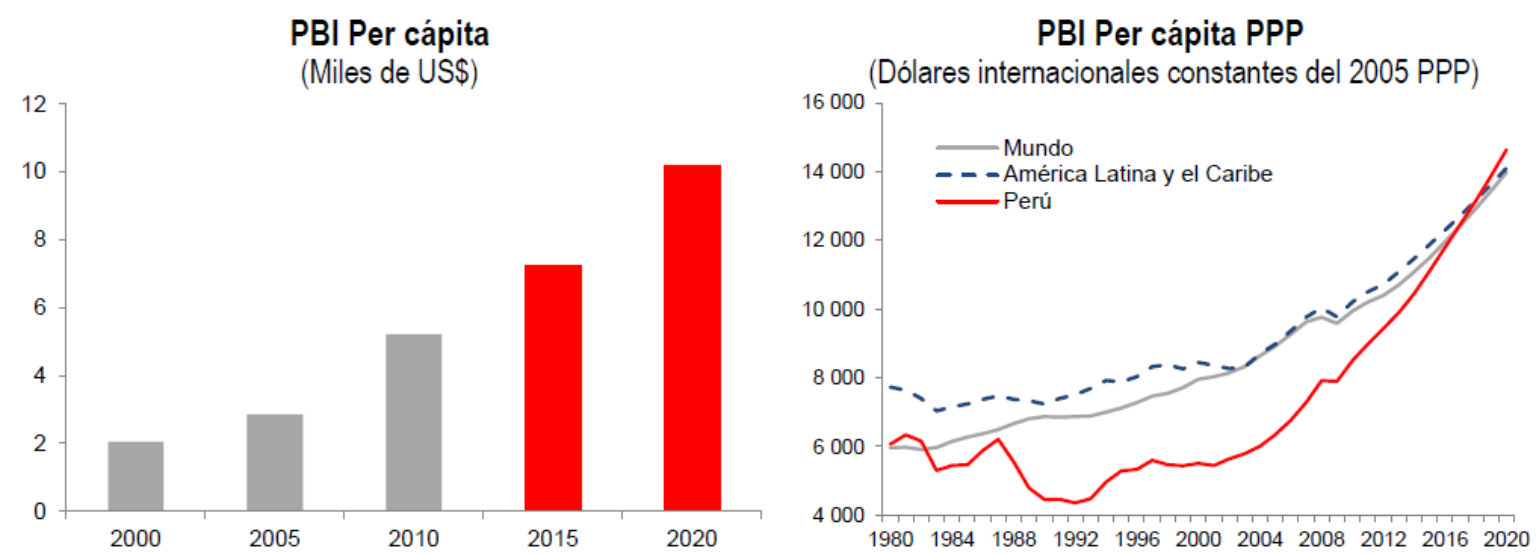

Fuente: MEF (2014)

Perú fue uno de los líderes en el crecimiento económico de Latinoamérica y la economía de mayor crecimiento en América del Sur en el 2014-2015 (MEF, 2014).

Los sectores económicos que más aportan al PIB nacional son Manufactura 16.5\% del PIB, Minería e Hidrocarburos el 14.4\% y Comercio 10.2\%.

La pobreza total se redujo de $58.5 \%$ en el 2004 a $25.8 \%$ en 2012 y $23.9 \%$ en el 2013 . La reducción se ha dado principalmente en las zonas y sectores más articulados a la dinámica de la economía; sin embargo, importantes segmentos de la población, como las zonas rurales más alejadas, se mantienen aún rezagados (INEI, 2014a). El Perú está entre los 38 países que ya alcanzaron las metas contra el hambre fijadas para el 2015. De estos países, 12 forman parte de América Latina y el Caribe (FAO, 2013) 


\section{Gráfico 2.3. Evolución de la pobreza y pobreza extrema, periodo $2004-2012$ en Perú}

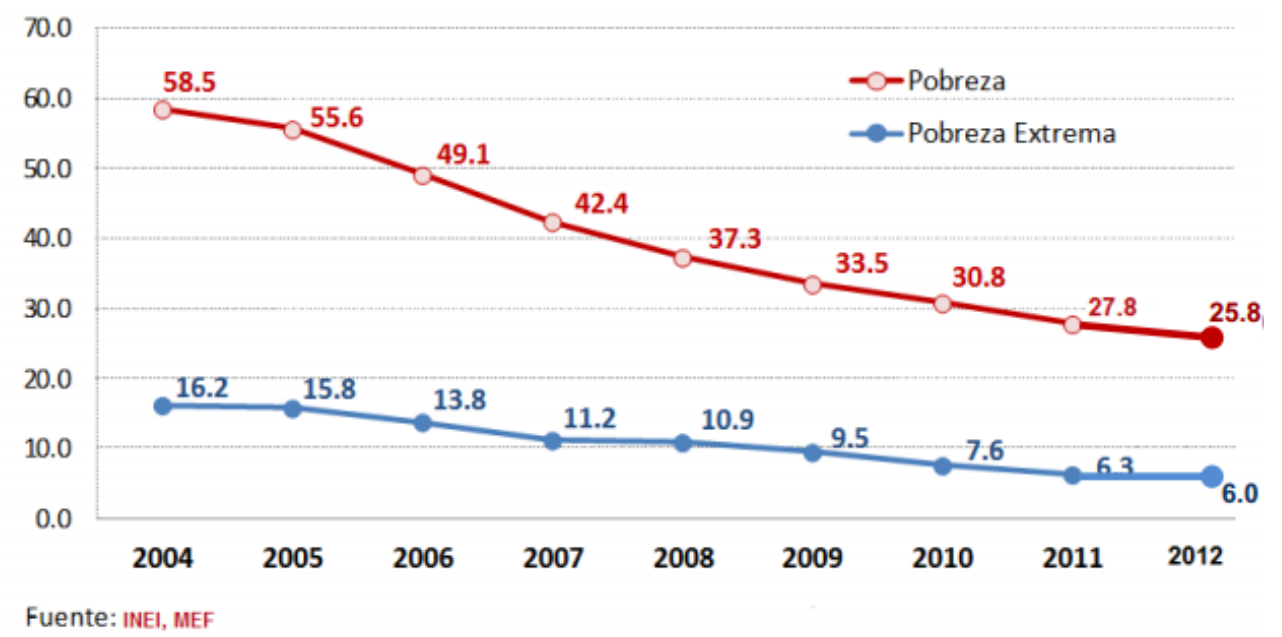

El ingreso real promedio per cápita mensual creció 13\% en los últimos cinco años (INEI, 2014b).

Durante el periodo comprendido entre el 2005 y el 2013, la economía peruana ha mostrado incrementos sostenidos en la Población Económicamente Activa (PEA) urbana ocupada como proporción de la PEA total, principalmente como resultado del crecimiento económico. En consecuencia, en el segundo trimestre de 2013, el 95,7\% de la población económicamente activa urbana del país, tenía un empleo (INEI, 2013).

Un factor que ha contribuido al crecimiento económico ha sido la de inversión extranjera directa (IED). Según datos del Banco Central de Reserva, Perú experimentó el año 2012 una IED equivalente al 6\% del PIB, lo que significó un incremento de 49\% con relación al año anterior. El flujo de IED en Perú pasó de representar el 1.5\% del PIB en el 2000 a superar el 6\% del PIB en el 2012 (BCRP, 2014)

Perú se ha consolidado como la tercera economía con mejor calificación crediticia después de Chile y México debido a una reducción sostenida de la deuda pública. Es importante esta significativa reducción de la deuda porque promueve la inversión tanto nacional como extranjera y permite estar mejor preparados para afrontar situaciones de desastres naturales (MEF, 2014).

Reducir la pobreza se hace cada vez más difícil, pues las poblaciones que aún continúan siendo pobres son aquellas que se encuentran menos integradas. Sacarlas de la pobreza 
requiere, además de crecimiento, inversión en infraestructura y telecomunicaciones para que se integren a los circuitos económicos. En el año 2011 el Perú se ubicaba en el puesto 14 de 18 países de Latinoamérica y el Caribe en el ranking de Oportunidades Humanas del Banco Mundial. Se hacían necesarias reformas que enfrentasen los problemas estructurales de pobreza y brechas urbano-rurales. En este contexto el actual gobierno impulsó el “crecimiento económico con inclusión social" como lineamiento de política económica con el objetivo de que este crecimiento también llegue a los más necesitados, asegurando un manejo técnico y profesional. La creación del Ministerio de Desarrollo e Inclusión Social en octubre 2011 y la puesta en marcha de la Estrategia Nacional de Desarrollo e Inclusión Social "Incluir para Crecer" buscan articular intervenciones públicas en distintos sectores como educación, salud, saneamiento y acceso a caminos (MEF, 2014).

Actualmente la economía mundial se encuentra en una fase de transición gradual hacia un nuevo equilibrio caracterizado por menores precios de materias primas, mayores costos financieros y, con ellos, un menor crecimiento de las economías emergentes.

De acuerdo con el documento “Marco Macroeconómico Multianual 2015 - 2017” del Ministerio de Economía y Finanzas, se tiene las siguientes proyecciones:

- Perú iniciará un proceso de aceleración de crecimiento en torno a 6,4\% en el periodo 2015-2017; con ello, se posicionará como una de las economías de mayor crecimiento en el mundo.

- La inversión privada crecerá, en promedio, 6,1\% en el periodo 2015-2017; hacia el final del horizonte de proyección será equivalente a 19,9\% del PIB. En sectores no transables como retail, inmobiliario, servicios y otros, la inversión privada crecería a un ritmo promedio anual de 10\% en el periodo 2014-2017, como reflejo del dinamismo del consumo interno.

- La inversión privada en megaproyectos de infraestructura, principalmente, bajo la modalidad de Asociaciones Público Privadas (APP) crecerá en torno a 30\% anual en términos reales en el periodo 2015-2017, el doble de lo registrado en el periodo 20112013. Se ampliará el ámbito de aplicación de las APP para desarrollar proyectos de investigación aplicada y/o innovación tecnológica.

- La inversión pública crecerá $11.7 \%$ en promedio en el periodo 2015 - 2017 pasando de 5.8\% del PIB en el 2013 a 7.1\% del PIB en el 2017. El consumo público, en términos reales, crecerá en torno a $5.9 \%$ en promedio. 
- Se mantendrá la tendencia decreciente de la deuda pública.

Perú forma parte de la "Alianza del Pacífico" junto con Chile, México y Colombia. En conjunto tienen una cartera de proyectos mineros estimada en más de US\$221,000 millones de inversión. En el caso del Perú se tienen identificados 50 proyectos mineros que demandarán una inversión aproximada de US\$ 59,500 millones, de los cuales el 60.3\% corresponde a cupríferos, y el $16.48 \%$ a proyectos auríferos ${ }^{10}$.

Los principales proyectos de infraestructura, bajo la modalidad de Asociación Público Privada, que el Estado peruano viene impulsando se muestran en la Tabla 2.1.

Tabla 2.1. Principales proyectos a ejecutarse en Perú en los próximos años.

\begin{tabular}{llcr}
\hline $\mathbf{N}^{\circ}$ & Proyecto & Departamento & $\begin{array}{r}\text { millones } \\
\text { US\$ }\end{array}$ \\
\hline 1. & Línea 2 del Metro & Lima & 5,075 \\
2. & $\begin{array}{l}\text { Modernización de la Refinería de Talara - } \\
\text { Petroperú }\end{array}$ & Piura & 3,500 \\
3. & Banda 4G & Cusco & 1,018 \\
4. & Aeropuerto Internacional de Chinchero & & 776 \\
5. & Nodo energético del Sur & Arequipa & 600 \\
6. & La Central Hidroeléctrica de Molloco & La Libertad & 574 \\
7. & Proyecto de irrigación Chavimochic - III Etapa & & 552 \\
8. & Longitudinal de la Sierra - Tramo 2 & & \\
\hline
\end{tabular}

Fuente: PROINVERSION (2014)

Para sostener un crecimiento económico en torno a 6,0\% más allá del año 2017 y evitar caer en la "trampa del ingreso medio" 11 es necesario continuar implementando medidas que apuntalen el PIB potencial de forma "extensiva" (mayor acumulación de capital y mano de obra capacitada) e "intensiva" (mayor productividad). Para lograr el crecimiento "intensivo"

\footnotetext{
${ }^{10}$ Cifras dadas por la presidenta de la Sociedad Nacional de Minería, Petróleo y Energía (SNMPE), Eva Arias de Sologuren el 11 de mayo de 2014. http://gestion.pe/economia

11 Llega un momento en la evolución económica de un país en que sus avances económicos lo colocan en el medio de la escala de ingresos per cápita de los países. Ya no es un país poco desarrollado (de ingresos bajos) ni tampoco un país desarrollado e industrializado (de ingresos altos).
} 
es necesario atacar problemas de la baja calidad de la educación, la baja productividad de la mano de obra, el mercado laboral poco flexible, las todavía limitadas fuentes de financiamiento para empresas medianas y pequeñas, la escasa inversión en ciencia y tecnología, la baja calidad de las instituciones, lo cual conlleva una baja diversificación de la oferta productiva y exportadora de alto valor agregado (MEF, 2014).

$\mathrm{Al}$ año 2012 el 82.5\% de viviendas en Perú tenían acceso a servicios de agua potable por red pública, sólo 61.8\% de viviendas tenían acceso a servicios de desagüe por red pública y el 91.1\% tenían acceso a energía eléctrica por red pública. Ver Gráfico.

Gráfico 2.4. Perú. Acceso a servicios de agua, desagüe y alumbrado eléctrico 2004 2012

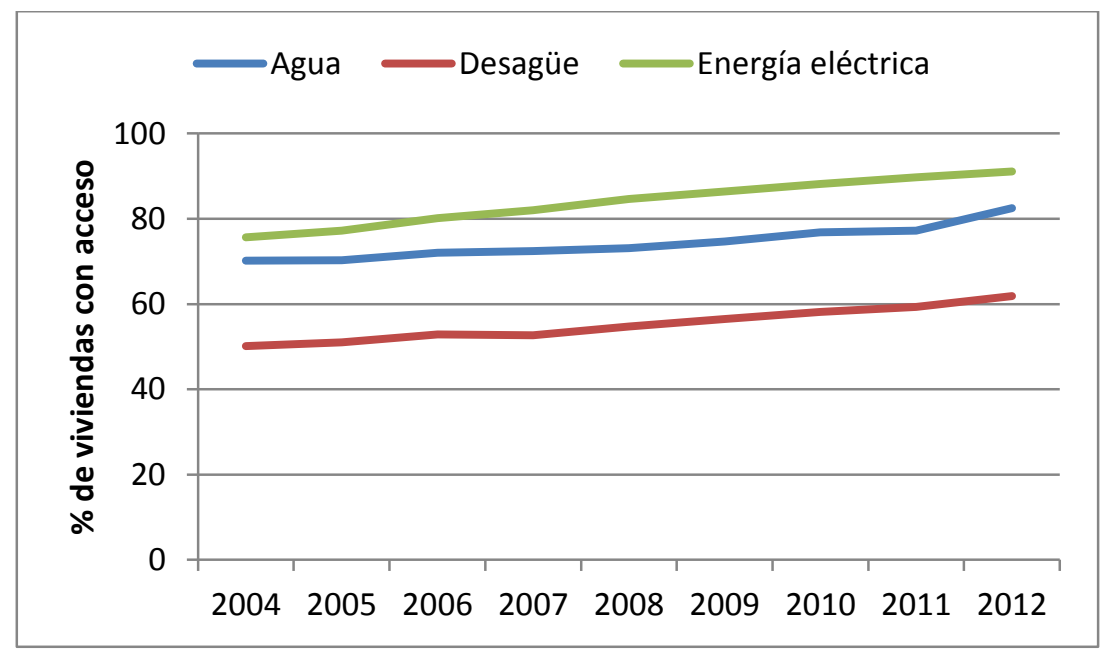

Fuente: Elaboración propia a partir de INEI (2014a). 


\subsubsection{Contexto socio económico de Piura}

El departamento de Piura es el departamento más poblado de Perú después de Lima. Tiene 1'814,622 habitantes y una superficie de 35,892 $49 \mathrm{Km}^{2}$. Sus coordenadas son $4^{\circ} 59^{\prime} \mathrm{S}$ $80^{\circ} 25^{\prime} \mathrm{O}$, se encuentra en la costa, en el noroeste de Perú a casi mil kilómetros de Lima.

Como sucede a nivel nacional, el crecimiento económico sostenido de los últimos años en Piura se ha reflejado en una disminución de la pobreza y en mejoras en las condiciones de vida de la población. Sin embargo, falta todavía un largo camino por recorrer para lograr la inclusión social. Piura es una de las regiones con mayor cantidad de recursos naturales en el país, tiene un importante capital humano y una estratégica ubicación geográfica (Gobierno Regional de Piura, 2013).

El departamento de Piura aporta el 4\% del valor agregado bruto nacional (PIB) y su aporte en algunos sectores económicos es considerable como en la pesca (47\%) y la manufactura (5\%). Otro aspecto donde Piura destaca es en población, pues con sus 1.7 millones de habitantes es el departamento más poblado del país después de Lima. Piura alberga al 6.1\% de la población total del país.

\section{Gráfico 2.5. Ubicación del departamento de Piura, Perú}

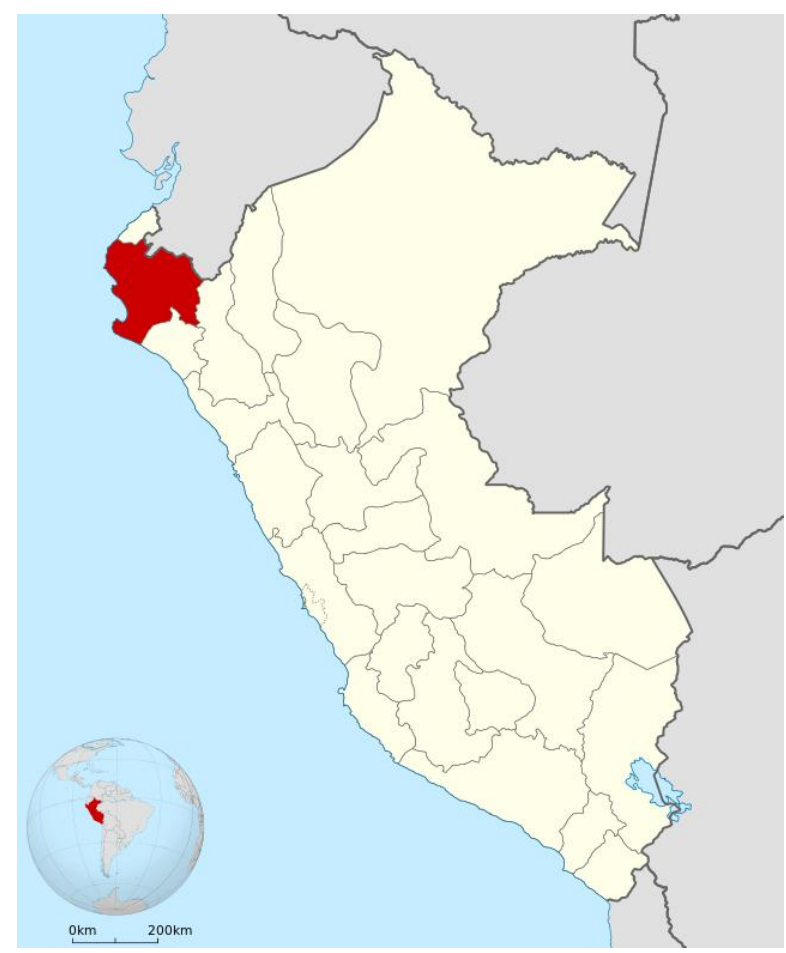


El PIB per cápita de Piura es mucho menor que el promedio nacional porque el PIB nacional está dado principalmente por lo que Lima, la capital del Perú, produce. En los últimos veinte años el PIB de Lima ha representado casi el 50\% del PIB nacional.

La principal actividad económica de Piura es la manufactura, que representa el 19\% del valor agregado bruto regional. Esto se debe a la refinación de petróleo, al procesamiento pesquero y al procesamiento de la producción frutícola y de biocombustibles.

Los sectores económicos que más han crecido en los últimos años son la manufactura, el comercio y la construcción.

La agricultura en Piura representó el 5\% del PBI nacional en el año 2012 y junto con el comercio genera la mayor cantidad de empleo. Piura destaca por ser una de las regiones de mayor potencial agrícola en la costa por su disponibilidad de agua y el clima templado que presenta durante todo el año. Piura ocupa un lugar de importancia a nivel nacional en ciertos cultivos; así, es el mayor productor de mango, limón y uva, el segundo en algodón, arroz y camote y el tercero en banano.

El ingreso promedio mensual proveniente del trabajo en Piura también creció en los últimos años.

El último dato de incidencia de pobreza que se tiene de Piura es del año 2010. La pobreza ha disminuido del 60.7\% en el año 2004 al 42.5\% en 2010 .

\section{Gráfico 2.6. Piura. Incidencia de pobreza monetaria total}

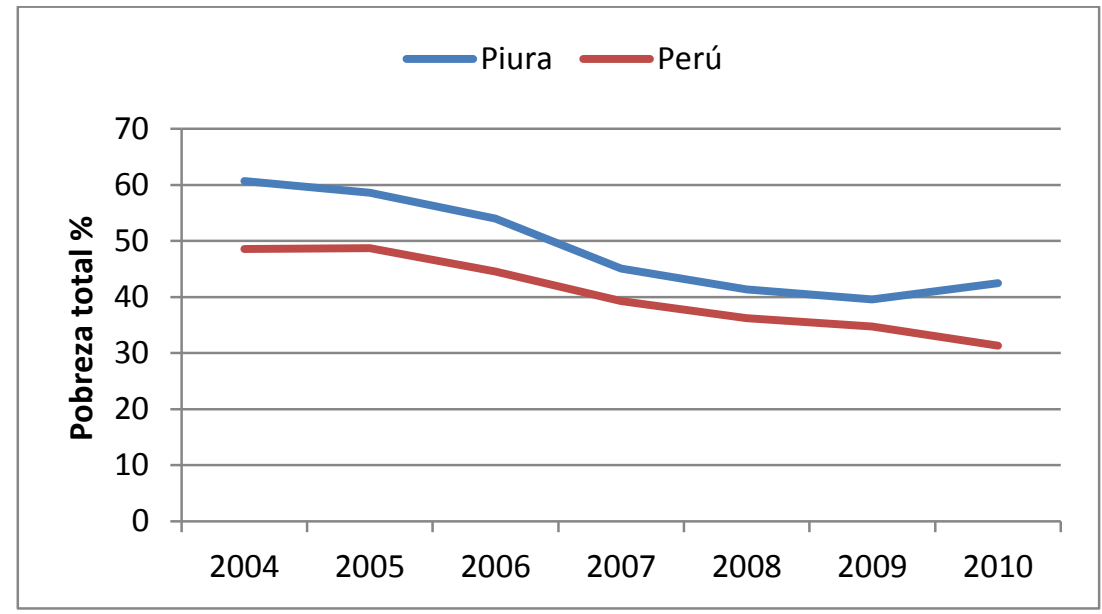

Fuente: Elaboración propia a partir de INEI (2014c)

La inversión privada y pública ha contribuido al crecimiento económico de Piura. Entre las principales inversiones de la última década resalta la inversión realizada para la producción 
de etanol. Piura cuenta actualmente con los proyectos de caña de azúcar para etanol con riego tecnificado más grandes del mundo (tres empresas ${ }^{12}$ destinan 45 mil Hectáreas). Asimismo se invirtieron US\$566 millones en la construcción de una planta de fosfatos en Bayóvar.

Las inversiones más importantes que se están llevando a cabo en Piura son: Proyecto de modernización de la refinería de Talara, a cargo de la empresa española Técnicas Reunidas (US\$ 3,500 millones), el Proyecto Hidroenergético del Alto Piura (US\$ 750 millones), la construcción de una planta cementera (US\$390 millones), entre otros.

Las inversiones más importantes a realizarse en los próximos años son: la construcción del Tren Trasandino (US $\$ 2,000$ millones) y el proyecto minero cuprífero Río Blanco (US $\$ 1,440$ millones).

A pesar del crecimiento económico en Piura los porcentajes de acceso a los servicios básicos son bajos. Al año 2012 el 80.7\% de viviendas en el departamento de Piura tenían acceso a servicios de agua potable por red pública, sólo el 57\% de viviendas tenían acceso a servicios de desagüe por red pública y el 88.4\% tenían acceso a alumbrado eléctrico por red pública. Ver Gráfico.

Gráfico 2.7. Piura. Acceso a servicios agua, desagüe y alumbrado eléctrico 2001 2012

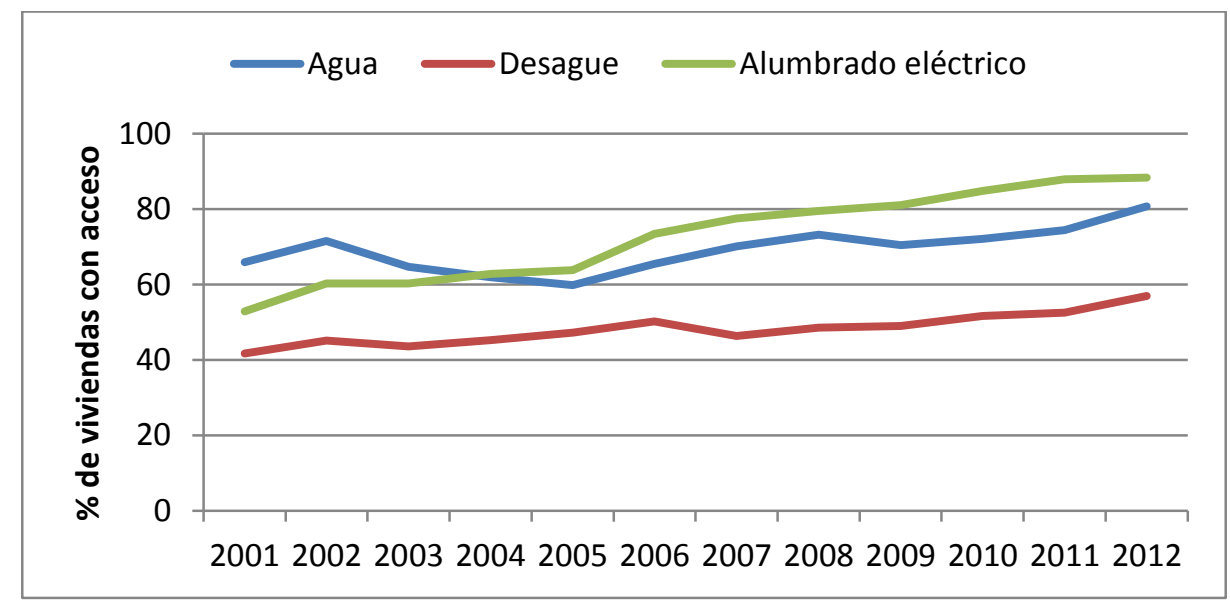

Fuente: Elaboración propia a partir de INEI (2014c)

\footnotetext{
12 La empresas productoras de etanol son Agrícola del Chira del Grupo Romero, Maple Etanol SRL y Corporación Miraflores S.A.
} 


\subsection{LA EDUCACIÓN SUPERIOR EN PIURA, PERÚ}

\subsubsection{La educación superior en Latinoamérica}

Para describir los aspectos relevantes de la Educación Superior (ES) en Latinoamérica revisaremos la evolución del sistema universitario utilizando las "Tres Grandes Reformas" identificadas por Rama (2006).

El siglo XX empezó con la Primera Reforma, la de Córdova en 1918 donde la universidad ya no era una institución de élite y dio cabida a la nueva clase media originada por la migración. Sus principales características fueron:

a. La educación superior era básicamente un monopolio en manos del Estado y manejaba un paradigma educativo y cultural homogeneizador.

b. Las Universidades eran autónoma y los Ministerios de Educación tenían un bajo nivel de injerencia.

c. La pertinencia estaba dada por los cuadros políticos y técnicos y no por el mercado o por las empresas.

d. Las Universidades producían muy poca innovación tecnológica y su eje era la formación de profesionales.

e. El presupuesto universitario estaba determinado en las instancias políticas y su financiamiento estaba casi exclusivamente basado en el gasto público.

f. No existía competencia al interior del sector universitario.

g. La ES era un servicio presencial y nacional.

h. Existían muy pocas instituciones privadas que eran en general sin fines de lucro de origen religiosas.

i. No existían mecanismos externos ni internos de control sobre la calidad de la ES sino que era la carrera docente y los mecanismos de ingreso el eje determinante de la calidad.

j. La estructura organizativa de estas Universidades públicas estaba basada en facultades, organizada la docencia en materias y las carreras en años lectivos.

k. Había una orientación hacia la formación a nivel de pregrado con una reducida diversificación de carreras.

Este modelo tradicional universitario latinoamericano del siglo XX sufrió muchos cambios en los años setenta debido principalmente al incremento de las instituciones privadas, el 
aumento de la matrícula y la reducción relativa del peso de la ES pública. La Segunda Reforma empezó en 1975 y tuvo como características las siguientes:

a. Incremento de la cobertura de la ES por parte de las instituciones privadas debido a principalmente al descrédito de la universidad pública como resultado de: la politización, la baja calidad y la mayor dificultad de ingreso por el establecimiento de cupos y restricciones.

b. La masificación, la feminización y el nuevo perfil del estudiante universitario. Los estudiantes universitarios pertenecían a todos los grupos sociales, étnicos, generacionales, religiosos y económicos.

c. Una excesiva diferenciación de las instituciones de ES, no en términos de opciones profesionales, sino en términos de calidad. Se ganó en acceso pero se perdió en calidad. No hubo una función reguladora del Estado.

d. En las universidades públicas: falta de integración con la sociedad y con los demandantes de empleo, bajísimos niveles generación de tecnologías y patentes, y una fuerte dificultad de introducir reformas y cambios. Disminuyó el financiamiento por parte del estado.

e. En las universidades privadas: La expansión se realizó sin control de la calidad. Su estructura docente es en general de profesores de tiempo parcial que carecen de una carrera académica (están asociados al ejercicio profesional y no a la investigación). La educación se hizo más profesionalizante porque casi no se produce investigación.

f. Un porcentaje muy bajo de los docentes tienen formación de doctorado. Pocos investigan y publican.

g. Sigue predominando la orientación hacia la formación a nivel de pregrado.

Actualmente (siglo XXI) los sistemas de ES latinoamericanos afrontan nuevos cambios tratando de adaptarse a las nuevas realidades: la globalización, la internacionalización de la ES y las nuevas tecnologías de información y comunicación. La Tercera Reforma, según Rama (2006), se da en un contexto complejo y tiene las siguientes características:

a. Desarrollo de mecanismos de aseguramiento de la calidad. Hay una lenta transformación de un estado educador a un estado evaluador.

b. Internacionalización de la ES a partir del ingreso de nuevos proveedores; y la conformación de tres sectores (público, privado local y privado internacional) en el marco de una amplia competencia global regulada en base a calidad. 
c. Nacimiento de la educación virtual no presencial y el desarrollo de nuevas modalidades pedagógicas. Nacimiento de una nueva competencia entre las instituciones de ES presenciales y las virtuales.

d. Nuevas demandas de educación, de habilidades y de destrezas por parte de la sociedad.

e. Orientación directa a la demanda. El nacimiento de una economía de la ES en la cual los demandantes requieren más libertad para escoger sus planes de estudio.

f. Diversidad universitaria: nuevas carreras, nuevas especializaciones, nuevas modalidades pedagógicas, alianzas internacionales, nuevos tipos de titulación, etc.

g. La educación permanente y la expansión de saberes en el postgrado (especializaciones, maestrías y doctorados).

h. Investigación en un contexto global.

Los datos concretos que sustentan etas características los mostramos a continuación ${ }^{13}$. Tenemos que el 60\% de la matrícula de ES, se concentra en tres países: Brasil (28\%), México $(17 \%)$ y Argentina (14\%). Le siguen en orden de importancia: Perú (6\%), Centroamérica $(6 \%)$, Chile (4\%), Bolivia (2\%), Caribe (1\%).

América Latina y el Caribe es la región del mundo que reúne una mayor proporción de matrícula privada en sus sistemas de ES, alcanzando hoy una cifra promedio en torno al $50 \%$. Los que tienen el mayor porcentaje (de entre 50 y 75\%) de estudiantes en instituciones de carácter privado, son Brasil, Chile, El Salvador, Colombia, Costa Rica, Nicaragua y República Dominicana. Los países que tienen una concentración de estudiantes de entre el 75\% y el 100\% en instituciones de carácter público, son Cuba, Uruguay, Bolivia, Panamá, Honduras y Argentina. En una situación intermedia, por así decirlo, esto es, países que tienen concentraciones de estudiantes importantes tanto en el sector público como en el privado, están Ecuador, México, Venezuela, Paraguay, Perú y Guatemala.

La tendencia de incremento de la participación de las instituciones de ES privadas ha ido en aumento en la región de forma constante. Esta tendencia se da también en algunos países desarrollados de comparación internacional como Corea y Estonia. En el caso de Gran Bretaña se tiene que, si bien sus instituciones de ES podrían ser calificadas como públicas al tener un financiamiento mayoritariamente de origen fiscal, sin embargo, por el hecho de

\footnotetext{
13 La mayoría de los datos han sido tomados del reporte "Tendencias de la Educación Superior en América Latina y el Caribe" (2008) elaborado por el Instituto Internacional de la UNESCO para la Educación Superior en América Latina y el Caribe (IESALC, 2008).
} 
tener un estatuto especial de corporaciones públicas autónomas, que deben generar recursos adicionales y cobran aranceles, son clasificadas por el gobierno de dicho país y por las estadísticas internacionales como instituciones privadas (Brunner, 2010).

En términos de la distribución del número de estudiantes por áreas de conocimiento y carreras, se mantiene una fuerte tendencia a la concentración de estudiantes en ciencias sociales, empresariales y jurídicas, que llegan a abarcar entre un 35\% (como en Argentina, Chile o Surinam), el 40\% (como en Brasil, Colombia, Guatemala, México y Panamá), y hasta el 50\% (como en El Salvador). En ciencias, la media regional es de alrededor del 10\% y en algunos casos ligeramente mayor. Las Ingenierías fluctúan entre el 7\% (Argentina) hasta el $29 \%$ (Colombia).

La movilidad internacional de estudiantes es un tema importante a tratar. Según Brunner (2010), se tiene que el porcentaje de estudiantes que se educan en el exterior es $2 \%$ a nivel global y 1\% a nivel de América Latina. Los estudiantes móviles provienen en su mayoría de algún país de la misma región latinoamericana, siete de cada diez alumnos extranjeros que estudian en alguna universidad latinoamericana son de origen latinoamericano. Los principales países receptores para los cuales se dispone de información son Cuba y, más atrás, Chile.

El docente universitario en América Latina ha tenido que adaptarse al nuevo entorno (descrito en el capítulo I) en un tiempo relativamente breve. La profesión de docente enfrenta muchos problemas: la escasez de recursos, la diversidad de funciones que tienen que cumplir, el reducido número de docentes a tiempo completo, entre otros (Brunner, 2010). El porcentaje de docentes con grado de doctor es menor que $15 \%$.

Las instituciones privadas cuentan con una cantidad pequeña de docentes a tiempo completo y con formación de posgrado. Los docentes universitarios se dedican principalmente a la enseñanza y el cultivo de sus especialidades, sin estar envuelto en tareas de investigación. Muchos trabajan simultáneamente en varias instituciones, dictando cursos bajo un régimen de contratación anual. Todo esto es consecuencia de la creciente demanda por ES privada.

El gasto público en ES se destina mayormente a gasto corriente de las instituciones, especialmente al pago de remuneraciones del personal académico y administrativo (Brunner, 2010).

Las maestrías en Perú: el caso de Piura 
Las universidades latinoamericanas están regularmente enfrentadas al dilema de si perseguir la investigación o limitarse a la educación (Rama, 2006). En la región, las universidades públicas son las únicas que realmente y de manera sistemática tienen como objetivo promover la investigación, y dentro de éstas, la investigación se concentra en unas pocas. Las mejores universidades latinoamericanas, de acuerdo con World Universities Ranking ${ }^{14}$, se muestran en la siguiente tabla.

Tabla 2.2. Mejores universidades de Latinoamérica según el World Universities Ranking

\begin{tabular}{cllc}
\hline $\mathbf{N}^{\circ}$ & Universidad & País & Posición global \\
\hline 1. & Universidad Nacional Autónoma de México & México & 51 \\
\hline 2. & Universidade de Sao Paulo & Brasil & 113 \\
\hline 3. & Universidade Estadual de Campinas & Brasil & 212 \\
\hline 4. & Universidad de Chile & Chile & 214 \\
\hline 5. & Universidade Federal do Rio de Janeiro & Brasil & 330
\end{tabular}

Fuente: www.webometrics.info

Uno de los factores que afectó la labor de investigación en la región ha sido la creciente demanda por ES, la cual fue absorbida mayoritariamente por instituciones dedicadas únicamente a la enseñanza. Mientras en el mundo aumentaba rápidamente la innovación tecnológica, en Latinoamérica aumentaba la participación del sector privado en la ES (Rama, 2006); (Brunner, 2010).

Hoy la investigación en los países latinoamericanos está asociada a la existencia de fondos concursables en organismos públicos a los cuales acceden en competencia las universidades y los centros de investigación tanto públicos como privados. La contribución estatal a I+D es muy baja y el sector privado invierte poco en este tema importando tecnología de acuerdo a sus requerimientos (Rama, 2006).

La globalización y el incremento de la competencia internacional obligan a las universidades a alcanzar estándares mundiales. Para algunas universidades la única respuesta podría ser especializarse en la investigación y la docencia en algunas áreas específicas del conocimiento, pero esta opción corre el riesgo de eliminar o debilitar, la capacidad de llevar a cabo estudios

${ }^{14}$ Mayor información en http://www.webometrics.info/index.html 
interdisciplinarios o multidisciplinarios. Para otras, la salida puede ser establecer alianzas o convenios con universidades e institutos de investigación de alto nivel en países desarrollados (CEPAL, 2009).

Tratar de nivelar las universidades con estándares internacionales tiene muchas ventajas, pero también riesgos y costos. Uno de los riesgos es que la agenda de investigación de las universidades puede parecerse más a la agenda internacional, mientras que los problemas nacionales ocupen un lugar secundario en favor de los problemas más globales. Las universidades entonces enfrentan un doble reto: ser más competitivas internacionalmente y al mismo tiempo preservar su importancia nacional y regional en temas económicos y sociales (CEPAL, 2009).

La demanda de estudios de posgrado en algunos países de Latinoamérica se incrementó de forma significativa en los años noventa. Los programas de maestría concentraron el mayor aumento con $65 \%$ de la matrícula de postgrado. El alza se ubica principalmente en las ciencias sociales y administrativas y esta tendencia parece haberse mantenido en los últimos 10 años (CEPAL, 2009). El postgrado está caracterizado por tener una mayor oferta de programas profesionales o de corte "profesionalizante" tanto en maestrías como en doctorados, especialmente en las áreas de ciencia y tecnología como ingeniería, en desmedro de los programas de postgrado de "investigación” (Sánchez, 2008). Según Sánchez los programas de postgrado que se imparten en América Latina, se parecen bastante a la enseñanza de pregrado por su excesiva escolaridad y poca importancia asignada al trabajo de producción intelectual.

El nivel de vinculación de las universidades y las empresas en los países latinoamericanos depende mucho del nivel de desarrollo alcanzado por sus respectivos sistemas nacionales de innovación (CEPAL, 2010). Se tiene algunos países con un nivel intermedio (Argentina, Brasil, Chile, México, y Uruguay) y otros con un nivel incipiente (los demás países de la región). Actualmente se reconoce cada vez más la necesidad de adoptar un enfoque de sistema, es decir debe involucrarse a los gobiernos, las universidades, los centros de investigación y el sector productivo.

Las universidades no son las únicas responsables de establecer los canales que harán llegar el conocimiento a las empresas, sino que éstas también desempeñan un rol fundamental al definir sus necesidades científicas y tecnológicas junto a las universidades, al precisar sus exigencias y al desarrollar la capacidad interna requerida para absorber los conocimientos. 
Asimismo, el Estado puede y debe influir en estos flujos mediante la implementación de políticas públicas, actuando sobre la oferta y la demanda de conocimiento.

La Comisión Económica para América Latina y el Caribe de la UNESCO - CEPAL (2010) recomienda algunos mecanismos e instrumentos para facilitar la relación entre las universidades y las empresas de modo que se logre un desarrollo con base en la ciencia, la tecnología y la innovación. Entre otros tenemos:

- Aumentar la masa crítica de personas dedicadas a las actividades de investigación.

- Las universidades deben aumentar la cantidad y calidad de sus publicaciones científicas y ampliar la investigación aplicada.

- Promover disciplinas con proyecciones más aplicadas, como la ingeniería.

- El sector productivo debe incrementar la inversión y la participación en actividades I+D promoviendo una "cultura innovadora".

Con el objetivo de avanzar en el camino de conversión de "universidades profesionales" a "universidades de investigación" se han llevado a cabo muchos esfuerzos. Uno de ellos ha sido la cumbre académica que se llevó a cabo en paralelo a la "Primera Cumbre de la Comunidad de Estados Latinoamericanos y Caribeños y la Unión Europea (CELAC-UE) de Jefes de Estado y de Gobierno", con el fin de incrementar las actividades de cooperación académica y científica entre Europa y Latinoamérica. En ella se firmó la Declaración de Santiago ${ }^{15}$ donde, entre otros temas, se ha expresado la voluntad de:

- Desarrollar el Espacio Euro-Latinoamericano de Educación Superior, Ciencia, Tecnología e Innovación.

- Fortalecer la formación, movilidad e intercambios estudiantiles, universitarios y profesionales, así como la cooperación científica y tecnológica.

- Implantar un sistema de acreditación de la educación superior común y un sistema de convalidación de estudios, reconocimiento de títulos de grado y post grado en ambas regiones.

- Valorizar las co-titulaciones y los títulos conjuntos euro-latinoamericanos de maestría y doctorado.

\footnotetext{
${ }^{15}$ Disponible en www.cumbreacademica-alcue.cl
} 
- Fortalecer la vinculación universidad-empresa a escala local (región, ciudad, territorio) en las dos regiones, para el desarrollo de la investigación, la formación profesional y la transferencia tecnológica, con el fin de acrecentar la productividad y la competitividad de las empresas, en especial de las micro, pequeñas y medianas empresas, con vistas a la creación de empleos de calidad.

Otro esfuerzo importante en este sentido lo constituye el proyecto "Vinculación de las universidades con su entorno para el desarrollo social y económico sostenible (VINCULAENTORNO), uno de los cuatro proyectos de la Comisión Europea, Alfa III, en los que participa activamente el IESALC ${ }^{16}$. El Objetivo de este proyecto es trasladar al marco latinoamericano la experiencia obtenida sobre la gestión y promoción de las actividades de Tercera Misión en las Instituciones de Educación Terciaria (IET) en Europa (IESALC, 2014).

Otro proyecto de convergencia de Latinoamérica con Europa es el proyecto Tuning América Latina. El objetivo que busca este proyecto desde el año 2004 es contribuir a la construcción de un Espacio de Educación Superior en América Latina a través de la convergencia curricular (Tuning América Latina, 2014) de forma similar al esfuerzo desplegado para la formación del Espacio Europeo de Educación Superior (EEES) ${ }^{17}$.

La necesaria vinculación de la universidad con sus entorno socio económico, que en los países desarrollados ya se da por sentado, es una preocupación frecuente en los países latinoamericanos. Así en la Conferencia Regional de Educación Superior 2008 llevada a cado en Cartagena - Colombia se acordó un plan de acción que tiene los siguientes lineamientos (IESALC, 2008):

- Impulsar la cobertura de la educación superior, tanto en pregrado como en postgrado, con calidad, pertinencia e inclusión social.

- Promover políticas de acreditación, evaluación y aseguramiento de la calidad.

- Fomentar la innovación educativa y la investigación en todos los niveles.

- Construir una agenda regional de ciencia, tecnología e innovación (CTI) para la superación de brechas y para el desarrollo sustentable de la región, acorde a las políticas generales de cada estado miembro.

\footnotetext{
${ }^{16}$ Instituto Internacional de la UNESCO para la Educación Superior en América Latina y el Caribe.

17 Para mayor información ver http://www.tuningal.org
} 
- Propugnar la integración regional latinoamericana y caribeña y la internacionalización de la educación superior en la región mediante, entre otras iniciativas, del ENLACES Espacio de Encuentro Latinoamericano y Caribeño de Educación Superior.

Existe otro esfuerzo importante de integración regional en Latinoamérica para mejorar la educación de postgrado. El Instituto Internacional de la UNESCO para la Educación Superior en América Latina y el Caribe (IESALC), en alianza con la Coordenação de Aperfeiçoamento de Pessoal de Nivel Superior (CAPES) de Brasil, con la Comisión Nacional de Evaluación y Acreditación Universitaria (CONEAU) de Argentina, y la Red Iberoamericana para la Acreditación de la Calidad de la Educación Superior (RIACES), está desarrollando un proyecto sobre los Sistemas de Evaluación y Certificación de Calidad de los Programas de Postgrado en América Latina y el Caribe. La propuesta conceptual, metodológica y operacional de dicho estudio ha sido ampliamente discutida y perfeccionada durante reuniones realizadas con la participación de distintos actores: representantes de gobiernos, de agencias y organismos de evaluación y acreditación, de redes universitarias, consejos de rectores y expertos en el tema de varios países de la región. 


\subsubsection{La educación superior en Perú}

La educación superior universitaria en Perú tiene las mismas características descritas para el caso general de Latinoamérica. Durante la última década hubo un aumento significativo del número de universidades (principalmente privadas), así como de la matrícula en la ES universitaria. De acuerdo con el Censo Nacional Universitario del año $2010^{18}$, a principios del 2010 existían en el Perú 100 universidades: 35 estatales y 65 privadas, frente a las 57 existentes en 1996 (28 públicas y 29 privadas).

\section{Gráfico 2.8. Perú: Número de universidades, por año censal, según tipo de} universidad

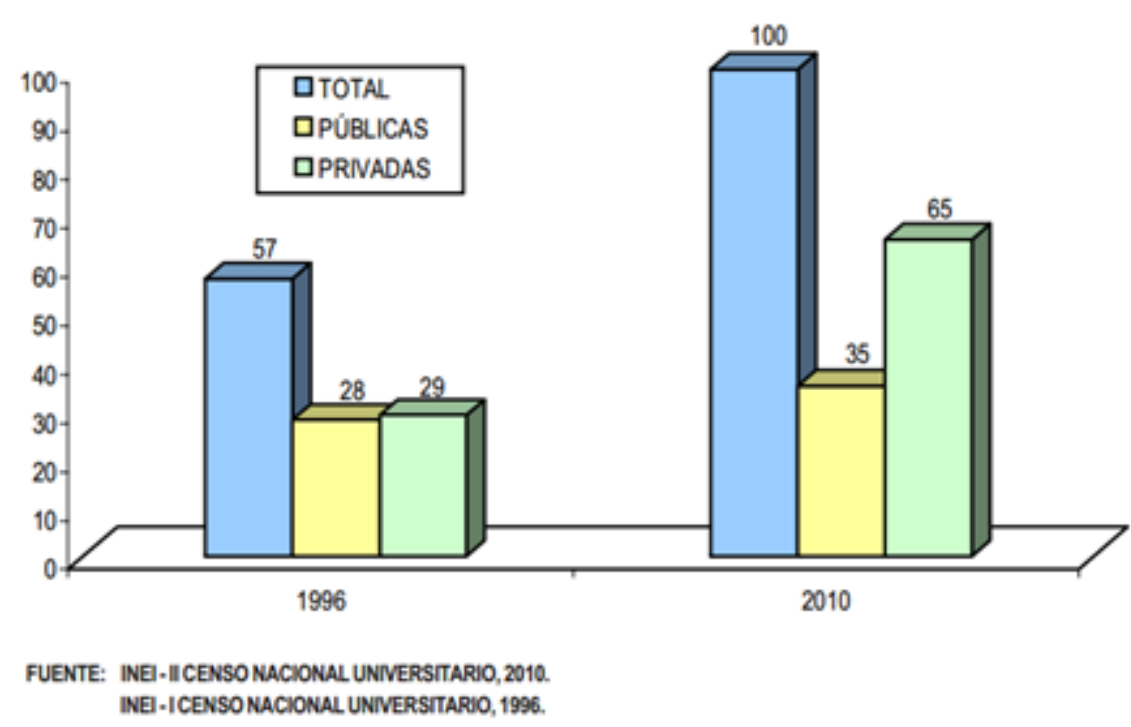

En el periodo 2005 al 2010 se crearon 16 nuevas universidades privadas y ninguna universidad pública. En el 2010 la población universitaria de pre-grado era 93\% con 782,970 alumnos y la de postgrado (maestrías, doctorados y segunda titulación) apenas el 7\% con 56,358 estudiantes $^{19}$. Sin embargo la tasa de crecimiento de 1996 a 2010 fue de $6.2 \%$ en pregrado y $12.4 \%$ en postgrado.

Este crecimiento ha obedecido a las reglas del libre mercado fomentado con la "Ley de universidad empresa" (Decreto Legislativo No 882 de 1996) que crea un tipo de universidad denominada “con fines de lucro". Desde entonces, cualquier persona natural o jurídica puede fundar, promover, conducir o gestionar una universidad privada, sólo con cumplir ciertos

\footnotetext{
${ }^{18}$ www.inei.gob.pe

${ }^{19}$ El Perú tiene la tasa de crecimiento de la matrícula en ES más alta el Latino América después de Venezuela y Uruguay.
} 
requisitos y estándares definidos por Consejo Nacional para Autorización de Funcionamiento de Universidades - CONAFU, entidad dirigida por ex-Rectores. Después de su autorización, las universidades pueden establecer programas (presenciales, semipresenciales, a distancia o virtuales) sin control de su pertinencia y calidad.

La Universidad Nacional Mayor de San Marcos, sigue siendo la universidad pública de mayor población de pre grado con 28,645 alumnos en el 2010 y una tasa anual de crecimiento de 2,1\%. En las universidades privadas se registran los crecimientos más notables. La Universidad Alas Peruanas, tuvo autorización de funcionamiento en el año 1996, no registra alumnos en ese año, pero en el 2010 muestra un total de 57,616 estudiantes de pre grado, siendo la universidad de mayor población del Perú. Otras universidades privadas de notable crecimiento al año 2010 son la Universidad Privada César Vallejo con 37163 alumnos de pregrado y la Universidad Católica Los Ángeles de Chimbote con 28,069 alumnos (INEI, 2010). Estas tres universidades ofrecen sus servicios en prácticamente todo el territorio nacional, a diferencia de la mayor parte de universidades cuyo ámbito de acción se concentra en un departamento.

Tanto la demanda como la oferta universitaria se han concentrado en carreras profesionales asociadas a las Ciencias Administrativas y Contables, al Derecho, a las Ciencias Sociales y a la Medicina Humana. El aumento de la oferta de estas carreras coincide con la creación de universidades privadas nuevas, así como filiales y sedes, centradas principalmente en este tipo de profesiones, cuyo mercado se encuentra saturado en algunas regiones (CINDA, 2011). El porcentaje de estudiantes que eligen las carreras de ingeniería se ha mantenido desde el 2007 al 2012 alrededor del 18\% (INEI, 2014b).

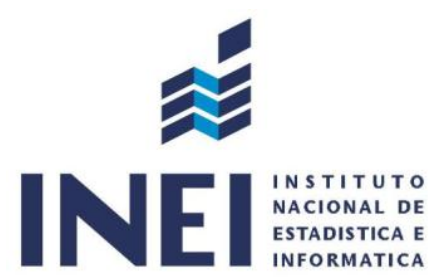

De acuerdo con los datos del Censo Nacional Universitario 2010 realizado por el Instituto Nacional de Estadística e Informática - INEI de Perú, la población de alumnos de post grado se encuentra distribuida de la siguiente manera: Maestría $(79,1 \%)$ que constituye la mayor parte de la población, seguido por Segunda Especialización $(13.7 \%)$ y Doctorado $(7,2 \%)$. En cuanto a la edad, la mitad de la población está entre los 25 y los 35 años.

Para los tres tipos de post grado, tanto para las universidades públicas como privadas, la mayor parte de alumnos ha nacido en el mismo departamento donde recibe sus clases y casi no hay estudiantes de otros países. 
El tiempo transcurrido entre la culminación de los estudios del pre grado y el inicio de post grado tanto en las universidades públicas como en las privadas es 6.9 años en la Segunda Especialización, 9.1 años en la Maestría y 16.4 años en el Doctorado.

El porcentaje de estudiantes de postgrado que estudian y trabajan a la vez es $88.1 \%$. La mayoría lo hace los fines de semana (el 48.7\% de estudiantes de maestría y el 64.7\% de los estudiantes de doctorado). En el caso de las maestrías además el 27.2\% de alumnos lo hace de manera inter diaria.

El 86,9\% de estudiantes de postgrado se autofinancia sus estudios, al 8.1\% le financian sus padres y al 2.9\% los cónyuges. Las empresas sólo financian los estudios del 2,7\% de los estudiantes y el $2 \%$ tiene beca.

El proyecto de tesis del 37.6\% de los estudiantes de postgrado está dirigido al área de Educación, le sigue el área de Economía, empresariales y afines con 21.3\% y las Ciencias de la Salud y Psicología con 16.2\%. El área de Ingeniería y tecnología sólo abarca el 10\%. Sólo el 33\% de ellos piensa emigrar al extranjero cuando termine sus estudios (INEI, 2010).

Un aspecto que se encuentra relegado en la educación superior universitaria peruana, tanto desde el sector público (por falta de presupuesto) como el privado (por prioridad del aspecto profesional y comercial), es el desarrollo de la función de investigación y producción de conocimiento propia de la universidad (cuya rentabilidad no se mide en el corto plazo, pero que resulta esencial para el desarrollo de un país). Este abandono de la función investigadora de la universidad, refuerza el alejamiento respecto a su entorno, y su falta de conexión con el sector productivo y el Estado. Actualmente no se cuenta con una instancia nacional independiente que promueva políticas de desarrollo de la educación superior peruana de manera articulada con el mercado laboral, las necesidades de las regiones y del país (CINDA, 2011).

Esta carencia se observa en la situación laboral de los docentes, especialmente aquellos de las universidades privadas, quienes trabajan por horas y se dedican a la enseñanza. Existe un aumento de la matricula y de la oferta de instituciones privadas, que no va acompañado de una política de incentivo y apoyo a la investigación e innovación que aporte a la formación profesional y al desarrollo del país (CINDA, 2011).

Solo el 3,6\% de los docentes de las universidades públicas y privadas ha terminado un doctorado (INEI, 2010) y el 52\% ha concluido estudios de maestría. Tres de cada 10 docentes 
tiene estudios de postgrado. Con respecto, al lugar de realización de los estudios de postgrado, solamente el 15,6\% los realizó en el extranjero.

Sobre el aspecto laboral del docente universitario, se tiene que el $34,7 \%$ son docentes ordinarios $^{20}, 58,3 \%$ son docentes contratados y el $0,6 \%$ son docentes extraordinarios ${ }^{21}$. En las universidades privadas, la mayor parte son docentes contratados $(80 \%)$ y en las universidades públicas la mayor parte son docentes ordinarios (73,4\%). El porcentaje de docentes que laboran en la misma universidad de la que egresaron es de $61.8 \%$ en las universidades públicas y el $22.5 \%$ en las privadas.

Sólo el 42.8\% de los docentes han realizado investigaciones en los últimos dos años. El área de conocimiento en la que con mayor frecuencia desarrollan las investigaciones es Ingeniería y tecnologías (21,2\%), luego le siguen las Ciencias de la Salud y Psicología (16,0\%), Educación $(15,4 \%)$, Economía, empresariales y afines $(12,2 \%)$ y Ciencias Sociales y Humanidades $(12,0 \%)$.

Una preocupación y reto de la ES en el Perú consiste en garantizar la calidad y la pertinencia de su oferta formativa. Para el Dr. (Guerra García, 2006), la proliferación de las maestrías que se ofrecen en el Perú se debe a la exigencia de los centros de trabajo a sus postulantes. También se debe a la fuente de recursos que constituyen los derechos académicos que se pagan en ambas: las universidades públicas y las privadas. Tales maestrías atienden sobre todo las expectativas de profesiones nuevas como son la Administración y Economía; en otras como las Ingenierías equivalen a la formación de especialistas (que desde hace cuatro décadas se ofrece en Medicina).

El crecimiento económico sostenido en los últimos años ha permitido mejorar sustancialmente indicadores como el PBI además de reducir significativamente la tasa de pobreza, sin embargo, este desempeño no ha ido de la mano con una mejora en los indicadores de competitividad y las actividades de investigación, desarrollo e innovación $(\mathrm{I}+\mathrm{D}+\mathrm{i})$. Esto se debe principalmente a la baja disponibilidad de investigadores e ingenieros dedicados a estas actividades (CONCYTEC, 2014); (WEF, 2013). Al año 2005 en las universidades peruanas se ofrecían 541 programas de maestría y 55 de doctorado, de las cuales el $32.34 \%$ y $16.36 \%$, respectivamente, corresponden a especialidades de ciencia y

\footnotetext{
${ }^{20} \mathrm{El}$ docente ordinario tiene mayor estabilidad laboral que el contratado.

${ }^{21}$ Los docentes extraordinarios pueden ser: Emérito, Honorario, Investigador o Visitante (INEI I. N., II Censo Nacional Universitario 2010, 2010).
} 
tecnología. De estos postgrados, son muy pocos los que tienen calidad académica internacionalmente competitiva. Muestra de ello es que sólo un $10 \%$ de sus estudiantes logra sustentar una tesis de grado (CONCYTEC, 2005).

Para el Consejo Nacional de Ciencia y Tecnología (CONCYTEC), ente rector del Sistema Nacional de Ciencia y Tecnología (SINACYT) en Perú, las causas que han originado este débil e ineficiente sistema nacional de innovación son:

\section{CONCYTEC}

Consejo Nacional de Ciencia.
Los resultados de investigación no responden a las

- Hay una insuficiente masa crítica de investigadores calificados.

- Hay insuficiente información sobre las condiciones del sistema.

- Bajos niveles de calidad de los centros de investigación.

- Deficiente gobernanza del SINACYT.

- Insuficientes incentivos para la innovación.

El gobierno peruano, con el apoyo de organismos multilaterales ha diseñado y ejecutado varios programas y proyectos de apoyo a la innovación tecnológica. Desde el año 2006, el Estado peruano con el apoyo del Banco Interamericano de Desarrollo (BID), implementó el programa de Ciencia y Tecnología (FINCYT), con el objetivo de promover la innovación tecnológica proporcionando recursos públicos para el financiamiento de una amplia gama proyectos, entre las cuales se pueden mencionar:

- Proyectos de innovación tecnológica en empresas

- Proyectos de investigación y desarrollo tecnológico en universidades y centros de investigación

- Fortalecimiento de capacidades para la ciencia y la tecnología, con becas y pasantías

- Proyectos de fortalecimiento y articulación del sistema nacional de innovación.

Actualmente, se ha viabilizado el Programa de Innovación para la Competitividad, el cual incluye financiamiento para:

- Proyectos de: innovación tecnológica

- Programas de desarrollo sectorial

- Emprendimientos tecnológicos

Las maestrías en Perú: el caso de Piura 
- Desarrollo de servicios de difusión tecnológica

- Proyectos de investigación científica y desarrollo tecnológico

- Equipamiento de unidades de investigación para la investigación científica e innovación tecnológica

- Acreditación de laboratorios

- Estudios para la promoción y desarrollo del mercado de innovación tecnológica

- Actividades orientadas a crear una cultura de innovación y competitividad

De acuerdo al Estrategia Nacional para el Desarrollo de la Ciencia, la Tecnología y la Innovación en el Perú (CONCYTEC, 2014) se tiene previsto invertir 2,648 millones de soles (715 millones de euros aproximadamente) en programas y proyectos para el desarrollo de la ciencia, la tecnología y la innovación en el periodo 2014-2016. Ver Tabla en Anexo.

Se trata de aprovechar el periodo de crecimiento económico que vive el Perú para invertir en estrategias que contribuyan a mejorar la competitividad del país. Una de estas es la formación de más ingenieros con calidad y pertinencia. Incluso, un ex Ministro de Economía de Perú llegó a decir en el Congreso Anual de Ejecutivos CADE 2010, quizá el foro nacional de ejecutivos más importante del país, que en Perú "Necesitamos un país de ingenieros, no solo de cocineros" (Carranza, 2010).

La nueva ley universitaria vigente en Perú es la Ley 30220 del año 2014. Esta ley creó la Superintendencia Nacional de Educación Superior Universitaria (SUNEDU) la cual supervisa la calidad de la educación, fiscaliza el uso de los recursos de las universidades y es la encargada de autorizar o denegar la creación de nuevas universidades en el país. Con esta nueva ley la acreditación de las carreras profesionales ya no sería voluntaria sino obligatoria. El grado de bachiller (cuando se terminan los estudios de pregrado) deja de ser automático. Según la nueva ley, que aún no está implementada, los alumnos deberán presentar una tesis para obtener este grado. Para obtener el título profesional (licenciatura) se requerirá un trabajo de suficiencia profesional, que puede ser a través de un curso de actualización o un examen. Asimismo, este grado solo podrá ser otorgado por la universidad en la que el alumno ha egresado.

En cuanto al financiamiento de la educación superior universitaria en Perú, el Estado solo financia al sector público básicamente con las asignaciones del Presupuesto General de la República, vía Tesoro Público, o por aportes del Canon y Sobrecanon (asignación indirecta 
a las universidades públicas a través de los gobiernos regionales quienes pueden financiar proyectos específicos a las universidades). Las universidades públicas además generan ingresos propios que provienen de la comercialización directa de productos y prestaciones de servicios. Este tipo de recursos han pasado a representar, en los últimos años, entre un cuarto y un tercio de los ingresos de la universidad pública. En el periodo 2006 - 2010 los recursos directamente recaudados han sido el 30.3\% (CINDA, 2011b).

Tabla2.3. Fuentes de presupuesto público para ES universitaria en Perú 2006- 2010

\begin{tabular}{lc}
\hline Fuentes & Porcentaje \\
\hline Recursos ordinarios & $57.6 \%$ \\
Recursos directamente recaudados & $30.3 \%$ \\
Canon, sobrecanon y regalías & $3.2 \%$ \\
Donaciones y transferencias & $8.9 \%$ \\
\hline Total & $\mathbf{1 0 0 \%}$ \\
\hline
\end{tabular}

Fuente: CINDA (2011b)

El financiamiento de las universidades privadas proviene casi enteramente del pago que efectúan sus alumnos por los servicios de enseñanza. Para la mayor parte de las universidades privadas un $95 \%$ de sus ingresos proviene de dicho concepto. El saldo restante es producto de donaciones privadas o, en algunos casos, de ingresos conexos vinculados -alquileres, inversiones inmobiliarias- que representan entre el 20\% y $30 \%$ de sus ingresos (CINDA, 2011b). 


\subsubsection{La Universidad de Piura}

\section{Gráfico 2.9. Universidad de Piura - campus Piura}
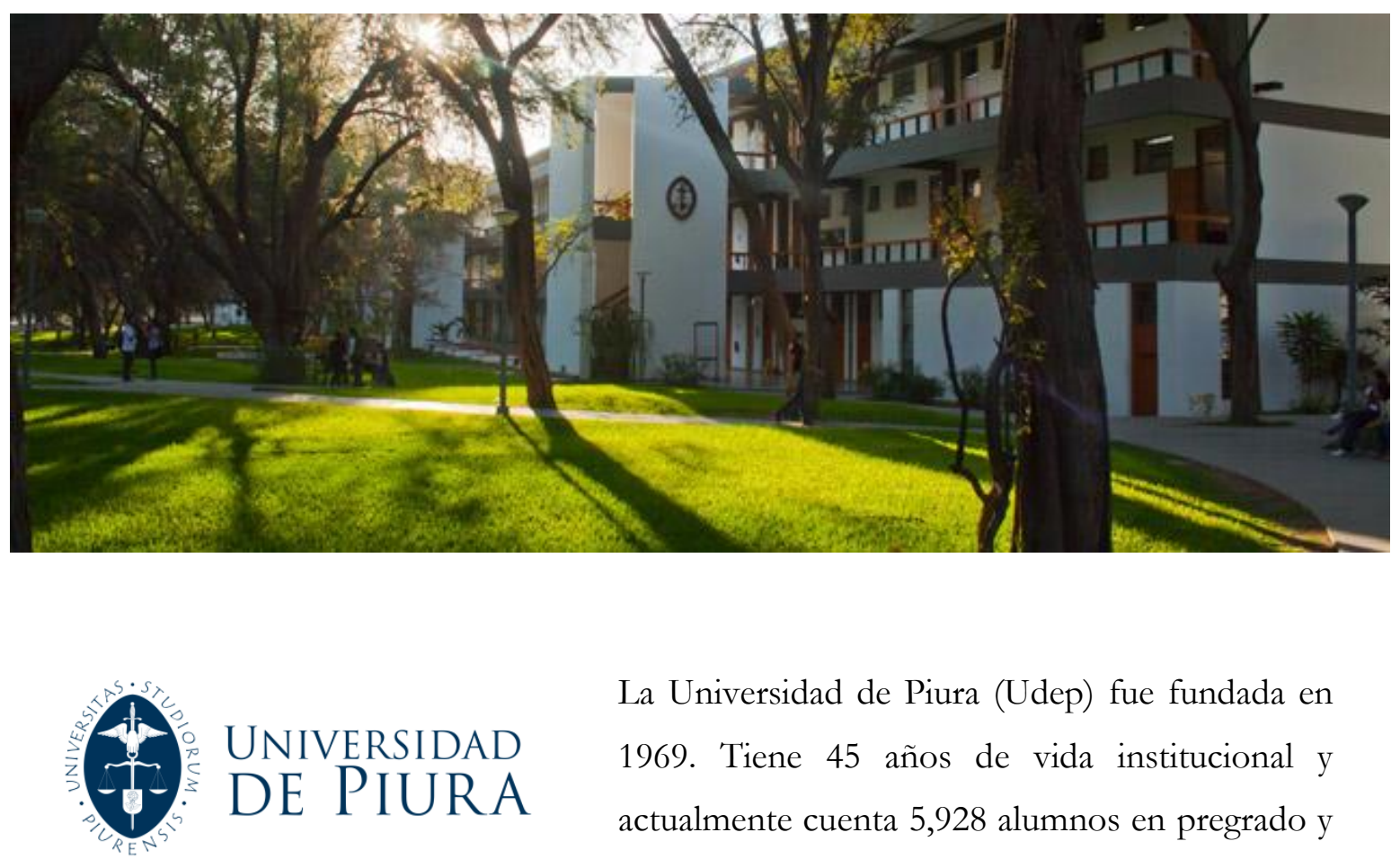

La Universidad de Piura (Udep) fue fundada en 1969. Tiene 45 años de vida institucional $y$ actualmente cuenta 5,928 alumnos en pregrado y 972 alumnos de postgrado ${ }^{22}$ repartidos en 6 facultades y una escuela de negocios. Cuenta con dos campus: uno en Piura (de 130 hectáreas) y otro en Lima. Tiene 6 facultades: Ingeniería, Ciencias económicas y Empresariales, Derecho, Educación, Comunicación y Humanidades. Su escuela de negocios tiene un MBA a tiempo completo que es considerado como uno de los mejores del país ${ }^{23}$.

\footnotetext{
22 Sin considerar los alumnos de cursos de extensión y diplomados.

${ }^{23}$ Según la última encuesta aplicada por Global Research Marketing - GRM a ejecutivos de Perú, el MBA de la Universidad de Piura es la mejor opción. También se ubica en los primeros puestos del Ranking de Eduniversal http://www.eduniversal-ranking.com/
} 
Tabla 2.4. Alumnos de pregrado Universidad de Piura 2014

\begin{tabular}{lrrr}
\hline Facultad & Piura & Lima & Total \\
\hline Ciencias Económicas y Empresariales & 1199 & 1034 & 2233 \\
Ingeniería & 1680 & 428 & 2108 \\
Derecho & 439 & 151 & 590 \\
Comunicación & 476 & & 476 \\
Ciencias de la Educación & 379 & & 379 \\
Humanidades & 92 & 50 & 142 \\
\hline Total & $\mathbf{4 2 6 5}$ & $\mathbf{1 6 6 3}$ & $\mathbf{5 9 2 8}$ \\
\hline
\end{tabular}

Fuente: elaboración propia a partir de datos de la Secretaría General

Tabla 2.5. Alumnos de postgrado Universidad de Piura 2014

\begin{tabular}{|c|c|c|c|c|c|}
\hline \multirow[t]{2}{*}{ Facultad } & \multicolumn{2}{|c|}{ Maestrías } & \multicolumn{2}{|c|}{ Doctorados } & \multirow[t]{2}{*}{ Total } \\
\hline & Piura & Lima & Piura & Lima & \\
\hline PAD - Escuela de Dirección & & 531 & & 17 & 548 \\
\hline Ingeniería & 143 & 78 & 9 & & 221 \\
\hline Ciencias Económicas y Empresariales & 74 & & & & 74 \\
\hline Ciencias de la Educación & 41 & 31 & & & 72 \\
\hline Derecho & 48 & & & & 48 \\
\hline Total & 306 & 640 & 9 & 17 & 963 \\
\hline
\end{tabular}

Fuente: elaboración propia a partir de datos de la Secretaría General

El total de docentes en la Udep es 463, de los cuales el 22\% tiene grado de doctor. El 80\% trabaja a tiempo completo.

Tabla 2.6. Número de docentes Universidad de Piura

\begin{tabular}{lrrrr}
\hline Grado & Piura & Lima & Total & Porcentaje \\
\hline Doctor & 78 & 22 & 100 & $22 \%$ \\
Magister & 89 & 59 & 148 & $32 \%$ \\
Licenciado & 97 & 66 & 163 & $35 \%$ \\
Bachiller & 28 & 24 & 52 & $11 \%$ \\
\hline Total & $\mathbf{2 9 2}$ & $\mathbf{1 7 1}$ & $\mathbf{4 6 3}$ & $\mathbf{1 0 0 \%}$ \\
\hline
\end{tabular}

Fuente: elaboración propia a partir de datos de la Secretaría General

De acuerdo al Ranking de America Economía, la Udep se encuentra entre las 10 primeras universidades del país y es (desde hace mucho tiempo) la mejor universidad no limeña. 
Tabla 2.7. Ranking 2013 - Mejores universidades de Perú según América Economía

\begin{tabular}{llllrr}
\hline $\mathbf{N}^{\circ}$ & Universidad & Ciudad & Régimen & $\begin{array}{r}\text { Alumnos } \\
\text { pregrado }\end{array}$ & $\begin{array}{r}\text { Año de } \\
\text { creación }\end{array}$ \\
\hline 1. & $\begin{array}{l}\text { Pontificia Universidad Católica del } \\
\text { Perú - PUCP }\end{array}$ & Lima & Privada & 17531 & 1917 \\
\hline 2. & $\begin{array}{l}\text { Universidad peruana Cayetano } \\
\text { Heredia }\end{array}$ & Lima & Privada & 3536 & 1969 \\
\hline 3. & $\begin{array}{l}\text { Universidad Nacional Mayor de San } \\
\text { Marcos }\end{array}$ & Lima & Pública & 28645 & 1551 \\
\hline 4. & Universidad de Lima & Lima & Privada & 14109 & 1962 \\
\hline 5. & Universidad del Pacífico & Lima & Privada & 2179 & 1962 \\
\hline 6. & $\begin{array}{l}\text { Universidad Nacional Agraria La } \\
\text { Molina }\end{array}$ & Lima & Pública & 4903 & 1902 \\
\hline 7. & Universidad Nacional de Ingeniería & Lima & Pública & 11034 & 1876 \\
\hline 8. & Universidad San Martín de Porres & Lima & Privada & 31046 & 1962 \\
\hline 9. & Universidad Peruana de Ciencias & Lima & Privada & 15504 & 1994 \\
\hline Aplicadas & Universidad de Piura & Piura / & Privada & 5232 & 1969 \\
\hline 10. & Lima & & & \\
\hline
\end{tabular}

Fuente: (América Economía, 2013)

La carrera de Ingeniería Industrial ofrecida por la Udep es considerada la quinta mejor a nivel nacional según este mismo Ranking.

Tabla 2.8. Ranking 2013 - Ingeniería Industrial en Perú según América Economía

\begin{tabular}{ccl}
\hline $\begin{array}{c}\text { Ranking } \\
2013\end{array}$ & $\begin{array}{c}\text { Ranking } \\
2012\end{array}$ & Universidad \\
\hline 1. & 1. & Universidad Nacional de Ingeniería \\
2. & 2. & Pontificia Universidad Católica del Perú - PUCP \\
3. & 3. & Universidad de Lima \\
4. & 4. & Universidad Nacional Mayor de San Marcos \\
5. & 5. & Universidad de Piura \\
\hline
\end{tabular}

Fuente: América Economía (2013)

La Universidad de Piura es una obra de apostolado corporativo del Opus Dei. Se inspira en una concepción humanista y cristiana de la vida, es por ello que promueve la fe católica y los valores cristianos dentro de un clima de total respeto a la libertad de los alumnos. Reconoce como Fundador a su primer Gran Canciller San Josemaría Escrivá de Balaguer, Fundador del Opus Dei. 
La especialidad de Educación Primaria de la facultad de Educación se convirtió en marzo del 2013 en la primera carrera en ser acreditada por el Estado Peruano bajo los estándares del Consejo de Evaluación, Acreditación y Certificación de la Calidad de la Educación Superior Universitaria - CONEAU.

La facultad de Ingeniería tiene a cargo una de las 18 maestrías que subvenciona el Consejo Nacional de Ciencia, Tecnología e Innovación Tecnológica de Perú - Concytec a nivel nacional con el fin de contribuir al desarrollo de la ciencia, tecnología e innovación en áreas prioritarias para el Perú. El Concytec ha otorgado quince becas integrales para cursar la Maestría en Ingeniería Mecánico Eléctrica con mención en Automática y Optimización, que se dictará en la Universidad de Piura en forma presencial y a tiempo completo. El Concytec también ha puesto a disposición becas para la realización del estudio de Doctorado en Ingeniería con mención en Automatización, Control y Optimización de Procesos de la Universidad de Piura, a través del Programa Cátedra ${ }^{24}$.

Tabla 2.9. Alumnos de pregrado en la facultad de ingeniería - Udep 2014

\begin{tabular}{lccc}
\hline Programa Académico & Campus Piura & Campus Lima & Total \\
\hline Ingeniería Industrial y de Sistemas & 448 & 339 & 787 \\
Ingeniería Mecánico Eléctrica & 384 & 0 & 384 \\
Ingeniería Civil & 587 & 0 & 587 \\
Arquitectura & 44 & 0 & 44 \\
Ciclo Introductorio & 217 & 89 & 306 \\
\hline Total & $\mathbf{1 , 6 8 0}$ & $\mathbf{4 2 8}$ & $\mathbf{2 , 1 0 8}$ \\
\hline
\end{tabular}

Fuente: elaboración propia a partir de datos de la Secretaría General de Udep

La facultad de Ingeniería es la más grande en número de alumnos, cuenta con 2,108 alumnos en pregrado y 245 en postgrado ${ }^{25}$. La distribución de los alumnos de ingeniería en pregrado y postgrado se muestras en las Tablas 2.9 y 2.10

\footnotetext{
${ }^{24}$ Las Cátedras CONCYTEC son Centros de Excelencia universitarias a nivel de postgrado, generados alrededor de un grupo de Profesores Investigadores de alto nivel que se dedican a tiempo completo a la enseñanza de los conocimientos en un doctorado o una maestría y a la investigación aplicada orientada al desarrollo de uno o varios sectores: www.concytec.gob.pe

${ }^{25} \mathrm{Sin}$ considerar los alumnos de cursos de extensión y diplomados
} 
Tabla 2.10. Alumnos de postgrado en la facultad de ingeniería - Udep 2014

\begin{tabular}{|c|c|c|c|}
\hline Maestría /Doctorado & Piura & Lima & Total \\
\hline $\begin{array}{lllll}\text { Doctorado en } & \text { Ingeniería con mención en }\end{array}$ & 9 & & 9 \\
\hline \multicolumn{4}{|l|}{$\begin{array}{l}\text { Automatización, Control y Optimización de Procesos - tiempo } \\
\text { completo }\end{array}$} \\
\hline Maestría en Ingeniería Mecánico Eléctrica tiempo completo & 15 & & 15 \\
\hline Maestría en Ingeniería Mecánico Eléctrica tiempo parcial & 29 & & 29 \\
\hline $\begin{array}{l}\text { Maestría en Ingeniería Civil con mención en Recursos Hídricos } \\
(*)\end{array}$ & 60 & & 60 \\
\hline Maestría en Ingeniería Civil con mención en Ingeniería Vial $(*)$ & 41 & 76 & 117 \\
\hline Maestría en Seguridad y Salud en el Trabajo $\left(^{*}\right)$ & 15 & & \\
\hline Total & 169 & 76 & 245 \\
\hline
\end{tabular}

Fuente: elaboración propia a partir de datos de la Secretaría General de Udep

(*) tiempo parcial

\subsection{CONCLUSIONES DEL CAPÍTULO II}

Los países latinoamericanos y en especial Perú han mostrado un crecimiento económico sostenido en los últimos años debido principalmente al aumento de los precios de los productos primarios y a las grandes reformas iniciadas en la década del 90. Esto ha permitido mejorar sustancialmente indicadores como el PBI además de reducir significativamente la tasa de pobreza.

En los últimos diez años Latinoamérica tuvo un crecimiento económico promedio de 4.2\% y Perú de 6\%. La pobreza monetaria en el periodo 2004 - 2012 disminuyó de $43 \%$ a $28.8 \%$ en Latinoamérica y de $58.5 \%$ a $25.8 \%$ en Perú.

Perú goza de un marco de estabilidad macroeconómica que le ha permitido disminuir su nivel de deuda, tener una mejor calificación crediticia internacional y atraer mayores inversiones. Hay muchas inversiones públicas y privadas previstas para los próximos años.

El buen desempeño económico no fue de la mano con una mejora significativa en los indicadores de competitividad y en las actividades de investigación, desarrollo e innovación $(\mathrm{I}+\mathrm{D}+\mathrm{i})$. La causa principal fue la baja disponibilidad de investigadores e ingenieros dedicados a estas actividades. Esta baja disponibilidad de ingenieros dedicados a actividades 
de investigación no es más que la punta del iceberg de baja calidad en la educación superior universitaria de Latinoamérica y el Perú.

Para entender mejor este problema es necesario conocer la evolución que ha tenido la educación superior latinoamericana. Esta ha pasado por tres grandes reformas. La primera empezó en 1918 y se caracterizó por la autonomía y el autogobierno de las universidades, la segunda reforma empezó en 1975 y estuvo caracterizada por la mercantilización de la educación superior en un modelo público - privado, altamente diversificada y con universidades de diferente calidad tratando de absorber la gran demanda de educación superior. La tercera reforma ha ocurrido a fines del siglo pasado y se caracteriza por la internacionalización de la educación superior, el establecimiento de sistemas de aseguramiento de calidad, la aparición de la educación virtual y la creación de universidades privadas con fines de lucro.

Estos cambios han originado que actualmente Latinoamérica sea la región del mundo que tiene la mayor proporción de matrícula privada (cerca del 50\%), la mayor cantidad de estudiantes se encuentren en las carreras de ciencias sociales, empresariales y jurídicas (los alumnos de las carreras de ciencias representan aproximadamente un 10\%), que el porcentaje de docentes con grado de doctor sea menor que $15 \%$ y que las instituciones privadas cuenten con una cantidad pequeña de docentes a tiempo completo.

La investigación depende generalmente de fondos concursables en organismos públicos, a los cuales acceden en competencia las universidades y los centros de investigación tanto públicos como privados. La contribución estatal a $\mathrm{I}+\mathrm{D}$ es muy baja y el sector privado invierte poco en este tema. La globalización obliga a las universidades a tratar de alcanzar estándares mundiales y para lograrlo tienen dos caminos: o especializarse en áreas específicas del conocimiento o establecer alianzas con universidades e institutos de alto nivel. El riesgo que se corre es que la agenda de investigación de las universidades puede parecerse más a la agenda internacional, mientras que los problemas nacionales ocupen un lugar secundario en favor de los problemas más globales.

En Latinoamérica hay una mayor oferta de programas de postgrado profesionales o de corte "profesionalizante" especialmente en las áreas de ciencia y tecnología como ingeniería, en desmedro de los programas de postgrado de "investigación". Esta realidad se debe tener muy en cuenta al momento de evaluar la pertinencia porque son diferentes las necesidades que atienden cada tipo de programa. En las maestrías profesionales se busca mejorar el 
desempeño profesional y laboral de los estudiantes y en las maestrías de investigación se busca desarrollar la capacidad de hacer generalizaciones, de plantear problemas y proponer proyectos de investigación, con rigor metodológico y juicio crítico.

Para mejorar en competitividad e innovación es necesario impulsar la investigación y por tanto impulsar las maestrías de investigación. Con el objetivo de avanzar en el camino de conversión de "universidades profesionales" a "universidades de investigación" se han llevado a cabo muchos esfuerzos. Uno de ellos es desarrollar el Espacio EuroLatinoamericano de Educación Superior, Ciencia, Tecnología e Innovación. La influencia europea en la educación superior latinoamericana se ha dado desde sus inicios y se mantiene hasta ahora.

La educación superior universitaria en Perú tiene las mismas características descritas para el caso general de Latinoamérica. Sin embargo hay algunos aspectos en los que Perú se encuentra rezagado como en la acreditación de la educación superior y en la investigación en las universidades ligadas al postgrado. Hay que tener en cuenta las características peruanas al respecto: casi el 80\% de los alumnos de postgrado son de maestría y de éstos el $60 \%$ han nacido en el mismo departamento. El 88\% estudia y trabaja a la vez y el $87 \%$ se autofinancia sus estudios.

El abandono en el que se encuentra la función investigadora de las universidades en Perú tiene muchas causas. Una de ellas se debe a las características de los docentes. En las universidades privadas, la mayor parte de los docentes trabajan por horas y se dedican sólo a la enseñanza. Entre universidades públicas y privadas solo el 3,6\% de los docentes ha terminado un doctorado.

Para revertir esta situación el Estado peruano a través del Consejo Nacional de Ciencia y Tecnología ha diseñado y ejecutado varios programas y proyectos de apoyo a la innovación tecnológica. Se espera invertir en estas actividades 716 millones de euros en el periodo 2014 - 2016, una cifra nunca antes vista en Perú. Las principales actividades son: financiamiento de proyectos de investigación, implementación de laboratorios, financiamiento de programas y becas de postgrado, implementación de parques tecnológicos, centros de excelencia, entre otros. Para ello se han definido programas y sectores económicos prioritarios para el desarrollo del país.

Es un buen momento para invertir en educación, en investigación e innovación para mejorar la competitividad y lograr un desarrollo sostenible. Esto es aún más necesario si se tiene en 
cuenta que muchos pobladores aún no tienen acceso a los servicios básicos como agua, desagüe y energía eléctrica. Por eso es muy importante mejorar la calidad y la pertinencia de la formación de postgrado en ingeniería, porque esta carrera y este nivel de formación necesitan estar muy vinculados con su entorno socio económico, para responder a las necesidades e intereses locales, nacionales y regionales.

\subsection{BIBLIOGRAFÍA DEL CAPÍTULO II}

América Economía. (2013). Ranking 2013 Perú. Las mejores universidades. Recuperado el junio de 2014, de http://rankings.americaeconomia.com

BCRP - Banco Central de Reserva de 1 Perú (2014). Estadísticas - Cuadros históricos.

Recuperado el junio de 2014, de http://www.bcrp.gob.pe/estadisticas.html

Brunner, J. (2010). "Globalización de la educación superior: crítica de su figura ideológica". Revista Iberoamericana de Educación Superior (RIES), , vol. I, núm.2, pp. 75-83.

Carranza, L. (2010). Congreso Anual de Ejecutivos 2010. Obtenido de Rumbo a la prosperidad, "la Agenda prioritaria de la competitividad": http://empresarioshaciendopais.pe/

CEPAL (2014). Balance económico actualizado de América Latina y el Caribe 2013. Recuperado en junio de 2014, de http://www.eclac.cl/publicaciones

CEPAL (2013). Balance preliminar de las economias de América Latina y el Caribe 2013.

Recuperado en junio de 2014, de http://www.eclac.cl/publicaciones

CEPAL (2013b). Panorama económico y social de América Latina y el Caribe 2013. Recuperado en junio de 2014, de http://www.eclac.cl

CEPAL (2010). Espacios iberoamericanos: vinculos entre universidades y empresas para el desarrollo tecnológico. Santiago de Chile.

CEPAL (2009). La educación superior y el desarrollo económico en América Latina. México D.F.: Publicaciones de las Naciones Unidas.

CINDA. (2011). Educación Superior en Iberoamérica. Informe 2011. Recuperado en junio de 2014, de www.cinda.cl

CINDA (2011b). La educación Superior en Perú 2005 - 2009. Recuperado en junio de 2014, de http://www.universia.net

CINDA (2014). Instituto Internacional para el Aseguramiento de la Calidad. Recuperado el junio de 2014, de www.cinda.cl/iac 
CONCYTEC (2014). Estrategia Nacional para el Desarrollo de la Ciencia, Tecnología e Innovación. Recuperado el junio de 2014, de www.concytec.gob.pe

CONCYTEC (2005). Plan Nacional Estratégico de Ciencia, Tecnología e Innovación para la competitividady desarrollo bumano 2006-2021. Recuperado el mayo de 2014, de www.concytec.gob.pe

Congreso de la República de Perú. (9 de julio de 2014). Ley universitaria. Ley 30220 Recuperado en mayo de 2015, de www2.congreso.gob.pe

FAO, (2013). Noticia. 38 paises alcanzan las metas contra el hambre fijadas para 2015. Recuperado el junio de 2014, de www.fao.org

Gobierno Regional de Piura. (2013). Plan estratégico de desarrollo regional concertado 2013 - 2016. Recuperado el junio de 2014, de www.regionpiura.gob.pe

Guerra García, R. (2006). Discurso de orden: 50 años de las universidades peruanas. Academia Nacional de Medicina. Anales 2006, (págs. 108-116). Lima.

Hinds, M. (2013). ¿Para dónde va América Latina? Análisis y Opinión de Revista América Economía. Obtenido de http://www.americaeconomia.com/analisis-opinion/para-dondeva-america-latina.

IESALC. (2008). Declaración y Plan de Acción de la Conferencia Regional de Educación Superior en América Latina y el Caribe 2008. Recuperado el junio de 2014, de www.iesalc.unesco.org.ve IESALC. (2014). VINCULAENTORNO. Recuperado el junio de 2014, de http://www.iesalc.unesco.org.ve

INEI (2014a). Evolución de la pobreza Monetaria 2009 - 2013. Informe Técnico. Recuperado el junio de 2014, de www.inei.gob.pe

INEI (2014b). Instituto Nacional de Estadística e Informática de Perú. Recuperado el junio de 2014, de Base de Datos ENAHO - Encuesta Nacional de Hogares: www.inei.gob.pe

INEI (2014c). Perú: Indicadores de Educación por departamentos 2001 - 2012. Recuperado el junio de 2014, de www.inei.gob.pe

INEI (2013). Perú: Evolución de los indicadores de empleo e ingreso por departamento 2004 - 2012. Recuperado el junio de 2014, de www.inei.gob.pe

INEI (2010). II Censo Nacional Universitario 2010. Recuperado el junio de 2014, de www.inei.gob.pe

MEF, Ministerio de Economía y Finanzas de Perú (2014). Marco Macroeconómico Mutianual 2015 - 2017. Recuperado en junio de 2014, de www.mef.gob.pe 
PROINVERSION (2014). Inversiones estratégicas- APP. Recuperado el junio de 2014, de www.proyectosapp.pe

Rama, C. (2006). La Tercera Reforma de la educación superior en América Latina. Buenos Aires: Fondo de Cultura Económica.

Tuning América Latina. (2014). Proyecto Tuning América Latina. Obtenido de http://www.tuningal.org

WEF - World Economic Forum (2013). Obtenido de www.wef.com

Yong Kim, J. (2013). Una América Latina con oportunidades para todos. Análisis y Opinión de Revista América Economía. 


\section{Capítulo III}

La pertinencia vista por los organismos de acreditación 


\section{Capítulo III}

\section{La pertinencia vista por los organismos de acreditación}

En este capítulo se determina que en los modelos de evaluación de maestrías en ingeniería existentes (que son los modelos con fines de acreditación) no se está evaluando la adecuación de los objetivos y resultados de la maestría a las necesidades reales de los estudiantes y las partes interesadas, es decir, no se está evaluando la pertinencia. Los modelos de acreditación en el contexto internacional evalúan principalmente la eficacia de los programas educativos, es decir, la capacidad que tienen los programas para lograr los objetivos educativos que declaran en su misión. Sin embargo, no se garantiza que esos objetivos y por tanto los resultados, satisfagan necesidades reales del entorno nacional o regional, un aspecto esencial en los países en vías de desarrollo.

El capítulo se divide en dos partes: en la primera parte se presentan los modelos de evaluación utilizados por los organismos de acreditación internacional de Europa, Estados Unidos y España y en la segunda parte se presentan los principales modelos de evaluación de Latinoamérica y el Perú. Se revisa si se está considerando o no criterios de evaluación de pertinencia. Se revisan los modelos de evaluación de los programas de postgrado en general porque hay muy pocos modelos específicos para maestrías en ingeniería aparte de los de ABET.

Para seleccionar los organismos internacionales se utiliza la clasificación desarrollada por Eaton (2007). Se revisa los modelos de: la European Association for Quality Assurance ENQA, el Council for Higher Education Accreditation (CHEA) de Estados Unidos, la International Network for Quality Assurance Agencies in Higher Education (INQAAHE), la Organización Mundial del Comercio - OMC y la Agencia Nacional de Evaluación de la Calidad y Acreditación - ANECA de España. También se revisa dos modelos específicos para programas de ingeniería: el de ABET de Estados Unidos y el modelo regional del proyecto EUR- ACE en Europa.

En la segunda parte se analiza los modelos de evaluación (criterios e indicadores) de los entes rectores de los sistemas de acreditación de México y Brasil así como los criterios de la Asociación Universitaria Iberoamericana de Postgrado (AUIP) y el Centro Interuniversitario de Desarrollo (CINDA). Para el caso de Perú se analiza los criterios del Consejo de Evaluación, Acreditación y Certificación de la Calidad de la Educación Superior Universitaria 
- CONEAU, los de la Pontificia Universidad Católica del Perú y los del Instituto de Calidad y Acreditación de Programas de Computación, Ingeniería y Tecnología - ICACIT.

Los modelos se revisaron usando el lente de la pertinencia, de acuerdo con el marco teórico y la definición planteada en el capítulo I. Esta revisión permite identificar algunos indicios de pertinencia con sus respectivas fuentes de verificación para plantear luego en el siguiente capítulo un modelo de evaluación de la pertinencia de maestrías en ingeniería en países en desarrollo.

\subsection{EVALUACIÓN DE LA PERTINENCIA EN LOS ORGANISMOS DE ACREDITACIÓN INTERNACIONAL}

\subsubsection{La evaluación y la acreditación}

La evaluación de una maestría es el proceso a través del cual se recoge y se interpreta, formal y sistemáticamente información, se producen juicios de valor a partir de esa información y se toman decisiones conducentes a mantener, proyectar, mejorar, revisar, ajustar, reformar o eliminar elementos de dicha maestría (AUIP, 2014).

De acuerdo con Felder \& Brent (2004); Olds, Moskal, \& Miller (2005) en la formación en ingeniería este proceso de evaluación consiste en dos etapas:

- Assessment: Recogida de los datos o evidencias (observaciones, mediciones, experimentos, encuestas, etc.) que pueden ser usados para responder a las preguntas de la evaluación o investigación.

- Evaluation. Interpretación efectuada utilizando los datos o evidencias recogidas en el assessment para responder a las preguntas de evaluación o investigación.

Un proceso de evaluación de un programa académico presupone:

- Definir los propósitos de la evaluación.

- Delimitar el objeto de la evaluación.

- Delimitar sus variables, elementos, indicadores y criterios, para establecer el nivel y calidad del programa en funcionamiento.

- Recolectar, analizar e interpretar información.

- Valorar la calidad del programa en su totalidad o en algunas de sus variables y elementos.

La pertinencia vista por los organismos de acreditación 
- Analizar los niveles de logro del programa evaluado.

- Identificar e incorporar los ajustes o cambios convenientes.

- Establecer procesos permanentes de ajuste, mejora, seguimiento y control.

Dependiendo del propósito de la evaluación, ésta puede ser formativa o sumativa. La evaluación es formativa cuando se pretende hacer ajustes o mejoras en el funcionamiento y es sumativa cuando se tiene que decidir si se mantiene, se modifica, se termina o se sustituye el programa. Ambos tipos de evaluación se pueden aplicar a la evaluación de los procesos, evaluación de los recursos, evaluación de los resultados, o evaluación del impacto (DiazPuente, 2003).

Los modelos de evaluación de programas de postgrado se encuentran en el corazón de los sistemas de aseguramiento de la calidad y deberían tener como fines: el control de la calidad, la rendición de cuentas (acreditación) o el mejoramiento de la calidad (Salazar, 2011). En la actualidad los modelos de evaluación existentes tienen como fin principalmente la acreditación. Las instituciones han pasado de evaluaciones con fines de mejora de la calidad a evaluaciones con fines de acreditación (Sanyal \& Martin, 2007).

Se entiende por aseguramiento de la calidad de la educación superior las acciones que llevan a cabo las instituciones educativas con el fin de asegurar que un programa o institución educativa es adecuada para sus fines (RIACES, 2004).

La acreditación reconoce la calidad de los programas o de la institución acreditada. Supone la evaluación respecto de estándares y criterios de calidad establecidos previamente por una agencia u organismo acreditador externo a la universidad o institución de educación superior. El procedimiento incluye usualmente una autoevaluación de la propia institución, así como una evaluación por un equipo de expertos externos. Las agencias u organismos acreditadores son a su vez acreditadas regularmente. En todos los casos es una validación temporal, por unos años. Se basa en un conjunto de principios, relativamente básicos y homogéneos, aunque la diversidad de modelos es extensa (RIACES, 2004).

Los sistemas de aseguramiento de la calidad y de acreditación han surgido entre otras cosas debido a:

- La existencia de muchos proveedores de educación superior, incluyendo a instituciones públicas, privadas, transnacionales y de educación a distancia o virtual. 
- La educación superior brindada por instituciones transnacionales ha originado una “fábrica de diplomas” y fraude académico en algunos casos.

- La calidad de las instituciones públicas de educación superior ha disminuido en diversos países debido a las restricciones económicas y a un cambio en las prioridades de inversión de recursos del estado.

- La movilidad profesional y los procesos de integración regional e internacional, donde es necesario el reconocimiento de títulos.

En el caso de las carreras de ingeniería y tecnología se tiene como alternativa a $\mathrm{ABET}^{26}$ (Accreditation Board for Engineering and Technology), que es la organización responsable en Estados Unidos de la acreditación de los programas de ingeniería y ciencia aplicada. Actualmente ABET otorga una acreditación internacional en muchos países.

Los modelos utilizados para el aseguramiento de la calidad y la acreditación varían mucho dependiendo del contexto. De acuerdo con Sanyal \& Martin (2007) hay diferentes tipos de acreditación. La acreditación puede ser obligatoria o voluntaria, puede acreditarse un programa o una institución. Dependiendo del nivel de cobertura geográfica, la acreditación puede ser subnacional, nacional, regional o internacional. Se puede acreditar sólo instituciones privadas o incluir también a las públicas, se puede utilizar un enfoque basado en estándares o un enfocado basado en la adecuación a los objetivos. El foco de la acreditación y por tanto lo que se revisa puede ser los resultados o los procesos. Existen muchos organismos de acreditación y la tendencia es a formar redes o asociaciones regionales con estándares comunes.

Para Eaton (2007a) la acreditación debe ser internacional dado que la educación superior es cada vez más universal e internacional. La movilidad estudiantil está aumentando y las corporaciones multinacionales cada vez dan más empleo a profesionales de todas partes del mundo.

Los actores principales en un espacio de acreditación internacional son: las instituciones de educación superior, los organismos de acreditación y de garantía de la calidad, los gobiernos nacionales, las asociaciones profesionales, las asociaciones estudiantiles y las organizaciones multinacionales como la UNESCO, la OCDE y la OMC. Durante los últimos años, estos actores han conseguido un progreso considerable al aferrarse a la dimensión de la calidad, la universalización y la internacionalización de la educación superior (Eaton, 2007b).

\footnotetext{
${ }^{26}$ Para mayor información ver www.abet.org
} 
De acuerdo con Rama (2008) el postgrado requiere procesos de evaluación y acreditación internacionales y el pregrado está asociado a la evaluación y acreditación local. El postgrado se rige principalmente por una regulación internacional y de mercado, y el pregrado se rige principalmente por una regulación nacional académica. La desventaja de la acreditación internacional es que, al basarse en estándares globales y criterios sólo técnicos, este tipo de acreditación implica una baja pertinencia local, es decir, una baja vinculación entre los objetivos planteados y las necesidades reales del entorno local.

Eaton (2007b) describe cinco modelos ideales de acreditación internacional y se presentan en la Tabla 3.1.

Según Eaton, cualquiera de estos modelos ofrece ventajas y desventajas. Por ejemplo, el modelo internacional ofrecería la mayor uniformidad de la calidad. Sin embargo, este modelo limitaría la capacidad de respuesta creativa a las cuestiones de la acreditación internacional, ya que todas las instituciones estarían sujetas a los mismos estándares de acreditación. Tanto el modelo nacional como el regional están menos centralizados y precisan de cierta coordinación en la toma de decisiones y en los estándares en un espacio de acreditación internacional. Ambos confían altamente en la reciprocidad y otros acuerdos, pero ponen trabas a la diversidad. El modelo institucional proporciona el mayor margen para la diversidad institucional en el espacio de acreditación internacional, pero limita la uniformidad. El modelo de mercado plantea dudas sobre si un espacio de acreditación internacional puede estar al servicio del bien público de forma efectiva. 
Tabla 3.1. Características de los modelos de acreditación internacional (Eaton, 2007)

\begin{tabular}{|c|c|}
\hline Modelo & Características \\
\hline Modelo nacional & $\begin{array}{l}\text { Los países podrían trabajar juntos para dirigir un espacio de } \\
\text { acreditación internacional, tomando acuerdos sobre estándares de } \\
\text { calidad nacionales distintos pero se puede establecer un organismo } \\
\text { internacional coordinador. El modelo nacional difiere del } \\
\text { internacional en que el primero confía en acuerdos sobre una serie } \\
\text { de estándares de calidad nacionales distintos, frente a los estándares } \\
\text { uniformes del enfoque internacional. }\end{array}$ \\
\hline Modelo regional & $\begin{array}{l}\text { El espacio de acreditación internacional lo dirigirían los pactos } \\
\text { voluntarios entre las agencias de acreditación o de garantía de la } \\
\text { calidad. Un ejemplo en este modelo sería el registro europeo } \\
\text { planteado por el proceso de Bolonia, el proyecto EUR-ACE en } \\
\text { Europa y la Asociación Universitaria Iberoamericana de Postgrado - } \\
\text { AUIP en latino América }\end{array}$ \\
\hline $\begin{array}{l}\text { Modelo } \\
\text { institucional }\end{array}$ & $\begin{array}{l}\text { Como el de los Estados Unidos, las universidades deberían hacerse } \\
\text { cargo de la autoridad y la responsabilidad de un espacio de } \\
\text { acreditación internacional. Las instituciones deberían encargarse de } \\
\text { los medios para trabajar juntas, quizá mediante asociaciones o la } \\
\text { creación organismos de acreditación u otras asociaciones colegiales } \\
\text { relacionados con la calidad como el Council for Higher Education } \\
\text { Accreditation (CHEA) o el Accreditation Board for Engineering and } \\
\text { Technology - ABET en Estados Unidos. }\end{array}$ \\
\hline $\begin{array}{l}\text { Modelo } \\
\text { internacional }\end{array}$ & $\begin{array}{l}\text { El espacio de acreditación internacional lo dirigirían las } \\
\text { organizaciones multinacionales como la UNESCO, o la International } \\
\text { Network for Quality Assurance Agencies in Higher Education } \\
\text { (INQAAHE). }\end{array}$ \\
\hline $\begin{array}{l}\text { Modelo de } \\
\text { mercado }\end{array}$ & $\begin{array}{l}\text { La responsabilidad y la autoridad de la gestión de un espacio de } \\
\text { acreditación internacional podrían residir en los acuerdos comerciales. } \\
\text { Sería como si los General Agreement on Trade in Services (GATS) } \\
\text { dirigieran un espacio de acreditación internacional. La competencia } \\
\text { entre los proveedores de educación superior impulsaría la calidad que } \\
\text { iría acompañada de una regulación que garantizaría los derechos de } \\
\text { los consumidores. Las instituciones que ofrecieran enseñanza de baja } \\
\text { calidad no serían capaces de competir y quedarían fuera de juego. Este } \\
\text { modelo se basaría en la oferta y la demanda, así como en la } \\
\text { competencia. La convergencia de las expectativas en torno a la calidad } \\
\text { podría darse o no, según si el mercado valora más la uniformidad o la } \\
\text { diversidad del producto de la educación superior. }\end{array}$ \\
\hline
\end{tabular}

Fuente: Eaton (2007a) 


\subsubsection{Modelos de acreditación internacional}

Utilizando la clasificación de los modelos de acreditación internacional desarrollada por Eaton podemos escoger un caso para cada modelo y analizar los criterios de evaluación utilizados. En el modelo regional la European Association for Quality Assurance - ENQA, en el modelo institucional el Council for Higher Education Accreditation (CHEA) de Estados Unidos, en el modelo internacional se analizó la International Network for Quality Assurance Agencies in Higher Education (INQAAHE) y en el modelo de mercado la Organización Mundial del Comercio - OMC. Si bien no existe un ejemplo real de acreditación internacional usando el modelo nacional, presentaremos los criterios utilizados por la Agencia Nacional de Evaluación de la Calidad y Acreditación - ANECA de España.

Gráfico 3.1. Organismos de acreditación internacional en los que se analizaron los criterios e indicadores de evaluación

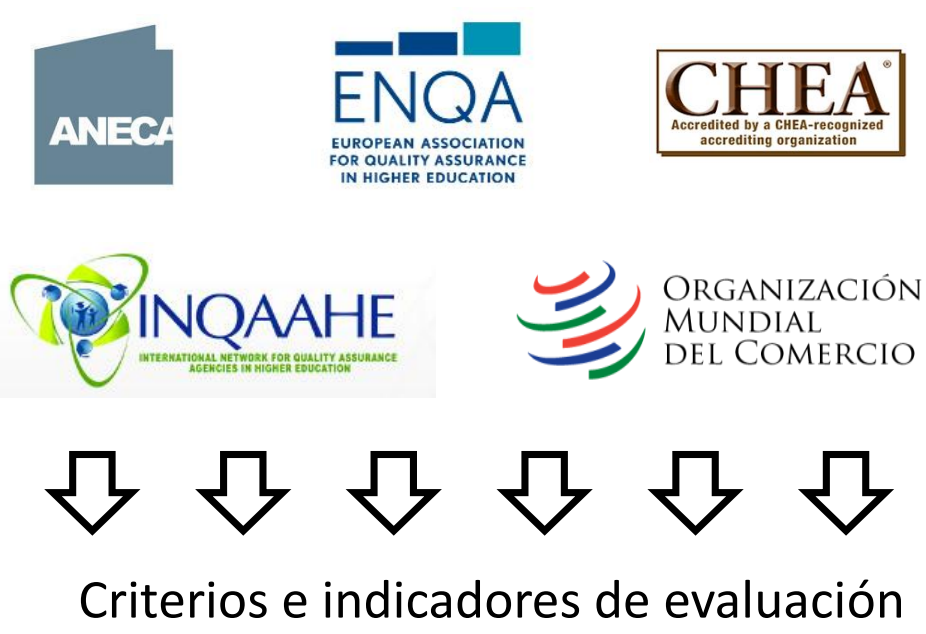

\subsubsection{Modelo nacional: ANECA en España}

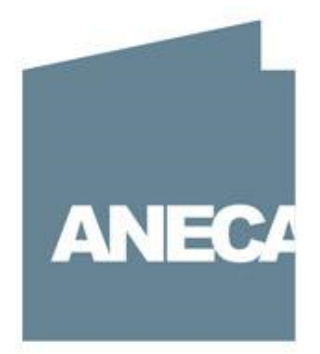

En España la Agencia Nacional de Evaluación de la Calidad y Acreditación - ANECA ha definido los criterios de evaluación mostrados en la Tabla 3.2.

La pertinencia vista por los organismos de acreditación 
Tabla 3.2. Criterios de evaluación de la Agencia Nacional de Evaluación de la Calidad y Acreditación - ANECA, España

\begin{tabular}{|c|c|c|}
\hline $\mathbf{N}^{\circ}$ & Factor & Criterio \\
\hline 1. & $\begin{array}{l}\text { Descripción } \\
\text { del Título }\end{array}$ & $\begin{array}{l}\text { Cada propuesta de Título debe recoger una descripción adecuada y } \\
\text { coherente con el nivel o efectos académicos, de manera que no induzca } \\
\text { a confusión sobre su contenido y, en su caso, efectos profesionales. }\end{array}$ \\
\hline 2. & Justificación & $\begin{array}{l}\text { Cada propuesta de Título debe ser relevante conforme a las experiencias } \\
\text { formativas o investigadoras, adecuada al ámbito académico al que hace } \\
\text { referencia y/o acorde con estudios similares existentes. }\end{array}$ \\
\hline 3. & Objetivos & $\begin{array}{l}\text { Los objetivos del Título deben ser pertinentes y las competencias a } \\
\text { adquirir por los estudiantes deben estar de acuerdo con las exigibles para } \\
\text { otorgar el Título y con las cualificaciones establecidas en el Espacio } \\
\text { Europeo de Educación Superior. }\end{array}$ \\
\hline 4. & $\begin{array}{l}\text { Acceso y } \\
\text { Admisión de } \\
\text { estudiantes }\end{array}$ & $\begin{array}{l}\text { El Título deberá disponer de unos sistemas accesibles que regulen e } \\
\text { informen claramente sobre las diferentes vías de acceso, admisión y } \\
\text { orientación al estudiante al inicio de sus estudios. }\end{array}$ \\
\hline 5. & $\begin{array}{l}\text { Planificación } \\
\text { de las } \\
\text { enseñanzas }\end{array}$ & $\begin{array}{l}\text { El Plan de estudios deberá constituir una propuesta de formación } \\
\text { diseñada de forma coordinada y tomando en consideración la dedicación } \\
\text { de los estudiantes en un periodo temporal determinado. }\end{array}$ \\
\hline & $\begin{array}{l}\text { Personal } \\
\text { Académico }\end{array}$ & $\begin{array}{l}\text { El profesorado y otros recursos humanos de apoyo a cada Título deben } \\
\text { ser adecuados para la consecución de los objetivos generales y } \\
\text { competencias previstas en la propuesta de Título. }\end{array}$ \\
\hline & $\begin{array}{l}\text { Recursos } \\
\text { materiales y } \\
\text { servicios }\end{array}$ & $\begin{array}{l}\text { Los recursos materiales y servicios necesarios para el desarrollo de las } \\
\text { actividades previstas deben ser adecuados para la consecución de los } \\
\text { objetivos y las competencias previstas en el plan de estudios. }\end{array}$ \\
\hline & $\begin{array}{l}\text { Resultados } \\
\text { previstos }\end{array}$ & $\begin{array}{l}\text { La propuesta del Título debe incluir una previsión de resultados } \\
\text { relacionados con la eficiencia del Título y los mecanismos generales para } \\
\text { la valoración de los resultados del aprendizaje de los estudiantes. }\end{array}$ \\
\hline & $\begin{array}{l}\text { Sistema de } \\
\text { Garantía de la } \\
\text { Calidad }\end{array}$ & $\begin{array}{l}\text { La propuesta del Título debe incluir un Sistema de Garantía de Calidad } \\
\text { que asegure el control, la revisión y mejora continua del mismo. }\end{array}$ \\
\hline & $\begin{array}{l}\text { Calendario de } \\
\text { implantación }\end{array}$ & $\begin{array}{l}\text { El proceso de implantación de las nuevas titulaciones debe estar } \\
\text { planificado en el tiempo, y previsto un mecanismo para acomodar, en su } \\
\text { caso, a los estudiantes procedentes de planes ya existentes al nuevo plan } \\
\text { de estudios. }\end{array}$ \\
\hline
\end{tabular}

Fuente: Protocolo de evaluación de grados y máster ANECA (2011) 


\subsubsection{Modelo regional: ENQA en Europa}

$\overline{E N Q A}$

EUROPEAN ASSOCIATION FOR QUALITY ASSURANCE IN HIGHER EDUCATION
En Europa, la European Association for Quality Assurance - ENQA

ha establecido los criterios de evaluación mostrados en la Tabla 3.3 para que sean adoptados por las agencias nacionales.

Tabla 3.3. Criterios para la garantía interna de calidad en el Espacio Europeo de

Educación Superior - European Association for Quality Assurance - ENQA

\begin{tabular}{|c|c|c|}
\hline $\mathbf{N}^{\circ}$ & Criterio & Descripción \\
\hline 1 & $\begin{array}{l}\text { Política y } \\
\text { procedimientos para la } \\
\text { garantía de calidad }\end{array}$ & $\begin{array}{l}\text { Las instituciones deben desarrollar e implantar una } \\
\text { estrategia para la mejora continua de la calidad. La } \\
\text { estrategia, la política y los procedimientos deben tener } \\
\text { un rango formal y estar públicamente disponibles. } \\
\text { Deben contemplar también el papel de los estudiantes y } \\
\text { de otros agentes implicados. }\end{array}$ \\
\hline 2 & $\begin{array}{l}\text { Aprobación, control y } \\
\text { revisión periódica de } \\
\text { los programas y títulos }\end{array}$ & $\begin{array}{l}\text { Las instituciones deberían disponer de mecanismos } \\
\text { formales para la aprobación, revisión periódica y control } \\
\text { de sus programas y títulos. }\end{array}$ \\
\hline 3 & $\begin{array}{l}\text { Evaluación de los } \\
\text { estudiantes }\end{array}$ & $\begin{array}{l}\text { Los estudiantes deben ser evaluados utilizando criterios, } \\
\text { normas y procedimientos que estén publicados y que } \\
\text { sean aplicados de manera coherente. }\end{array}$ \\
\hline 4 & $\begin{array}{l}\text { Garantía de calidad del } \\
\text { profesorado }\end{array}$ & $\begin{array}{l}\text { Las instituciones deben disponer de medios que } \\
\text { garanticen que el personal docente está capacitado y es } \\
\text { competente para su trabajo. Esos medios deben darse a } \\
\text { conocer a quienes lleven a cabo evaluaciones externas y } \\
\text { serán recogidos en los informes. }\end{array}$ \\
\hline 5 & $\begin{array}{l}\text { Recursos de aprendizaje } \\
\text { y apoyo a los } \\
\text { estudiantes }\end{array}$ & $\begin{array}{l}\text { Las instituciones deben garantizar que los recursos } \\
\text { disponibles para apoyar el aprendizaje de los estudiantes } \\
\text { son adecuados y apropiados para cada uno de los } \\
\text { programas ofrecidos. }\end{array}$ \\
\hline 6 & $\begin{array}{l}\text { Sistemas de } \\
\text { información }\end{array}$ & $\begin{array}{l}\text { Las instituciones deben garantizar que recopilan, } \\
\text { analizan y utilizan información pertinente para la gestión } \\
\text { eficaz de sus programas de estudio y otras actividades. }\end{array}$ \\
\hline 7 & Información pública & $\begin{array}{l}\text { Las Instituciones deben publicar con regularidad } \\
\text { información actualizada, imparcial y objetiva, tanto } \\
\text { cuantitativa como cualitativa, sobre los programas y } \\
\text { títulos que ofrecen. }\end{array}$ \\
\hline
\end{tabular}

Fuente: ENQA (2009) 


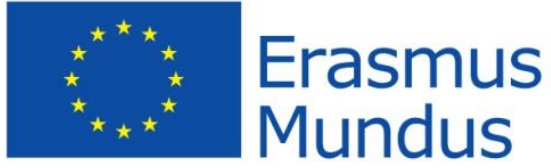

En este marco definido por la ENQA se han establecido algunos criterios para la evaluación de la calidad de los máster Erasmus Mundus (Máster conjunto o con doble titulación impartido por tres o más universidades de diferentes países del EEES) con el fin de que la Comunidad Europea apruebe su financiamiento. En este tipo de máster es importante que se de una integración, es decir, la percepción del máster por parte de los estudiantes como un único título, y no como la mezcla de diferentes títulos que se imparten y se gestionan de forma separada. Esta integración debe percibirse en tres niveles: académica, organizativa y de gestión (Bengoetxea \& Arteaga, 2009). En la Tabla 3.4 se muestran los criterios de evaluación de la calidad de los máster Erasmus Mundus.

Tabla 3.4. Criterios de evaluación de los Master Erasmus Mundus

\begin{tabular}{ll}
\hline Criterio & Aspectos a considerar \\
\hline Calidad e integración & $\bullet$ Duración de las titulaciones \\
académica & - La innovación y el valor añadido \\
& - Admisión y selección de estudiantes \\
& Equivalencia horizontal y vertical de créditos \\
\hline Calidad e integración & $\bullet$ Movilidad \\
organizativa & - Servicios ofrecidos a los estudiantes \\
& Política de tasas \\
\hline Calidad en la gestión & - Integración interna de la cooperación del consorcio no desde \\
del programa & el punto de vista externo de los estudiantes, sino internamente \\
& desde la perspectiva de los socios institucionales.
\end{tabular}

Fuente: Bengoetxea \& Arteaga (2009)

\subsubsection{Modelo institucional: CHEA en Estados Unidos}

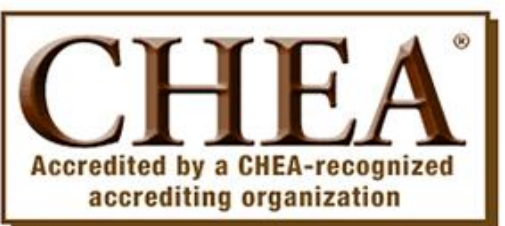

El Council for Higher Education Accreditation - CHEA es una organización a nivel nacional, privada y sin fines de lucro que coordina la actividad de acreditación en los Estados Unidos. Está formada por casi tres mil universidades e instituciones de educación superior (colleges) y reconoce a unas 60 agencias acreditadoras de instituciones y programas en Estados Unidos ${ }^{27}$. CHEA garantiza la calidad

${ }^{27}$ https://www.chea.org

La pertinencia vista por los organismos de acreditación 
estableciendo expectativas de calidad, principalmente a través del reconocimiento formal de organizaciones de acreditación. Desarrolla los criterios que debe cumplir una agencia de acreditación para ser reconocida en Estados Unidos. Los criterios utilizados por el CHEA, que ponen énfasis sobre todo en la garantía de la calidad académica y en la mejora de una institución o un programa (Eaton, 2007b); (Palomares \& García, 2008), se muestran en la Tabla 3.5.

Tabla 3.5. Criterios de evaluación del Council for Higher Education Accreditation CHEA de Estados Unidos

\begin{tabular}{ll}
\hline Criterio & Aspectos a considerar \\
\hline $\begin{array}{l}\text { Aumentar la calidad } \\
\text { académica. }\end{array}$ & $\begin{array}{l}\text { Los organismos acreditadores tienen una definición clara } \\
\text { de la calidad académica y expectativas específicas de que } \\
\text { las instituciones o los programas que acreditan dispongan } \\
\text { de protocolos para determinar si se cumplen los criterios } \\
\text { estándar de calidad. }\end{array}$ \\
\hline $\begin{array}{l}\text { Mostrar la rendición de } \\
\text { cuentas. }\end{array}$ & $\begin{array}{l}\text { Los organismos acreditadores tienen criterios estándar } \\
\text { que exigen que las instituciones y los programas } \\
\text { proporcionen información coherente y fiable sobre la } \\
\text { calidad académica y el rendimiento de los estudiantes. }\end{array}$ \\
\hline $\begin{array}{l}\text { Fomentar, si conviene, el } \\
\text { autoexamen y planificar los } \\
\text { cambios y las mejoras }\end{array}$ & $\begin{array}{l}\text { Los organismos acreditadores fomentan el autoexamen } \\
\text { para promover el cambio y las mejoras necesarias a través } \\
\text { de la autoevaluación continua en las instituciones y los } \\
\text { necesarias. }\end{array}$ \\
\hline $\begin{array}{l}\text { programas. } \\
\text { adecuados e imparciales en la } \\
\text { toma de decisiones. }\end{array}$ & $\begin{array}{l}\text { Los organismos acreditadores mantienen políticas y } \\
\text { procedimientos adecuados e imparciales, entre los que se } \\
\text { incluyen sistemas efectivos de revisión y balances. }\end{array}$ \\
\hline $\begin{array}{l}\text { Demostrar la reevaluación } \\
\text { continua de las prácticas de } \\
\text { acreditación. }\end{array}$ & $\begin{array}{l}\text { Los organismos acreditadores llevan a cabo un } \\
\text { autoexamen de sus actividades de acreditación. }\end{array}$ \\
\hline $\begin{array}{l}\text { Disponer de suficientes } \\
\text { recursos. }\end{array}$ & $\begin{array}{l}\text { Los organismos acreditadores tienen y mantienen } \\
\text { recursos previsibles y estables. }\end{array}$ \\
\hline
\end{tabular}

Fuente: Eaton (2007 b); Palomares \& García (2008) 


\subsubsection{Modelo internacional: la Red INQAAHE}

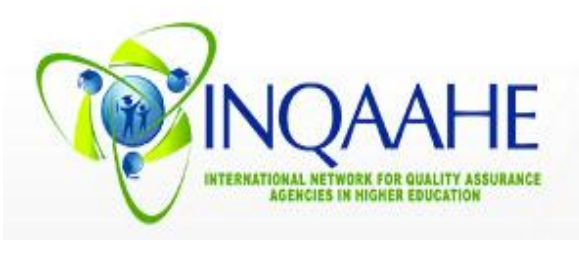

La Red Internacional de Agencias para la Garantía de la Calidad en la Educación Superior (INQAAHE) es una asociación mundial de más de 180 organizaciones en 100 países que trabajan en la teoría y la práctica de aseguramiento de la calidad en la educación superior ${ }^{28}$. La Red trata los temas con una perspectiva general y ha formulado criterios de buenas prácticas para las agencias de garantía de la calidad Lemaitre (2004). Para la Red una agencia debería tener los siguientes 9 principios de funcionamiento que se muestran en la Tabla 3.6.

La INQAAHE también estipula que la misión de una agencia de garantía de la calidad es asegurar la calidad, el desarrollo continuo y el rendimiento eficaz de las instituciones de educación superior y sus sistemas y programas de acuerdo con la declaración y los objetivos de su misión, de forma que puedan ganarse la confianza de sus principales grupos de interés. Esta misión se logra a través de mecanismos de evaluación reconocidos dentro de un marco independiente, neutral y transparente.

Tabla 3.6. Principios de funcionamiento de las agencias de garantía de la calidad según la Red INQAAHE

\begin{tabular}{cl}
\hline $\mathbf{N}^{\circ}$ & \multicolumn{1}{c}{ Criterio } \\
\hline 1. & Considerar el cliente como centro de atención \\
\hline 2. & Liderazgo sólido \\
\hline 3. & Participación de los actores implicados \\
\hline 4. & Centrarse en los indicadores de insumos, procesos y resultados \\
\hline 5. & Toma de decisiones basada en pruebas \\
\hline 6. & Reconocimiento de la mejora continua \\
\hline 7. & Permitir la autonomía institucional en asuntos académicos \\
\hline 8. & Optimizar los beneficios de los actores implicados \\
\hline 9. & Garantizar el seguimiento de las acciones de mejora \\
\hline
\end{tabular}

Fuente: Lemaitre (2004)

Los objetivos estratégicos de una agencia de garantía de la calidad son: i) ganarse la confianza de los actores implicados en los resultados de la educación superior; ii) respaldar el proceso de acreditación de garantía de la calidad de acuerdo con los requisitos internos de las

${ }^{28}$ Para mayor información ver http://www.inqaahe.org/ 
instituciones y sus programas; iii) ayudar a las instituciones de educación superior a establecer sistemas de garantía interna de la calidad por medio del autoaprendizaje; iv) mejorar la capacitación en el proceso de garantía de la calidad para la acreditación; v) facilitar el desarrollo y la aplicación de estándares de referencia apropiados (benchmarks) para los programas académicos; vi) integrar procesos sostenibles que combinen sistemas de garantía de la calidad de las instituciones y procesos de revisión y acreditación externas; vii) apoyar la mejora continua de la calidad, y viii) cooperar con otras agencias de acreditación.

Existe un período de transición durante el cual se da apoyo a las instituciones para que éstas desarrollen sistemas de garantía de la calidad y mejoren los estándares académicos mientras se establece y desarrolla la agencia.

\subsubsection{Modelo de mercado: OMC}

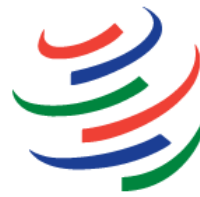

\section{ORGANIZACIÓN MUNDIAL DEL COMERCIO}

La educación superior es considerada por la Organización Mundial del Comercio (OMC) como un servicio exportable y por tanto está incluido en

las negociaciones del Acuerdo General de Comercio de Servicios (AGCS) o GATS por sus siglas en inglés: General Agreement on Trade in Services.

El Acuerdo tiene como meta alcanzar la liberalización total de los servicios educativos a escala mundial. Define cuatro mecanismos fundamentales: el suministro transfronterizo (educación a distancia, universidades virtuales), el consumo en el extranjero (estudiantes que se desplazan a otros países para hacer sus estudios), la presencia comercial (sucursales o franquicias de instituciones de educación superior extranjeras), y la presencia de personas naturales como profesores o investigadores que trabajan en el exterior (Van Ginkel \& Rodrígues Días, 2007).

Numerosas asociaciones de universidades de gran prestigio y destacados investigadores han señalado que la inclusión de la educación superior en el GATS atenta contra el carácter de bien público de ese nivel educativo y representa una amenaza contra la calidad, la pertinencia y la equidad de la oferta, y hace depender a la gran mayoría de los países en vías de desarrollo de los proveedores multinacionales de servicios educativos (Yarzábal, 2005). 
Los compromisos que los gobiernos se comprometen a asumir bajo el AGCS quedan establecidos en dos categorías de obligaciones. Unas obligaciones generales como el trato de la nación más favorecida (art. II) que indica que si se concede una ventaja especial a un país, se tiene que hacer lo mismo con los demás miembros de la OMC. Y unas obligaciones específicas que se aplican sólo a esos sectores que cada gobierno ha acordado explícitamente abrir a la competencia extranjera e incluye los principios del "tratamiento nacional" (que implica dar a cualquier inversor extranjero un trato igual al que se da a uno nacional) y del "acceso al mercado" (que implica que no se puede limitar el número de proveedores, es decir, cualquier empresa puede competir libremente) ${ }^{29}$.

\subsubsection{Modelos de acreditación de maestría en ingeniería}

Los organismos de acreditación de programas de ingeniería que se analizaron fueron ABET en América y el proyecto European Accreditation of Engineering Programmes (EUR-ACE) de la European Network for Accreditation of Engineering Education (ENAEE).

Gráfico 3.2. Organismos de acreditación de programas de ingeniería en los que se analizaron los criterios e indicadores de evaluación
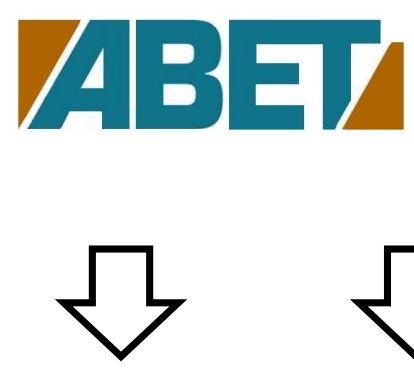
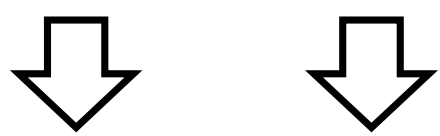

European
Accreditation Accreditation
of Engineering of Engineering EUR-ACE

Criterios e indicadores de valuación

\subsubsection{Modelo institucional: ABET en América}
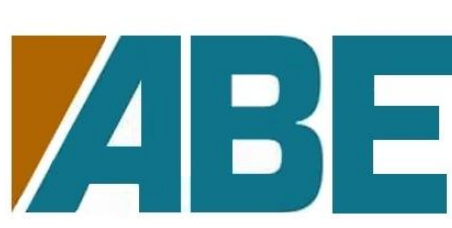

Accreditation Board for Engineering and Technology

- ABET es una federación de 33 asociaciones profesionales de Estados Unidos ligadas a la ingeniería y la tecnología incluyendo ASCE, ASME, IEEE, entre

${ }^{29}$ Más información en www.wto.org 
otras, con más de 70 años de experiencia en el aseguramiento de la calidad de la educación superior. ABET otorga una acreditación internacional de reconocido prestigio que certifica que el plan de estudios de un programa académico forma a sus titulados en las competencias requeridas por la profesión de acuerdo a unos estándares de calidad. El modelo de calidad de ABET para la evaluación de programas consta de 9 criterios mostrados en la Tabla 3.7

Tabla 3.7. Criterios ABET para acreditación de programas de ingeniería

\begin{tabular}{cl}
\hline $\mathbf{N}^{\circ}$ & \multicolumn{1}{c}{ Criterio } \\
\hline 1. & Estudiantes \\
\hline 2. & Objetivos educativos de programa \\
\hline 3. & Resultados del estudiante \\
\hline 4. & Mejora continua \\
\hline 5. & Plan de estudios \\
\hline 6. & Cuerpo docente \\
\hline 7. & Facilidades \\
\hline 8. & Apoyo \\
\hline 9. & Criterios de programa \\
\hline
\end{tabular}

Fuente: ABET (2009)

Se utilizan los mismos criterios tanto para el pregrado como para el postgrado. Para ABET (2009) los "objetivos educativos del programa" son las declaraciones generales que describen lo que se espera que los graduados alcancen algunos años después de la graduación y están basados en las necesidades de las partes interesadas del programa. ABET pone énfasis en la evaluación de los "resultados de aprendizaje" del estudiante, a los cuales define como declaraciones breves que describen lo que el estudiante debe saber y ser capaz de hacer al momento de la graduación. Estos se relacionan con las habilidades, conocimiento y comportamiento que los estudiantes adquieren a lo largo de su progreso en el programa. En la Tabla 3.8 se muestran los resultados de aprendizaje definidos por ABET.

Tabla 3.8. Resultados del estudiante ABET

\begin{tabular}{cl}
\hline Resultado & \multicolumn{1}{c}{ Descripción } \\
\hline a. & Capacidad de aplicar conocimientos de matemáticas, ciencias e ingeniería. \\
\hline b. & $\begin{array}{l}\text { Capacidad de diseñar y llevar a cabo experimentos, así como de analizar e } \\
\text { interpretar datos. }\end{array}$ \\
\hline c. & $\begin{array}{l}\text { Capacidad para diseñar un sistema, un componente o un proceso que } \\
\text { satisfaga las necesidades planteadas dentro de restricciones realistas, por } \\
\text { ejemplo, en los aspectos económico, ambiental, social, político, ético, de } \\
\text { salud y seguridad, de capacidad de fabricación, y de sostenibilidad. }\end{array}$ \\
\hline d. & Capacidad de desenvolverse en equipos multidisciplinarios. \\
\hline e. & Capacidad de identificar, formular y resolver problemas de ingeniería. \\
\hline
\end{tabular}




\begin{tabular}{cl}
\hline f. & Compresión de las responsabilidades éticas y profesionales. \\
\hline g. & Capacidad de comunicarse con eficacia. \\
\hline h. & $\begin{array}{l}\text { Una educación lo bastante amplia como para comprender las repercusiones } \\
\text { de las soluciones de ingeniería en un contexto global, económico, ambiental } \\
\text { y de la sociedad. }\end{array}$ \\
\hline i. & $\begin{array}{l}\text { Reconocimiento de la necesidad del aprendizaje permanente y la capacidad } \\
\text { para encararlo. }\end{array}$ \\
\hline j. & Conocimiento de temas contemporáneos. \\
\hline k. & $\begin{array}{l}\text { Capacidad de utilizar las técnicas, las habilidades y las herramientas de la } \\
\text { ingeniería moderna necesarias para la práctica de la ingeniería. }\end{array}$ \\
\hline
\end{tabular}

Fuente: ABET (2009)

El modelo de ABET tiene el enfoque de "evaluación de resultados". Lo que interesa realmente es saber si los estudiantes desarrollaron las competencias genéricas establecidas por ABET para todas las carreras de ingeniería (Tabla 3.8) y las competencias específicas de cada programa. Este enfoque viene siendo utilizado desde el año 2000. Anteriormente el enfoque era el de una "evaluación de procesos". Se asume que los programas educativos en el siglo XXI ya tienen estandarizados los procesos necesarios para lograr los resultados esperados. Para Ocampo (2010) ${ }^{30}$ esto no necesariamente es cierto en todos los países. Si se quiere garantizar la calidad de los programas de ingeniería en los países en desarrollo, todavía es necesario verificar que los procesos se desarrollen de acuerdo a ciertos estándares de calidad, es decir, todavía no se ha superado la fase de "evaluación de procesos"31.

\subsubsection{Modelo regional: El proyecto EUR- ACE en Europa}

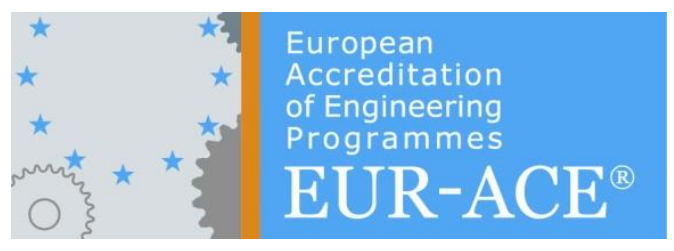

En Europa se tiene una experiencia importante en lo que es acreditación en ingeniería. La European Network for Accreditation of Engineering Education (ENAEE), una red formada por importantes agencias nacionales de acreditación en ingeniería de Alemania, Francia, Italia, Reino Unido entre otros, ha implementado el proyecto European Accreditation of Engineering Programmes (EUR-ACE) para otorgar una etiqueta de calidad internacional adicional a la acreditación otorgada por los organismos nacionales (Payzin, 2010). En la Tabla 3.9 se muestran los criterios de evaluación utilizados por el Proyecto EURACE:

${ }^{30}$ Presidente del Consejo de Acreditación de la Enseñanza de la Ingeniería (CACEI) - México. 
Tabla 3.9. Criterios de evaluación - Proyecto EUR-ACE

\begin{tabular}{|c|c|c|}
\hline $\mathbf{N}^{\circ}$ & $\begin{array}{l}\text { Directriz para } \\
\text { acreditación }\end{array}$ & Criterio a ser valorado \\
\hline \multirow[t]{3}{*}{1.} & \multirow{3}{*}{$\begin{array}{l}\text { Necesidades, Objetivos y } \\
\text { Resultados }\end{array}$} & 1.1 Necesidades de las partes interesadas \\
\hline & & 1.2 Objetivos educativos \\
\hline & & 1.3 Resultados de programa \\
\hline \multirow[t]{3}{*}{2.} & \multirow[t]{3}{*}{ Procesos educativos } & 2.1 Planificación \\
\hline & & 2.2 Entrega \\
\hline & & 2.3 Evaluación de los aprendizajes \\
\hline \multirow[t]{4}{*}{3.} & \multirow[t]{4}{*}{ Recursos y Asociaciones } & 3.1 Personal Académico y de apoyo \\
\hline & & 3.2 Instalaciones \\
\hline & & 3.3 Recursos Financieros \\
\hline & & 3.4 Asociaciones \\
\hline \multirow[t]{2}{*}{4.} & \multirow{2}{*}{$\begin{array}{l}\text { Evaluación del proceso } \\
\text { educativo }\end{array}$} & 4.1 Estudiantes \\
\hline & & 4.2 Graduados \\
\hline \multirow[t]{2}{*}{5.} & \multirow[t]{2}{*}{ Sistema de Gestión } & 5.1 Organización y proceso de toma de decisiones \\
\hline & & 5.2 Sistema de Aseguramiento de la Calidad \\
\hline
\end{tabular}

Fuente: (EUR-ACE, 2008)

\subsubsection{Tratamiento de la pertinencia en los organismos de acreditación}

De acuerdo con la teoría de evaluación de programas y proyectos, podemos hacer varios tipos de evaluación dependiendo de qué evaluamos. Por ejemplo evaluamos la eficacia cuando verificamos si los resultados e impacto alcanzados están de acuerdo con los objetivos planteados inicialmente en el proyecto o programa. Evaluamos la eficiencia cuando verificamos si las realizaciones o resultados alcanzados son los que corresponderían a los medios utilizados. Evaluamos la pertinencia cuando verificamos si los objetivos planteados en el proyecto o programa satisfacen necesidades reales del entorno o si resuelven problemas de los beneficiarios del proyecto (Diaz-Puente, 2003). En el presente apartado trataremos de averiguar si los organismos de acreditación internacional consideran dentro de sus modelos, la evaluación de la pertinencia. 
Gráfico 3.3. Tipos de evaluación de un programa formativo

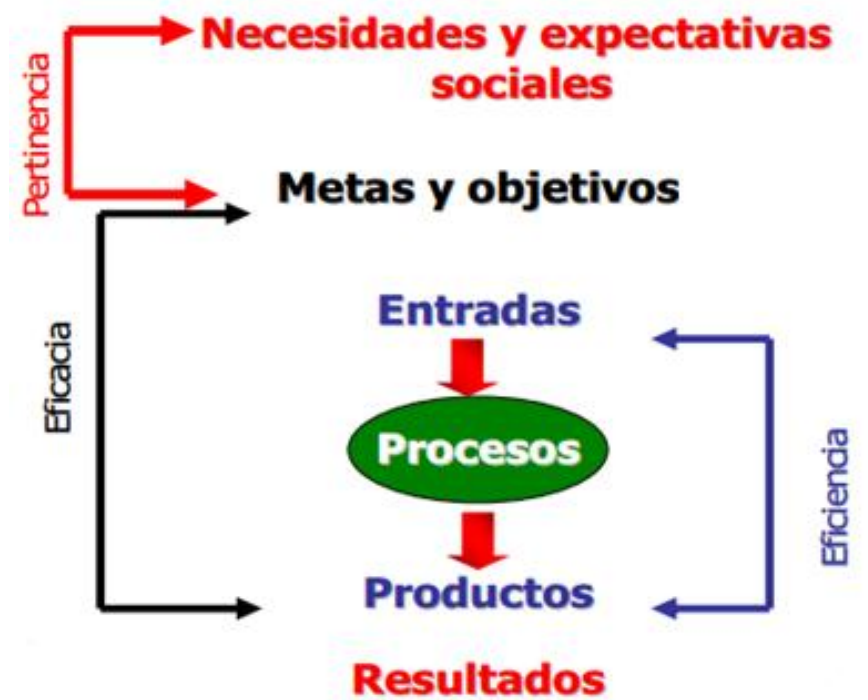

Fuente: Adaptado de Loredo et. al (2009)

Se revisó los criterios de evaluación utilizados por los organismos de acreditación presentados en el apartado anterior: International Network for Quality Assurance Agencies in Higher Education -INQAAHE, Accreditation Board for Engineering and Technology ABET, la Asociación Universitaria Iberoamericana de Postgrado - AUIP y el Proyecto European Accreditation Of Engineering Programmes (EUR-ACE) de la European Network for Accreditation of Engineering Education (ENAEE). Para valorar los modelos de acreditación utilizados por estos organismos de acreditación se revisó también la información publicada en artículos y páginas web sobre los criterios de evaluación utilizados y si entre estos criterios se encuentra el de la pertinencia del programa.

\subsubsection{Pertinencia global}

Los modelos de evaluación revisados sí consideran criterios de pertinencia global tal como la hemos definido, pues siguen modelos de acreditación internacional y establecen estándares de calidad que todo programa educativo debe tener en el mundo (como ANECA, ENQA y CHEA). 
ABET ha establecido las competencias genéricas y específicas de programa que todo ingeniero en el mundo debe tener y esas son las que verifica. La OMC sigue un modelo de mercado y considera que la educación superior es un bien exportable, que se comercializa a nivel global. El proyecto EUR-ACE en Europa otorga una etiqueta de calidad internacional adicional a la entregada por los organismos nacionales correspondientes.

\subsubsection{Pertinencia local}

La International Network for Quality Assurance Agencies in Higher Education -INQAAHE sólo brinda Directrices de Buenas Prácticas para las agencias de acreditación en educación superior que conforman la red. (Blackmur, 2008) sostiene que estas directrices, en su forma actual, son inadecuadas como un modelo de aseguramiento de la calidad para las agencias de acreditación nacionales. Los criterios de la Red INQAAHE son muy generales y no consideran la evaluación de la pertinencia local de los programas formativos. Esto se puede entender considerando que la red sigue un modelo de acreditación internacional basada en estándares internacionales. De igual forma la ENQA en Europa y CHEA en Estados Unidos sólo han establecido criterios de evaluación para que sean adoptados por las agencias nacionales y regionales de acreditación. Y para la OMC la pertinencia local no existe, solo ha adecuado las normas internacionales de comercio de bienes y servicios a los servicios de educación superior.

El modelo de ANECA considera en el factor $\mathrm{N}^{\circ} 3$ Objetivos que los objetivos del título deben ser pertinentes y las competencias a desarrollar deben estar de acuerdo con las cualificaciones establecidas en el Espacio Europeo de Educación Superior. Sin embargo cuando se revisa el detalle del documento "Protocolo de evaluación de grados y master" (ANECA, 2011) no se encuentran indicadores de pertinencia local.

ABET evalúa principalmente resultados de aprendizaje (Olds, Moskal, \& Miller, 2005) en el último año de estudios o en el primer año de egreso, así como el logro de los objetivos educativos (luego de unos cinco años de egreso). Es decir efectúa principalmente una evaluación de la eficacia del programa. Dentro de los criterios utilizados por ABET no figura el de la pertinencia local del programa formativo. 
El modelo utilizado por el proyecto European Accreditation of Engineering Programmes (EUR-ACE) considera como primera variable de evaluación "Necesidades, Objetivos y Resultados". Se pregunta: ¿han sido identificadas las necesidades de las partes interesadas (estudiantes, la industria, las asociaciones de ingeniería, etc.)? Une la definición de los objetivos y resultados esperados del programa con las necesidades del entorno, es decir, sí evalúa la pertinencia local del programa.

El modelo de EUR - ACE tiene una ventaja importante: los usuarios de los programas formativos (estudiantes) de los países integrantes de la Red tienen la garantía de una calidad internacional, necesaria en un programa de postgrado, y también cuentan con la garantía de calidad respaldada por un organismo nacional, que tiene en cuenta las realidades locales y nacionales. Este modelo mixto se adecúa bien a las necesidades de una acreditación internacional y a las necesidades de evaluación de la pertinencia local de dichos programas.

En general, como indican Van Ginkel \& Rodrígues Días (2007), la evaluación de la pertinencia local en las instituciones de educación superior no es un planteamiento muy respaldado. Según los autores, la apertura de las economías y la privatización de la educación originaron la adopción de estándares de excelencia como instrumentos para conseguir la calidad de los programas educativos sin importar la pertinencia local. Se ha priorizado los aspectos comerciales y se está considerando la educación superior como un bien comercial que es regulado de acuerdo con los principios que establece la Organización Mundial del Comercio.

Se concluye entonces que los modelos de acreditación en el contexto internacional evalúan principalmente resultados de aprendizaje y la capacidad de los programas (o instituciones) para lograr los objetivos educativos que dichos programas declaran en su misión. Sin embargo, no se garantiza que esos objetivos y por tanto los resultados, satisfagan necesidades reales del entorno nacional o regional, un aspecto esencial en los países en vías de desarrollo. En un contexto económico de libre mercado, de internacionalización de la educación y movilidad, la acreditación de las maestrías sigue un modelo de acreditación internacional y no se cuenta en la mayoría de los casos con criterios e indicadores para evaluar la pertinencia. Un camino para cubrir este vacío es contar tanto con la acreditación internacional para garantizar la eficacia del programa (obtención de logros de aprendizaje) y con la acreditación nacional para garantizar además la pertinencia de dicho programa.

La pertinencia vista por los organismos de acreditación 


\subsection{EVALUACIÓN DE MAESTRÍAS EN PERÚ}

\subsubsection{Modelos de evaluación de programas de postgrado en Latinoamérica}

En algunos países de Latinoamérica como Brasil, México, Argentina, Colombia y Cuba se tienen experiencias de valuación de programas de postgrado desde hace veinte años, sin embargo en otros países como Perú el tema es nuevo. Actualmente existen tres tendencias en los procesos de evaluación: la primera es el esfuerzo desplegado para acreditar la calidad en todos los países. La segunda, es una tendencia para distinguir, por motivos prácticos el carácter de obligatoriedad versus voluntariedad de los procesos. La tercera tendencia, es el surgimiento de nuevos criterios e indicadores de calidad, llamados de "segunda generación", en correspondencia con los cambios y transformaciones de carácter pedagógico que se presentan en los modelos de formación de postgrado (Cruz \& Martos, 2010).

Para Cruz \& Martos (2010) los propósitos de los modelos de evaluación siguen siendo los mismos:

- Mejorar la calidad.

- Crear y fortalecer una cultura de evaluación para rendición de cuentas.

- Someterse a procesos de aseguramiento, reconocimiento o acreditación de la calidad.

Por el peso relativo de sus sistemas de educación superior y la experiencia ganada en este campo se ha escogido para su revisión a los modelos nacionales de evaluación del Postgrado en México y Brasil además de los modelos regionales utilizados por la Asociación Universitaria Iberoamericana de Postgrado (AUIP) y el Centro Interuniversitario de Desarrollo (CINDA).

La pertinencia vista por los organismos de acreditación 
Gráfico 3.4. Modelos de evaluación de postgrados en Latinoamérica que fueron revisados
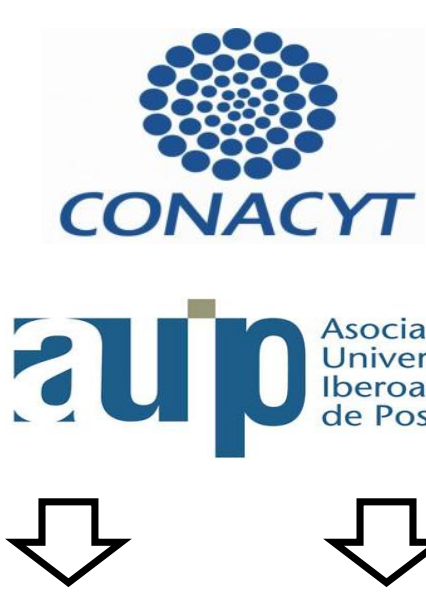

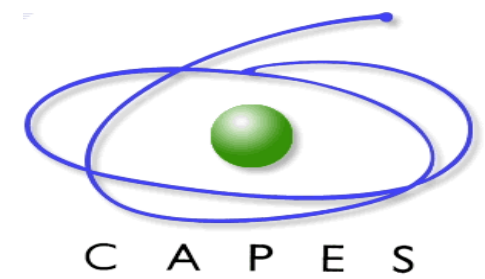

Asociación

Universitaria

Iberoamericana
de Postgrado
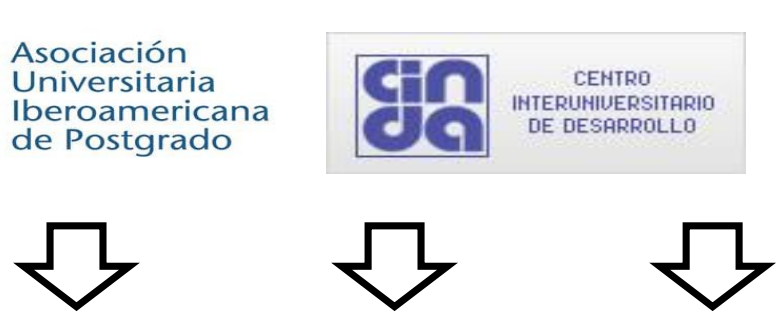

Criterios e indicadores de evaluación

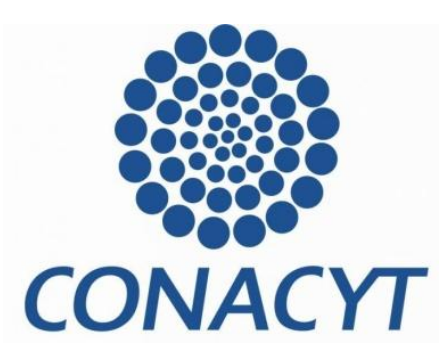

En México la evaluación del postgrado está a cargo del Programa Nacional de Posgrados de Calidad (PNPC). Este programa es impulsado por el Consejo Nacional de Ciencia y Tecnología (CONACYT) y la Subsecretaría de Educación reconocimiento a la calidad de la formación de los programas de postgrado se lleva a cabo mediante rigurosos procesos de evaluación por pares académicos, y se otorga a los programas que muestran haber cumplido los más altos estándares de calidad y pertinencia (CONACYT, 2014).

El modelo de evaluación del PNPC es de carácter cualitativo-cuantitativo y reconoce dos orientaciones de programas de posgrado (profesional y de investigación). Se basa en el paradigma formación-investigación-vinculación en el caso de los programas de investigación y en el paradigma formación-desempeño del trabajo profesional-innovación para el caso de los programas profesionales. 
Gráfico 3.5. Paradigma del modelo de evaluación de postgrados en México

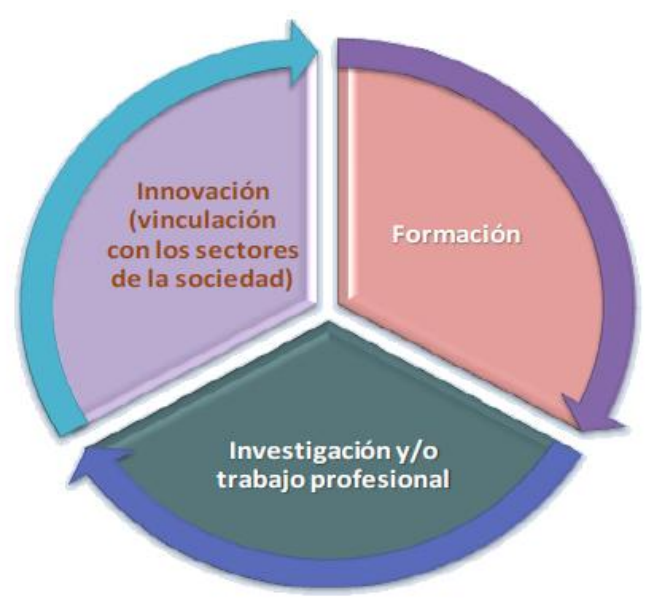

Los programas que resultan aprobados en el proceso de la evaluación académica se integran en el Padrón del Programa Nacional de Posgrados de Calidad y está conformado por los cuatro niveles mostrados en la Tabla 3.10.

Tabla 3.10. Niveles de acreditación de programas de postgrado en México

\begin{tabular}{cll}
\hline Nivel & Nombre & Características \\
\hline IV & $\begin{array}{l}\text { Competencia } \\
\text { internacional. }\end{array}$ & $\begin{array}{l}\text { Programas que tienen colaboraciones en el ámbito } \\
\text { internacional a través de convenios que incluyen la movilidad } \\
\text { de estudiantes y profesores, la codirección de tesis y } \\
\text { proyectos de investigación conjuntos. }\end{array}$ \\
\hline III & Consolidados. & $\begin{array}{l}\text { Programas que tienen reconocimiento nacional por la } \\
\text { pertinencia e impacto en la formación de recursos humanos } \\
\text { de alto nivel, en la productividad académica y en la } \\
\text { colaboración con otros sectores de la sociedad. }\end{array}$ \\
\hline II & En desarrollo. & $\begin{array}{l}\text { Programas con una prospección académica positiva } \\
\text { sustentada en su plan de mejora y en las metas factibles de } \\
\text { alcanzar en el mediano plazo. }\end{array}$ \\
\hline I & $\begin{array}{l}\text { De reciente } \\
\text { creación. }\end{array}$ & $\begin{array}{l}\text { Programas que satisfacen los criterios y estándares básicos del } \\
\text { marco de referencia del PNPC. }\end{array}$ \\
\hline
\end{tabular}

Fuente: CONACYT (2014)

El objetivo central del PNPC es el reconocimiento público a los programas de posgrado, en diferentes áreas del conocimiento, de las instituciones de educación superior y centros de investigación, por la calidad y pertinencia de sus resultados y operación. Se trata de programas que cuentan con núcleos académicos sólidos, altas tasas de graduación, infraestructura necesaria y una productividad científica, humanística o tecnológica acorde al programa. 
El modelo de evaluación del PNPC contempla tres elementos: 1). El compromiso institucional 2). Las categorías y criterios del modelo, y 3). El plan de mejora del programa. Los aspectos que debe incluir el compromiso institucional así como los criterios de evaluación del modelo se muestran en la Tabla 3.11.

Tabla 3.11. Criterios de evaluación del postgrado - PNPC, México

Elemento/ Criterio de evaluación

\section{Categoría}

\begin{tabular}{ll} 
Compromiso & A.1 Compromiso institucional \\
Institucional & A.2 Sistema Interno de Aseguramiento de la calidad \\
& A.3 Evaluación institucional del desempeño del posgrado \\
\hline
\end{tabular}

\begin{tabular}{|c|c|}
\hline \multirow{4}{*}{$\begin{array}{l}\text { Estructura personal } \\
\text { académico }\end{array}$} & 1. Plan de estudios \\
\hline & 2. Proceso de enseñanza aprendizaje \\
\hline & 3. Núcleo Académico Básico \\
\hline & 4. Líneas de generación y/o aplicación del conocimiento \\
\hline \multirow[t]{4}{*}{ Estudiantes } & 5. Ingreso de estudiantes \\
\hline & 6. Seguimiento de estudiantes \\
\hline & 7. Movilidad de estudiantes \\
\hline & 8. Dedicación de los estudiantes \\
\hline \multirow[t]{2}{*}{ Infraestructura } & 9. Espacios, laboratorios, talleres y equipamiento \\
\hline & 10. Biblioteca y tecnologías de información y comunicación \\
\hline \multirow{5}{*}{$\begin{array}{l}\text { Resultados y } \\
\text { vinculación }\end{array}$} & 11. Pertinencia, cobertura y evolución del programa \\
\hline & 12. Efectividad del posgrado \\
\hline & $\begin{array}{l}\text { 13. Contribución al conocimiento y/o a la atención / solución } \\
\text { de problemas del entorno }\end{array}$ \\
\hline & 14. Vinculación \\
\hline & 15. Financiamiento \\
\hline
\end{tabular}

Fuente: CONACYT (2013)

La pertinencia vista por los organismos de acreditación 


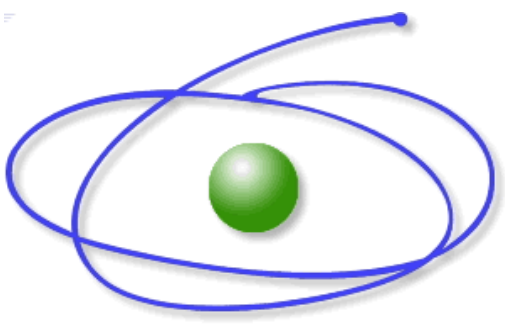

C A P E S

En Brasil la evaluación del postgrado tiene una experiencia de casi 50 años. Está a cargo de la Coordinación de Perfeccionamiento de Personal Superior (CAPES), que evalúa postgrados desde 1976. El CAPES forma parte del Sistema Nacional de Evaluación de la Educación Superior (SINEAES) y se encuentra bajo la autoridad del Ministerio de Educación pero goza de mucha autonomía. CAPES desempeña tres actividades principales: 1) la evaluación de los programas brasileños de postgrado, 2) el pago de becas y auxilios a investigadores y sobre todo a estudiantes de maestría y doctorado, 3) el mantenimiento de un portal de papers que incluye más de 12.000 títulos, la mayor parte de ellos en inglés. CAPES organiza la evaluación sistemática de aproximadamente 2300 programas, de los cuales unos 1200 son doctorados.

CAPES es la única entidad en Brasil que puede cerrar programas de mala calidad (y lo hace). Por eso se considera que el postgrado de Brasil tiene calidad internacional. Los criterios de evaluación utilizados se encuentran en la Tabla 3.12.

Tienen una valoración adicional los programas de doctorado que satisfacen los criterios anteriores y además: a) Presenten desempeño equivalente a centros internacionales de excelencia en el área; b) Tengan un nivel de desempeño altamente diferenciado en relación a los demás programas del área. 
Tabla 3.12. Criterios de evaluación de programas de Postgrado - CAPES, Brasil

\begin{tabular}{|c|c|c|}
\hline $\mathbf{N}^{\circ}$ & Variable & Criterio \\
\hline \multirow[t]{3}{*}{1.} & \multirow{3}{*}{$\begin{array}{l}\text { Propuesta } \\
\text { del } \\
\text { programa }\end{array}$} & $\begin{array}{l}\text { a. Coherencia académica con áreas de concentración, líneas de } \\
\text { investigación y currículo. }\end{array}$ \\
\hline & & $\begin{array}{l}\text { b. Disponibilidad de plan estratégico, con claro entendimiento } \\
\text { interno sobre los objetivos y metas. }\end{array}$ \\
\hline & & $\begin{array}{l}\text { c. Calidad y adecuación de la infraestructura disponible en la } \\
\text { institución. }\end{array}$ \\
\hline \multirow[t]{4}{*}{2.} & \multirow{4}{*}{$\begin{array}{l}\text { Cuerpo } \\
\text { docente } \\
(20 \%)\end{array}$} & $\begin{array}{l}\text { a. Perfil de titulación, diversificación de formación, experiencia, } \\
\text { compatibilidad con el programa. }\end{array}$ \\
\hline & & $\begin{array}{l}\text { b. Adecuación y dedicación a la docencia, formación e } \\
\text { investigación. }\end{array}$ \\
\hline & & $\begin{array}{l}\text { c. Distribución de las actividades de investigación y de formación } \\
\text { entre los docentes del programa. }\end{array}$ \\
\hline & & $\begin{array}{l}\text { d. Contribución en el pregrado, por su repercusión en la } \\
\text { formación de futuros alumnos del posgrado. }\end{array}$ \\
\hline \multirow[t]{4}{*}{3.} & \multirow{4}{*}{$\begin{array}{l}\text { Cuerpo } \\
\text { discente } \\
(30 \%)\end{array}$} & $\begin{array}{l}\text { a. Volumen y ritmo de formación de alumnos de magister y } \\
\text { doctorado. }\end{array}$ \\
\hline & & b. Distribución de las orientaciones entre los docentes. \\
\hline & & c. Calidad de las publicaciones resultantes. \\
\hline & & $\begin{array}{l}\text { d. Eficiencia del programa con alumnos becados, en cuanto a } \\
\text { tiempo de titulación y calificación del comité evaluador, con } \\
\text { miembros externos al programa. }\end{array}$ \\
\hline \multirow[t]{3}{*}{4.} & \multirow{3}{*}{$\begin{array}{l}\text { Producción } \\
\text { intelectual } \\
(40 \%)\end{array}$} & $\begin{array}{l}\text { a. Publicación de papers de circulación internacional en los } \\
\text { extractos superiores del Qualis. }\end{array}$ \\
\hline & & b. Distribución en el cuerpo docente. \\
\hline & & c. Producción técnica, patentes, producción artística, si pertinente. \\
\hline \multirow[t]{3}{*}{5.} & \multirow[t]{3}{*}{$\begin{array}{l}\text { Inserción } \\
\text { social }(10 \%)\end{array}$} & $\begin{array}{l}\text { a. Impacto regional y nacional del programa, con producción de } \\
\text { libros para la enseñanza en el pregrado. }\end{array}$ \\
\hline & & $\begin{array}{l}\text { b. Integración y cooperación con otros centros de investigación en } \\
\text { regiones menos desarrolladas. }\end{array}$ \\
\hline & & c. Visibilidad o transparencia en la actuación del programa. \\
\hline
\end{tabular}

Fuente: Unicamp (2011) 


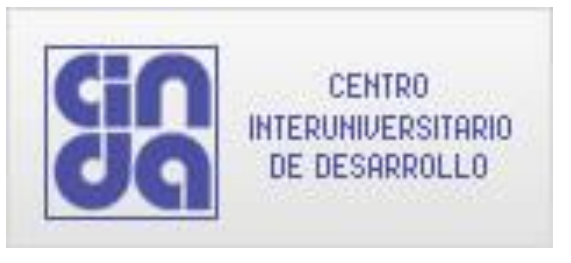

El Centro Interuniversitario de Desarrollo, CINDA, es una corporación internacional sin fines de lucro, con personalidad jurídica otorgada por los Estados de Colombia y Chile. Cuenta con la participación de destacadas universidades en la mayoría de los países latinoamericanos, así como en España e Italia. Ofrece servicios de consultoría, acreditación y evaluación de la calidad a través del Instituto Internacional para el Aseguramiento de la Calidad (IAC).

El modelo de CINDA parte de la premisa que "calidad" no es un concepto absoluto sino relativo y el referente lo establece la propia institución cuando define su misión, objetivos, metas y estrategias, aun cuando pueda haber aspectos en los que sea necesario atenerse a exigencias establecidas por agentes externos (González \& Espinoza, 2008).

CINDA acredita instituciones y programas. El proceso tiene tres etapas: 1) Autoevaluación conducida por la institución, 2) Evaluación externa, 3) Dictamen e informe emitidos por el Consejo Académico del IAC.

Para la acreditación de programas o carreras, CINDA (2014) verifica que:

- El programa tiene claramente definido el perfil de egreso de sus estudiantes

- El programa cuenta con las condiciones necesarias para lograr los objetivos de aprendizaje definidos en dicho perfil

- El programa puede demostrar que los resultados obtenidos en el proceso formativo tanto en términos de eficacia como de eficiencia - son adecuados

- El programa tiene instalados mecanismos útiles para la evaluación y mejora de la calidad de sus procesos y resultados.

La acreditación considera la evaluación de todas las modalidades mediante las cuales se obtiene el título comprometido en el programa, así como las distintas sedes o localidades donde éste se ofrece.

CINDA (2014) ha establecido dos parámetros fundamentales para definir la calidad de una carrera o programa: El primero se refiere a la consistencia interna, esto es, el grado de ajuste de las políticas, mecanismos y acciones de la institución y de la unidad responsable por la carrera o programa con las prioridades institucionales y sus propósitos declarados. El segundo parámetro está dado por los requerimientos, normas o criterios establecidos por la 
comunidad académica o profesional correspondiente. Estos se recogen en los criterios de calidad del IAC ( $\mathrm{y}$, cuando sea pertinente, en estándares adicionales definidos para una carrera o función específica) y se expresan en la consistencia externa de la carrera o programa con dichos requerimientos.

En el marco de este enfoque, los criterios de evaluación de CINDA (2014) se organizan en las tres dimensiones fundamentales mostradas en la Tabla 3.13:

Tabla 3.13. Dimensiones a evaluar para la acreditación de programas - CINDA

\begin{tabular}{|c|c|}
\hline Dimensión & Características \\
\hline $\begin{array}{l}\text { Perfil de egreso } \\
\text { y resultados }\end{array}$ & $\begin{array}{l}\text { Es el conjunto de conocimientos, habilidades y actitudes que todo } \\
\text { profesional o técnico debe dominar al momento de titularse y el grado } \\
\text { en que la institución puede dar cuenta de su definición y logro. Este } \\
\text { perfil se construye considerando al menos los siguientes elementos: } \\
\text { - El ajuste de las acciones y resultados con las prioridades } \\
\text { institucionales y los propósitos declarados para el programa. } \\
\text { - Los requerimientos establecidos por la comunidad académica o } \\
\text { profesional directamente vinculada al programa. }\end{array}$ \\
\hline $\begin{array}{l}\text { Condiciones de } \\
\text { operación }\end{array}$ & $\begin{array}{l}\text { Recursos y procesos que la institución pone a disposición del } \\
\text { programa para lograr el perfil de egreso definido. }\end{array}$ \\
\hline $\begin{array}{l}\text { Capacidad de } \\
\text { autorregulación } \\
\text { del programa }\end{array}$ & $\begin{array}{l}\text { Identificación de sus fortalezas y debilidades así como la formulación } \\
\text { de un plan de mejora realista y verificable. }\end{array}$ \\
\hline
\end{tabular}

Fuente: Elaboración propia a partir de CINDA (2014)

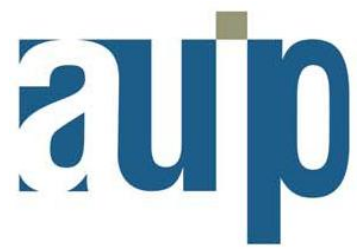

Asociación

Universitaria

Iberoamericana de Postgrado
La Asociación Universitaria Iberoamericana de Postgrado -AUIP- es un organismo internacional no gubernamental reconocido por la UNESCO, dedicada al fomento de los estudios de postgrado y doctorado en Iberoamérica. Actualmente está integrada por 185 prestigiosas instituciones de educación superior de España, Portugal, América Latina y el Caribe. Colabora en procesos de evaluación interna, externa y acreditación (AUIP, 2014).

AUIP publica una "Guía de Autoevaluación” para programas de postgrado desde el año 1991. En su quinta edición del año 2009 ha definido como criterios de evaluación los mostrados en la Tabla 3.14 .

La pertinencia vista por los organismos de acreditación 
Tabla 3.14. Criterios de evaluación de programas de postgrado - Asociación Universitaria Iberoamericana de postgrado - AUIP

\begin{tabular}{cll}
\hline $\mathbf{N}^{\circ}$ & Variable & Elementos \\
\hline 1. & Estudiantes & Admisión \\
& & Perfil de ingreso \\
\hline 2. & Profesores & Formación \\
& & Experiencia \\
& & Dedicación al programa \\
& & Producción intelectual \\
\hline 3. & Plan de Formación & Fundamentación \\
& & Ámbito de conocimiento \\
& & Objetivos \\
& & Contenidos \\
& & Metodología \\
& & Evaluación \\
& & Recursos \\
& & Ejecución del programa \\
\hline 4. & Investigación científica, desarrollo & Titulación \\
& tecnológico, innovación y & Innovación. \\
& desempeño profesional de alta & Desempeño profesional de alta calidad \\
& calidad & \\
\hline 5. & Gestión & Organización \\
& & Recursos \\
\hline 6. & Entorno y pertinencia & Institucional \\
& & Geográfico - político \\
& & Académico y científico \\
\hline 7. & Egresados e impacto & Vinculación \\
\hline & & Perfil \\
\hline & Desempeño \\
\hline & Eariables \\
& & Estrategias de mejora \\
\hline
\end{tabular}
Fuente: AUIP (2009) $)^{32}$

AUIP identifica ocho variables que pueden ser objeto de evaluación y entre ellas considera la de "Entorno y Pertinencia". Considera que la forma en la que el programa de postgrado se vincula con su entorno incide en la calidad académica. Incluye elementos como: misión y objetivos de la institución, ámbito de influencia del programa, relaciones efectivas que el programa mantiene con otras instancias académicas, sociales, científicas, productivas y de servicios, a nivel regional, nacional e internacional, así como la manera en la que el programa responde a las demandas sociales del entorno en el que está situado.

${ }^{32}$ http://www.auip.org/images/stories/DATOS/PDF/2009/guia_autoevaluacion_web.pdf 
La AUIP también considera una variable llamada "Egresados e impacto" donde se evalúa el perfil previsto y logrado por el egresado, su permanencia y desempeño en el programa, al igual que su aporte efectivo al desarrollo cultural, socioeconómico, científico y tecnológico.

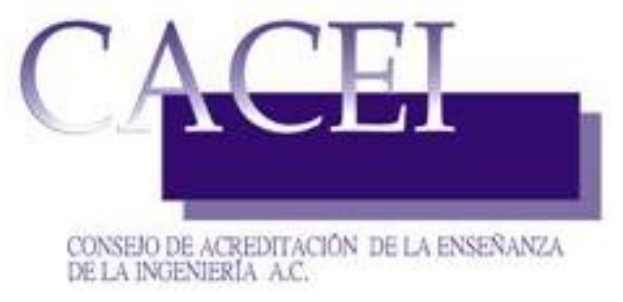

A nivel de Latinoamérica existen organismos de acreditación específicos para programas de ingeniería como CACEI en México pero la experiencia hasta ahora se centra en el pregrado. El Institute of Electrical and Electronics Engineers - IEEE promueve la creación de organismos acreditadores locales acordes a las necesidades de cada país y recomienda a los miembros del IEEE que se organicen para crearlos (IEEE, 2012).

Asimismo existen esfuerzos para lograr una acreditación regional en ingeniería como el "Acuerdo Latinoamericano sobre Acreditación en Ingeniería" - ALAI que tiene como objetivos más importantes:

- Sistemas de acreditación compatibles y reconocimientos como "Substancialmente Equivalentes".

- Establecimiento de estándares y parámetros latinoamericanos para acreditación de programas de enseñanza de la ingeniería.

- Intercambio de pares evaluadores

- Intercambio de experiencias de acreditación

- Participación en reconocimientos para la movilidad profesional

El primer comité coordinador de ALAI se formó en Noviembre de 2011 con representantes de Argentina, Centroamérica, Chile y México. Actualmente lo integran:

1. Argentina: Consejo Federal de Decanos de Ingeniería (CONFEDI)

2. Bolivia: Comité Ejecutivo de la Universidad Boliviana (CEUB)

3. Brasil: Asociaçiáo Brasileira de Educaçao em Engenharia (ABENGE)

4. Brasil: Conselho Federal de Engenharia, Arquitectura e Agronomia (CONFEA)

5. Chile: Acredita S. A.

6. Chile: Consejo de Decanos de Facultades de Ingeniería (CONFEDI)

7. Colombia: Asociación Colombiana de Facultades de Ingeniería (ACOFI) 
8. Paraguay: Centro Paraguayo de Ingenieros

9. México: Consejo de Acreditación de la Enseñanza de la Ingeniería (CACEI)

\subsubsection{Modelos de evaluación de programas de postgrado en Perú}

En este apartado se analiza los modelos de evaluación utilizados por el Consejo de Evaluación, Acreditación y Certificación de la Calidad de la Educación Superior Universitaria - CONEAU (2011); el Instituto de Calidad y Acreditación de Programas de Computación, Ingeniería y Tecnología - ICACIT y la Pontificia Universidad Católica de Perú (una de las mejores universidades de Perú según los últimos ranking). Se identifica luego los indicadores que evalúan la pertinencia de una maestría de acuerdo a lo planteado en el marco teórico del primer capítulo.

Gráfico 3.6. Modelos de evaluación de postgrados en Perú que fueron analizados

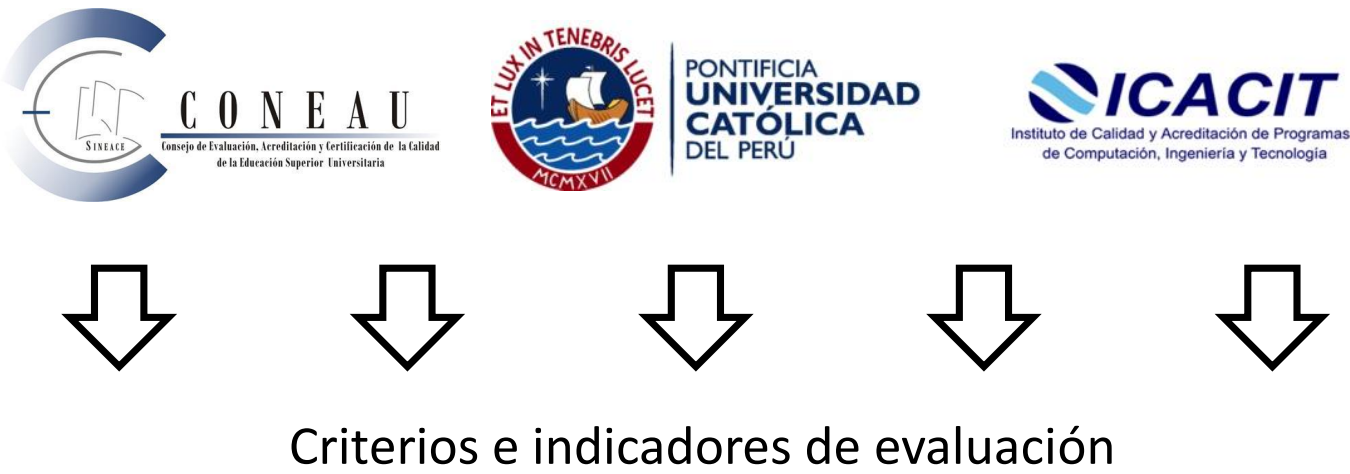

El sistema de aseguramiento de la calidad de la educación superior en Perú tiene como ente rector al Consejo de Evaluación, Acreditación y Certificación de la Calidad de la Educación Superior Universitaria - CONEAU. Esta entidad pública es encargada de definir los criterios e indicadores de evaluación para el proceso de acreditación y certificación de las instituciones y programas de educación superior universitaria. La acreditación por ahora es voluntaria.

La pertinencia vista por los organismos de acreditación 


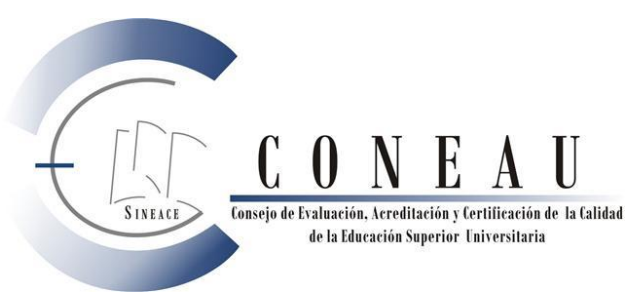

El CONEAU maneja 84 estándares para la evaluación de un programa de maestría en general. En la Tabla 3.15 se muestran las dimensiones, factores y criterios utilizados.

Tabla 3.15. Criterios para la acreditación de programas de maestría CONEAU -

Perú

\begin{tabular}{|c|c|c|c|}
\hline Dimensión & Factor & Criterio & Estándar \\
\hline \multirow{2}{*}{$\begin{array}{l}\text { Gestión de } \\
\text { programa }\end{array}$} & \multirow{2}{*}{$\begin{array}{l}\text { Planificación, } \\
\text { organización, } \\
\text { dirección y control }\end{array}$} & Planificación estratégica & $1-5$ \\
\hline & & Organización, dirección y control & $6-14$ \\
\hline \multirow{6}{*}{$\begin{array}{l}\text { Formación del } \\
\text { estudiante }\end{array}$} & \multirow{5}{*}{$\begin{array}{l}\text { Enseñanza } \\
\text { Aprendizaje }\end{array}$} & Proyecto educativo & $15-27$ \\
\hline & & $\begin{array}{l}\text { Estrategias de enseñanza } \\
\text { aprendizaje }\end{array}$ & 28 y 29 \\
\hline & & $\begin{array}{l}\text { Desarrollo de las actividades de } \\
\text { enseñanza aprendizaje }\end{array}$ & $30-34$ \\
\hline & & $\begin{array}{l}\text { Evaluación del aprendizaje y } \\
\text { acciones de mejora }\end{array}$ & 35 y 36 \\
\hline & & Estudiantes y egresados & $37-46$ \\
\hline & Investigación & $\begin{array}{l}\text { Generación y evaluación de } \\
\text { proyectos de investigación }\end{array}$ & $47-56$ \\
\hline \multirow{6}{*}{$\begin{array}{l}\text { Servicios de } \\
\text { apoyo para la } \\
\text { formación del } \\
\text { estudiante }\end{array}$} & \multirow[t]{2}{*}{ Docentes } & Labor de enseñanza & $57-64$ \\
\hline & & Labor de investigación & $65-72$ \\
\hline & $\begin{array}{l}\text { Infraestructura y } \\
\text { equipamiento }\end{array}$ & $\begin{array}{l}\text { Ambientes y equipamiento para la } \\
\text { enseñanza-aprendizaje, } \\
\text { investigación, administración y } \\
\text { bienestar }\end{array}$ & 73 y 74 \\
\hline & Bienestar & $\begin{array}{l}\text { Implementación de programas de } \\
\text { bienestar }\end{array}$ & $75-78$ \\
\hline & Recursos financieros & $\begin{array}{l}\text { Financiamiento de la } \\
\text { implementación del programa de } \\
\text { posgrado }\end{array}$ & $79-81$ \\
\hline & Grupos de interés & $\begin{array}{l}\text { Vinculación con los grupos de } \\
\text { interés }\end{array}$ & $82-84$ \\
\hline
\end{tabular}

Fuente: CONEAU (2010)

Los estándares que evalúan la pertinencia de una maestría en el modelo de evaluación del CONEAU, de acuerdo a lo planteado en el marco teórico, se muestran en la Tabla 2.17. 
Tabla 3.16. Estándares que evalúan la pertinencia de una maestría en el modelo de CONEAU - Perú

\begin{tabular}{|c|c|c|}
\hline Criterio & Estándar & Fuente de verificación \\
\hline \multirow[t]{4}{*}{$\begin{array}{l}\text { Proyecto } \\
\text { Educativo }\end{array}$} & $\begin{array}{l}\text { 15. La Unidad Académica justifica la } \\
\text { oferta de la maestría. }\end{array}$ & $\begin{array}{l}\text { Informe sobre el estudio de la } \\
\text { demanda social de la maestría }\end{array}$ \\
\hline & $\begin{array}{l}\text { 23. El plan de estudios vincula el } \\
\text { proceso de enseñanza-aprendizaje con } \\
\text { el proceso de investigación. }\end{array}$ & Plan de estudios \\
\hline & $\begin{array}{l}\text { 25. El plan de estudios incorpora los } \\
\text { resultados de la investigación de la } \\
\text { maestría }\end{array}$ & $\begin{array}{l}\text { Informe sobre resultados de } \\
\text { investigación } \\
\text { Informe sobre evaluación del plan de } \\
\text { estudios } \\
\text { Plan de estudios }\end{array}$ \\
\hline & $\begin{array}{l}\text { 26. El plan de estudios se evalúa } \\
\text { anualmente para su actualización }\end{array}$ & $\begin{array}{l}\text { Informe sobre evaluación del plan de } \\
\text { estudios } \\
\text { Plan de estudios } \\
\text { Procedimiento documentado }\end{array}$ \\
\hline $\begin{array}{l}\text { Estrategias } \\
\text { de } \\
\text { enseñanza } \\
\text { aprendizaje }\end{array}$ & $\begin{array}{l}\text { 28. Los estudiantes están de acuerdo } \\
\text { con las estrategias de enseñanza } \\
\text { aprendizaje aplicadas. }\end{array}$ & $\begin{array}{l}\text { Informe de evaluación } \\
\text { Encuestas y entrevistas a estudiantes } \\
\text { Informe del gabinete pedagógico } \\
\text { GII-22 Satisfacción sobre la } \\
\text { aplicación de estrategias de enseñanza } \\
\text { - aprendizaje }\end{array}$ \\
\hline $\begin{array}{l}\text { Estudiantes } \\
\text { y egresados }\end{array}$ & $\begin{array}{l}\text { 45. La unidad Académica tiene un } \\
\text { sistema implementado de seguimiento } \\
\text { del egresado. }\end{array}$ & $\begin{array}{l}\text { Documentos que sustentan la } \\
\text { implementación del sistema } \\
\text { Instrumentos de evaluación utilizados } \\
\text { GII-46 Tiempo transcurrido entre } \\
\text { egreso y graduación } \\
\text { GII-47 Porcentaje de graduados } \\
\text { GII-48 Impacto del grado } \\
\text { GII-49 Porcentaje de egresados que } \\
\text { ejercen docencia universitaria } \\
\text { GII-50 Porcentaje de graduados } \\
\text { admitidos en programas académicos } \\
\text { en el extranjero }\end{array}$ \\
\hline
\end{tabular}


Tabla 3.16. Estándares que evalúan la pertinencia de una maestría en el modelo de CONEAU - Perú (Continuación)

\begin{tabular}{lll}
\hline Criterio & Estándar & Fuente de verificación \\
\hline Generación y & 47. Los trabajos de investigación de la & Reglamento de grados \\
evaluación de & maestría aplican teorías o & Informe de evaluación \\
proyectos de & conocimientos ya establecidos para la & \\
investigación & generación de otros en el área & \\
& disciplinar correspondiente. & \\
\cline { 2 - 3 } & 53. Se realizan eventos donde se & Registros de asistencia \\
& difunden y discuten, entre estudiantes, & Encuestas y entrevistas a docentes \\
& docentes y comunidad, las & GII-57 Número de eventos de \\
& investigaciones realizadas en la & difusión de resultados de \\
& Maestría & investigación \\
\hline Vinculación & 82. La Maestría cuenta con un comité & $\begin{array}{l}\text { Resolución de creación del comité } \\
\text { con los }\end{array}$ \\
grupos de & consultivo integrado por & consultivo \\
interés & gctas de las reuniones del comité \\
& grupos de interés & consultivo \\
\cline { 2 - 3 } & 84. Los grupos de interés consideran & Encuestas y entrevistas a grupos de \\
& que su participación contribuye al & interés \\
desarrollo de la Maestría & GIII - 117 Satisfacción de los grupos \\
& & de interés. \\
\hline
\end{tabular}

Fuente: CONEAU (2010)

Creemos que el enfoque utilizado por el CONEAU para el diseño de estos estándares es el del modo 1 de Gibbons, es decir se piensa en una universidad estructurada por disciplinas donde la función de la universidad es de "transferir" conocimiento en lugar de “intercambiar” conocimiento y tecnología. Se aprecia claramente en los estándares 47 y 53. Lo positivo del modelo es la inclusión de un "Comité Consultivo" para vincular la maestría con los grupos de interés o partes interesadas.

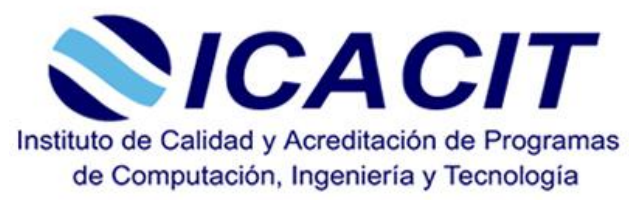

computación, ingeniería y tecnología en ingeniería en Perú. Los criterios utilizados por ICACIT para la acreditación de programas de ingeniería (incluyendo maestrías) han sido tomados de la traducción de los criterios de ABET hecha por el Institute of Electrical and Electronics Engineers - IEEE Inc. Los criterios para evaluar una maestría se muestran en la Tabla 3.17. Programas de Computación, Ingeniería y Tecnología - ICACIT es una acreditadora especializada que evalúa programas de

El Instituto de Calidad y Acreditación de 
Tabla 3.17. Criterios de evaluación ICACIT

\begin{tabular}{cl}
\hline $\mathbf{N}^{\circ}$ & Variable \\
\hline 1. & Estudiantes \\
2. & Objetivos educativos de programa \\
3. & Resultados de programa \\
4. & Mejora continua \\
5. & Plan de estudios \\
6. & Cuerpo docente \\
7. & Facilidades \\
8. & Apoyo \\
9. & Criterios de programa \\
\hline Fuente: & ICACIT (2014)
\end{tabular}

Si bien no existen estándares al nivel de detalle de CONEAU, el criterio "2. Objetivos educativos del Programa" incluye la creación de un Consejo Consultivo, el cual debe participar activamente en la actualización del plan de estudios y en el sistema de mejora continua. Asimismo se pide una revisión periódica de los propios objetivos educativos, basada en las necesidades de los distintos grupos de interés.

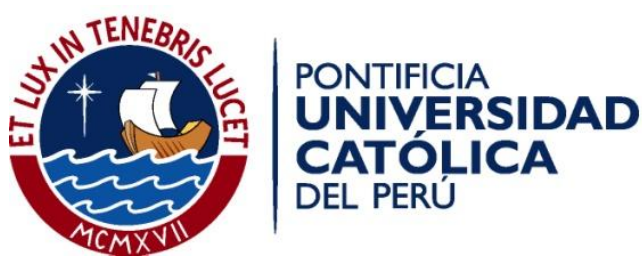

Para la Pontificia Universidad católica del Perú PUCP la "calidad universitaria" es un concepto dinámico, modificable e inagotable que abraca todos los ámbitos de acción de la universidad como el proceso formativo, la investigación y los servicios. Se trata entonces de la capacidad de respuesta que tiene la institución a las necesidades cambiantes del entorno buscando la mejora permanente. El modelo de autoevaluación de la PUCP tiene tres dimensiones de análisis: diseño del programa formativo, implementación del programa y resultados del programa. En la Tabla 3.18 se muestra las áreas consideradas en el modelo. 
Tabla 3.18. Modelo de autoevaluación de las maestrías de la PUCP

\begin{tabular}{|c|c|}
\hline DIMENSION & AREA \\
\hline \multirow{2}{*}{$\begin{array}{l}\text { Diseño del programa de } \\
\text { formación }\end{array}$} & Objetivo \\
\hline & Plan de estudios \\
\hline \multirow{5}{*}{$\begin{array}{l}\text { Implementación del } \\
\text { programa de formación }\end{array}$} & Selección de postulantes \\
\hline & Procedencia de los postulantes \\
\hline & Profesores \\
\hline & Soporte administrativo \\
\hline & Satisfacción con los espacios e instalaciones educativas \\
\hline \multirow{4}{*}{$\begin{array}{l}\text { Resultados del programa de } \\
\text { formación }\end{array}$} & Rendimiento académico de los estudiantes \\
\hline & Satisfacción con la formación impartida \\
\hline & Satisfacción con la formación recibida \\
\hline & Desempeño académico/profesional de loa egresados \\
\hline
\end{tabular}

Fuente: PUCP (2009)

En el modelo de evaluación de la PUCP se identificaron los indicadores para la evaluación de la pertinencia de una maestría de acuerdo a lo planteado en el marco teórico. Los resultados se muestran en la Tabla 3.19.

El modelo de la PUCP también se basa en una estructura de producción de conocimiento del Modo 1 de Gibbons, como lo muestra claramente el indicador 7. Sólo se percibe una vinculación con el entorno a través de encuestas a egresados y empleadores. No se exige al programa de maestría la realización de investigaciones centradas en problemas ni se exige la participación de los docentes en redes o asociaciones de investigación aplicada. 
Tabla 3.19. Estándares que evalúan la pertinencia de una maestría en el modelo de PUCP

\begin{tabular}{|c|c|c|}
\hline Área & Indicador & Fuente de verificación \\
\hline $\begin{array}{l}\text { Plan de } \\
\text { estudios }\end{array}$ & $\begin{array}{l}\text { 7. Existencia de líneas de investigación o } \\
\text { áreas de especialización que orientan y } \\
\text { refuerzan el desarrollo de las tesis. }\end{array}$ & $\begin{array}{l}\text { Entrevista al Coordinador de la } \\
\text { maestría } \\
\text { Encuesta a estudiantes } \\
\text { Encuesta a profesores } \\
\text { Documento que contenga las líneas } \\
\text { de investigación de la maestría. } \\
\end{array}$ \\
\hline \multirow{4}{*}{$\begin{array}{l}\text { Satisfacción } \\
\text { con la } \\
\text { formación } \\
\text { recibida }\end{array}$} & $\begin{array}{l}\text { 31. Nivel de satisfacción de estudiantes } \\
\text { con la formación recibida. }\end{array}$ & Encuesta a estudiantes \\
\hline & $\begin{array}{l}\text { 32. Nivel de satisfacción de los egresados } \\
\text { con la formación recibida (con dos a tres } \\
\text { años de egreso) }\end{array}$ & Encuesta a egresados \\
\hline & $\begin{array}{l}\text { 33. Nivel de satisfacción de los } \\
\text { empleadores con el desempeño de los } \\
\text { egresados (con dos a tres años de egreso) }\end{array}$ & Encuesta a empleadores \\
\hline & $\begin{array}{l}\text { 34. Existencia de un sistema de } \\
\text { seguimiento al desempeño de egresados: } \\
\text { - Estudios realizados sobre la ubicación, } \\
\text { ámbito, calidad e impacto del trabajo de } \\
\text { los egresados. } \\
\text { - Estudios o registros realizados sobre la } \\
\text { cantidad de graduados que cuentan con } \\
\text { producción académica o desempeño } \\
\text { profesional sobresaliente (cargos) }\end{array}$ & $\begin{array}{l}\text { Entrevista al Coordinador de la } \\
\text { maestría } \\
\text { Encuesta a egresados } \\
\text { Encuesta a empleadores }\end{array}$ \\
\hline
\end{tabular}

\subsubsection{Evaluación con fines de acreditación en la Universidad de Piura}

La Udep ha tomado como política institucional acreditar sus principales carreras. En el año 2011 creó la Oficina de Innovación y Calidad Educativa (ICE) con el objetivo de mejorar el sistema de innovación y gestión de la calidad educativa de la Universidad, además de desarrollar los procesos de acreditación de los programas de de pregrado y posgrado de toda la universidad. Esta oficina depende del Vicerrectorado de Investigación y Ordenación Académica.

La carrera de Educación Primaria de la facultad de Ciencias de la Educación se convirtió en el año 2013 en la primera carrera en la Udep y la primera en Perú en ser acreditada bajo los estándares del CONEAU. Esta experiencia ganada ha servido de base para impulsar la 
acreditación de otras carreras, especialmente en las facultades de Derecho ${ }^{33}$ e Ingeniería, siguiendo el modelo de calidad del CONEAU.

El proceso acreditación normado por el CONEAU tiene 4 fases: 1. Etapa previa al proceso de acreditación (Informar al CONEAU el inicio del proceso, designar el Comité Interno responsable, y capacitar a los miembros del Comité); 2. Autoevaluación; 3. Evaluación externa; y 4. Acreditación. La facultad de Ingeniería ya ha implementado la primera fase y está por iniciar la primera autoevaluación de sus tres carreras. En su plan estratégico, la facultad de Ingeniería tiene previsto no solo la acreditación nacional de sus carreras otorgada por el CONEAU sino que también pretende lograr la acreditación internacional otorgada por ABET.

La acreditación de la calidad universitaria en Perú está muy poco desarrollada. A mayo de 2014 solo catorce carreras en nueve universidades de Perú han sido acreditadas por el $\mathrm{CONEAU}^{34}$. Esta situación podría mejorar pues el proyecto de la nueva Ley Universitaria considera obligatorios los procesos de evaluación, acreditación y certificación para todas las carreras profesionales universitarias y el plazo para lograrlo es de 7 años.

\subsection{CONCLUSIONES DEL CAPÍTULO III}

En la actualidad los modelos de evaluación de los programas de postgrado existentes tienen como fin principalmente la acreditación. Las instituciones han pasado de evaluaciones con fines de mejora de la calidad a evaluaciones con fines de acreditación.

Los modelos utilizados para el aseguramiento de la calidad y la acreditación varían mucho dependiendo del contexto. De acuerdo con Sanyal \& Martin (2007) hay diferentes tipos de acreditación. La acreditación puede ser obligatoria o voluntaria, puede acreditarse un programa o una institución. Dependiendo del nivel de cobertura geográfica, la acreditación puede ser subnacional, nacional, regional o internacional. Se puede acreditar sólo instituciones privadas o incluir también a las públicas, se puede utilizar un enfoque basado en estándares o un enfocado basado en la adecuación de los objetivos y para los objetivos. El foco de la acreditación y por tanto lo que se revisa puede ser los resultados o los procesos.

\footnotetext{
${ }^{33}$ En Perú hay tres carreras que tienen que ser acreditadas obligatoriamente: medicina, educación y derecho; en las otras carreras es voluntario. Aunque no hay sanciones para quienes no se acrediten, se ha previsto algunas medidas de fomento.

${ }^{34}$ Diario Gestión del 20 de mayo de 2014: www.gestion.pe
} 
Existen muchos organismos de acreditación y la tendencia es a formar redes o asociaciones regionales con estándares comunes.

Para Eaton (2007a) la acreditación debe ser internacional dado que la educación superior es cada vez más universal e internacional. La movilidad estudiantil está aumentando y las corporaciones multinacionales cada vez dan más empleo a profesionales de todas partes del mundo.

Luego de revisar diferentes modelos y criterios de evaluación de maestrías encontramos que dichos modelos de acreditación en el contexto internacional evalúan principalmente resultados de aprendizaje y la capacidad de los programas (o instituciones) para lograr los objetivos educativos que dichos programas declaran en su misión. Sin embargo, no se garantiza que esos objetivos y por tanto los resultados, satisfagan necesidades reales del entorno nacional o regional, un aspecto esencial en los países en vías de desarrollo. La acreditación de las maestrías en ingeniería sigue un modelo de acreditación internacional y no se cuenta en la mayoría de los casos con criterios e indicadores para evaluar la pertinencia local.

Por ejemplo el modelo de ABET tiene un enfoque de "evaluación de resultados" y no de "evaluación de procesos". Se asume que los programas educativos en el siglo XXI ya tienen estandarizados los procesos necesarios para lograr los resultados esperados. Esto se puede entender en los países desarrollados o con sistemas de acreditación ya consolidados. Sin embargo, no necesariamente es cierto en los países en desarrollo, donde si se quiere garantizar la calidad de los programas, todavía es necesario verificar que los procesos se desarrollen de acuerdo a ciertos estándares mínimos de calidad (Ocampo, 2010). Es necesario tener en cuenta esto en la construcción del modelo de evaluación de la pertinencia para no sólo considerar indicadores de pertinencia personal (resultados de aprendizaje) sino también indicadores de pertinencia global, social e institucional.

El postgrado en Latinoamérica también se evalúa principalmente con fines de acreditación. En Perú hay muy poca experiencia en evaluación del postgrado, los países con mayor experiencia en este tema son Brasil y México. En el caso de Brasil la evaluación está a cargo de la Coordinación de Perfeccionamiento de Personal Superior (CAPES), una entidad pública que se encuentra bajo la autoridad del Ministerio de Educación pero que goza de mucha autonomía. Se puede decir que Brasil tiene los mejores postgrados de Latinoamérica pues CAPES tiene autoridad para cerrar, y de hecho lo hace, los programas de postgrado que 
no cumplen con sus estándares de calidad. Esta calidad superior de los postgrados de Brasil (y de la investigación) respecto de sus pares latinoamericanos hace que las universidades brasileñas lideren todos los ranking de universidades en Latinoamérica.

En México, se da mucho énfasis a la investigación y la vinculación del postgrado con el entorno. Por eso la evaluación del postgrado la lidera el Consejo Nacional de Ciencia y Tecnología - CONACYT y se basa en el paradigma "formación-investigación-vinculación" en el caso de los postgrados de investigación y en el paradigma "formación-desempeño del trabajo profesional-innovación" para el caso de los postgrados de tipo profesional. En este modelo se distinguen cuatro niveles de acreditación: Los programas de reciente creación, los programas en desarrollo, los programas consolidados (que otorga mucho peso a la pertinencia local) y los programas de competencia internacional (que tienen colaboraciones en el ámbito internacional para proyectos de investigación conjuntos). Esta clasificación es coherente con lo que sucede en la realidad nacional mexicana, que es parecida a la de los demás países latinoamericanos.

Existen también asociaciones de universidades que tratan de impulsar la evaluación del postgrado en Latinoamérica como la Asociación Universitaria Iberoamericana de Postgrado - AUIP y el Centro Internacional de Desarrollo - CINDA. El modelo de CINDA parte de la premisa que "calidad" no es un concepto absoluto sino relativo y el referente lo establece la propia institución cuando define su misión, objetivos, metas y estrategias. Por eso sólo verifica que el programa tenga definido un perfil de egreso y resultados, verifica las condiciones de operación y verifica la capacidad de autorregulación del programa.

AUIP identifica ocho variables que pueden ser objeto de evaluación y entre ellas considera la de "Entorno y Pertinencia". Considera que la forma en la que el programa de postgrado se vincula con su entorno incide en la calidad académica. AUIP también considera una variable llamada "Egresados e impacto" donde se evalúa el perfil previsto y logrado por el egresado, su permanencia y desempeño en el programa, al igual que su aporte efectivo al desarrollo cultural, socioeconómico, científico y tecnológico.

En Perú, el Consejo de Evaluación, Acreditación y Certificación de la Calidad de la Educación Superior Universitaria - CONEAU ha definido un modelo de calidad para la evaluación de las maestrías. El modelo considera algunos indicadores de pertinencia (adecuación del programa a las necesidades e intereses de los estudiantes y de las partes 
interesadas) pero considera a la universidad organizada de acuerdo a las disciplinas científicas, lo que no facilita el trabajo y la investigación interdisciplinaria.

En este contexto internacional, regional y nacional en el que se encuentra la Universidad de Piura (Udep), se hace necesario evaluar, con fines de mejora, las maestrías que actualmente imparte. La facultad de Ingeniería está interesada en mejorar su oferta de postgrado, actualmente cuenta con cuatro maestrías profesionales a tiempo parcial, una maestría a tiempo completo y un doctorado a tiempo completo. La Udep es una universidad relativamente joven, tiene 45 años pero goza de un prestigio reconocido a nivel nacional, principalmente por su facultad de Ingeniería.

Considerando el contexto socio económico, la realidad de la educación superior y el postgrado descritos para Latinoamérica, para Perú y para Piura, queda claro que sea cual sea la misión establecida por una universidad latinoamericana, si ésta desea prevalecer en el tiempo, entonces debe considerar como una prioridad la función de investigación y de producción de conocimiento con visibilidad internacional. En el caso de la formación en ingeniería esta investigación conviene que sea aplicada y centrada en problemas nacionales y regionales. En concreto: investigación en las universidades sí, pero contextualizada, en temas prioritarios y en asociación con otros centros de investigación o universidades globales. En las maestrías en ingeniería se necesita pertinencia local con visibilidad internacional.

La pertinencia de la que hablamos es la definida en el capítulo I, es decir, la que tiene los siguientes componentes: pertinencia global, pertinencia personal, pertinencia institucional y pertinencia social. No se debe impulsar un "cambio pendular" 35 en los sistemas de postgrado, es decir, no se debe pasar de un sistema local de producción del conocimiento a un sistema global dejando de atender las necesidades locales y nacionales. Se debe cumplir lo de siempre: pensar en global y luego actuar en local.

\footnotetext{
${ }^{35}$ es decir abandonar un sistema cerrado que se ha sido considerado como cierto durante un tiempo para sustituirlo por otro sistema ubicado al otro extremo, al que nos aferramos con la misma fuerza que el primero. Este cambio no es conveniente porque olvida lo bueno del sistema viejo y además ignora el verdadero valor del sistema nuevo.

(http://www.javiermalonda.com/2010/04/tipos-de-cambio-de-creencias/)
} 


\subsection{BIBLIOGRAFÍA DEL CAPÍTULO III}

ANECA (2011). Protocolo de evaluación para la verificación de titulos universitarios oficiales (Grado y Máster). Recuperado el mayo de 2014, de www.aneca.es

AUIP - Asociación Universitaria Iberoamericana de Posgrado (2014). Guía de Autoevaluación. Recuperado el junio de 2014, de www.auip.org

Bengoetxea, E; Arteaga, J. (2009). La evaluación de postgrados internacionales en la Unión Europea. Ejemplos de buenas prácticas de programas europeos. Revista de Universidad y Sociedad del Conocimiento.

Blackmur, D. (2008). A critical analysis of the INQAAHE Guidelines of Good Practice for higher education quality assurance agencies. En Higher Education, (Vol. 56, págs. 723 - 734).

INDA (2014). Instituto Internacional para el Aseguramiento de la Calidad. Recuperado el junio de 2014, de www.cinda.cl/iac

CONACYT (2013). Marco de referencia para la evaluación y seguimiento de programas de posgrado. Recuperado en junio de 2014, de www.conacyt.mx

CONACYT (2014). PNCP - Programa Nacional de Posgrados de Calidad - México. Recuperado en junio de 2014, de www.conacyt.mx

CONEAU (2010). Modelo de calidad para la acreditación de programas de posgrado, modalidad presencial, y estándares para maestrías y doctorados. Recuperado el junio de 2014, de www.coneau.gob.pe

CONEAU (2011). Consejo de Evaluación, Acreditación y Certificación de la Calidad de la Educación Superior Universitaria, Modelo de Calidad para la acreditación de programas de postgrado.

Cruz, V., \& Martos, F. (2010). Evaluación de la calidad de los programas de maestría y doctorado en Iberoamérica. Revista Digital Universitaria, 11 (5), 1 - 13.

Diaz-Puente, J. (2003). Tesis Doctoral. Diseño y aplicación de un modelo para el seguimiento y evaluación del Desarrollo Rural en la UE . Madrid.

Eaton, J. (2007 a). Un espacio de acreditación internacional. En Global University Network for Innovation, La Educación Superior en el mundo 2007: Acreditación para la Garantía de la Calidad, Qué está en juego. Barcelona: Mundi Prensa Libros SA.

Eaton. J. (2007 b). Consejo de Acreditación de la Educación Superior, la Acreditación y el reconocimiento en Estados Unidos. En En Global University Network for Innovation, La 
Educación Superior en el mundo 2007: Acreditación para la Garantía de la Calidad, Qué está en juego (págs. 278-281). Barcelona: Mundi Prensa Libros SA.

ENQA (2009). Standards and Guidelines for Quality Assurance in the European Higher Education Area. Recuperado el mayo de 2014, de www.enqa.eu

Felder, R., \& Brent, R. (2004). The ABC's of engineering education: ABET, Bloom's taxonomy, cooperative learning, and so on. Proceedings of the 2004 American Society for Engineering Education Annual Conference \& Exposition.

González, E., \& Espinoza, O. (2008). Calidad de la Educación Superior: Conceptos y Modelos. (C. S. Chile, Ed.) Calidad en la Educación (28), 247 - 276.

ICACIT. (2014). Instituto de Calidady Acreditación de Programas de Computación, Ingeniería y Tecnología. Recuperado el junio de 2014, de www.icacit.org.pe

IEEE (abril de 2012). Acreditación de programas de ingeniería en América Latina: presente y futuro. Recuperado el junio de 2014, de www.ewh.ieee.org

Lemaitre, M. J. (2004). INQAAHE principles of good practice. Quality in Higher Education, 10(2).

Loredo, J., Romero, R., \& Inda, P. (2009). Una alternativa de evaluación docente en el posgrado de la Universidad Iberoamericana, ciudad de México. X Congreso Nacional de Investigación Educativa. Veracruz.

Ocampo, F. (2010). Quality in engineering education - A Latin American point of view. International leadership colloquium on quality insurance, accreditation and assessment in bigher education. Madrid.

Olds, B., Moskal, B., \& Miller, R. (2005). “Assessment in engineering education: Evolution, approaches and collaborations". Journal of Engineering Education, 94, 1, 13-25.

Payzin, E. (2010). Developments in Engineering Education in Europe, ASME 2010 International Leadership, may 2010 Istanbul.

Palomares, D. \& García, A (2008). Evaluación de las instituciones de educación superior: revisión bibliográfica de sistema de indicadores. Revista española de documentación científica, 31, 2.

PUCP, P. U. (2009). Guia de autoevaluación de la formación para programas de maestría.

Recuperado el junio de 2014, de www.pucp.edu.pe/dape

Rama, C. (2008). El nacimiento de la acreditación internacional. En Primer Congreso Internacional de Evaluación y Acreditación,. Campeche, México.

RIACES, R. I. (2004). Glosario Internacional de Evaluación de la Calidad y Acreditación. Madrid. 
Salazar, J. (2011). Modelos de aseguramiento de la calidad de la educación superior (Centro

Interuniversitario de Desarrollo - CINDA, Proyecto ALFA. Recuperado el 04 de Julio de 2012, de http://www.cinda.cl/proyecto_alfa/htm/documentos.htm

Sanyal, B., \& Martin, M. (2007). Garantía de la Calidad y el papel de la Acreditación: Una Visión Global. En Global University Network for Innovation. En La Educación Superior en el mundo 2007: Acreditación para la Garantía de la Calidad, Qué está en juego (págs. 3-17). Barcelona: Mundi Prensa Libros SA.

Unicamp, U. E. (2011). Postgrados en Brasil. Recuperado el junio de 2014, de www.ime.unicamp.br

Van Ginkel, H. J., \& Rodrígues Días, M. A. (2007). Retos institucionales y políticos de la acreditación en el ámbito internacional. En Global University Network for Innovation. En La Educación Superior en el mundo 2007: Acreditación para la Garantía de la Calidad, Qué está en juego (págs. 37-57). Barcelona: Mundi Prensa Libros SA.

Yarzábal, L. (2005). Internacionalización de la educación superior: de la cooperación académica al comercio de servicios. . Cuadernos de Investigación en la Educación, (20). 
Capítulo IV

Modelo de evaluación de la pertinencia de maestrías en ingeniería 


\section{Capítulo IV.}

\section{Modelo de evaluación de la pertinencia de maestrías en ingeniería}

En los capítulos precedentes se muestra que es necesaria la mejora de la calidad y la pertinencia de la formación de postgrado en ingeniería para la competitividad, la sostenibilidad del crecimiento económico y el desarrollo de Latinoamérica y Perú. Esto implica atender a las necesidades e intereses reales de los estudiantes, las partes interesadas y el entorno socio económico local - nacional.

El modelo de evaluación de la pertinencia de maestrías en ingeniería que se describe a continuación considera: a) El marco teórico de la pertinencia de la educación superior; b) El marco contextual dado por el contexto socio económico y la educación superior en Latino América y Perú; c) Los modelos de evaluación del postgrado en ingeniería dados por los organismos de acreditación internacional y los modelos existentes en Latinoamérica y Perú; d) el concepto de pertinencia planteado en la presente tesis.

Este capítulo se divide en tres partes: en la primera se presentan los principios y características del modelo, en la segunda se definen los factores de pertinencia de una maestría en ingeniería así como los indicadores y fuentes de verificación, y en la tercera se establece los pasos a seguir en el proceso de evaluación (estructuración), los instrumentos para la recogida de información (encuestas y entrevistas) y recomendaciones para el análisis de la información y el juicio.

Los principios y características del modelo presentados en la primera parte consideran que se trata de una evaluación intermedia (de una maestría existente), que tiene fines de mejora y que es temática (interesa evaluar la pertinencia). En esta parte se recuerda el concepto de pertinencia presentado en el capítulo I y se define las partes interesadas en un programa de maestría en ingeniería.

En la segunda parte se definen cuatro factores de pertinencia teniendo en cuenta los tipos y dimensiones de la pertinencia presentadas en el capítulo I. Para cada factor se identifican indicadores y fuentes de verificación, de acuerdo a las conclusiones de los capítulos precedentes. En total se tienen 25 indicadores. 
Finalmente se establece los pasos a seguir en el proceso de evaluación (estructuración), los instrumentos para la recogida de información (encuestas y entrevistas) y recomendaciones para el análisis de la información y el juicio.

El objetivo de la evaluación es generar una experiencia de aprendizaje que ayude a mejorar la maestría en un aspecto importantísimo como es la pertinencia. El objetivo no es otorgar un índice de pertinencia, sino proponer acciones y estrategias para mejorar los indicadores, de modo que los objetivos y resultados del programa formativo se adecúen cada vez más a las necesidades e intereses de los estudiantes y las partes interesadas. Los resultados de la evaluación y las lecciones aprendidas sirven asimismo para la planificación y diseño de nuevos programas de maestría.

\subsection{PRINCIPIOS, CARACTERÍSTICAS Y DEFINICIONES}

\subsubsection{Principios y características del modelo}

La pertinencia es importante en dos momentos de un programa de maestría: al inicio (en el diseño) y durante su funcionamiento. Es importante identificar bien las necesidades e intereses reales de los beneficiarios y las partes interesadas para que los objetivos del programa se adecúen a ellos.

En la presente investigación se considera una maestría que ya está funcionando y ya tiene egresados, por tanto se trata de la evaluación de la pertinencia de un programa en su etapa de funcionamiento. En este caso, a diferencia de la etapa de planificación y diseño, ya se tiene en marcha los procesos y algunos resultados, es por tanto una evaluación intermedia.

Es asimismo una evaluación temática porque analiza transversalmente un tema: la pertinencia. Es una evaluación formativa porque el objetivo es el aprendizaje y la mejora continua. Y es una evaluación externa porque conviene que la realice un profesional ajeno a la maestría. 
Tabla 4.1. Tipificación de la evaluación propuesta

\begin{tabular}{ll}
\hline \multicolumn{1}{c}{ Clasificación } & \multicolumn{1}{c}{ Tipo } \\
\hline Según el momento de la realización & Intermedia \\
\hline Según el contenido & Temática \\
\hline Según la utilidad & Formativa \\
\hline Según el responsable de la evaluación & Externa \\
\hline
\end{tabular}

Fuente: Elaboración propia a partir de (Diaz-Puente, 2003) y (AUIP, 2009)

El modelo asume que las competencias establecidas por el programa de maestría siguen siendo válidas en el momento de la evaluación de la pertinencia. Por tanto no se considera el levantamiento de información para verificar si son adecuadas o no las competencias definidas por el programa ${ }^{36}$.

El presente modelo considera dos subprocesos: "assessment" y "evaluation". El assessment consiste en la recogida de la información de acuerdo a unos indicadores y fuentes de verificación previamente definidos y luego las personas a cargo de la evaluación del programa deberán realizar la evaluation, es decir, la interpretación de dicha información y la emisión de un juicio al respecto (Olds, Moskal, \& Miller, 2005).

El modelo es coherente con lo afirmado por (Olds, Moskal, \& Miller, 2005), en cuanto que lo que debe impulsar una investigación educativa y una evaluación, debe ser las preguntas y no los métodos. Los evaluadores pueden examinar lo que ellos deseen conocer escogiendo la mejor metodología posible para responder a las preguntas.

Esta propuesta no pretende cambiar los modelos de calidad para la evaluación de programas de maestría con fines de acreditación. Según esta propuesta la pertinencia podría considerarse como una característica transversal que debe estar en todos los componentes de un modelo de calidad.

Las características del modelo, que derivan del marco anteriormente expuesto, son las siguientes: la participación, el aprendizaje, la complementación y la sencillez.

La participación: El modelo incluye la participación de todas las partes interesadas en el proceso de evaluación (estudiantes, egresados, docentes, directivos). No finaliza hasta que se

\footnotetext{
${ }^{36}$ Se puede considerar las competencias propuestas por ABET o IPMA para los programas de formación en ingeniería.
} 
decida cerrar el programa de maestría. La participación aspira a que todos los implicados se beneficien al máximo con los esfuerzos de la evaluación.

E1 aprendizaje: Las actividades de evaluación son consideradas como un proceso sistemático de aprendizaje que activa la retroalimentación de todos los implicados (estudiantes, docentes, directivos, entre otros). Este aprendizaje constituye el medio para la creación de un capital social que genere continuas mejoras en la planificación y gestión de la maestría.

La sencillez: El modelo no precisa de unos elevados conocimientos de educación superior, conocimientos estadísticos ni financieros.

La complementación: En todas las actividades de evaluación es necesario combinar distintas fuentes de información complementarias para asegurar la solidez de los trabajos. Hay fuentes primarias (la información es generada y recogida ex profeso por el proceso de evaluación) y otras fuentes secundarias (datos ya disponibles), una cuantitativa (información cuantificable como los resultados de las encuestas) y otra cualitativa (información difícil de cuantificar, resultado de las entrevistas).

\subsubsection{Concepto de pertinencia de una maestría en ingeniería}

De acuerdo con lo planteado en el apartado 1.2.2. una maestría en ingeniería es pertinente si los objetivos que se plantea se adecúan a las necesidades de formación de los estudiantes, si se adecúan a los intereses de la universidad y si resuelven problemas del contexto socioeconómico contribuyendo al desarrollo de su comunidad.

Existen dos tipos de pertinencia: la pertinencia global y la pertinencia local. La pertinencia global implica que la maestría esté insertada en un sistema integrado de producción del conocimiento y que por tanto cumpla con estándares internacionales. La pertinencia local tiene tres dimensiones: una personal, una institucional y una social. La pertinencia personal debe buscar la mejora del desempeño profesional y del nivel de competitividad de los estudiantes de modo que éstos puedan acceder por ejemplo a mejores salarios y ascensos. La pertinencia institucional significa alinear los objetivos de la maestría a la misión, objetivos estratégicos y políticas de la universidad que la acoge. Y la pertinencia social implica conectar a la maestría con problemas, necesidades y prioridades nacionales y regionales. 


\section{Gráfico 1.3. Dimensiones de la pertinencia de una maestría en ingeniería}

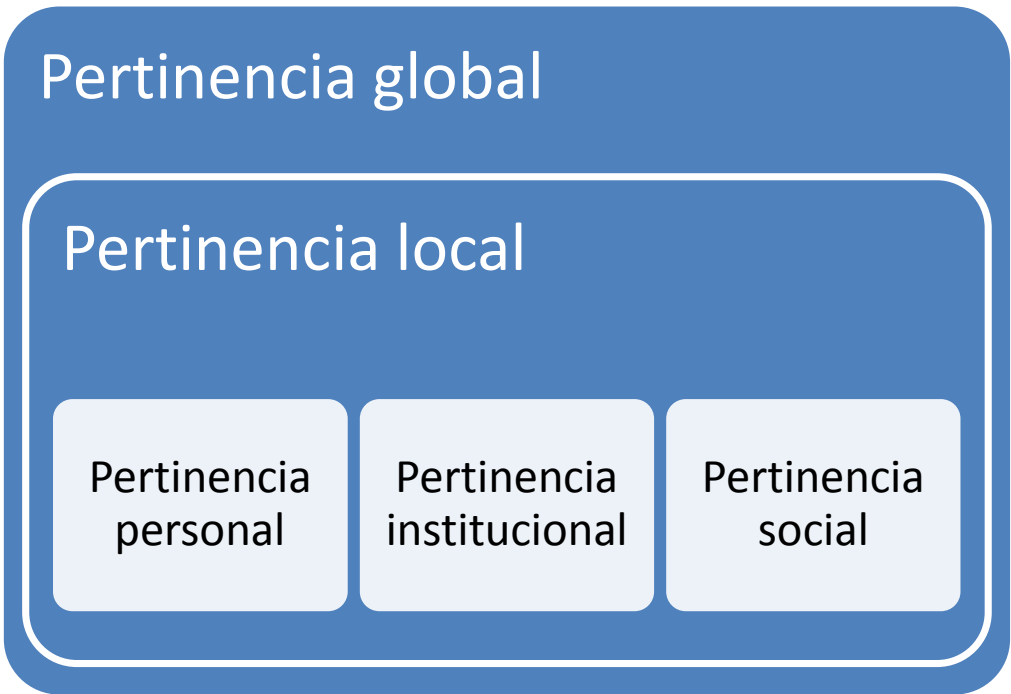

Fuente: Elaboración propia

\subsubsection{Beneficiarios y partes interesadas en una maestría en ingeniería}

Los principales beneficiarios de un programa de maestría en ingeniería son los estudiantes. El modelo presentado puede aplicarse a maestrías a tiempo completo y maestrías a tiempo parcial, a maestrías profesionales y maestrías de investigación. En el caso particular de una maestría a tiempo parcial se considera que los estudiantes acuden a la universidad por una necesidad de formación permanente, principalmente porque desean especializarse en una rama de la ingeniería para mejorar su desempeño laboral. Necesitan conocimiento especializado para aplicar lo aprendido e innovar en su labor profesional, así como para tener un grado más que les permita tener una hoja de vida más competitiva.

Los empleadores, financien o no la maestría, también son beneficiarios de estos programas, pues les impacta la mejora en el desempeño laboral de los estudiantes. La comunidad local y nacional también es beneficiaria pues contará con profesionales más competitivos para resolver sus problemas y atender sus demandas.

La universidad que imparte la maestría es una de las principales partes interesadas pues a través de esta maestría está cumpliendo parte de su misión, no sólo la de docencia sino también la de investigación, integración con su comunidad y contribución al desarrollo. 


\subsection{CONTENIDO}

\subsubsection{Factores de pertinencia}

Se tienen cuatro factores de pertinencia estrechamente ligados a los tipos y dimensiones de pertinencia establecidos en el apartado 1.2.2.

\section{Gráfico 4.1. Factores de pertinencia}

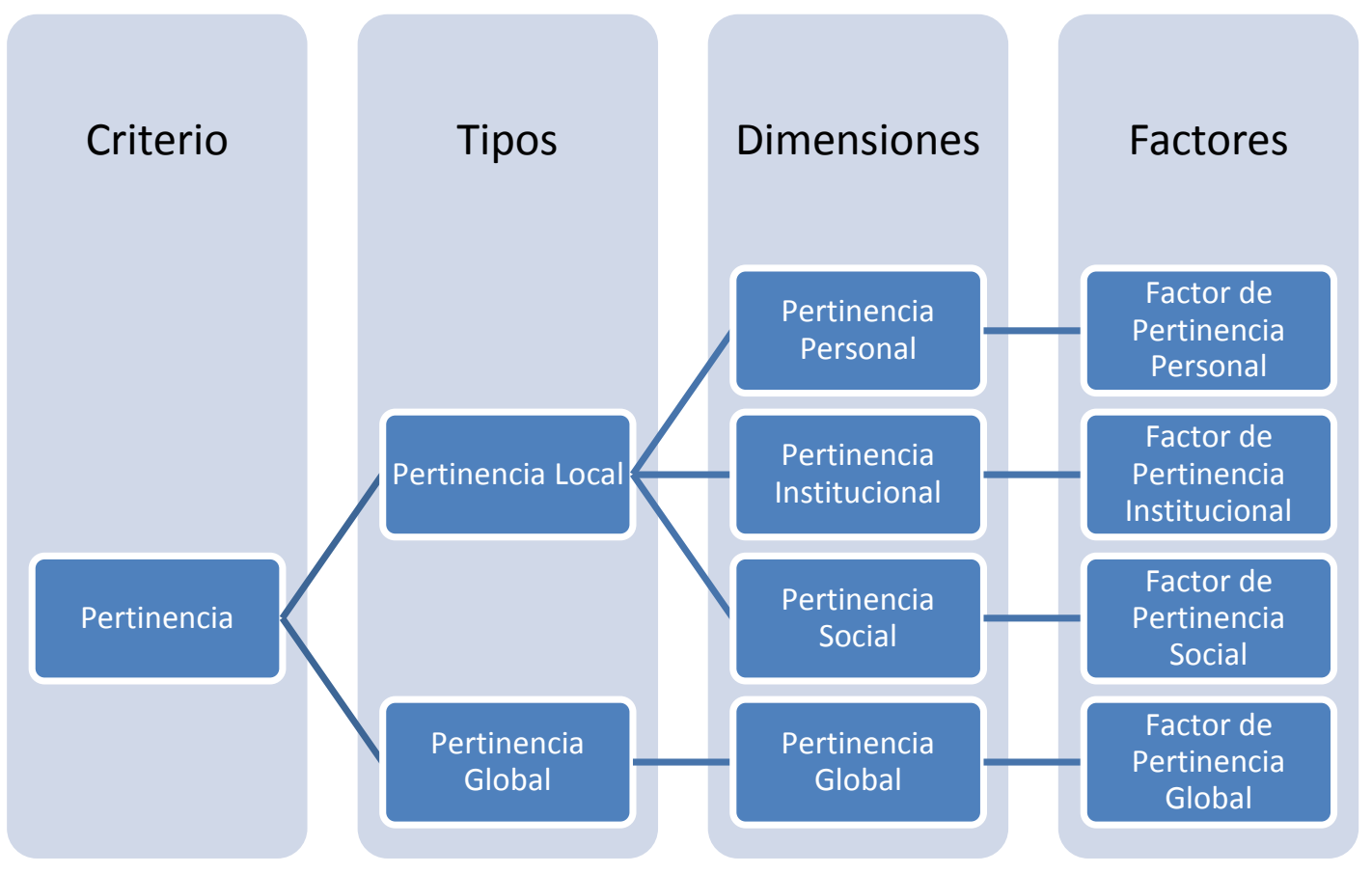

Fuente: Elaboración propia

Hay Pertinencia Personal si hay satisfacción personal de los estudiantes y egresados. Un egresado del programa estará contento si la maestría le ayudó a: mejorar su desempeño laboral, a desarrollar competencias, a mejorar su situación laboral y si está en contacto con él después de terminar el programa. Los empleadores a su vez estarán satisfechos si el mejor desempeño laboral de estos estudiantes logrado por la maestría redunda en beneficio de la compañía. Debe existir una adecuación de los contenidos (plan de estudios) con las necesidades e intereses de los estudiantes.

Hay Pertinencia Institucional si hay concordancia entre la gestión de la maestría y los intereses de la Universidad, es decir, si los objetivos de la maestría se adecúan a los intereses de la universidad. Es necesaria la correspondencia entre la dirección y administración de la maestría con las políticas, procedimientos de trabajo y valores de la universidad que la acoge. 
La maestría es pertinente si ayuda a la universidad a cumplir con su misión de investigación y le da visibilidad, es decir, si los docentes de la maestría investigan y publican usando el nombre de dicha universidad.

Hay Pertinencia Social si hay vinculación con el entorno socio - económico local y nacional, si atiende necesidades del mercado laboral y si está alineada a las prioridades de desarrollo económico, locales y nacionales. Asimismo, la maestría sería más pertinente socialmente hablando si los proyectos de fin de máster tienen aplicación o resuelves problemas de las empresas locales y nacionales.

Habrá Pertinencia Global si la maestría cumple estándares de calidad internacionales, si existe vinculación de los docentes y la investigación con el entorno nacional y global. Un programa de maestría es más pertinente si la investigación científica que promueve es multidisciplinaria y centrada en problemas, si el desarrollo de las asignaturas promueve la innovación y el aprendizaje basado en proyectos.

\subsubsection{Indicadores y fuentes de verificación}

Los indicadores se seleccionan considerando los conceptos, características y tendencias de:

- La educación superior y su pertinencia.

- El Modo 2 de Gibbons y la metodología GESPLAN para la producción de conocimiento.

- La formación de postgrado en ingeniería.

- Organismos internacionales de acreditación: criterios de evaluación e indicadores

- Organismos latinoamericanos y peruanos de acreditación del postgrado: criterios de evaluación e indicadores.

Esta selección considera siempre la necesaria vinculación de la universidad y la maestría con su entorno, para satisfacer sus necesidades, atender sus demandas e intereses y resolver sus problemas. 


\section{Gráfico 4.2. Identificación de indicadores de evaluación}

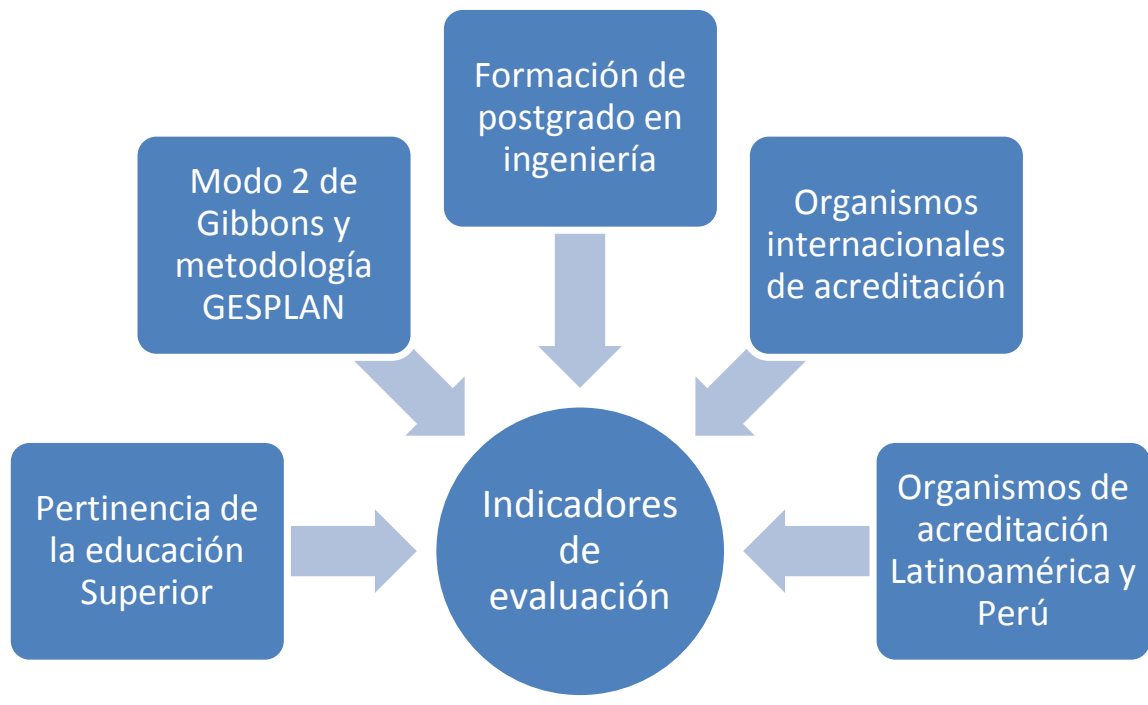

\section{Vinculación de la universidad y la maestría con su entorno}

Fuente: Elaboración propia

En la Tabla 4.2 se muestran los aspectos de pertinencia identificados en este proceso de elaboración del modelo de evaluación.

Realizando siempre consultas a expertos en el tema en Piura, Lima y Madrid se identifican varios aspectos de una maestría en ingeniería que puedan dar indicios de qué tan vinculada está la maestría con su entorno, qué tanto satisface las necesidades de los estudiantes, empleadores y comunidad y qué tanto ayuda a la universidad a cumplir con sus misiones. Estos aspectos dan lugar a los indicadores y sus fuentes de verificación: encuestas a estudiantes, docentes, egresados y empleadores, así como entrevistas a directivos de la maestría y directivos de la universidad. 
Tabla 4.2. Aspectos de pertinencia identificados

\begin{tabular}{|c|c|c|c|c|c|c|}
\hline $\begin{array}{l}\text { Pertinencia } \\
\text { educación } \\
\text { superior }\end{array}$ & $\begin{array}{c}\text { Vinculación } \\
\text { con el } \\
\text { entorno }\end{array}$ & $\begin{array}{l}\text { Modo } 2 \text { de } \\
\text { Gibbons y } \\
\text { Metodología } \\
\text { GESPLAN }\end{array}$ & $\begin{array}{l}\text { Formación } \\
\text { de postgrado } \\
\text { en ingeniería }\end{array}$ & $\begin{array}{c}\text { Organismos } \\
\text { internacionales } \\
\text { de acreditación }\end{array}$ & $\begin{array}{l}\text { Organismos de } \\
\text { acreditación } \\
\text { Latinoamérica } \\
\text { y Perú }\end{array}$ & Aspecto de pertinencia \\
\hline $\mathrm{X}$ & & & & & $\mathrm{X}$ & Ayuda a un mejor desempeño laboral. \\
\hline \multirow[t]{2}{*}{$\mathrm{X}$} & & & & & $\mathrm{X}$ & Los temas son de interés del estudiante. \\
\hline & $\mathrm{X}$ & & & & $\mathrm{X}$ & Sistema de seguimiento al desempeño de egresados \\
\hline $\mathrm{X}$ & & & & & $\mathrm{X}$ & Ayuda a recibir un aumento de salario, ascenso. \\
\hline \multirow[t]{4}{*}{$\mathrm{X}$} & & & & & $\mathrm{X}$ & Syllabus actualizados considerando estudiantes y egresados. \\
\hline & & & & $\mathrm{X}$ & & Correspondencia misión y objetivos con el plan de estudios. \\
\hline & & $\mathrm{X}$ & & & & Número de alumnos. Ratio admitidos/postulantes. \\
\hline & $\mathrm{X}$ & $\mathrm{X}$ & $\mathrm{X}$ & $\mathrm{X}$ & $\mathrm{X}$ & Los docentes publican papers en ISI o Scopus. \\
\hline $\bar{X}$ & & & & & $\mathrm{X}$ & $\begin{array}{l}\text { Coherencia maestría - universidad en misión, objetivos y } \\
\text { valores. }\end{array}$ \\
\hline \multirow[t]{2}{*}{$\mathrm{X}$} & & & & & $\mathrm{X}$ & $\begin{array}{l}\text { Coherencia maestría - universidad en procedimientos de } \\
\text { trabajo. }\end{array}$ \\
\hline & & $\mathrm{X}$ & & & $\mathrm{X}$ & Programas de pregrado relacionados con la maestría. \\
\hline $\mathrm{X}$ & $\mathrm{X}$ & $\mathrm{X}$ & & & & Aprovecha oportunidades locales y nacionales. \\
\hline $\mathrm{X}$ & $\mathrm{X}$ & $\mathrm{X}$ & & & & Relación con prioridades de desarrollo local o nacional. \\
\hline $\mathrm{X}$ & $\mathrm{X}$ & $\mathrm{X}$ & & & $\mathrm{X}$ & Satisface necesidades reales de la localidad y del país. \\
\hline \multirow[t]{10}{*}{$\mathrm{X}$} & $\mathrm{X}$ & & $\mathrm{X}$ & & & $\begin{array}{l}\text { Proyectos de fin de máster resuelven problemas en las } \\
\text { empresas. }\end{array}$ \\
\hline & $\mathrm{X}$ & & & & $\mathrm{X}$ & Relación con programas de otras instituciones. \\
\hline & & & & $\mathrm{X}$ & $\mathrm{X}$ & Comité consultivo integrado por grupos de interés. \\
\hline & $\mathrm{X}$ & $\mathrm{X}$ & & $\mathrm{X}$ & & Los docentes participan en redes y asociaciones. \\
\hline & $\mathrm{X}$ & & & $\mathrm{X}$ & & Los docentes poseen movilidad académica. \\
\hline & & $\mathrm{X}$ & & $\mathrm{X}$ & $\mathrm{X}$ & $\begin{array}{l}\text { Los docentes incorporan resultados de investigaciones } \\
\text { actuales. }\end{array}$ \\
\hline & & $\mathrm{X}$ & $\mathrm{X}$ & & & La organización facilita la investigación multidisciplinaria. \\
\hline & $\mathrm{X}$ & $\mathrm{X}$ & & & & Proyectos de investigación con financiamiento externo. \\
\hline & & $\mathrm{X}$ & $\mathrm{X}$ & & & Se promueve la transdisciplinariedad y la innovación. \\
\hline & & & $\mathrm{X}$ & & & Enfoque de aprendizaje basado en proyectos. \\
\hline
\end{tabular}

Fuente: Elaboración propia

Modelo de evaluación de la pertinencia de maestrías en ingeniería 
Tabla 4.3. Número de indicadores por factor de pertinencia.

\begin{tabular}{lc}
\hline Factor & Número de Indicadores \\
\hline Factor de pertinencia personal & 5 \\
Factor de pertinencia institucional & 7 \\
Factor de pertinencia social & 6 \\
Factor de pertinencia global & 7 \\
\hline
\end{tabular}

Fuente: Elaboración propia

Los indicadores y fuentes de verificación para cada factor de pertinencia se muestran en la Tabla 4.4. 
Tabla 4.4. Indicadores y fuentes de verificación para evaluar la pertinencia de maestrías en ingeniería

\begin{tabular}{|c|c|c|c|}
\hline Factor & $\mathbf{N}^{\circ}$ & Indicador & Fuente de verificación \\
\hline \multirow[t]{5}{*}{$\begin{array}{l}\text { Pertinencia } \\
\text { Personal }\end{array}$} & A & $\begin{array}{l}\text { Los conocimientos adquiridos en la maestría } \\
\text { ayudaron a un mejor desempeño laboral. }\end{array}$ & Encuesta a estudiantes, egresados y empleadores \\
\hline & B & $\begin{array}{l}\text { Los temas dictados durante la maestría se } \\
\text { relacionan con los temas del trabajo o son de } \\
\text { interés del estudiante. }\end{array}$ & Encuesta a estudiantes y egresados \\
\hline & $\mathrm{C}$ & $\begin{array}{l}\text { Funciona un sistema de seguimiento al desempeño } \\
\text { de egresados }\end{array}$ & $\begin{array}{l}\text { Encuesta a egresados } \\
\text { Entrevista a directivos de la maestría y directivos de la } \\
\text { universidad. }\end{array}$ \\
\hline & $\mathrm{D}$ & $\begin{array}{l}\text { Cursar la maestría ayudó a mejorar la situación } \\
\text { laboral del egresado (recibir un aumento de salario, } \\
\text { un ascenso u obtener un mejor empleo). }\end{array}$ & Encuesta a egresados \\
\hline & $\mathrm{E}$ & $\begin{array}{l}\text { La actualización de los syllabus considera la } \\
\text { opinión de estudiantes y egresados. }\end{array}$ & Encuesta a docentes \\
\hline \multirow[t]{4}{*}{$\begin{array}{l}\text { Pertinencia } \\
\text { Institucional }\end{array}$} & $\mathrm{F}$ & Número de alumnos en la maestría. & $\begin{array}{l}\text { Entrevista a directivos de la maestría } \\
\text { Revisión documental: Informes Anuales. }\end{array}$ \\
\hline & G & Ratio admitidos/postulantes en la maestría. & $\begin{array}{l}\text { Entrevista a directivos de la maestría } \\
\text { Revisión documental: Informes anuales. }\end{array}$ \\
\hline & $\mathrm{H}$ & $\begin{array}{l}\text { Los docentes (tiempo completo o tiempo parcial) } \\
\text { han publicado algún paper en ISI, Scopus o Scient } \\
\text { Direct utilizando el nombre de la universidad, en } \\
\text { los dos últimos años. }\end{array}$ & Encuesta a docentes \\
\hline & I & $\begin{array}{l}\text { La misión y objetivos de la maestría son } \\
\text { coherentes con la misión, objetivos y valores de la } \\
\text { universidad. }\end{array}$ & $\begin{array}{l}\text { Entrevista a directivos de la maestría y directivos de la } \\
\text { universidad. }\end{array}$ \\
\hline
\end{tabular}




\begin{tabular}{|c|c|c|c|}
\hline Factor & $\mathbf{N}^{\circ}$ & Indicador & Fuente de verificación \\
\hline & $\mathrm{J}$ & $\begin{array}{l}\text { La gestión de la maestría se desarrolla de acuerdo a } \\
\text { las políticas y procedimientos de trabajo de la } \\
\text { universidad. }\end{array}$ & $\begin{array}{l}\text { Entrevista a directivos de la maestría y directivos de la } \\
\text { universidad. }\end{array}$ \\
\hline & $\mathrm{K}$ & $\begin{array}{l}\text { Existe correspondencia entre la misión y objetivos } \\
\text { de la maestría con el plan de estudios. }\end{array}$ & $\begin{array}{l}\text { Encuestas a estudiantes y egresados. } \\
\text { Entrevista a directivos de la maestría. } \\
\text { Revisión documental: página web, plan de estudios. }\end{array}$ \\
\hline & $\mathrm{L}$ & $\begin{array}{l}\text { La universidad ofrece programas de pregrado o } \\
\text { especialización relacionados con la maestría. }\end{array}$ & Entrevista a Directivos de la maestría \\
\hline \multirow[t]{6}{*}{$\begin{array}{l}\text { Pertinencia } \\
\text { Social }\end{array}$} & $\mathrm{M}$ & $\begin{array}{l}\text { La maestría aprovecha las oportunidades locales y } \\
\text { nacionales para beneficio de sus estudiantes y } \\
\text { docentes. }\end{array}$ & $\begin{array}{l}\text { Encuesta a estudiantes, docentes y egresados. } \\
\text { Entrevista a directivos }\end{array}$ \\
\hline & $\mathrm{N}$ & $\begin{array}{l}\text { El plan de estudios se relaciona con las prioridades } \\
\text { de desarrollo local o nacional. }\end{array}$ & $\begin{array}{l}\text { Entrevista a directivos de la maestría y directivos de la } \\
\text { universidad. } \\
\text { Revisión documental (planes de desarrollo regional y } \\
\text { nacional, plan nacional de competitividad) }\end{array}$ \\
\hline & $\mathrm{O}$ & $\begin{array}{l}\text { El plan de estudios ayuda a satisfacer necesidades } \\
\text { reales de la localidad y del país. }\end{array}$ & Encuestas a estudiantes, docentes y egresados. \\
\hline & $\mathrm{P}$ & $\begin{array}{l}\text { Los proyectos de fin de máster tienen aplicación o } \\
\text { resuelven problemas en las empresas }\end{array}$ & $\begin{array}{l}\text { Encuestas a egresados y empleadores. } \\
\text { Entrevista a directivos de la maestría. }\end{array}$ \\
\hline & $\mathrm{Q}$ & $\begin{array}{l}\text { Existen relaciones efectivas con programas } \\
\text { similares de otras universidades, empresas, } \\
\text { agencias gubernamentales, ONG, entre otros. }\end{array}$ & $\begin{array}{l}\text { Entrevista a directivos de la maestría. } \\
\text { Revisión documental (convenios, acuerdos) }\end{array}$ \\
\hline & $\mathrm{R}$ & $\begin{array}{l}\text { La maestría cuenta con un comité consultivo } \\
\text { integrado por representantes de los principales } \\
\text { grupos de interés }\end{array}$ & $\begin{array}{l}\text { Encuesta a empleadores } \\
\text { Entrevistas a directivos de la maestría y directivos de la } \\
\text { universidad. } \\
\text { Revisión documental (Resolución de creación del } \\
\text { Comité y actas) }\end{array}$ \\
\hline
\end{tabular}




\begin{tabular}{|c|c|c|c|}
\hline Factor & $\mathbf{N}^{\circ}$ & Indicador & Fuente de verificación \\
\hline \multirow[t]{7}{*}{$\begin{array}{l}\text { Pertinencia } \\
\text { Global }\end{array}$} & $\mathrm{S}$ & $\begin{array}{l}\text { Los docentes participan en redes o asociaciones } \\
\text { científicas y profesionales }\end{array}$ & $\begin{array}{l}\text { Encuesta a docentes } \\
\text { Entrevista a directivos de la maestría y directivos de la } \\
\text { universidad. }\end{array}$ \\
\hline & $\mathrm{T}$ & Los docentes poseen movilidad académica & $\begin{array}{l}\text { Encuesta a docentes. } \\
\text { Entrevista a directivos de la maestría y directivos de la } \\
\text { universidad. }\end{array}$ \\
\hline & $\mathrm{U}$ & $\begin{array}{l}\text { Los docentes actualizan los syllabus incorporando } \\
\text { los resultados de sus investigaciones o los } \\
\text { resultados de investigaciones recientes en el tema. }\end{array}$ & Encuesta a docentes \\
\hline & $\mathrm{V}$ & $\begin{array}{l}\text { La organización de la universidad facilita la } \\
\text { investigación multidisciplinaria y centrada en } \\
\text { problemas }\end{array}$ & $\begin{array}{l}\text { Encuesta a docentes } \\
\text { Entrevistas a directivos de la maestría y directivos de la } \\
\text { universidad. } \\
\text { Revisión documental (Reglamento de Organización y } \\
\text { Funciones de la Universidad). }\end{array}$ \\
\hline & $\mathrm{W}$ & $\begin{array}{l}\text { Los docentes participan en proyectos de } \\
\text { investigación con financiamiento externo (nacional } \\
\text { o internacional) }\end{array}$ & $\begin{array}{l}\text { Encuesta a docentes } \\
\text { Entrevistas a directivos de la maestría y directivos de la } \\
\text { universidad. } \\
\text { Revisión documental (proyectos y contratos). }\end{array}$ \\
\hline & $\mathrm{X}$ & $\begin{array}{l}\text { Las asignaturas promueven la transdisciplinariedad } \\
\text { y la innovación }\end{array}$ & $\begin{array}{l}\text { Encuesta a estudiantes, docentes y egresados. } \\
\text { Entrevista a directivos de la maestría. } \\
\text { Revisión documental (plan de estudios) }\end{array}$ \\
\hline & $\mathrm{Y}$ & $\begin{array}{l}\text { Se utiliza un enfoque de aprendizaje basado en } \\
\text { proyectos }\end{array}$ & Encuesta a estudiantes, docentes y egresados. \\
\hline
\end{tabular}

Fuente: Elaboración propia 


\subsection{IMPLEMENTACIÓN DEL MODELO}

\subsubsection{Estructuración}

Gráfico 4.3. Estructuración de la evaluación de la pertinencia de maestrías en ingeniería.

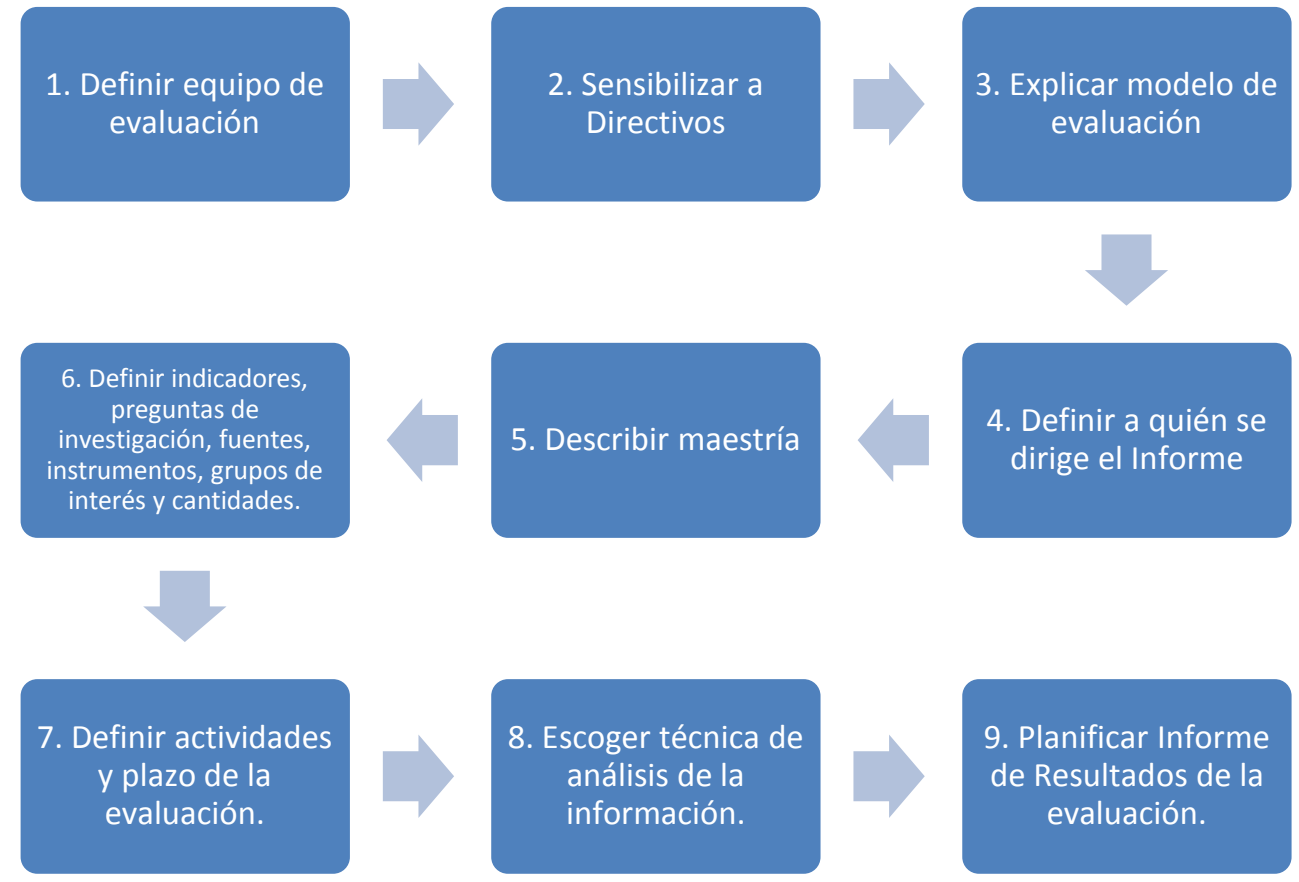

Fuente: Elaboración propia

La organización de la evaluación tiene los siguientes pasos:

1. Definir el equipo de evaluación (o el encargado de la evaluación). El Responsable debe ser un profesional externo a la maestría, ajeno a la gestión y control del programa, con las competencias necesarias y que entienda perfectamente el modelo de evaluación a aplicar.

2. Sostener reuniones de sensibilización con la dirección y la comisión académica de la maestría. Debe quedar claro el por qué y para qué de la evaluación: generar una experiencia de aprendizaje con fines de mejora continua y sostenibilidad de la maestría. Se necesita un compromiso y liderazgo del director de la maestría y de la comisión académica para llevar adelante este proceso.

3. Explicar el modelo de evaluación (fundamentos, objetivos, factores, indicadores, etc.) a la comisión académica y las partes interesadas que se considere conveniente. Se trata de una 
evaluación intermedia que pone énfasis en los procesos pero que se complementa con una evaluación de resultados.

4. Definir a quién se presentará el informe de evaluación: sólo a la dirección de la maestría o también a la dirección del departamento, de la facultad (o escuela) y de la universidad.

5. Describir las características de la maestría a evaluar: si es profesional o de investigación, si es a tiempo completo o a tiempo parcial, el tiempo de funcionamiento, las estrategias pensadas a futuro para la maestría, para el departamento, para la universidad, etc.

6. Definir los indicadores a utilizar, las preguntas de investigación, las fuentes de verificación, los instrumentos de recogida de información (encuestas, entrevistas, etc.), los grupos de interés (estudiantes, docentes, egresados, empleadores, directivos, etc) y el número de personas en cada grupo de interés. Se debe definir a qué directivos se va a entrevistar: director de la maestría, decano y vicedecano de investigación y postgrado de la facultad de ingeniería, gerente administrativo, vicerrector de investigación y rector de la universidad, entre otros.

7. Planificar las actividades de recogida de la información y el plazo para culminar la evaluación hasta la presentación del informe. Debido que generalmente el número de personas en cada grupo es relativamente bajo (menor que o cercano a 100), se empleará un muestreo no probabilístico por conveniencia, es decir, se recogerá información de la mayor cantidad posible de personas. En el caso de estudiantes, las encuestas se pueden aplicar en un momento de la clase. En el caso de los egresados y los empleadores, se puede aplicar una encuesta on line. Considerando que la tasa de respuesta on line es usualmente baja, se debe llamar por teléfono para recordarles que deben llenar la encuesta enviada por email. En el caso de los docentes se puede aplicar una encuesta on line a todos y reforzar con entrevista a aquellos que se considere conveniente, por el aporte que puedan hacer a la investigación.

8. Escoger la técnica de análisis de la información. Como se utiliza una escala Likert en las encuestas se recomienda presentar los resultados con gráficos de barra y mostrar la respuesta más frecuente, agrupando las categorías ${ }^{37}$. Luego comparar las respuestas a una misma pregunta por grupos diferentes. Identificar los indicadores donde hay coincidencia de una alta pertinencia entre los diferentes grupos, los indicadores donde hay coincidencia de una baja pertinencia y aquellos indicadores donde es necesaria una revisión posterior.

\footnotetext{
37 Se puede agrupar la categoría "Muy de acuerdo" con "De acuerdo" y "Muy en desacuerdo" con "En desacuerdo".
} 
Para ello es necesaria la triangulación de los resultados y la técnica propuesta se explica en el apartado 3.3.3.

9. Planificar el informe de resultados de la evaluación. Se recomienda presentar los resultados utilizando la clasificación de factores de pertinencia: Pertinencia Personal, Pertinencia Institucional, Pertinencia Social y Pertinencia Global. Se debe indicar las fortalezas y debilidades de la maestría en cada factor. Las recomendaciones deben incluir las acciones que se deben emprender para superar las debilidades y aprovechar las fortalezas de modo que se garantice la pertinencia y por tanto la calidad de la maestría. Considerar también recomendaciones para el diseño de nuevas maestrías en el departamento académico.

\subsubsection{Observación}

El modelo propone recoger información para describir un programa que ya está funcionando en relación a un aspecto de éste, la pertinencia. Esta descripción debe estar orientada por los indicadores y fuentes de verificación propuestos.

Se recoge información de dos tipos de fuentes: 1) fuentes primarias: estudiantes, docentes, egresados, empleadores, directivos de la maestría y directivos de la universidad; y 2) fuentes secundarias: análisis documental. La mayor parte de la información recogida se puede cuantificar con la aplicación de encuestas tipo Likert, pero hay información de tipo cualitativa que se recoge en las entrevistas y que complementa a la información cuantitativa.

Debido que los grupos de personas a los que están dirigidas las encuestas y las entrevistas son muy reducidos, se emplea un muestreo no probabilístico por conveniencia, recogiendo información de la mayor cantidad de personas posible. Los resultados de la aplicación de estos instrumentos sólo permiten extraer conclusiones de tipo descriptivo.

Para garantizar la validez interna de las encuestas se debe tener mucho cuidado de redactar bien las afirmaciones utilizadas, de modo que se mida lo que realmente se quiere medir (Patton, M.Q., 2002).

Existen otras técnicas para la recogida de información como los grupos focales, el análisis de conversación, las observaciones, la etnografía y el meta análisis pero que no se están considerando en la presente investigación. 


\subsubsection{Encuestas}

Las preguntas de investigación para las encuestas a estudiantes, docentes, egresados y empleadores se muestran en la Tabla 4.5.

Tabla 4.5. Preguntas de evaluación - Encuestas

\begin{tabular}{|c|c|c|c|c|c|}
\hline tog & Pregunta & 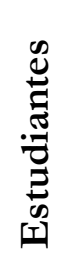 & 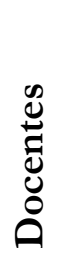 & 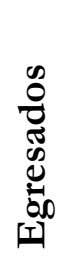 & 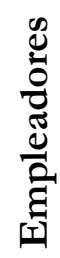 \\
\hline $\mathrm{A}$ & $\begin{array}{l}\text { ¿Los conocimientos adquiridos en la maestría ayudaron a un } \\
\text { mejor desempeño laboral? }\end{array}$ & $\mathrm{x}$ & & $\mathrm{x}$ & $\mathrm{x}$ \\
\hline $\mathrm{B}$ & $\begin{array}{l}\text { ¿Los temas dictados durante la maestría se relacionan con los } \\
\text { temas del trabajo o son de interés del estudiante? }\end{array}$ & $\mathrm{x}$ & & $\mathrm{x}$ & \\
\hline $\mathrm{C}$ & $\begin{array}{l}\text { ¿Funciona un sistema de seguimiento al desempeño de } \\
\text { egresados? }\end{array}$ & & & $x$ & \\
\hline $\mathrm{D}$ & $\begin{array}{l}\text { ¿Cursar la maestría ayudó a mejorar la situación laboral del } \\
\text { egresado (recibir un aumento de salario, un ascenso u obtener } \\
\text { un mejor empleo)? }\end{array}$ & & & $\mathrm{x}$ & \\
\hline $\mathrm{E}$ & $\begin{array}{l}\text { ¿La actualización de los syllabus considera la opinión de } \\
\text { estudiantes y egresados? }\end{array}$ & & $\mathrm{x}$ & & \\
\hline $\mathrm{H}$ & $\begin{array}{l}\text { ¿Los docentes (tiempo completo o tiempo parcial) han } \\
\text { publicado algún paper en ISI, Scopus o Scient Direct } \\
\text { utilizando el nombre de la universidad, en los dos últimos } \\
\text { años? }\end{array}$ & & $\mathrm{x}$ & & \\
\hline K & $\begin{array}{l}\text { ¿Hay correspondencia entre la misión y objetivos de la } \\
\text { maestría con el plan de estudios de la maestría? }\end{array}$ & $\mathrm{x}$ & & $\mathrm{x}$ & \\
\hline $\mathrm{M}$ & $\begin{array}{l}\text { ¿La maestría aprovecha las oportunidades locales y nacionales } \\
\text { para beneficio de sus estudiantes y docentes? }\end{array}$ & $\mathrm{x}$ & $\mathrm{x}$ & $\mathrm{x}$ & $\mathrm{x}$ \\
\hline $\mathrm{O}$ & $\begin{array}{l}\text { ¿El plan de estudios ayuda a satisfacer necesidades reales de la } \\
\text { localidad y del país? }\end{array}$ & $\mathrm{x}$ & & $\mathrm{x}$ & \\
\hline $\mathrm{P}$ & $\begin{array}{l}\text { ¿Los proyectos de fin de máster tienen aplicación o resuelven } \\
\text { problemas en las empresas? }\end{array}$ & & & $\mathrm{x}$ & $\mathrm{x}$ \\
\hline $\mathrm{R}$ & $\begin{array}{l}\text { ¿La maestría cuenta con un comité consultivo integrado por } \\
\text { representantes de los principales grupos de interés? }\end{array}$ & & & & $\mathrm{x}$ \\
\hline S & $\begin{array}{l}\text { ¿Los docentes participan en redes o asociaciones científicas y } \\
\text { profesionales? }\end{array}$ & & $x$ & & \\
\hline $\bar{T}$ & ¿Los docentes poseen movilidad académica? & & $\mathrm{x}$ & & \\
\hline $\mathrm{U}$ & $\begin{array}{l}\text { ¿Los docentes actualizan los syllabus incorporando los } \\
\text { resultados de sus investigaciones o los resultados de } \\
\text { investigaciones recientes en el tema? }\end{array}$ & & $\mathrm{x}$ & & \\
\hline $\mathrm{V}$ & $\begin{array}{l}\text { ¿ La organización de la universidad facilita la investigación } \\
\text { multidisciplinaria y centrada en problemas? }\end{array}$ & & $\mathrm{x}$ & & \\
\hline W & $\begin{array}{l}\text { ¿Los docentes participan en proyectos de investigación con } \\
\text { financiamiento externo (nacional o internacional)? }\end{array}$ & & $\mathrm{x}$ & & \\
\hline
\end{tabular}




\begin{tabular}{|c|c|c|c|c|c|}
\hline 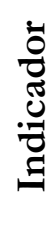 & Pregunta & 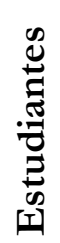 & 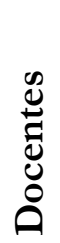 & 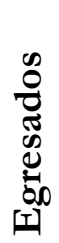 & $\frac{\stackrel{\infty}{0}}{\frac{0}{0}}$ \\
\hline $\mathrm{X}$ & $\begin{array}{l}\text { ¿Las asignaturas promueven la transdisciplinariedad y la } \\
\text { innovación? }\end{array}$ & $\mathrm{x}$ & $\mathrm{x}$ & $\mathrm{x}$ & \\
\hline $\mathrm{Y}$ & ¿Se utiliza un enfoque de aprendizaje basado en proyectos? & $\mathrm{x}$ & $\mathrm{x}$ & $\mathrm{x}$ & \\
\hline & TOTAL & 7 & 10 & 10 & 4 \\
\hline
\end{tabular}

Fuente: Elaboración propia

A los cuatro grupos de interés (estudiantes, docentes, egresados y empleadores) se les debe pedir que indiquen su nivel de acuerdo con las declaraciones contenidas en los indicadores de pertinencia establecidos en el modelo. Con estos resultados el investigador está en capacidad de evaluar si estos grupos consideran que la formación recibida es adecuada en cada uno de los factores de pertinencia de la maestría.

De acuerdo con Puerzer \& Rooney (2002) la encuesta para cada grupo se diseña haciendo la misma pregunta, cuando corresponde, y ofreciendo las mismas alternativas para responderla. Esto es importante para luego poder triangular la información.

En los Anexos A, B, C y D se muestran las encuestas para estudiantes, docentes, egresados y empleadores respectivamente. Se utiliza la escala de Likert para que sea fácil la agregación y la comparación de resultados.

\subsubsection{Entrevistas a directivos}

Con la entrevista a directivos de la maestría y directivos de la universidad se busca obtener información de tipo cualitativo para complementar la información obtenida a través de encuestas y obtener las fuentes de información para el análisis documental de acuerdo al modelo. Se trata de indagar sobre el nivel de pertinencia de la maestría teniendo como referencia los indicadores mostrados en el apartado 3.2.2. Se propone una entrevista semi estructurada con las preguntas mostradas en la Tabla 4.6. 
Tabla 4.6. Preguntas de evaluación - Entrevistas

\begin{tabular}{|c|c|c|c|}
\hline 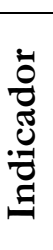 & Pregunta & 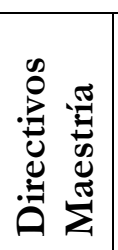 & 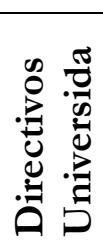 \\
\hline $\mathrm{C}$ & ¿Funciona un sistema de seguimiento al desempeño de egresados? & $\mathrm{x}$ & $\mathrm{x}$ \\
\hline $\mathrm{F}$ & ¿Número de alumnos de la maestría? & $\mathrm{x}$ & \\
\hline G & ¿Ratio admitidos/postulantes? & $\mathrm{x}$ & \\
\hline $\mathrm{I}$ & $\begin{array}{l}\text { ¿La misión, objetivos y estrategias de la maestría son coherentes con la } \\
\text { misión, objetivos y estrategias de la Universidad? }\end{array}$ & $\mathrm{x}$ & $x$ \\
\hline $\mathrm{J}$ & $\begin{array}{l}\text { ¿La gestión de la maestría se desarrolla de acuerdo a las políticas y } \\
\text { procedimientos de trabajo de la Universidad? }\end{array}$ & $\mathrm{x}$ & $\mathrm{x}$ \\
\hline $\bar{K}$ & $\begin{array}{l}\text { ¿Existe correspondencia entre la misión y objetivos de la maestría con el } \\
\text { plan de estudios? }\end{array}$ & $\mathrm{x}$ & \\
\hline $\mathrm{L}$ & $\begin{array}{l}\text { ¿La universidad ofrece programas de pregrado o especialización } \\
\text { relacionados con la maestría? }\end{array}$ & $\mathrm{x}$ & \\
\hline $\mathrm{M}$ & $\begin{array}{l}\text { ¿La maestría aprovecha las oportunidades locales y nacionales para } \\
\text { beneficio de sus estudiantes y docentes? }\end{array}$ & $x$ & $x$ \\
\hline $\mathrm{N}$ & $\begin{array}{l}\text { ¿El plan de estudios se relaciona con las prioridades de desarrollo local o } \\
\text { nacional? }\end{array}$ & $\mathrm{x}$ & $\mathrm{x}$ \\
\hline $\mathrm{P}$ & $\begin{array}{l}\text { ¿Los proyectos de fin de máster tienen aplicación o resuelven problemas } \\
\text { en las empresas? }\end{array}$ & $x$ & \\
\hline Q & $\begin{array}{l}\text { ¿Existen relaciones efectivas con programas similares de otras } \\
\text { universidades, empresas, agencias gubernamentales, ONG, entre otros? }\end{array}$ & $x$ & \\
\hline $\mathrm{R}$ & $\begin{array}{l}\text { ¿La maestría cuenta con un comité consultivo integrado por } \\
\text { representantes de los principales grupos de interés? }\end{array}$ & $x$ & $x$ \\
\hline S & $\begin{array}{l}\text { ¿Los docentes participan en redes o asociaciones científicas y } \\
\text { profesionales? }\end{array}$ & $\mathrm{x}$ & $\mathrm{x}$ \\
\hline$\overline{\mathrm{T}}$ & ¿Los docentes poseen movilidad académica? & $\mathrm{x}$ & $\mathrm{x}$ \\
\hline $\mathrm{V}$ & $\begin{array}{l}\text { ¿La organización de la universidad facilita la investigación } \\
\text { multidisciplinaria y centrada en problemas? }\end{array}$ & $\mathrm{x}$ & $\mathrm{x}$ \\
\hline $\mathrm{W}$ & $\begin{array}{l}\text { ¿Los docentes participan en proyectos de investigación con } \\
\text { financiamiento externo (nacional o internacional)? }\end{array}$ & $x$ & $x$ \\
\hline $\mathrm{X}$ & ¿Las asignaturas promueven la transdisciplinariedad y la innovación? & $\mathrm{x}$ & \\
\hline $\mathrm{Y}$ & ¿Se utiliza un enfoque de aprendizaje basado en proyectos? & $\mathrm{x}$ & \\
\hline & TOTAL & 17 & 8 \\
\hline
\end{tabular}

Fuente: Elaboración propia

En los Anexos E y F se tiene las guías de entrevistas a directivos de la maestría y directivos de la universidad respectivamente. 


\subsubsection{Análisis documental}

Se trata de obtener información de fuentes secundarias, teniendo como referencia los indicadores de evaluación. Los documentos que se pueden revisar son:

- Informes Anuales de la maestría.

- Plan de estudios de la maestría.

- Página web de la maestría.

- Planes de desarrollo regional elaborados por el Gobierno.

- Planes nacionales de Competitividad

- Planes nacionales para el desarrollo de la ciencia, la tecnología y la Innovación.

- Convenios con otras instituciones para el desarrollo del postgrado.

- Reglamento de Organización y Funciones de la universidad.

- Manual de Organización y Funciones de la universidad.

- Ideario de la universidad o documento declarativo de la misión y valores.

- Contratos e informes de proyectos de investigación de docentes de la maestría. 


\subsubsection{Análisis de la información}

Se puede triangular la información recogida tomando como referencia el trabajo de (Pappas, Kampe, Hendricks, \& Kander, 2004) generando "gráficos de cuadrante" con los resultados de ciertos indicadores de pertinencia de la maestría y comparar el nivel de acuerdo entre dos grupos de interés. Los gráficos deben estar divididos con una línea vertical y una horizontal en el valor promedio de los indicadores analizados en el gráfico. Un ejemplo se tiene en el Gráfico 4.4.

\section{Gráfico 4.4. Ejemplo de Gráfico de Cuadrante}

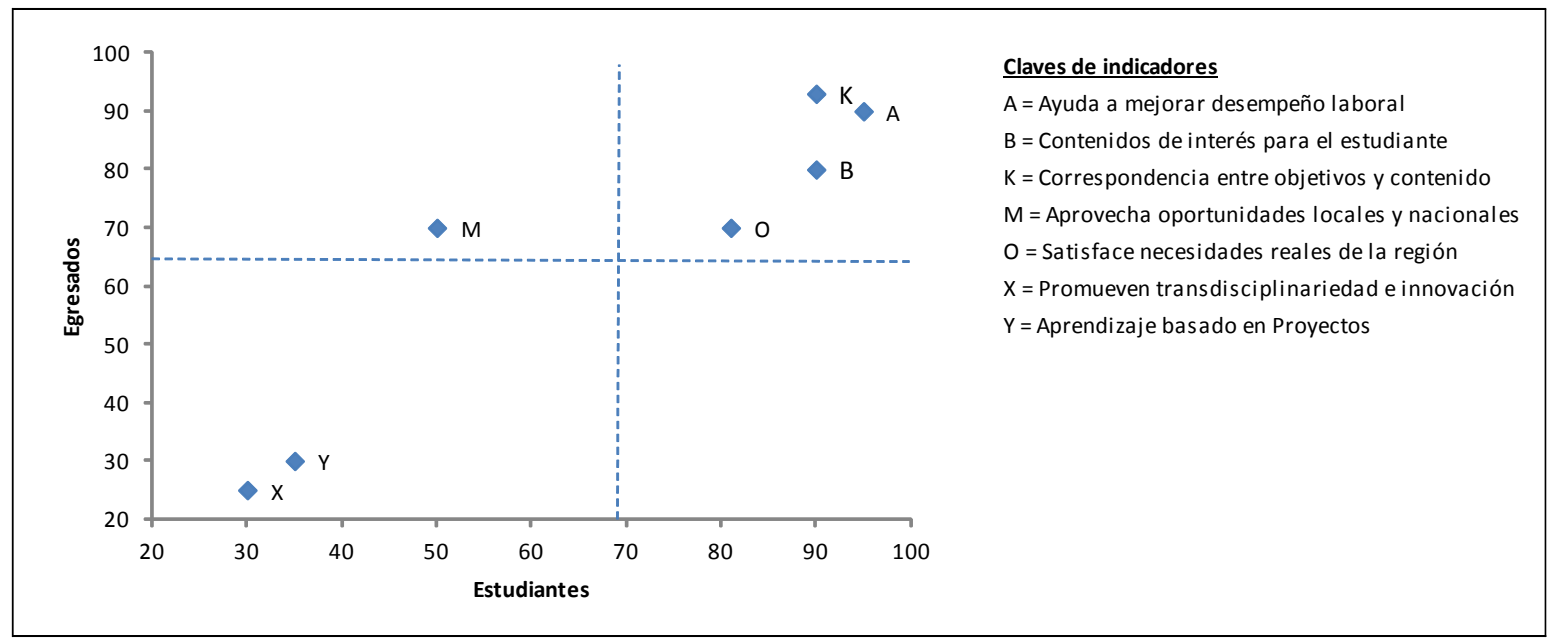

Fuente: Elaboración propia

Los cuadros resultantes muestran los cuatro cuadrantes y puede interpretarse de la siguiente manera:

La acción requerida para una mejora continua del programa será diferente dependiendo de dónde se ubicó cada indicador analizado. Dicho gráfico permite identificar rápidamente qué necesidades e intereses de los estudiantes y empleadores están siendo adecuadamente atendidos y cuáles no.

Se recomienda elaborar un gráfico de cuadrante para comparar los resultados obtenidos de los estudiantes y los egresados. Los indicadores comunes son siete: A,B,K,M,O,X,Y. 
Tabla 4.7. Análisis de la información - Técnica de los Gráficos de Cuadrante.

\begin{tabular}{|c|c|c|}
\hline Cuadrante & Característica & Interpretación \\
\hline $\begin{array}{l}\text { Cuadrante } \\
\text { suroeste }\end{array}$ & $\begin{array}{l}\text { Coincidencia en la } \\
\text { percepción de una } \\
\text { baja pertinencia }\end{array}$ & $\begin{array}{l}\text { Los resultados de las evaluaciones incluidas en este } \\
\text { cuadrante indican que los grupos que se están } \\
\text { contrastando están de acuerdo en que existen } \\
\text { deficiencias en la atención de algunas de sus } \\
\text { necesidades o intereses (indicadores de pertinencia del } \\
\text { programa de maestría). }\end{array}$ \\
\hline $\begin{array}{l}\text { Cuadrante } \\
\text { noreste }\end{array}$ & $\begin{array}{l}\text { Coincidencia en la } \\
\text { percepción de una } \\
\text { alta pertinencia }\end{array}$ & $\begin{array}{l}\text { Los resultados de las evaluaciones incluidas en este } \\
\text { cuadrante revelan contundentemente que se están } \\
\text { atendiendo necesidades e intereses reales de los } \\
\text { grupos que se están contrastando ya que están de } \\
\text { acuerdo en esos aspectos del programa de maestría. } \\
\text { Este es el cuadrante óptimo para una maestría con } \\
\text { pertinencia. }\end{array}$ \\
\hline $\begin{array}{l}\text { Cuadrantes } \\
\text { sudeste y } \\
\text { noroeste }\end{array}$ & $\begin{array}{l}\text { Es necesaria una } \\
\text { revisión }\end{array}$ & $\begin{array}{l}\text { Los resultados de las evaluaciones incluidas en estos } \\
\text { cuadrantes revelan que es necesaria una revisión de la } \\
\text { forma en que se ha hecho la evaluación. Asimismo } \\
\text { permite averiguar también, en caso de que la } \\
\text { evaluación haya sido correctamente diseñada, que hay } \\
\text { que revisar las estrategias, actividades y objetivos de la } \\
\text { maestría en los aspectos analizados. }\end{array}$ \\
\hline
\end{tabular}

Fuente: Elaboración propia a partir de (Pappas, Kampe, Hendricks, \& Kander, 2004)

Para comparar los resultados de otros grupos de interés como estudiantes y docentes, docentes y egresados, etc., se pueden elaborar tablas donde se pueda visualizar el grado de coincidencia de las respuestas en las encuestas.

Hay algunos indicadores que sólo tienen una fuente de verificación y por tanto no se puede hacer la triangulación. En ese caso, en el informe de resultados de la evaluación se debe indicar el valor obtenido para el indicador. Si se tratara de un indicador cualitativo se debe indicar el porcentaje que está muy de acuerdo o simplemente de acuerdo con la afirmación utilizada en la encuesta para dicho indicador. Por ejemplo, indicar el porcentaje de docentes 
que respondieron estar de acuerdo o muy de acuerdo con la afirmación: "La organización de la universidad facilita la investigación multidisciplinaria y centrada en problemas".

El sesgo en la investigación se minimiza designado como responsable de la evaluación a un profesional externo a la maestría.

\subsubsection{Juicio}

El juicio se estructura de acuerdo a los factores de pertinencia identificados por el modelo de evaluación: Pertinencia Personal, Pertinencia Institucional, Pertinencia Social y Pertinencia Global. Para cada una de estas dimensiones, se debe indicar primero los resultados de los indicadores que tienen coincidencia en la percepción (de una baja o de una alta pertinencia), luego se debe presentar los indicadores que tienen menor coincidencia. En este último caso se debe indicar las actividades que se realizaron para acercarnos más al valor real de estos indicadores y cuáles fueron los resultados obtenidos.

Con esto se obtiene un juicio general acerca del nivel de pertinencia de la maestría y se puede dar recomendaciones para mejorar los puntos débiles y mantener los puntos fuertes, a la luz de la información recogida y analizada.

El informe debe incluir también algunas recomendaciones para el departamento académico considerando que la maestría no se encuentra aislada, sino que se encuentra dentro de un sistema de producción de conocimiento. Finalmente el informe debe considerar recomendaciones a tener en cuenta en el diseño de nuevas maestrías.

\subsection{CONCLUSIONES DEL CAPÍTULO IV}

La pertinencia es importante en dos momentos de un programa de maestría: al inicio (en el diseño) y durante su ejecución. Es importante identificar bien las necesidades e intereses reales de los beneficiarios y las partes interesadas para que los objetivos del programa se adecúen a ellos.

En la presente investigación se considera una maestría que ya está funcionando y ya tiene egresados, por tanto se trata de la evaluación de la pertinencia de un programa en su etapa de realización. El modelo propuesto trata de generar una experiencia de aprendizaje entre los principales grupos de interés de la maestría: estudiantes, docentes, directivos, egresados y 
empleadores con el fin de mejorar un aspecto de la maestría, la pertinencia. Es por tanto, una evaluación de tipo Intermedia, Temática, Formativa y Externa.

El modelo asume que las competencias establecidas por el programa de maestría siguen siendo válidas en el momento de la evaluación de la pertinencia. Por tanto no se considera el levantamiento de información para verificar si son adecuadas o no las competencias definidas por el programa ${ }^{38}$.

Existen dos subprocesos: "assessment" y "evaluation”. Assessment consiste en la recogida de información de acuerdo a los indicadores y fuentes de verificación y Evaluation consiste en la interpretación y emisión de un juicio respecto de la pertinencia de la maestría, a cargo de las personas encargadas.

Las principales características del modelo son: la participación, el aprendizaje, la sencillez y la complementariedad de las fuentes: primarias y secundarias y los enfoques: cualitativo y cuantitativo.

Los indicadores de evaluación propuestos en el modelo están agrupados en cuatro factores de pertinencia coherentes con la definición de pertinencia de una maestría en ingeniería. Los factores son: factor de pertinencia personal, factor de pertinencia institucional, factor de pertinencia social y factor de pertinencia global.

Estos indicadores consideran los conceptos, características y tendencias de: la pertinencia de la educación superior, el Modo 2 de Gibbons y la metodología GESPLAN para la producción de conocimiento, la formación de postgrado en ingeniería así como los criterios de evaluación e indicadores de los organismos internacionales, los organismos latinoamericanos y los organismos peruanos de acreditación. Estos últimos son revisados con la lupa de la pertinencia. En la Tabla 4.4. Se detallan los 25 indicadores que componen el modelo y sus respectivas fuentes de verificación.

Antes de efectuarse la evaluación, ésta debe planificarse. La estructuración del proceso de evaluación debe responder a las preguntas ¿quién va a evaluar?, ¿qué va a evaluar?, ¿para qué?, ¿cómo?, ¿con qué?, ¿a quién va a dirigir el informe de resultados y las recomendaciones?, ¿a quiénes y cuántos se va a encuestar o entrevistar?, ¿cómo se va a analizar la información?, entre otras.

\footnotetext{
${ }^{38}$ Se puede considerar las competencias propuestas por ABET o IPMA para los programas de formación en ingeniería.
} 
Es muy importante definir las preguntas de la investigación porque éstas orientarán los instrumentos de recojo de información. Si bien en el presente modelo se recomienda el uso de encuestas, entrevistas y análisis documental, también podría agregarse, si se considera conveniente, el uso de otras técnicas como los grupos focales y las observaciones, entre otras. El modelo ya contiene unos modelos de encuestas y guías de entrevista, de acuerdo a los indicadores planteados.

El modelo permite triangular información, es decir comparar los resultados obtenidos para un mismo indicador a partir de diferentes fuentes de información. De esta forma se puede tener mayor certeza en el valor obtenido para un indicador si hay coincidencia en la percepción entre diferentes grupos de interés (estudiantes, docentes, egresados y empleadores). Por ello se recomienda el análisis de la información utilizando los gráficos de cuadrante explicados en el apartado 4.3.3.

Se recomienda estructurar el informe de resultados de la evaluación de acuerdo a los factores de pertinencia, empezando con las fortalezas del programa establecidas por los indicadores con valor alto y coincidencia alta. Luego presentar los indicadores con valor bajo y coincidencia alta para finalmente presentar los indicadores que no arrojaron mucha coincidencia entre los grupos de interés y aquellos indicadores que no se pueden triangular.

Lo más importante en el proceso de evaluación es identificar las acciones que se deben emprender para mejorar o sostener el nivel de pertinencia de la maestría encontrado utilizando como referencia el presente modelo. 


\subsection{BIBLIOGRAFÍA DEL CAPÍTULO IV}

AUIP (2009). Evaluación de Programas de Postgrado - Guia de Autoevaluación. Recuperado el junio de 2014, de www.auip.org

Diaz-Puente, J. (2003). Tesis Doctoral. Diseño y aplicación de un modelo para el seguimiento y evaluación del Desarrollo Rural en la UE. Madrid.

Olds, B., Moskal, B., \& Miller, R. (2005). “Assessment in engineering education: Evolution, approaches and collaborations". Journal of Engineering Education, 94, 1, 13-25.

Pappas, E., Kampe, S., Hendricks, R., \& Kander, R. (2004). “An Assessment Analysis Methodology and Its Application to an Advanced Engineering Communications Program". Journal of Engineering Education, 233 - 246.

Patton, M.Q. (2002). Qualitative Evaluation and Research Methods, 3rd ed. Thousand Oaks, CA: Sage Publications, 2002.

Puerzer, R.; Rooney, D. (2002). "The Alumni Survey as an Effective Assessment Tool for Small Engineering Programs”. Journal of Engineering Education, 109 - 116. 
Capítulo V

Aplicación del modelo de evaluación de la pertinencia en la Universidad de Piura,

Perú 


\section{Capítulo V \\ Aplicación del modelo de evaluación de la pertinencia en la Universidad de Piura, Perú}

El modelo de evaluación de la pertinencia descrito en el capítulo anterior fue aplicado en la maestría en Ingeniería Civil con mención en Ingeniería Vial de la Universidad de Piura. El objetivo fue extraer lecciones de experiencia de estos casos concretos de estudio para su replicación en otras maestrías. Se siguió los pasos establecidos en el capítulo anterior, apartado 3.3.1. Estructuración de la evaluación. Se utilizó las encuestas, las guías de entrevista, la técnica para el análisis de la información y las recomendaciones para la elaboración del informe, planteadas en el capítulo III.

El análisis de la información y el juicio fue efectuado a partir de los resultados de las encuestas, las entrevistas y el análisis documental, teniendo como referencia los factores de pertinencia. Se valoró si la maestría tenía una alta, media o baja pertinencia personal, pertinencia institucional, pertinencia social y pertinencia global. Las recomendaciones de mejora se obtuvieron de los mismos indicadores del modelo de evaluación utilizado.

\subsection{ESTRUCTURACIÓN}

La maestría en Ingeniería Civil con mención en Ingeniería Vial es una maestría profesional, no es de investigación y se dicta a tiempo parcial. Las clases son quincenales: viernes de 05:30 p.m a 10:30 p.m y sábado de 08:30 a.m a 01:30 p.m. Los alumnos de la maestría alternan el trabajo con el estudio. La inversión total es 30 mil nuevos soles (8,100 euros aprox.). El programa dura 4 ciclos (2 años).

La maestría busca que el egresado esté capacitado para el diseño, construcción y gestión de carreteras, con conocimientos básicos en Ingeniería de Transportes. Es importante su participación en la toma de decisiones dirigidas a presupuestos y planificación de obra para el diseño, la supervisión y la construcción de vías, pues será capaz de incorporar nuevas tecnologías y materiales o crear nuevas alternativas, acordes con la realidad local específica (UDEP, 2014). 
Este programa inició en el año 2003 y ya tiene cinco promociones de egresados. Cuenta con 25 docentes (15 de la Universidad de Piura y 10 de universidades extranjeras).

Se designó como responsable de la evaluación al doctorando, Erick Miñán Ubillús, que es ingeniero industrial por la Universidad de Piura, es profesor universitario del curso en Dirección de Proyectos y Algebra Lineal en la Udep, campus Piura y es externo a la maestría. Asimismo tiene experiencia en las áreas de organización y métodos, logística y gestión de proyectos (de alcance nacional y financiamiento externo en el sector público).

Se tuvo reuniones de sensibilización con la dirección y la comisión académica de la maestría. Se definió como objetivo de la evaluación generar una experiencia de aprendizaje con fines de mejora continua y sostenibilidad. El director de la maestría asumió el compromiso y liderazgo para llevar adelante este proceso.

Se explicó el modelo de evaluación (fundamentos, objetivos, factores, indicadores, etc.) a la comisión académica de la maestría y al Decano de la Facultad de Ingeniería. Se acordó que el informe de evaluación sería presentado al Director de la maestría y al Decano.

Se acordó utilizar todos los indicadores planteados en el modelo así como las preguntas de investigación, las fuentes de verificación, los modelos de encuestas y las guías de entrevista. Los directivos de la universidad que se acordó entrevistar fueron: el Decano de la Facultad de Ingeniería, la Vice Decana de Investigación y Postgrado de la Facultad de Ingeniería, La Gerente General y el Rector de la universidad.

La población correspondiente a los grupos de interés se muestra en la Tabla 5.1

Tabla 5.1. Población de los grupos de interés - Maestría en Ingeniería Vial

\begin{tabular}{lc}
\hline Grupo & Población \\
\hline Estudiantes 2012-2014 & 40 \\
Docentes & 25 \\
Egresados & 128 \\
Empleadores & 40 \\
Directivos de maestría & 1
\end{tabular}

Aplicación del modelo de evaluación de la pertinencia en la Universidad de Piura, Perú 
Fuente: Dirección de la maestría en Ingeniería Vial

El contexto socio económico de Piura y de Perú se ha descrito en los apartados 2.1.2. y 2.1.3. Después de Lima, Piura es el departamento más poblado de Perú y un polo de desarrollo junto a Arequipa y Trujillo. El contexto es de crecimiento económico sostenido y disminución de la pobreza en los últimos diez años, con deficiencias en educación superior, ciencia, tecnología e innovación y con dificultades para atender el creciente mercado laboral con personal competente.

El contexto institucional de la maestría, dado por la Universidad de Piura, se describe en el apartado 2.2.3. La Universidad de Piura es una organización privada sin fines de lucro. Es una obra de apostolado corporativo del Opus Dei. Se inspira en una concepción humanista y cristiana de la vida, promueve la fe católica y los valores cristianos dentro de un clima de respeto a la libertad de los alumnos. Fue fundada en 1969 (tiene 45 años) y es considerada una de las 10 mejores universidades de Perú según el Ránking de América Economía Intelligence (América Economía, 2013).

Es importante indicar que si bien el Consejo de Evaluación, Acreditación y Certificación de la Calidad de la Educación Superior Universitaria - CONEAU ha definido un modelo de calidad para maestrías, la acreditación de maestrías en Perú no es obligatoria.

El plazo otorgado para la evaluación fue de tres meses: abril, mayo y junio de 2014. Debido que el número de personas en cada grupo es bajo (menor que o cercano a 100), se escogió un muestreo no probabilístico por conveniencia, es decir, recoger información de la mayor cantidad posible de personas. Fue correcto hacer esto porque la valoración que se buscaba era de tipo descriptivo.

Para la presentación de resultados se acordó utilizar como marco los factores de pertinencia: personal, institucional, social y global, de acuerdo a lo planteado en el modelo de evaluación. Se trianguló los resultados obtenidos para un mismo indicador utilizando fuentes diferentes utilizando el Gráfico de Cuadrante descrito en el apartado 4.3.3. y tablas. Se acordó que el informe debía incluir acciones para mejorar los aspectos de la maestría que denotaran baja pertinencia y recomendaciones de cara al lanzamiento de nuevas maestrías en el departamento académico.

Aplicación del modelo de evaluación de la pertinencia en la Universidad de Piura, Perú 


\subsection{OBSERVACIÓN}

\subsubsection{Resultados de encuestas}

Se utilizó las encuestas incluidas en el modelo de evaluación propuesto en el capítulo III. Fueron validadas previamente por expertos de la Universidad de Piura y fueron probadas con una muestra pequeña de estudiantes, egresados y empleadores. Las encuestas fueron aplicadas entre abril y junio de 2014. Debido al reducido número de personas en cada grupo se utilizó un muestreo no probabilístico por conveniencia, es decir se buscó encuestar a la mayor cantidad posible de personas.

El total de personas que respondieron la encuesta en cada grupo de interés se muestra en la Tabla 5.2.

En el caso de estudiantes, las encuestas se aplicaron en clase. En el caso de los docentes, egresados y empleadores la encuesta fue on line. Se envió un correo electrónico indicando las instrucciones para llenar la encuesta y el link hacia la plataforma Google Drive. Considerando que usualmente la tasa de respuesta on line es baja, se decidió llamar por teléfono para recordarles que debían llenar la encuesta enviada por email.

Tabla 5.2. Total de personas que respondieron la encuesta.

\begin{tabular}{lc}
\hline Grupo & Población \\
\hline Estudiantes año 2014 & 31 \\
Docentes & 20 \\
Egresados & 36 \\
Empleadores & 15 \\
\hline
\end{tabular}

Fuente: Elaboración propia

En el caso de los docentes, además de la encuesta on line se reforzó con entrevista a algunos docentes del campus Piura, por el aporte en información cualitativa que podían hacer a la investigación. En el caso de los empleadores se contactó con aquellos cuyos datos pudieron proporcionar los estudiantes que no han cambiado de empleo desde que empezaron a estudiar la maestría.

De acuerdo con los resultados de la encuesta, la población de estudiantes, que está en su segundo año de maestría, se compone de la siguiente manera: el 84\% trabaja en el sector construcción, el 77\% de ellos se desempeña en el área de Ingeniería o en el área de Proyectos 
de la empresa, todos son ingenieros civiles (equivalente a ingeniero de Caminos, Canales y puertos en España). Las tres cuartas partes, $74 \%$ son egresados de universidades cercanas a la ciudad de Piura (Piura, Lambayeque y Cajamarca). Y el 42\% son trabajadores independientes (autónomos) o son dueños de una pequeña empresa donde trabajan. La población de egresados es muy parecida.

El 35\% de los docentes tiene grado de doctor, y el 65\% tiene grado de magíster. El 60\% son de la Universidad de Piura y el 40\% son de otras universidades, todas extranjeras. Todos trabajan en una universidad pero están ligados al entorno profesional a través de servicios de consultoría y/o proyectos de investigación, no hay ningún docente de la maestría que pertenezca sólo al sector empresarial. El 85\% son ingenieros civiles (o su equivalente en el extranjero).

Las instituciones donde trabajan los egresados se compone de la siguiente manera: $80 \%$ son empresas privadas (incluye a los que tienen su propia empresa) y $20 \%$ son entidades públicas. El 82\% pertenece al sector construcción, el 69\% tiene menos de 50 trabajadores y el 93\% se encuentran ubicadas en ciudades cercanas a la ciudad de Piura.

Las respuestas a las preguntas sobre la pertinencia de la maestría se muestran en la Tablas 5.3, 5.4, 5.5 y 5.6. Se ha agrupado las categorías "Muy de acuerdo" con "De acuerdo" y "Muy en desacuerdo" con "En desacuerdo".

Si bien el análisis de cada indicador se presenta en el apartado 5.3. se puede apreciar que la mayoría de estudiantes, docentes, egresados y empleadores están de acuerdo o muy de acuerdo con las declaraciones, lo que implica una alta pertinencia de la maestría. Hay algunos aspectos a mejorar pero éstos se analizan más adelante.

Para mostrar los resultados por indicador se han construido gráficos de barra.

Aplicación del modelo de evaluación de la pertinencia en la Universidad de Piura, Perú 
Tabla 5.3. Resultados de la encuesta a ESTUDIANTES - Maestría en Ingeniería Civil con mención en Ingeniería Vial

\begin{tabular}{|c|c|c|c|c|c|}
\hline Factor & $\mathbf{N}^{\circ}$ & Pregunta & $\begin{array}{c}\text { Muy en } \\
\text { desacuerdo o } \\
\text { en } \\
\text { Desacuerdo }\end{array}$ & $\begin{array}{c}\text { Ni de } \\
\text { acuerdo ni } \\
\text { en } \\
\text { desacuerdo }\end{array}$ & $\begin{array}{c}\text { Muy de } \\
\text { acuerdo o } \\
\text { De acuerdo }\end{array}$ \\
\hline \multirow[t]{2}{*}{$\begin{array}{c}\text { Pertinencia } \\
\text { Personal }\end{array}$} & A & $\begin{array}{l}\text { Los conocimientos adquiridos en la maestría ayudaron a un } \\
\text { mejor desempeño laboral. }\end{array}$ & $0 \%$ & $0 \%$ & $100 \%$ \\
\hline & $\mathrm{B}$ & $\begin{array}{l}\text { Los temas dictados durante la maestría se relacionan con los } \\
\text { temas del trabajo o son de interés del estudiante. }\end{array}$ & $0 \%$ & $3 \%$ & $97 \%$ \\
\hline $\begin{array}{l}\text { Pertinencia } \\
\text { Institucional }\end{array}$ & $\bar{K}$ & $\begin{array}{l}\text { Existe correspondencia entre la misión y objetivos de la } \\
\text { maestría con el plan de estudios. }\end{array}$ & $0 \%$ & $10 \%$ & $90 \%$ \\
\hline \multirow[t]{2}{*}{$\begin{array}{c}\text { Pertinencia } \\
\text { Social }\end{array}$} & $\mathrm{M}$ & $\begin{array}{l}\text { La maestría aprovecha las oportunidades locales y nacionales } \\
\text { para beneficio de sus estudiantes y docentes. }\end{array}$ & $0 \%$ & $23 \%$ & $77 \%$ \\
\hline & $\mathrm{O}$ & $\begin{array}{l}\text { El plan de estudios ayuda a satisfacer necesidades reales de la } \\
\text { localidad y del país. }\end{array}$ & $3 \%$ & $16 \%$ & $81 \%$ \\
\hline \multirow{2}{*}{$\begin{array}{c}\text { Pertinencia } \\
\text { Global }\end{array}$} & $\mathrm{X}$ & $\begin{array}{l}\text { Las asignaturas promueven la transdisciplinariedad y la } \\
\text { innovación. }\end{array}$ & $0 \%$ & $10 \%$ & $90 \%$ \\
\hline & $\bar{Y}$ & Se utiliza un enfoque de aprendizaje basado en proyectos. & $0 \%$ & $19 \%$ & $81 \%$ \\
\hline
\end{tabular}

Fuente: Elaboración propia 
Tabla 5.4. Resultados de la encuesta a DOCENTES - Maestría en Ingeniería Civil con mención en Ingeniería Vial

\begin{tabular}{|c|c|c|c|c|c|}
\hline Factor & $\mathbf{N}^{\circ}$ & Pregunta & $\begin{array}{c}\text { Muy en } \\
\text { desacuerdo o } \\
\text { en } \\
\text { Desacuerdo }\end{array}$ & $\begin{array}{l}\text { Ni de } \\
\text { acuerdo ni } \\
\text { en } \\
\text { desacuerdo }\end{array}$ & $\begin{array}{c}\text { Muy de } \\
\text { acuerdo o } \\
\text { De acuerdo }\end{array}$ \\
\hline $\begin{array}{c}\text { Pertinencia } \\
\text { Personal }\end{array}$ & $\mathrm{E}$ & $\begin{array}{l}\text { La actualización de los syllabus considera la opinión de } \\
\text { estudiantes y egresados. }\end{array}$ & $0 \%$ & $40 \%$ & $60 \%$ \\
\hline $\begin{array}{l}\text { Pertinencia } \\
\text { Institucional }\end{array}$ & $\mathrm{H}$ & $\begin{array}{l}\text { Los docentes (tiempo completo o tiempo parcial) han } \\
\text { publicado algún paper en ISI, Scopus o Scient Direct } \\
\text { utilizando el nombre de la universidad, en los dos últimos } \\
\text { años. }\end{array}$ & $10 \%$ & $35 \%$ & $55 \%$ \\
\hline $\begin{array}{l}\text { Pertinencia } \\
\text { Social }\end{array}$ & $\mathrm{M}$ & $\begin{array}{l}\text { La maestría aprovecha las oportunidades locales y nacionales } \\
\text { para beneficio de sus estudiantes y docentes. }\end{array}$ & $0 \%$ & $10 \%$ & $90 \%$ \\
\hline \multirow{7}{*}{$\begin{array}{l}\text { Pertinencia } \\
\text { Global }\end{array}$} & $\mathrm{S}$ & $\begin{array}{l}\text { Los docentes participan en redes o asociaciones científicas y } \\
\text { profesionales. }\end{array}$ & $0 \%$ & $5 \%$ & $95 \%$ \\
\hline & $\mathrm{T}$ & Los docentes poseen movilidad académica. & $0 \%$ & $20 \%$ & $80 \%$ \\
\hline & $\mathrm{U}$ & $\begin{array}{l}\text { Los docentes actualizan los syllabus incorporando los } \\
\text { resultados de sus investigaciones o los resultados de } \\
\text { investigaciones recientes en el tema. }\end{array}$ & $0 \%$ & $5 \%$ & $95 \%$ \\
\hline & $\mathrm{V}$ & $\begin{array}{l}\text { La organización de la universidad facilita la investigación } \\
\text { multidisciplinaria y centrada en problemas. }\end{array}$ & $30 \%$ & $40 \%$ & $30 \%$ \\
\hline & W & $\begin{array}{l}\text { Los docentes participan en proyectos de investigación con } \\
\text { financiamiento externo (nacional o internacional). }\end{array}$ & $30 \%$ & $25 \%$ & $45 \%$ \\
\hline & $\mathrm{X}$ & $\begin{array}{l}\text { Las asignaturas promueven la transdisciplinariedad y la } \\
\text { innovación. }\end{array}$ & $0 \%$ & $10 \%$ & $90 \%$ \\
\hline & $\mathrm{Y}$ & Se utiliza un enfoque de aprendizaje basado en proyectos. & $10 \%$ & $0 \%$ & $90 \%$ \\
\hline
\end{tabular}

Fuente: Elaboración propia

Aplicación del modelo de evaluación de la pertinencia en la Universidad de Piura, Perú 
Tabla 5.5. Resultados de la encuesta a EGRESADOS - Maestría en Ingeniería Civil con mención en Ingeniería Vial

\begin{tabular}{|c|c|c|c|c|c|}
\hline Factor & $\mathbf{N}^{\circ}$ & Pregunta & $\begin{array}{c}\text { Muy en } \\
\text { desacuerdo o } \\
\text { en } \\
\text { Desacuerdo }\end{array}$ & $\begin{array}{c}\text { Ni de } \\
\text { acuerdo ni } \\
\text { en } \\
\text { desacuerdo }\end{array}$ & $\begin{array}{c}\text { Muy de } \\
\text { acuerdo o } \\
\text { De acuerdo }\end{array}$ \\
\hline \multirow{4}{*}{$\begin{array}{c}\text { Pertinencia } \\
\text { Personal }\end{array}$} & $\mathrm{A}$ & $\begin{array}{l}\text { Los conocimientos adquiridos en la maestría ayudaron a un } \\
\text { mejor desempeño laboral. }\end{array}$ & 0 & $6 \%$ & $94 \%$ \\
\hline & B & $\begin{array}{l}\text { Los temas dictados durante la maestría se relacionan con los } \\
\text { temas del trabajo o son de interés del estudiante. }\end{array}$ & 0 & $11 \%$ & $89 \%$ \\
\hline & $\mathrm{C}$ & $\begin{array}{l}\text { Funciona un sistema de seguimiento al desempeño de } \\
\text { egresados }\end{array}$ & $28 \%$ & $36 \%$ & $36 \%$ \\
\hline & $\mathrm{D}$ & $\begin{array}{l}\text { Cursar la maestría ayudó a mejorar la situación laboral del } \\
\text { egresado (recibir un aumento de salario, un ascenso u } \\
\text { obtener un mejor empleo). }\end{array}$ & $17 \%$ & $0 \%$ & $83 \%$ \\
\hline $\begin{array}{l}\text { Pertinencia } \\
\text { Institucional }\end{array}$ & $\mathrm{K}$ & $\begin{array}{l}\text { Existe correspondencia entre la misión y objetivos de la } \\
\text { maestría con el plan de estudios. }\end{array}$ & $0 \%$ & $8 \%$ & $92 \%$ \\
\hline \multirow{3}{*}{$\begin{array}{c}\text { Pertinencia } \\
\text { Social }\end{array}$} & $\mathrm{M}$ & $\begin{array}{l}\text { La maestría aprovecha las oportunidades locales y nacionales } \\
\text { para beneficio de sus estudiantes y docentes. }\end{array}$ & $11 \%$ & $0 \%$ & $89 \%$ \\
\hline & $\mathrm{O}$ & $\begin{array}{l}\text { El plan de estudios ayuda a satisfacer necesidades reales de la } \\
\text { localidad y del país. }\end{array}$ & $28 \%$ & $0 \%$ & $72 \%$ \\
\hline & $\bar{P}$ & $\begin{array}{l}\text { Los proyectos de fin de máster tienen aplicación o resuelven } \\
\text { problemas en las empresas. }\end{array}$ & $39 \%$ & $28 \%$ & $33 \%$ \\
\hline \multirow{2}{*}{$\begin{array}{c}\text { Pertinencia } \\
\text { Global }\end{array}$} & $\mathrm{X}$ & $\begin{array}{l}\text { Las asignaturas promueven la transdisciplinariedad y la } \\
\text { innovación. }\end{array}$ & $0 \%$ & $17 \%$ & $83 \%$ \\
\hline & $\mathrm{Y}$ & Se utiliza un enfoque de aprendizaje basado en proyectos. & $19 \%$ & $6 \%$ & $75 \%$ \\
\hline
\end{tabular}

Fuente: Elaboración propia

Aplicación del modelo de evaluación de la pertinencia en la Universidad de Piura, Perú 
Tabla 5.6. Resultados de la encuesta a EMPLEADORES - Maestría en Ingeniería Civil con mención en Ingeniería Vial

\begin{tabular}{cccccc}
\hline Factor & $\mathbf{N}^{\circ}$ & \multicolumn{1}{c}{ Pregunta } & $\begin{array}{c}\text { Muy en } \\
\text { desacuerdo o } \\
\text { en } \\
\text { Desacuerdo }\end{array}$ & $\begin{array}{c}\text { Ni de } \\
\text { acuerdo ni } \\
\text { en } \\
\text { desacuerdo }\end{array}$ & $\begin{array}{c}\text { Muy de } \\
\text { acuerdo o } \\
\text { De acuerdo }\end{array}$ \\
\hline $\begin{array}{c}\text { Pertinencia } \\
\text { Personal }\end{array}$ & $\mathrm{A}$ & $\begin{array}{l}\text { Los conocimientos adquiridos en la maestría ayudaron a un } \\
\text { mejor desempeño laboral. }\end{array}$ & $0 \%$ & $13 \%$ & $87 \%$ \\
\hline Pertinencia & $\mathrm{M}$ & $\begin{array}{l}\text { La maestría aprovecha las oportunidades locales y nacionales } \\
\text { para beneficio de sus estudiantes y docentes. }\end{array}$ & $13 \%$ & $20 \%$ & $67 \%$ \\
\cline { 2 - 6 } & $\mathrm{P}$ & $\begin{array}{l}\text { Los proyectos de fin de máster tienen aplicación o resuelven } \\
\text { problemas en las empresas. }\end{array}$ & $40 \%$ & $27 \%$ & $33 \%$ \\
\cline { 2 - 6 } & $\mathrm{R}$ & $\begin{array}{l}\text { La maestría cuenta con un comité consultivo integrado por } \\
\text { representantes de los principales grupos de interés. }\end{array}$ & $27 \%$ & $53 \%$ & $20 \%$ \\
\hline
\end{tabular}

Fuente: Elaboración propia 
$\underline{\text { Indicadores de Pertinencia personal: }}$

Gráfico 5.1. Indicador A - Los conocimientos adquiridos en la maestría ayudaron a un mejor desempeño laboral.

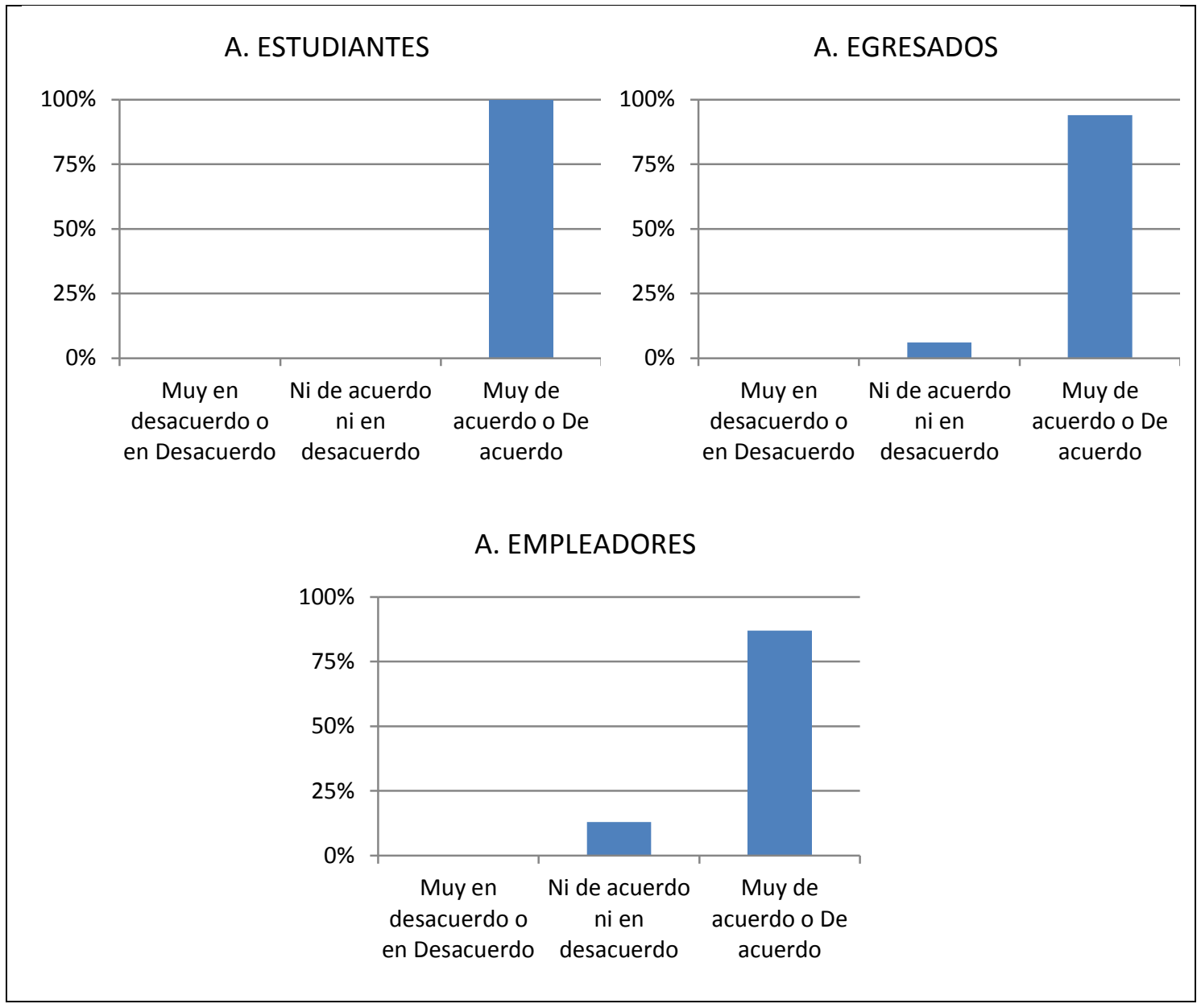

Aplicación del modelo de evaluación de la pertinencia en la Universidad de Piura, Perú 
Gráfico 5.2. Indicador B - Los temas dictados durante la maestría se relacionan con los temas del trabajo o son de interés del estudiante.

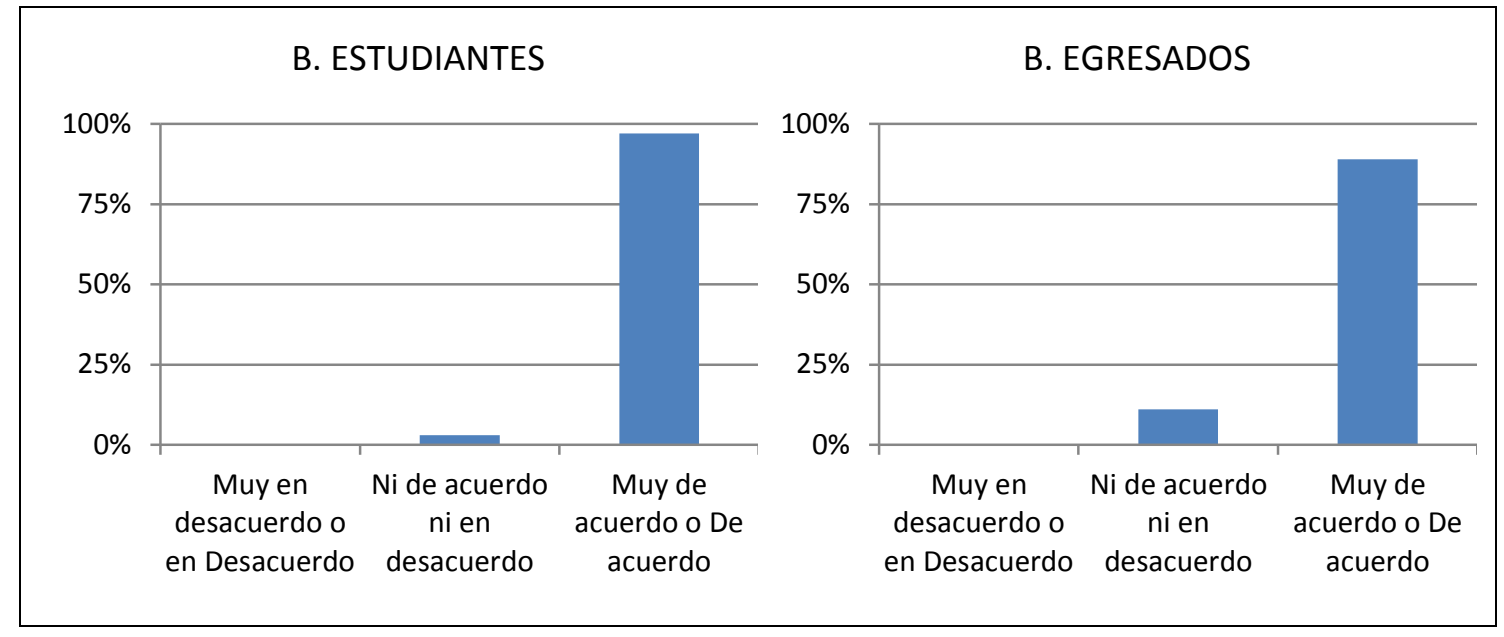

Gráfico 5.3. Indicador C - Funciona un sistema de seguimiento al desempeño de egresados.

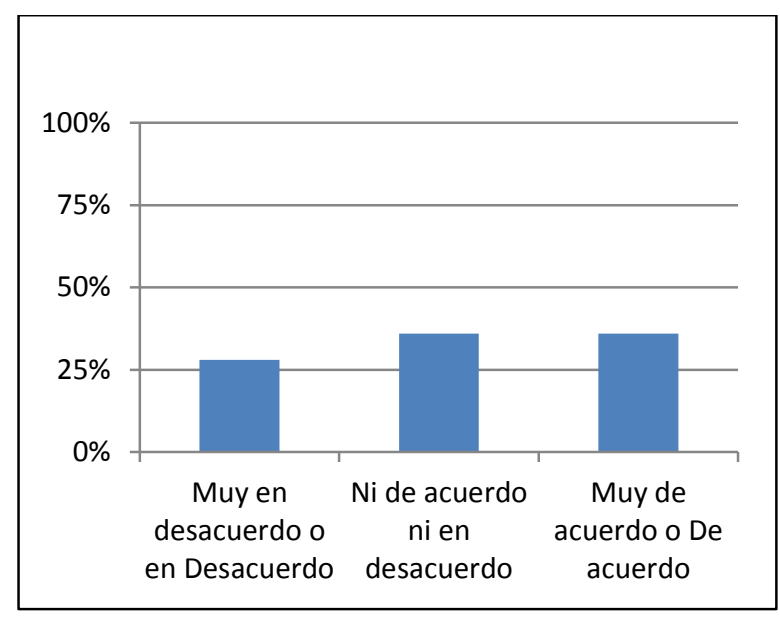

Aplicación del modelo de evaluación de la pertinencia en la Universidad de Piura, Perú 
Gráfico 5.4. Indicador D - Cursar la maestría ayudó a mejorar la situación laboral del egresado.

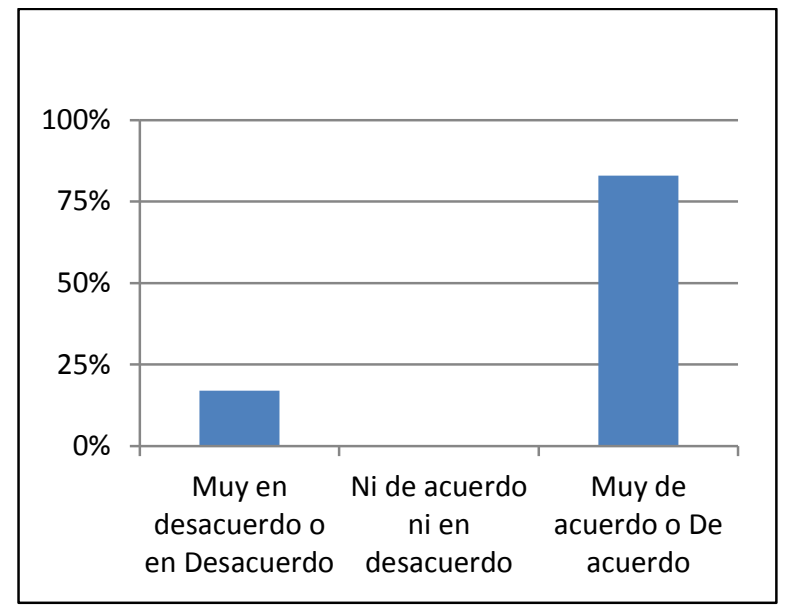

Gráfico 5.5. Indicador E - La actualización de los syllabus considera la opinión de estudiantes y egresados.

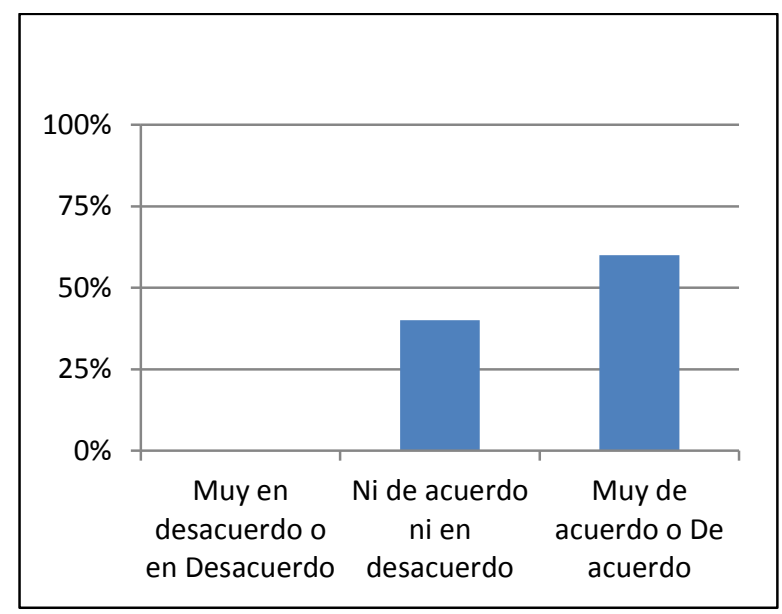

Aplicación del modelo de evaluación de la pertinencia en la Universidad de Piura, Perú 
Indicadores de Pertinencia Institucional:

Gráfico 5.6. Indicador H - Los docentes han publicado algún paper en ISI, Scopus o Scient Direct utilizando el nombre de la universidad, en los dos últimos años.

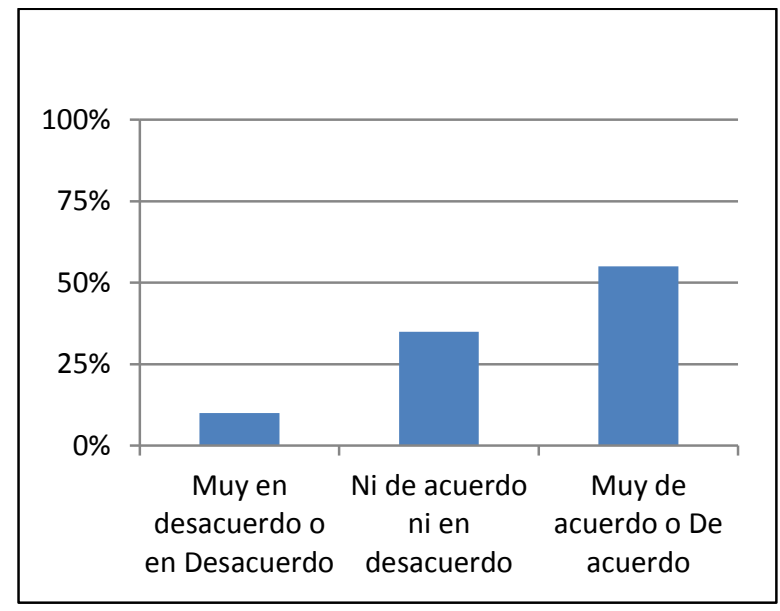

Gráfico 5.7. Indicador K - Existe correspondencia entre la misión y objetivos de la maestría con el plan de estudios.

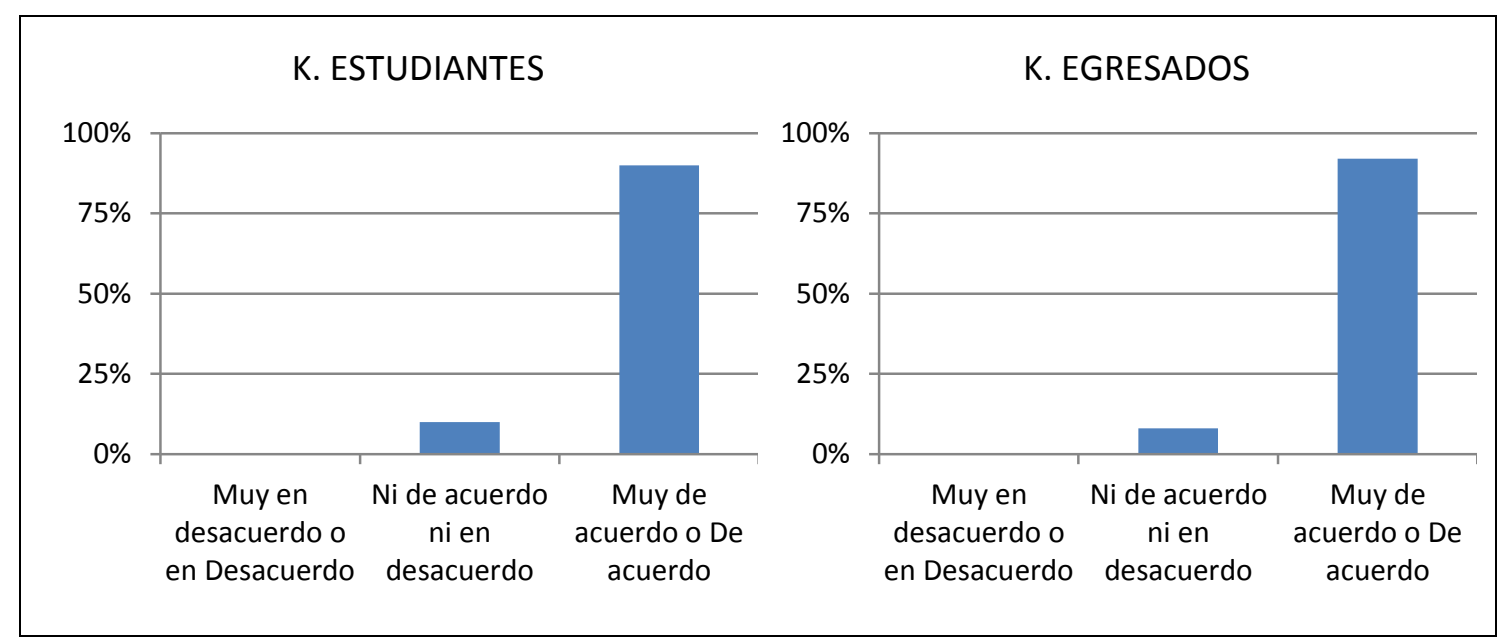

Aplicación del modelo de evaluación de la pertinencia en la Universidad de Piura, Perú 
Indicadores de Pertinencia Social:

Gráfico 5.8. Indicador M - La maestría aprovecha las oportunidades locales y nacionales para beneficio de sus estudiantes y docentes.

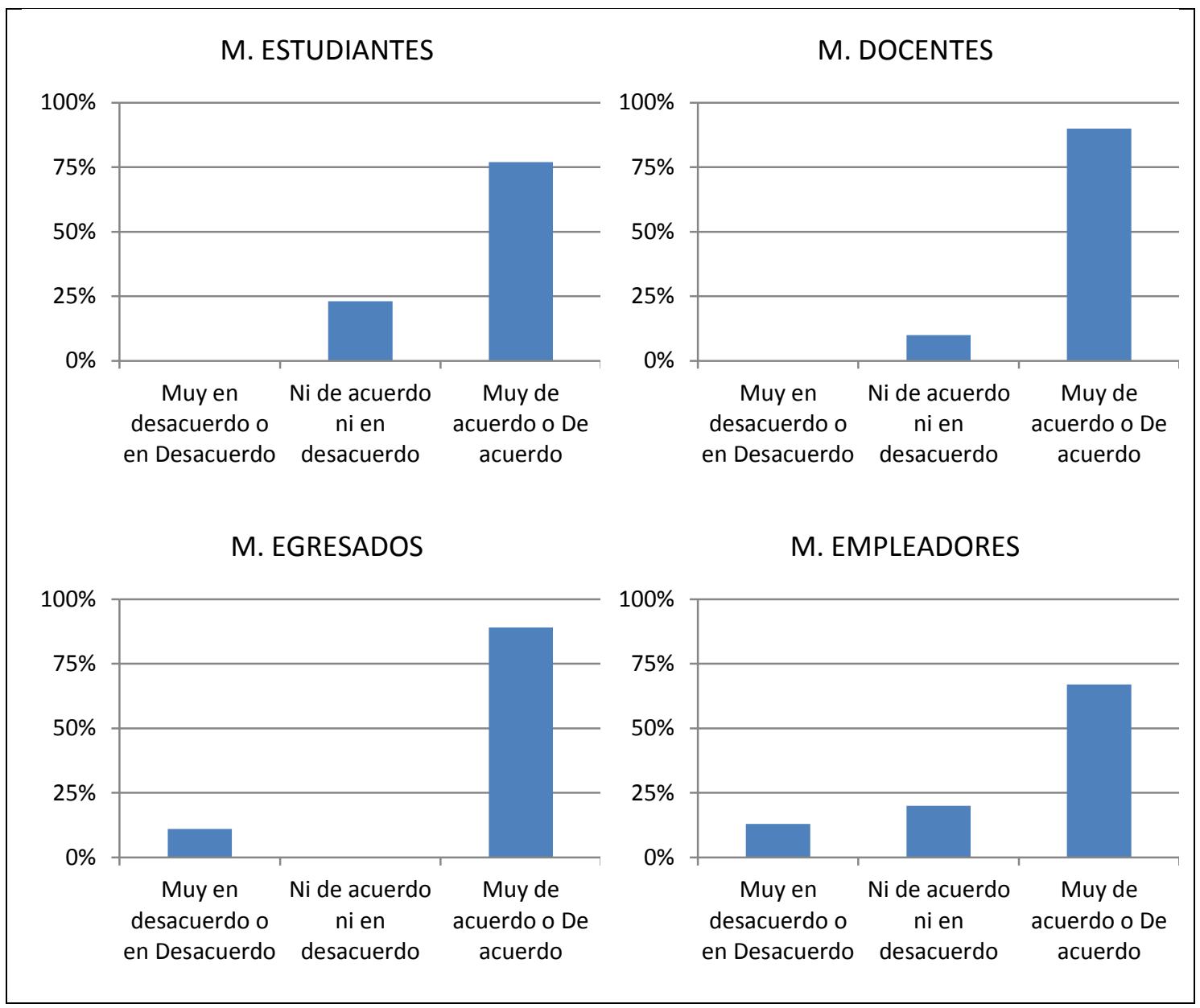

Aplicación del modelo de evaluación de la pertinencia en la Universidad de Piura, Perú 
Gráfico 5.9. Indicador $\mathrm{O}$ - El plan de estudios ayuda a satisfacer necesidades reales de la localidad y del país.

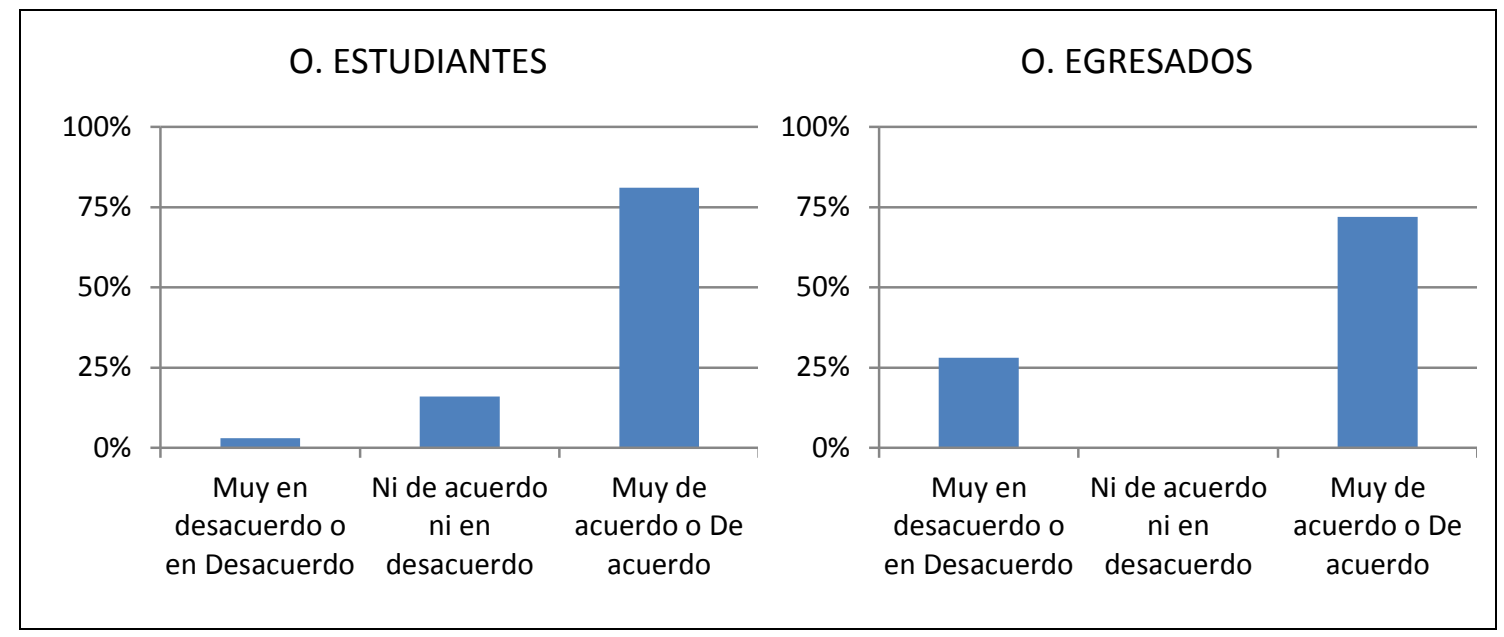

Gráfico 5.10. Indicador P - Los proyectos de fin de máster tienen aplicación o resuelven problemas en las empresas.

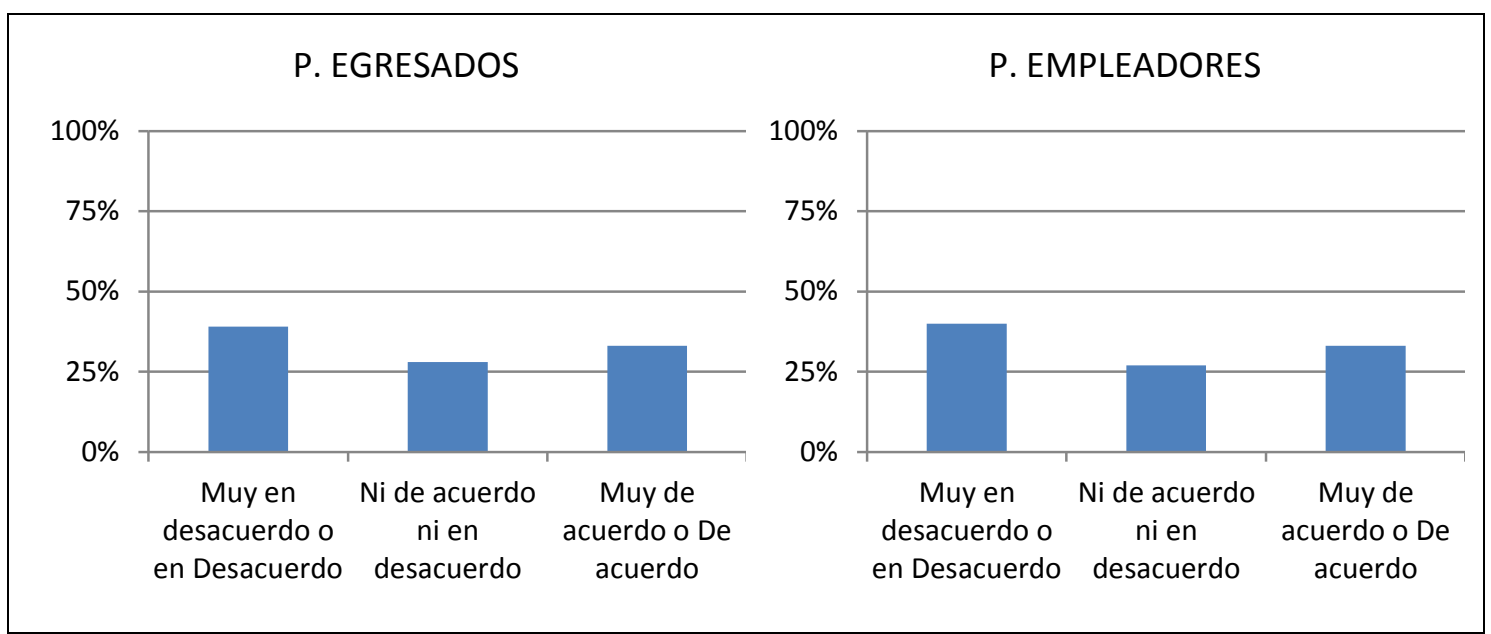


Gráfico 5.11. Indicador R - La maestría cuenta con un comité consultivo integrado por representantes de los principales grupos de interés.

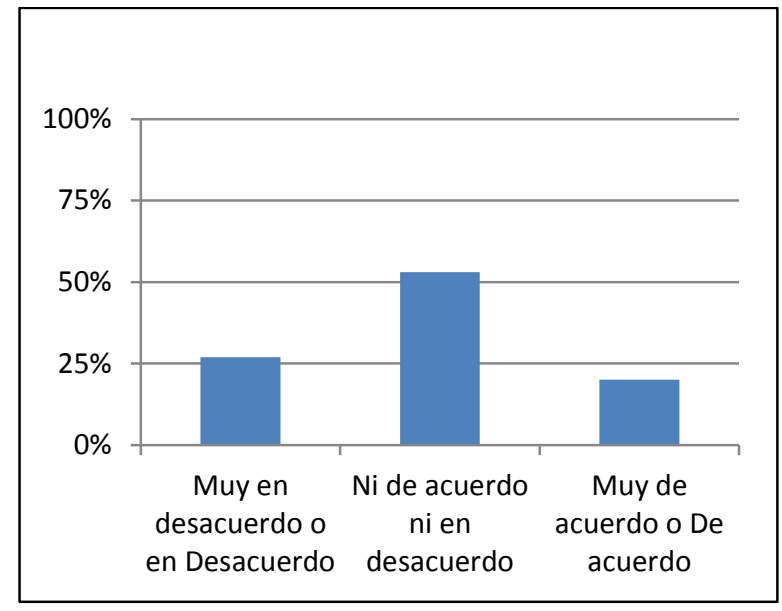

Indicadores de Pertinencia Global:

Gráfico 5.12. Indicador S - Los docentes participan en redes o asociaciones científicas y profesionales.

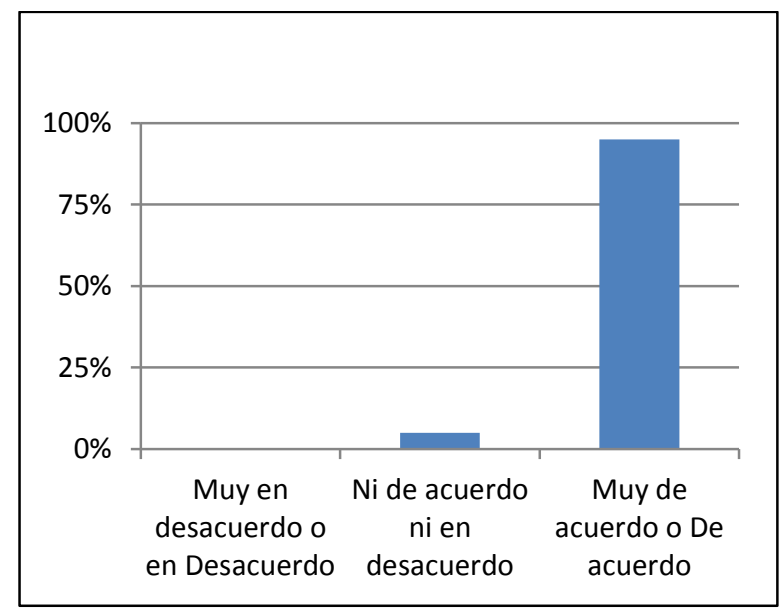

Aplicación del modelo de evaluación de la pertinencia en la Universidad de Piura, Perú 
Gráfico 5.13. Indicador T - Los docentes poseen movilidad académica.

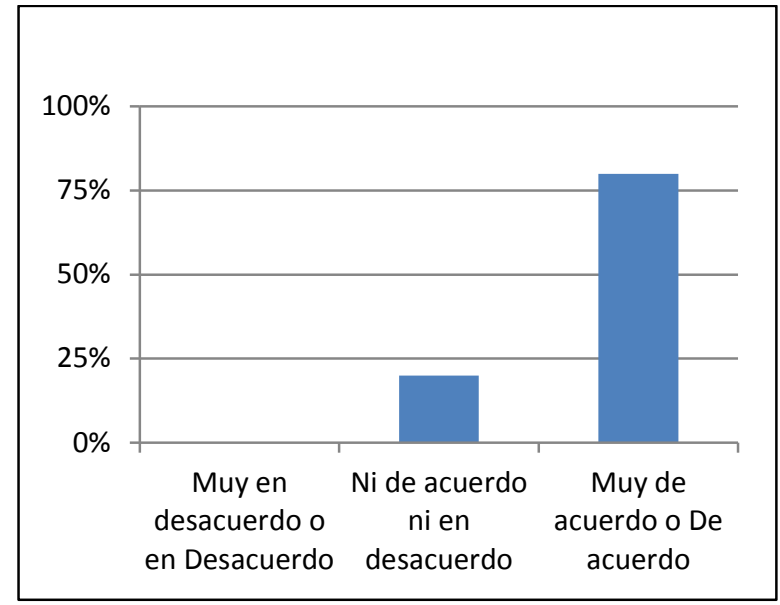

Gráfico 5.14. Indicador U - Los docentes actualizan los syllabus incorporando los resultados de sus investigaciones o los resultados de investigaciones recientes.

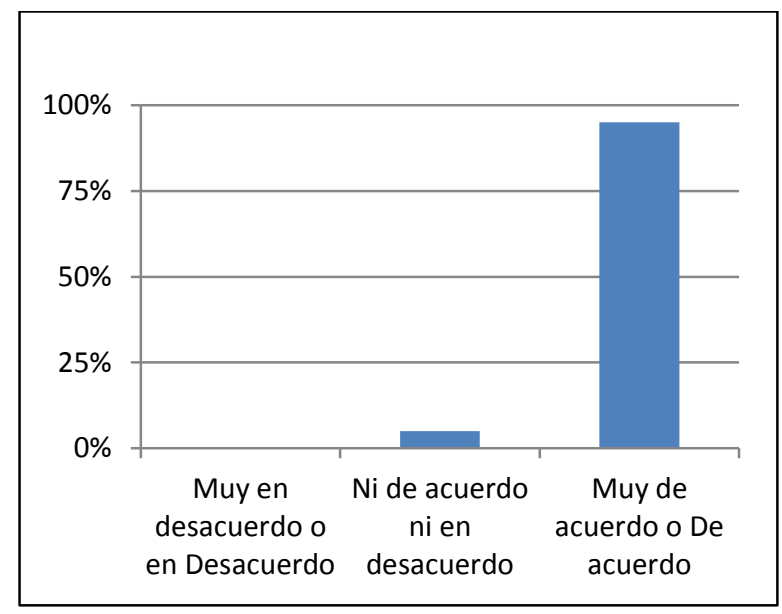


Gráfico 5.15. Indicador V - La organización de la universidad facilita la investigación multidisciplinaria y centrada en problemas.

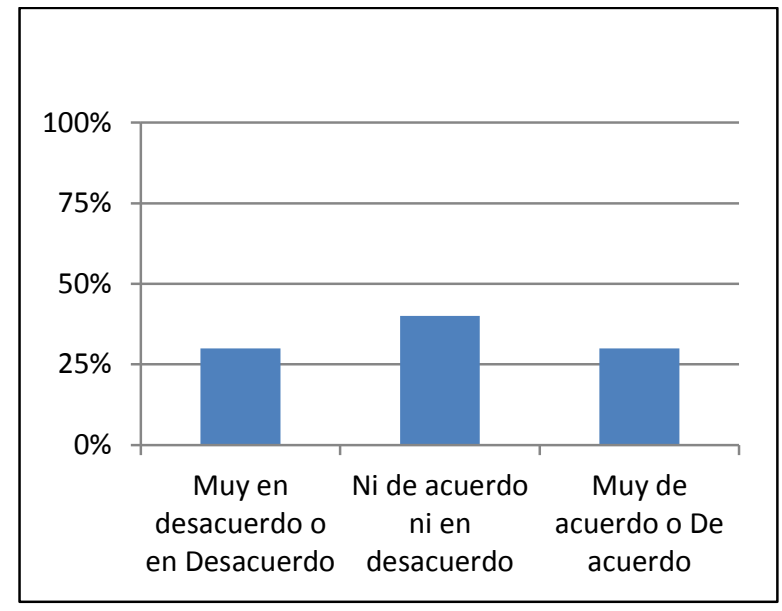

Gráfico 5.16. Indicador W - Los docentes participan en proyectos de investigación con financiamiento externo (nacional o internacional).

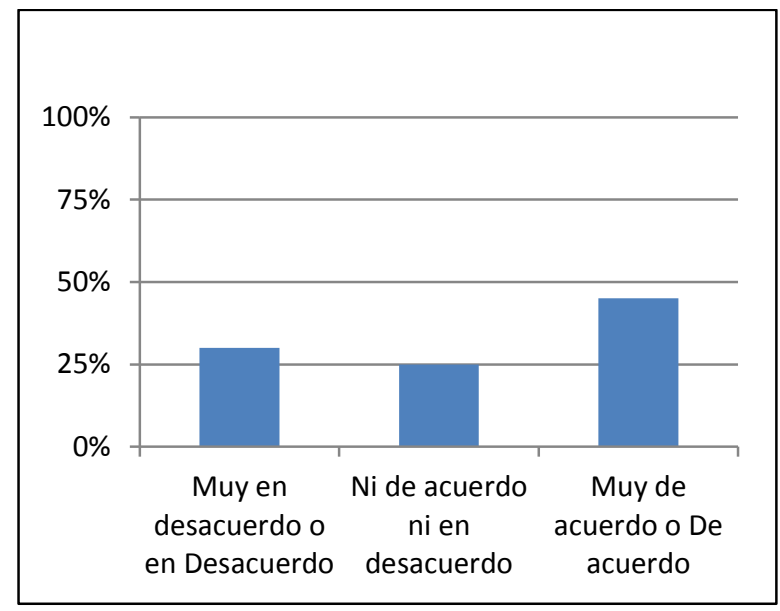


Gráfico 5.17. Indicador X - Las asignaturas promueven la transdisciplinariedad y la innovación.

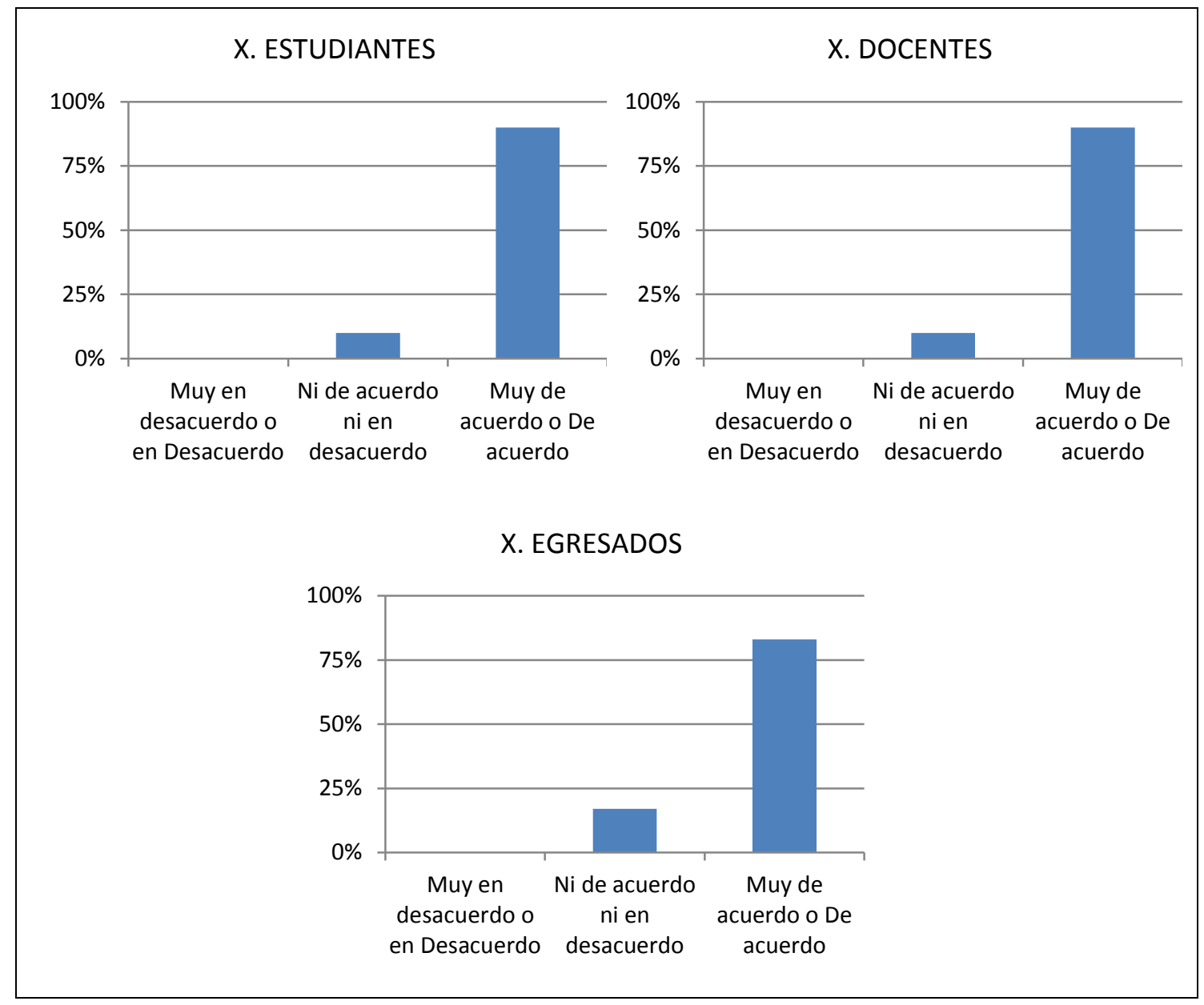


Gráfico 5.18. Indicador Y - Se utiliza un enfoque de aprendizaje basado en proyectos.

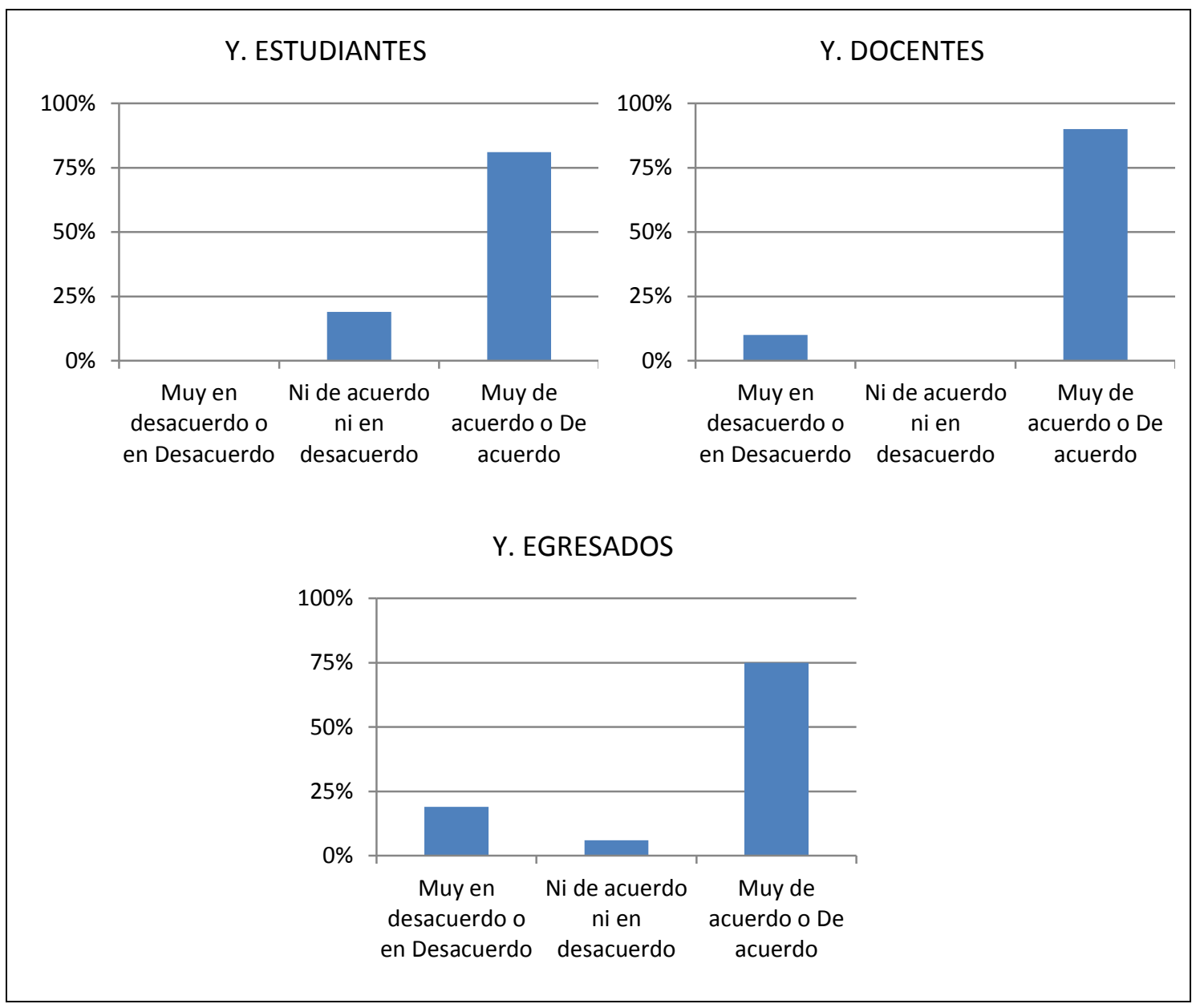

\subsubsection{Resultados de entrevistas}

Se entrevistó al Director de la maestría y a 4 directivos de la universidad: el Decano de la Facultad de Ingeniería, la Vice Decana de Investigación y Postgrado de la Facultad de Ingeniería, La Gerente General y el Rector de la universidad.

Las entrevistas fueron semi estructuradas, de acuerdo a la guía propuesta en el apartado 4.3.2.2. Como siempre hay al inicio, una resistencia natural a ser evaluado, por eso es importante recalcar el objetivo de la evaluación: la experiencia de aprendizaje y la mejora continua. Al final, las entrevistas se realizaron sin inconvenientes.

A continuación se presentan los resultados de las entrevistas realizadas. Cuando correspondía se hizo el cruce de información haciendo la revisión documental correspondiente. 
La maestría satisface una demanda educativa de la región. Antes de su lanzamiento se hicieron estudios de mercado para conocer la demanda de la maestría y se ha llegado a ocupar todas las vacantes ofrecidas en los años que viene funcionando. En la tabla se muestra el número de admitidos y matriculados en los años que viene funcionando la maestría.

Tabla 5.7. Maestría en Ingeniería Vial - Número de alumnos matriculados por año.

\begin{tabular}{cccc}
\hline Año & Postulantes & Admitidos & $\begin{array}{c}\text { Ratio postulantes } \\
\text { /admitidos }\end{array}$ \\
\hline 2003 & 35 & 27 & 1.29 \\
2004 & 30 & 23 & 1.30 \\
2009 & 35 & 27 & 1.29 \\
2011 & 45 & 39 & 1.15 \\
2012 & 45 & 40 & 1.12 \\
2014 & 40 & 30 & 1.33 \\
\hline
\end{tabular}

Fuente: Dirección de maestría en Ingeniería Vial - Udep

La misión, objetivos y valores de la maestría son coherentes con la misión, objetivos y estrategias de la Universidad. Un claro ejemplo es la inclusión en el plan de estudios de los módulos: "Persona, Familia y Empresa", mostrando coherencia con la formación humanística y en valores que promueve la universidad (Universidad de Piura, 2008). Este enfoque lo tienen todas las maestrías de la Universidad de Piura.

La gestión de la maestría sí se desarrolla de acuerdo a las políticas y procedimientos de trabajo de la Universidad (Universidad de Piura, 2011). Sin embargo, esto no es una fortaleza sino una debilidad porque la universidad no cuenta con una Escuela de Postgrado que estandarice algunos procedimientos administrativos que faciliten la vida académica de los estudiantes y de los docentes de la maestría. Se entiende que la Universidad de Piura ya ha estandarizado los procedimientos del pregrado y que está pendiente aún el postgrado ${ }^{39}$. Por ahora el primero está subordinado al segundo.

Se encontró que la maestría no cuenta con un sistema formal de seguimiento al desempeño de egresados. Si bien se desarrollan algunas actividades referidas a este tema como: requerimientos de capacitación y actualización, necesidades de oferta laboral, difusión de

\footnotetext{
${ }^{39}$ Aspectos del postgrado que son diferentes al pregrado: la evaluación, los horarios, la cobranza, el pago a docentes, la emisión de certificados, entre otros.
}

Aplicación del modelo de evaluación de la pertinencia en la Universidad de Piura, Perú 
eventos, cursos, bolsa de trabajo, el sistema no está institucionalizado ni a nivel de universidad ni a nivel de Facultad.

Uno de los requisitos para ser admitido en el programa es tener el grado de Bachiller o título en Ingeniería Civil (equivalente a la Ingeniería de Caminos, Canales y Puertos en España) y la Universidad de Piura sí ofrece esa carrera. Dentro de los programas de especialización (diplomados) relacionados con la maestría existe el diplomado en "Gerencia de proyectos bajo el enfoque del PMI".

La maestría si aprovecha las oportunidades de desarrollo local y nacional porque buena parte del boom de la construcción que vive actualmente el Perú, se debe a la fuerte inversión pública y privada que se está realizando en caminos, al ser muy elevado el déficit de infraestructura del país (Gobierno Regional de Piura, 2013). Los contenidos del plan de estudios están relacionados con las orientaciones de desarrollo local, regional, nacional; y con las tendencias del ejercicio profesional existentes (Consejo Nacional de Competitividad de Perú, 2013).

El requisito para recibir el grado de Máster es la realización de una "tesis” y esto actualmente es un problema. Se tiene sólo un 15\% de graduados. La principal razón es que la maestría es de tipo profesional y no una maestría de investigación y eso no ha estado claro desde un inicio. Por ello, muchos planes de "tesis" no cumplen los requisitos de originalidad, de generar nuevo conocimiento ni de hacer generalizaciones teóricas y por ello son rechazados. Al parecer, no se tiene claro que dicha maestría, por el enfoque que tiene no debe exigir una "tesis" sino que debe exigir un "proyecto de fin de máster", es decir, un trabajo que consista en presentar una solución técnica sobre un caso que el participante esté enfrentando en su vida profesional o una investigación aplicada para atender alguna necesidad de la región.

La maestría ha promovido la continuidad en las relaciones efectivas con programas similares de otras universidades amigas en USA, Latinoamérica y Europa, a través de semanas internacionales (visitas), intercambio de profesores y el lanzamiento de una maestría similar en otro país como Ecuador. También se mantiene contacto con empresas y agencias gubernamentales para la matrícula de algunos de sus trabajadores, realización de seminarios, bolsa de trabajo, entre otros. Si bien existe ese vínculo con algunas empresas y entidades estatales, la maestría sin embargo no cuenta institucionalmente con un comité consultivo integrado por representantes de los principales grupos de interés. 
Los docentes de la maestría se podrían clasificar en tres tipos: los docentes de universidades extranjeras, los académicos nacionales (básicamente profesores de la Universidad de Piura) y los profesionales nacionales (ejecutivos de empresas de prestigio). Se trata que los tres tipos estén en cantidades iguales. Los docentes de universidades extranjeras sí participan en redes o asociaciones científicas y profesionales y poseen movilidad académica, sin embargo los otros no tanto.

La organización de la universidad no facilita la investigación multidisciplinaria y centrada en problemas, su organización se basa en disciplinas académicas. No existe un sistema institucionalizado para promover el diseño y ejecución de proyectos de investigación. Actualmente hay esfuerzos aislados de algunos docentes para la ejecución de proyectos de investigación e innovación con financiamiento del Consejo Nacional de Ciencia, tecnología e Innovación - CONCYTEC, aunque la investigación en ingeniería vial (tema de la maestría) no es una prioridad nacional según el documento "Estrategia Nacional para el desarrollo de la Ciencia, Tecnología e Innovación de Perú” (CONCYTEC, 2014).

Los syllabus son actualizados de acuerdo a los requerimientos de los estudiantes y egresados, una prueba de ello es que en la versión de la maestría dictada en la ciudad de Lima, no se considera, a sugerencia de los estudiantes, el tema relacionado al fenómeno El Niño, un fenómeno climático que afecta sólo a la región norte del Perú. Otro tema es el referido al transporte urbano, el crecimiento económico ha hecho que la ciudad de Piura crezca muy rápido y que el tránsito sea hoy un problema principal. También a sugerencia de estudiantes y egresados, se está incidiendo en técnicas y herramientas de ingeniería de tránsito y seguridad vial (Universidad de Piura, 2014b).

La maestría, por el enfoque profesional que tiene, promueve mucho la innovación, lo que es reforzado con políticas de la universidad y políticas gubernamentales nacionales. La debilidad está en no promover institucionalmente la transdisciplinariedad y este problema se entiende porque, como se dijo anteriormente, la universidad tiene una organización basada en disciplinas. Entonces el plan de estudios y por tanto los syllabus de las asignaturas se organizan también de acuerdo a lo que las disciplinas producen. Este marco dificulta también desarrollar un enfoque de aprendizaje basado en proyectos.

Existen algunas políticas o formas de operar de la universidad que pueden afectar la pertinencia de la maestría. Hay la percepción de que uno de los criterios para decidir el lanzamiento de una maestría es la necesaria inclusión de docentes a tiempo completo de la 
universidad en la plana docente de la maestría con el fin de aumentar los ingresos de dichos docentes. Esto implicaría forzar la selección de los profesores de la maestría y no cumplir en algunos casos con el perfil requerido.

\subsubsection{Resultados del análisis documental}

En la revisión documental se revisó los siguientes documentos:

- Informes Anuales de la maestría.

- Plan de estudios de la maestría (Universidad de Piura, 2014b).

- Página web de la maestría (UDEP, 2014).

- Plan de Desarrollo Regional Concertado de Piura (Gobierno Regional de Piura, 2013)

- Agenda de Competitividad 2012 - 2013 de Perú (Consejo Nacional de Competitividad de Perú, 2013).

- Estrategia Nacional para el desarrollo de la Ciencia, Tecnología e Innovación de Perú (CONCYTEC C. N., 2014).

- Convenios con otras instituciones para el desarrollo del postgrado.

- MOF de la universidad (Universidad de Piura, 2011).

- Ideario de la universidad (Universidad de Piura, 2008).

- Contratos e informes de proyectos de investigación de docentes nacionales.

\subsection{ANÁLISIS DE LA INFORMACIÓN}

En la Tabla 5.8 se presenta la suma de los resultados de las categorías "Muy de acuerdo" y

"De acuerdo" en los indicadores correspondientes a cada grupo de interés. 
Tabla 5.8. Resultado de encuestas de la maestría en Ingeniería Vial - Suma de "Muy de acuerdo" y "De acuerdo"

\begin{tabular}{|c|c|c|c|c|c|}
\hline $\mathbf{N}^{\circ}$ & Indicador & Estudiantes & Docentes & Egresados & Empleadores \\
\hline $\mathrm{A}$ & $\begin{array}{l}\text { Los conocimientos adquiridos en la maestría ayudaron a un } \\
\text { mejor desempeño laboral. }\end{array}$ & $100 \%$ & & $94 \%$ & $87 \%$ \\
\hline $\mathrm{B}$ & $\begin{array}{l}\text { Los temas dictados durante la maestría se relacionan con los } \\
\text { temas del trabajo o son de interés del estudiante. }\end{array}$ & $97 \%$ & & $89 \%$ & \\
\hline $\mathrm{C}$ & $\begin{array}{l}\text { Funciona un sistema de seguimiento al desempeño de } \\
\text { egresados }\end{array}$ & & & $36 \%$ & \\
\hline $\mathrm{D}$ & $\begin{array}{l}\text { Cursar la maestría ayudó a mejorar la situación laboral del } \\
\text { egresado (recibir un aumento de salario, un ascenso u obtener } \\
\text { un mejor empleo). }\end{array}$ & & & $83 \%$ & \\
\hline$E$ & $\begin{array}{l}\text { La actualización de los syllabus considera la opinión de } \\
\text { estudiantes y egresados. }\end{array}$ & & $60 \%$ & & \\
\hline $\mathrm{H}$ & $\begin{array}{l}\text { Los docentes (tiempo completo o tiempo parcial) han } \\
\text { publicado algún paper en ISI, Scopus o Scient Direct } \\
\text { utilizando el nombre de la universidad, en los dos últimos } \\
\text { años. }\end{array}$ & & $55 \%$ & & \\
\hline $\mathrm{K}$ & $\begin{array}{l}\text { Existe correspondencia entre la misión y objetivos de la } \\
\text { maestría con el plan de estudios. }\end{array}$ & $90 \%$ & & $92 \%$ & \\
\hline $\mathrm{M}$ & $\begin{array}{l}\text { La maestría aprovecha las oportunidades locales y nacionales } \\
\text { para beneficio de sus estudiantes y docentes. }\end{array}$ & $77 \%$ & $90 \%$ & $89 \%$ & $67 \%$ \\
\hline $\mathrm{O}$ & $\begin{array}{l}\text { El plan de estudios ayuda a satisfacer necesidades reales de la } \\
\text { localidad y del país. }\end{array}$ & $81 \%$ & & $72 \%$ & \\
\hline $\mathrm{P}$ & $\begin{array}{l}\text { Los proyectos de fin de máster tienen aplicación o resuelven } \\
\text { problemas en las empresas. }\end{array}$ & & & $33 \%$ & $33 \%$ \\
\hline $\mathrm{R}$ & $\begin{array}{l}\text { La maestría cuenta con un comité consultivo integrado por } \\
\text { representantes de los principales grupos de interés. }\end{array}$ & & & & $20 \%$ \\
\hline
\end{tabular}

Aplicación del modelo de evaluación de la pertinencia en la Universidad de Piura, Perú 


\begin{tabular}{|c|c|c|c|c|c|}
\hline $\mathbf{N}^{\circ}$ & Indicador & Estudiantes & Docentes & Egresados & Empleadores \\
\hline S & $\begin{array}{l}\text { Los docentes participan en redes o asociaciones científicas y } \\
\text { profesionales. }\end{array}$ & & $95 \%$ & & \\
\hline $\mathrm{T}$ & Los docentes poseen movilidad académica. & & $80 \%$ & & \\
\hline $\mathrm{U}$ & $\begin{array}{l}\text { Los docentes actualizan los syllabus incorporando los } \\
\text { resultados de sus investigaciones o los resultados de } \\
\text { investigaciones recientes en el tema. }\end{array}$ & & $95 \%$ & & \\
\hline$\overline{\mathrm{V}}$ & $\begin{array}{l}\text { La organización de la universidad facilita la investigación } \\
\text { multidisciplinaria y centrada en problemas. }\end{array}$ & & $30 \%$ & & \\
\hline W & $\begin{array}{l}\text { Los docentes participan en proyectos de investigación con } \\
\text { financiamiento externo (nacional o internacional). }\end{array}$ & & $45 \%$ & & \\
\hline $\mathrm{X}$ & $\begin{array}{l}\text { Las asignaturas promueven la transdisciplinariedad y la } \\
\text { innovación. }\end{array}$ & $90 \%$ & $90 \%$ & $83 \%$ & \\
\hline $\bar{Y}$ & Se utiliza un enfoque de aprendizaje basado en proyectos. & $81 \%$ & $90 \%$ & $75 \%$ & \\
\hline
\end{tabular}

Fuente: Elaboración propia 
Para el caso de estudiantes y egresados, que comparten 7 indicadores, se elaboró un Gráfico de Cuadrante. El objetivo fue comparar los resultados obtenidos y verificar la coincidencia de una alta o de una baja pertinencia de la maestría en determinados aspectos.

\section{Gráfico 5.19. Nivel de acuerdo con las declaraciones basadas en los indicadores de pertinencia - Resultados de la encuesta aplicada a estudiantes vs resultados egresados}

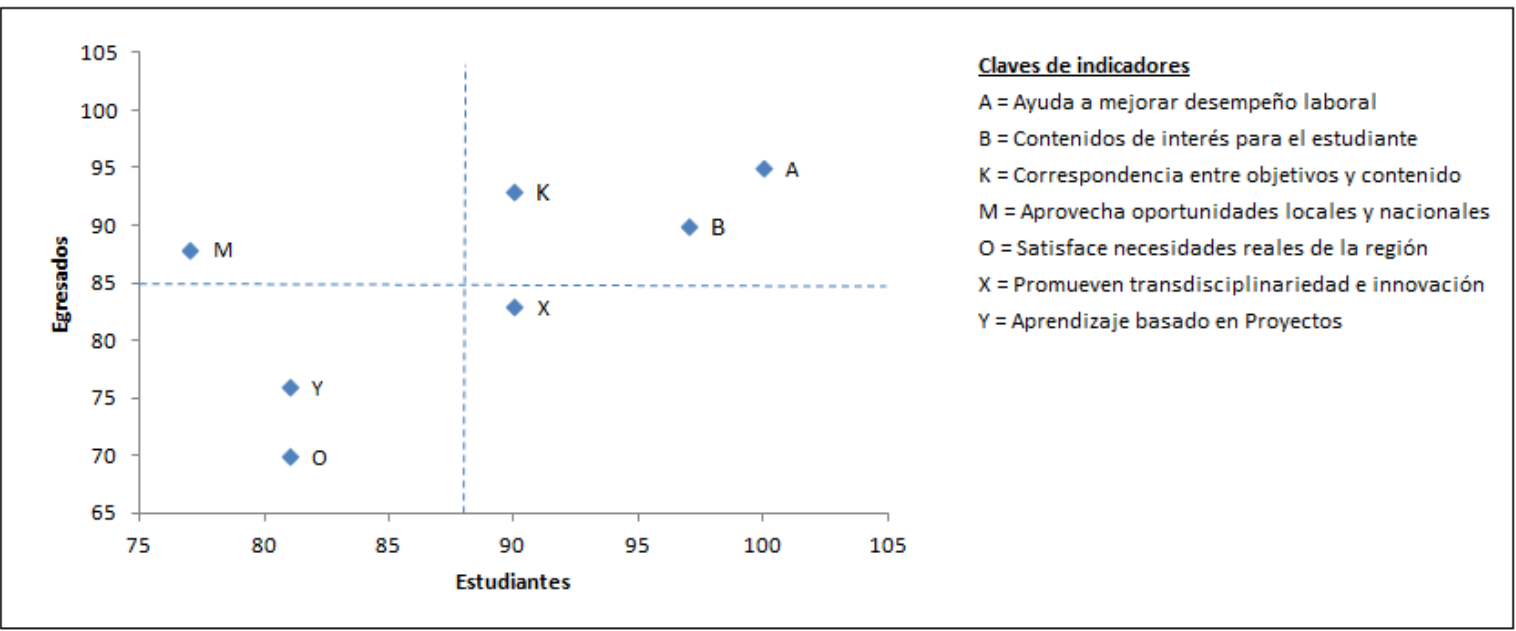

Fuente: Elaboración propia

Encontramos que hay coincidencia en la percepción de una alta pertinencia de la maestría especialmente en los siguientes aspectos: ayuda a los estudiantes a mejorar su desempeño laboral, brinda contenidos de interés para los estudiantes y hay correspondencia entre los objetivos planteados por la maestría y los contenidos desarrollados.

Si bien se ha trazado en el gráfico las líneas vertical y horizontal en el promedio de los valores, para cumplir con el gráfico de cuadrante, en este caso no se podría decir que existe la percepción de una baja pertinencia de la maestría en lo correspondiente a los indicadores $\mathrm{O}$ y Y porque sus valores no son bajos: $81 \%$ en el caso de estudiantes. Asimismo, se puede ver una diferencia en el grado de acuerdo respecto del indicador M, es decir, los estudiantes están más de acuerdo que los egresados con que la maestría aprovecha las oportunidades locales y nacionales en beneficio de sus estudiantes y docentes.

De la tabla de resultados es interesante extraer los correspondientes a los grupos de estudiantes, docentes y egresados, para los indicadores M,X,Y. 
Tabla 5.9. Resultados de los indicadores $M, X, Y$ para estudiantes, docentes $y$ egresados de la maestría en Ingeniería Vial

\begin{tabular}{clccc}
\hline Indicador & Breve descripción & Estudiantes & Docentes & Egresados \\
\hline M & $\begin{array}{l}\text { La maestría aprovecha las } \\
\text { oportunidades locales y } \\
\text { nacionales para beneficio de sus } \\
\text { estudiantes y docentes. }\end{array}$ & $77 \%$ & $90 \%$ & $89 \%$ \\
\hline $\mathrm{X}$ & $\begin{array}{l}\text { Las asignaturas promueven la } \\
\text { transdisciplinariedad y la } \\
\text { innovación }\end{array}$ & $90 \%$ & $90 \%$ & $83 \%$ \\
\hline Y & $\begin{array}{l}\text { Se utiliza un enfoque de } \\
\text { aprendizaje basado en proyectos }\end{array}$ & $81 \%$ & $90 \%$ & $75 \%$ \\
\hline
\end{tabular}

Fuente: Elaboración propia

El resultado es la suma de las categorías "De acuerdo" y "Muy de acuerdo".

Los resultados son altos y se encuentran en un rango muy cercano a la media aritmética en cada caso. Por tanto se puede concluir que la maestría sí provecha las oportunidades locales y nacionales para beneficio de sus estudiantes y docentes, las asignaturas promueven la transdisciplinariedad y la innovación y sí se utiliza un enfoque de aprendizaje basado en proyectos.

De la tabla de resultados también se puede comparar el grado de acuerdo entre los egresados y los empleadores en relación a las declaraciones de los indicadores A, M y P.

Tabla 5.10. Resultados de los indicadores A, M, P para egresados y empleadores de la maestría en Ingeniería Vial

\begin{tabular}{clcc}
\hline Indicador & Breve descripción & Egresados & Empleadores \\
\hline A & $\begin{array}{l}\text { Los conocimientos adquiridos en la } \\
\text { maestría ayudaron a un mejor desempeño } \\
\text { laboral. }\end{array}$ & $94 \%$ & $87 \%$ \\
\hline M & $\begin{array}{l}\text { La maestría aprovecha las oportunidades } \\
\text { locales y nacionales para beneficio de sus } \\
\text { estudiantes y docentes. }\end{array}$ & $89 \%$ & $67 \%$ \\
\hline P & $\begin{array}{l}\text { Los proyectos de fin de máster tienen } \\
\text { aplicación o resuelven problemas en las } \\
\text { empresas. }\end{array}$ & $33 \%$ & $33 \%$ \\
\hline
\end{tabular}

Fuente: Elaboración propia

El resultado es la suma de las categorías "De acuerdo" y "Muy de acuerdo". 
El indicador P muestra una clara debilidad de la maestría que ya había sido advertida en la entrevista al Director: los proyectos de fin de máster.

En cuanto a los indicadores que no se pueden triangular con los resultados de las encuestas tenemos los siguientes:

Tabla 5.11. Resultados de indicadores no triangulados. Docentes de maestría en Ingeniería Vial

\begin{tabular}{clc}
\hline Indicador & \multicolumn{1}{c}{ Descripción } & Resultado \\
\hline $\mathrm{E}$ & $\begin{array}{l}\text { La actualización de los syllabus considera la opinión de } \\
\text { estudiantes y egresados. }\end{array}$ & $60 \%$ \\
\hline $\mathrm{H}$ & $\begin{array}{l}\text { Los docentes (tiempo completo o tiempo parcial) han } \\
\text { publicado algún paper en ISI, Scopus o Scient Direct } \\
\text { utilizando el nombre de la universidad, en los dos últimos } \\
\text { años. }\end{array}$ & $55 \%$ \\
\hline $\mathrm{S}$ & $\begin{array}{l}\text { Los docentes participan en redes o asociaciones científicas y } \\
\text { profesionales. }\end{array}$ & $95 \%$ \\
\hline $\mathrm{T}$ & $\begin{array}{l}\text { Los docentes poseen movilidad académica. } \\
\mathrm{U}\end{array}$ & $\begin{array}{l}\text { Los docentes actualizan los syllabus incorporando los } \\
\text { resultados de sus investigaciones o los resultados de } \\
\text { investigaciones recientes en el tema. }\end{array}$ \\
\hline $\mathrm{V}$ & $\begin{array}{l}\text { La organización de la universidad facilita la investigación } \\
\text { multidisciplinaria y centrada en problemas. }\end{array}$ & $80 \%$ \\
\hline $\mathrm{W}$ & $\begin{array}{l}\text { Los docentes participan en proyectos de investigación con } \\
\text { financiamiento externo (nacional o internacional). }\end{array}$ & $30 \%$ \\
\hline
\end{tabular}

Fuente: Elaboración propia

El resultado es la suma de las categorías "De acuerdo" y "Muy de acuerdo".

Tabla 5.12. Resultados de indicadores no triangulados. Egresados y empleadores de maestría en Ingeniería Vial

\begin{tabular}{clc}
\hline Indicador & \multicolumn{1}{c}{ Descripción } & Resultado \\
\hline $\mathrm{C}$ & $\begin{array}{l}\text { Funciona un sistema de seguimiento al desempeño de } \\
\text { egresados }\end{array}$ & $36 \%$ \\
\hline $\mathrm{D}$ & $\begin{array}{l}\text { Cursar la maestría ayudó a mejorar la situación laboral del } \\
\text { egresado (recibir un aumento de salario, un ascenso u obtener } \\
\text { un mejor empleo). }\end{array}$ & $83 \%$ \\
\hline $\mathrm{R}$ & $\begin{array}{l}\text { La maestría cuenta con un comité consultivo integrado por } \\
\text { representantes de los principales grupos de interés. }\end{array}$ & $20 \%$ \\
\hline
\end{tabular}

Fuente: Elaboración propia

El resultado es la suma de las categorías "De acuerdo" y "Muy de acuerdo". 


\subsection{JUICIO}

De acuerdo con los resultados mostrados en los apartados anteriores se pueden emitir los siguientes juicios acerca de la pertinencia de la maestría en Ingeniería Civil con mención en Ingeniería Vial:

\section{Pertinencia Personal}

La maestría tiene una alta pertinencia personal: ayuda a mejorar el desempeño laboral de los estudiantes, los temas dictados son de interés para ellos y cuando egresan, la maestría les permite mejorar si situación laboral (recibir un mejor salario). Los aspectos que hay que mejorar son dos: institucionalizar un sistema de seguimiento al desempeño del egresado y actualizar los syllabus considerando más la opinión de los estudiantes y egresados.

\section{Pertinencia Institucional}

La maestría tiene alta pertinencia institucional: ha cumplido con las metas de vacantes todos los años, siempre ha habido más postulantes que admitidos. La misión y objetivos de la maestría son coherentes con la misión, objetivos y valores de la Universidad de Piura. La gestión de la maestría se desarrolla de acuerdo a las políticas y procedimientos de trabajo de la Universidad de Piura y existe correspondencia entre los objetivos de la maestría y lo que realmente se dicta. El aspecto a mejorar es el nivel de producción científica de sus docentes, especialmente los nacionales, de manera que otorguen más visibilidad internacional a la universidad.

\section{Pertinencia Social}

La maestría tiene una alta pertinencia social. Esto se debe principalmente a que Perú está pasando por una etapa de crecimiento económico sostenido y un boom en el sector construcción. La maestría aprovecha esta oportunidad para tener más casos de estudio y una aplicabilidad inmediata de los conocimientos vertidos, por tanto satisface una necesidad local y nacional. Asimismo, cuenta con relaciones efectivas con universidades de otros países como Canadá, Argentina y Ecuador lo que permite el intercambio de profesores. Los aspectos a mejorar son dos: el primero es aumentar el número de titulados con proyectos de fin de máster que resuelvan problemas o signifiquen la aplicación de una técnica de ingeniería vial. El segundo aspecto consiste en institucionalizar la participación de los diferentes grupos de interés (empleadores, egresados, estudiantes, etc.) en la mejora de la gestión de la maestría con la conformación de un Comité Consultivo. 


\section{Pertinencia Global}

La pertinencia global de la maestría se considera media. Se cumplen varios estándares internacionales de calidad como contar con profesores extranjeros, la movilidad de los docentes, las redes o asociaciones a las que pertenecen los docentes y la actualización de los syllabus. Sin embargo falta cumplir otros, que son muy importantes para la visibilidad internacional de la maestría y de la Universidad de Piura.

La maestría es de tipo profesional, pero la investigación sigue siendo importante. Actualmente se considera a la docencia y a la investigación en el postgrado como dos caras de una misma moneda. En este caso de maestría profesional, la investigación debe ser aplicada, centrada en problemas locales y nacionales pero siempre con visibilidad internacional. Es este aspecto en el que falla un poco la maestría en Ingeniería Vial. Las causas son muchas, una de ellas es la misma organización de la universidad que no facilita la investigación multidisciplinaria y centrada en problemas. Esto origina que prácticamente no existan proyectos de investigación con financiamiento externo en los que participen docentes de la maestría, lo que a su vez origina que haya pocas publicaciones de los docentes en revistas indexadas de prestigio internacional.

\subsection{CONCLUSIONES DEL CAPÍTULO V}

El modelo permite evaluar el nivel de pertinencia de la maestría. Es posible valorar el grado de satisfacción de las necesidades e intereses de los estudiantes y de la universidad que la acoge, así como el grado de vinculación de la maestría con su entorno local/nacional y con el sistema internacional de educación superior universitaria.

El modelo permite emitir un juicio de carácter descriptivo sobre la pertinencia de la maestría. Se puede usar, para cada dimensión de la pertinencia, las categorías: baja, media y alta pertinencia. Esta valoración es la que corresponde, pues el número de personas que integran cada grupo de interés es bajo y los indicadores son de tipo cualitativo. La información recogida con las encuestas se complementa con la recogida con las entrevistas y el análisis documental para poder emitir un juicio integral. Lo importante es identificar las oportunidades de mejora o las debilidades que es necesario superar y el modelo de evaluación orienta ese proceso de manera objetiva.

Aplicación del modelo de evaluación de la pertinencia en la Universidad de Piura, Perú 
Se ha tenido algunas dificultades como una resistencia inicial a la evaluación que fue superada con reuniones de sensibilización donde se explicó el modelo, así como la importancia y los objetivos de la evaluación. Asimismo inicialmente se tuvo una baja tasa de respuesta a las encuestas on line. Para superarla se llamó por teléfono con el fin reiterarles el pedido de llenado de la encuesta, agradeciendo de antemano su colaboración.

El gráfico de cuadrante para comparar los resultados de la encuesta a estudiantes con los resultados de la encuesta a egresados es útil principalmente cuando se tiene tanto valores muy altos como valores muy bajos, en los dos casos. Cuando todos los valores son altos o todos los valores son bajos no tiene sentido utilizarlo porque sería como que todo el gráfico conforma uno de los cuadrantes.

Para presentar los resultados de la evaluación es muy recomendable seguir siempre el esquema de las cuatro dimensiones de la pertinencia (presentando los indicadores en orden alfabético) para facilitar el análisis y para que las conclusiones sean más contundentes.

La maestría evaluada es de tipo profesional, a tiempo parcial, en una universidad privada sin fines de lucro y en un contexto socio económico de crecimiento sostenido pero con muchas necesidades de formación profesional por parte del mercado laboral y profesional.

La maestría no ha tenido problemas en cubrir sus vacantes en todas las versiones que ha tenido, sin embargo el reto está en que la maestría sea de calidad y sea sostenible. Para ello tiene que ser pertinente, es decir, satisfacer las necesidades de formación de sus estudiantes, ayudar a la universidad a cumplir su misión, insertándola en el sistema global de producción de conocimiento aprovechando las oportunidades que le brinda el entorno local y nacional.

Si bien se trata de la evaluación de una maestría que ya tiene años funcionando, las conclusiones sirven también a la facultad de Ingeniería y en general a la Universidad de Piura para el diseño de nuevas maestrías. Hay aspectos a mejorar que dependen más de arreglos institucionales como el sistema de seguimiento al desempeño de egresados, la conformación de comités consultivos, incentivos para la elaboración de proyectos de fin de máster, la organización de la universidad de modo que se facilite la investigación interdisciplinaria y centrada en problemas, entre otros. 


\subsection{BIBLIOGRAFÍA DEL CAPÍTULO V}

América Economía. (2013). Ranking 2013 Perú. Las mejores universidades . Recuperado el junio de 2014, de http://rankings.americaeconomia.com

CONCYTEC, C. N. (mayo de 2014). Estrategia Nacional para el Desarrollo de la Ciencia, Tecnología e Innovación. Recuperado el junio de 2014, de www.concytec.gob.pe

Consejo Nacional de Competitividad de Perú. (2013). Agenda de Competitividad 2012-2013 de Perú. Recuperado el junio de 2014, de www.cnc.gob.pe

Gobierno Regional de Piura. (2013). Plan Estratégico de Desarrollo Regional Concertado 2013 2016 , Piura. Recuperado el junio de 2014, de http://www.regionpiura.gob.pe

UDEP, U. d. (2014). Maestría en Ingeniería Civil con mención en Ingeniería Vial - Campus Piura. Recuperado el junio de 2014, de http://udep.edu.pe

Universidad de Piura. (2008). Ideario de la Universidad de Piura. Piura, Perú.

Universidad de Piura. (2011). Manual de Organización y Funciones. Piura, Perú. 
Capítulo VI

Conclusiones 


\section{CAPÍTULO VI}

\subsection{CONCLUSIONES}

La primera conclusión, que verifica el cumplimiento de una de las hipótesis, es que los modelos de evaluación de maestrías, utilizados por los organismos de acreditación internacional, en el mundo, en Latinoamérica y en Perú, tienen un enfoque de evaluación de la eficacia de los programas y por tanto no evalúan directamente la pertinencia. Lo que hacen es verificar el cumplimiento de los objetivos planteados a partir de los resultados obtenidos pero no garantizan que esos objetivos planteados y por tanto los resultados que obtendrán luego, satisfagan necesidades reales de los estudiantes y de las partes interesadas en la maestría, un aspecto muy importante en los países en desarrollo.

La presente investigación concluye que es posible diseñar un modelo de evaluación de la pertinencia de maestrías en ingeniería y para hacerlo se ha tenido que definir primero lo que se entiende por pertinencia, quiénes son las partes interesadas en una maestría y qué necesidades e intereses mínimos tienen de acuerdo a unas características y misiones de la universidad y de la formación de postgrado en ingeniería comúnmente aceptadas, de además de las propias de cada caso.

Una de las primeras aportaciones de esta tesis es la definición de la pertinencia de una maestría en ingeniería. Esta definición podría incluso aplicarse al caso de otras carreras, pero el modelo de evaluación variaría en los indicadores considerados.

Consideramos dos tipos de pertinencia: pertinencia local y pertinencia global. La pertinencia global consiste básicamente en cumplir estándares internacionales y estar conectado al sistema global de producción de conocimiento. La pertinencia local tiene tres dimensiones: una dimensión personal (satisfacer necesidades de los estudiantes), una dimensión institucional (satisfacer necesidades e intereses de la institución que acoge la maestría) y una dimensión social (vincularse con el entorno local, satisfacer necesidades y atender demandas de la comunidad local y nacional).

Esta definición ayuda a resolver el problema o paradigma creado alrededor del concepto de pertinencia de la educación superior (actualmente predomina el enfoque economicista que considera que un programa es pertinente sólo cuando responden a demandas del Mercado, 
su producción es eficiente en términos de aplicabilidad inmediata, son rentables y permiten obtener financiamiento externo).

El concepto operativo de la pertinencia definido en la presente investigación ha permitido identificar indicadores de evaluación y fuentes de verificación a partir del marco teórico y contextual descrito y analizado en los capítulos I y II.

De la revisión bibliográfica efectuada y las consultas realizadas se encontró que es una práctica muy utilizada en la evaluación de programas formativos en ingeniería el uso de métodos cuantitativos y cualitativos de evaluación, así como fuentes primarias y secundarias. Por tanto se puede aplicar este enfoque en el modelo propuesto y complementar la información utilizando encuestas, entrevistas y análisis de documentos. Las encuestas nos dan una fotografía del momento que se complementa con las entrevistas a directivos, quienes tienen una visión estratégica de la maestría. Es muy importante la opinión de los egresados de la maestría porque ellos tienen una visión integral desde el lado de los beneficiarios del programa.

En el diseño del modelo se ha considerado clave las siguientes ideas:

- La universidad tiene 3 misiones: docencia, investigación y extensión. Las universidades han perdido el monopolio de producción y trasferencia de conocimiento, deben ser pertinentes. Esta pertinencia se mide en función de lo que la sociedad espera de la universidad y la universidad hace. Es por tanto necesaria una vinculación con el entorno.

- Para que una universidad tenga pertinencia es recomendable que se organice según el Modo 2 de producción de conocimiento de Gibbons, es decir, que se inserte en un sistema integrado de producción de conocimiento donde la investigación es multidisciplinaria y centrada en problemas. De esta forma será más fácil que la universidad atienda las necesidades y demandas de su entorno. Actualmente la mayoría de universidades están organizadas según el modo 1 es decir por disciplinas científicas, lo que no facilita la pertinencia.

- La metodología de producción de conocimiento del Grupo GESPLAN aterriza este Modo 2 de Gibbons y puede ser considerado como referencia para la identificación de indicadores de pertinencia.

- Las carreras de ciencia y tecnología como ingeniería, que en su esencia debe atender necesidades y resolver los problema de su entorno, necesita ser pertinente y más aún la 
formación de postgrado donde la docencia y la investigación deberían ser dos caras de una misma moneda.

- En los países en desarrollo como los latinoamericanos, donde actualmente se vive una etapa de crecimiento económico sostenido pero bajos niveles de calidad de la educación superior y bajos niveles de competitividad es aún más urgente que la formación de postgrado en ingeniería sea pertinente. Las universidades sí deben investigar, pero debe ser una investigación aplicada, que le de visibilidad internacional atendiendo las necesidades de su entorno local y nacional.

La investigación concluye también que es posible aplicar el modelo en un caso concreto. Si bien el modelo fue aplicado en una maestría profesional, a tiempo parcial, etc., por la manera en que está planteado, se podría aplicar sin problemas en otros casos porque los factores de pertinencia, los indicadores y las fuentes de verificación son sencillos y de uso común en los procesos de evaluación de programas formativos. La diferencia estará en la forma y los medios que se utilicen para recoger la información. Incluso en una maestría on line se puede aplicar encuestas, entrevistas y analizar documentos.

El modelo podría asignar un valor numérico a cada dimensión de la pertinencia y se podría ponderar estas dimensiones para obtener un valor numérico final para la pertinencia de la maestría, y con esto hacer una lista ordenada o ranking de varias maestrías. Sin embargo se ha preferido no hacerlo porque usualmente el número de personas en cada grupo de interés, que son las fuentes primarias de la evaluación, son muy reducidos y por tanto se prefiere emitir juicios de carácter descriptivo usando la escala: alta, media y baja. Pero podría hacerse si se tiene grupos más grandes.

Es muy importante tener en cuenta la complementariedad de todos los trabajos de evaluación, de manera que cada evaluación pueda tener acceso a los resultados de la anterior y que sus resultados sirvan a las posteriores.

Es importante también tener en cuenta que los resultados de la evaluación a este nivel son de interés de otros niveles de gestión porque puede tener implicancia para ellos. Por ejemplo, los resultados de la evaluación de una maestría impactan también en el departamento académico, en la carrera asociada, en la facultad y en la misma universidad. 
Si bien la evaluación considerada en el modelo es temática, los resultados ayudan a la buena marcha global de la maestría y pueden servir de base por ejemplo para futuros procesos de acreditación.

\subsection{FUTURAS LÍNEAS DE INVESTIGACIÓN}

A partir de las conclusiones obtenidas y de la aplicación del modelo diseñado, se plantean las siguientes futuras líneas de investigación:

- Diseñar y validar un modelo de planificación de maestrías en ingeniería que garanticen su pertinencia. En el presente trabajo se ha propuesto un modelo para evaluar la pertinencia de una maestría que ya está funcionando y las conclusiones de la evaluación podrían modificar mucho el rumbo que esté llevando el programa si éste no se adecúa a necesidades reales. Sin embargo, si desde la etapa de diseño se identifican bien las necesidades e intereses de los estudiantes, de la universidad y de las partes interesadas y se establecen objetivos y procesos de acuerdo a esas necesidades, la pertinencia podría estar garantizada.

- Estudiar las maestría profesionales a tiempo parcial. Centrarse sólo en este tipo de maestría que son las más abundantes en los países en desarrollo y plantear una metodología y herramientas para facilitar la elaboración de proyectos de fin de máster que resuelvan problemas concretos del sector productivo.

- Evaluar la pertinencia de doctorados en ingeniería. En este caso varían las necesidades e intereses de los estudiantes y de la universidad que lo imparte. 
Bibliografía General 


\section{BIBLIOGRAFÍA GENERAL}

ABET. (2009). Obtenido de

http://www.abet.org/forms.shtml\#For_Engineering_Programs_Only

Abreu L.F.; Cruz, V.\& Martos, F. (2009). Introducción. En Asociación Universitaria Iberoamericana de Postgrado AUIP, Evaluación de Programas de Postgrado. En Guía de autoevaluación (págs. pags. 11-13). Salamanca: AUIP.

Altbach, P., \& Knight, J. (2007). The Internationalization of Higher Education:

Motivations and Realities. Journal of Studies in International Education, Vol. 11, 3-4, 290-305.

América Economía. (2013). Ranking 2013 Perú. Las mejores universidades . Recuperado el junio de 2014, de http://rankings.americaeconomia.com

ANECA, A. N. (11 de febrero de 2011). Protocolo de evaluación para la verificación de titulos universitarios oficiales (Grado y Máster). Recuperado el mayo de 2014, de www.aneca.es

Arias, V. (1998). La enseñanza de Post - Grado en Ingeniería. Rev. Inst. investig. Fac. minas metal cienc. Geogr. Universidad Nacional Mayor de San Marcos (Vols. Vol.1, No.1).

Augustine, N., \& Vest, C. (1994). Engineering Education for a Changing World. Joint Project by the Engineering Deans Council and the Corporate Roundtable of the American Society for Engineering Education, ASEE.

AUIP, A. U. (2009). Evaluación de Programas de Postgrado - Guía de Autoevaluación. Recuperado el junio de 2014, de www.auip.org

BCRP, B. C. (2014). Estadísticas - Cuadros históricos. Recuperado el junio de 2014, de http://www.bcrp.gob.pe/estadisticas.html

Bengoetxea, E; Arteaga, J. (2009). La evaluación de postgrados internacionales en la Unión Europea. Ejemplos de buenas prácticas de programas europeos. Revista de Universidad y Sociedad del Conocimiento.

Blackmur, D. (2008). A critical analysis of the INQAAHE Guidelines of Good Practice for higher education quality assurance agencies. En Higher Education, (Vol. 56, págs. 723 - 734).

Brunner, J. (2010). "Globalización de la educación superior: crítica de su figura ideológica". Revista Iberoamericana de Educación Superior (RIES), , vol. I, núm.2, pp. 75-83.

Carranza, L. (2010). Congreso Anual de Ejecutivos 2010. Obtenido de Rumbo a la prosperidad, "la Agenda prioritaria de la competitividad": http://empresarioshaciendopais.pe/

Cazorla, A. (27 de diciembre de 2015). Una Universidad para la empresa y la sociedad. El Mundo, España. 
Cazorla, A. (4 de setiembre de 2013). Conferencia "UPM: hacia una Universidad de investigación, Gesplan". Simposio "De una universidad profesional a una universidad de investigación: Una oportunidad para Latinoamérica". Quito, Ecuador.

Cazorla, A., De los Ríos, I., \& Salvo, M. (2004). Modelos de planificación para un desarrollo ruraly local. (D. d. Madrid, Ed.) Madrid.

Cazorla, A., De los Ríos, I., \& Yagüe, J. L. (2011). Trabajando con la gente. En J. Olvera, R. mendoza, N. Pérez, \& I. De los Ríos, Modelos para el desarrollo rural con enfoque territorial en México (págs. 9 - 46). México: Colegio de Postgraduados, Campus Puebla.

CEPAL, C. E. (abril de 2014). Balance económico actualizado de América Latina y el Caribe 2013. Recuperado el junio de 2014, de http://www.eclac.cl/publicaciones

CEPAL, C. E. (diciembre de 2013). Balance preliminar de las economías de América Latina y el Caribe 2013. Recuperado el junio de 2014, de http://www.eclac.cl/publicaciones

CEPAL, C. E. (2010). Espacios iberoamericanos: vinculos entre universidades y empresas para el desarrollo tecnológico. Santiago de Chile.

CEPAL, C. E. (2009). La educación superior y el desarrollo económico en América Latina. México D.F.: Publicaciones de las Naciones Unidas.

CEPAL, C. E. (abril de 2013b). Panorama económico y social de América Latina y el Caribe 2013. Recuperado el 2014 de junio, de http://www.eclac.cl

CINDA. (octubre de 2011). Educación Superior en Iberoamérica. Informe 2011. Recuperado el junio de 2014, de www.cinda.cl

CINDA. (mayo de 2011). La educación Superior en Perú 2005 - 2009. Recuperado el junio de 2014, de http:/ /www.universia.net

CINDA, C. I. (2009). Universia. Obtenido de http://www.cinda.cl/proyecto_alfa/downoad_finales/8MarcodereferenciaparaelProyectos obreAQ.pdf

CINDA, C. I. (2014). Instituto Internacional para el Aseguramiento de la Calidad. Recuperado el junio de 2014, de www.cinda.cl/iac

Clark, B. R. (1998). The Entrepreneurial University: Demand and Response. . Tertiary Education and Management, , 4, 1, 5-16.

CONACYT, C. N. (2004). Obtenido de http://www.siicyt.gob.mx/siicyt/docs/contenido/ingenieria.pdf

CONACYT, C. N. (abril de 2013). Marco de referencia para la evaluación y seguimiento de programas de posgrado. Recuperado el junio de 2014, de www.conacyt.mx 
CONACYT, C. N. (2014). PNCP - Programa Nacional de Posgrados de Calidad-México. Recuperado el junio de 2014, de www.conacyt.mx

CONCYTEC, C. N. (mayo de 2014). Estrategia Nacional para el Desarrollo de la Ciencia, Tecnología e Innovación. Recuperado el junio de 2014, de www.concytec.gob.pe

CONCYTEC, C. N. (noviembre de 2005). Plan Nacional Estratégico de Ciencia, Tecnología e Innovación para la competitividad y desarrollo bumano 2006-2021. Recuperado el mayo de 2014, de www.concytec.gob.pe

CONEAU, C. d. (diciembre de 2010). Modelo de calidad para la acreditación de programas de posgrado, modalidad presencial, y estándares para maestrías y doctorados. Recuperado el junio de 2014, de www.coneau.gob.pe

CONEAU-a. (2011). Consejo de Evaluación, Acreditación y Certificación de la Calidad de la Educación Superior Universitaria, Modelo de Calidad para la acreditación de programas de postgrado.

Congreso de la República de Perú. (mayo de 2013). Proyecto de Ley. Nueva Ley universitaria. Recuperado el mayo de 2014, de www2.congreso.gob.pe

Consejo Nacional de Competitividad de Perú. (2013). Agenda de Competitividad 2012-2013 de Perú. Recuperado el junio de 2014, de www.cnc.gob.pe

Cortes, F. (2006). La relación universidad-entorno socioeconómico y la innovación. Ingeniería e Investigación.

Cruz, V. (2003). Calidad de la enseñanza en el postgrado y su acreditación internacional. Santiago de Cali: Universidad del V alle.

Cruz, V., \& Martos, F. (2010). Evaluación de la calidad de los programas de maestría y doctorado en Iberoamérica. Revista Digital Universitaria, 11 (5), 1 - 13.

D’Este, P. C.-M.-G. (2009). Documento de base para un "Manual de Indicadores de Vinculación de la universidad con el entorno socioeconómico": un marco para la discusión. Ingenio. Instituto de Gestión de la Innovación y del Conocimiento.

De Miguel, M. (2003). Calidad de la enseñanza universitaria y desarrollo profesional del profesorado. Revista de Educación,331, 13-34.

Diaz-Puente, J. (2003). Tesis Doctoral. Diseño y aplicación de un modelo para el seguimiento y evaluación del Desarrollo Rural en la UE. Madrid.

Didriksson, A. \&. (2007). La nueva responsabilidad social y la pertinencia de las universidades. En Global University Network for Innovation. En La Educación Superior en el mundo 2007: Acreditación para la Garantía de la Calidad, Qué está en juego (págs. XL-XLV).

Barcelona: Mundi Prensa Libros SA. 
Eaton, J. (2007 a). Un espacio de acreditación internacional. En Global University Network for Innovation, La Educación Superior en el mundo 2007: Acreditación para la Garantía de la Calidad, Qué está en juego. Barcelona: Mundi Prensa Libros SA.

Eaton. J. (2007 b). Consejo de Acreditación de la Educación Superior, la Acreditación y el reconocimiento en Estados Unidos. En En Global University Network for Innovation, La Educación Superior en el mundo 2007: Acreditación para la Garantía de la Calidad, Qué está en juego (págs. 278-281). Barcelona: Mundi Prensa Libros SA.

ENQA, E. N. (2009). Standards and Guidelines for Quality Assurance in the European Higher Education Area. Recuperado el mayo de 2014, de www.enqa.eu

Etzkowitz, H., Webster, A., Gebhardt, C., \& Cantisano Terra, B. R. (2000). The future of the university and the university of the future: evolution of ivory tower to entrepreneurial paradigm. Research Policy, 29, 313-330.

Eun, J-H.; Lee, K.; Wu, G. (2006). "Explaining the "University-run enterprises" in China: A theoretical framework for university-industry relationship in developing countries and its application to China". Research Policy, 35 , 1329-1346.

EUR-ACE. (2008). Framework Standards for the Accreditation of Engineering Programmes. Recuperado el 2014, de www.enaee.eu

European Comission. (1999). Evaluating socio-economics programmes, Glosary of 300 concepts and technical terms- Means Collection (Vol. 6). Luxembourg: Office for official publications of the European Communities.

FAO, F. a. (junio de 2013). Noticia. 38 países alcanzan las metas contra el hambre fijadas para 2015. Recuperado el junio de 2014, de www.fao.org

Felder, R., \& Brent, R. (2004). The ABC's of engineering education: ABET, Bloom's taxonomy, cooperative learning, and so on. Proceedings of the 2004 American Society for Engineering Education Annual Conference \& Exposition.

Fernández , A. (2010). La formación de postgrado: fortaleza real y potencial de la Universidad. En Instituto Internacional de la Unesco para la Educación Superior en América Latina y el Caribe, La Universidad latinoamericana en discusión. Caracas: UCV - UNESCO-IESALC.

Fernandez Pello, C. (4 de setiembre de 2013). Conferencia: Berkeley: una universidad de investigación. Simposio: De una universidad profesional a una universidad de investigación: Una oportunidad para Latinoamérica. Quito, Ecuador.

Fernández, I., Vega-Jurado, J., \& Huanca-Lopez, R. (2007). “¿La relación universidad empresa en América Latina: apropiación incorrecta de modelos foráneos?”. Journal of Technology Management and Innovation, vol. 2, N². 
Fischman, G., \& Haas, E. (18 de 06 de 2011). Nostalgia, emprendedorismo y redención: modelos discursivos sobre la universidad. Revista Iberoamericana de Educación Superior (RIES), 3-34.

Gibbons, M. (1998). "Higher Education Relevance in the 21st Century". UNESCO World Conference on Higher Education. Paris.

Gobierno Regional de Piura. (2013). Plan Estratégico de Desarrollo Regional Concertado 2013 2016 , Piura. Recuperado el junio de 2014, de http://www.regionpiura.gob.pe

Gola, M. (2003). Premises to accreditation. A minimum set of accreditation requirements in accreditation models in higher education experiences and perspectives in ENQA. En Workshops Reports 3, European Network for Quality Assurance in Higher Education, Helsinki (págs. 25-31).

González, E., \& Espinoza, O. (2008). Calidad de la Educación Superior: Conceptos y Modelos. (C. S. Chile, Ed.) Calidad en la Educación (28), 247 - 276.

Green, D. . (1994). Wat is Quality in Higher Education? London, SRHE/Open Univetsity Press, 1994.

Guerra García, R. (2006). Discurso de orden: 50 años de las universidades peruanas. Academia Nacional de Medicina. Anales 2006, (págs. 108-116). Lima.

Hansen, J., \& Lehmann, M. (2006). "Agents of change: universities as development hubs". Journal of Cleaner Production, 14, 820-829.

Hinds, M. (2013). ¿Para dónde va América Latina? Análisis y Opinión de Revista América Economía. Obtenido de http://www.americaeconomia.com/analisis-opinion/para-dondeva-america-latina.

ICACIT. (2014). Instituto de Calidady Acreditación de Programas de Computación, Ingeniería y Tecnología. Recuperado el junio de 2014, de www.icacit.org.pe

IEEE, I. o. (abril de 2012). Acreditación de programas de ingeniería en América Latina: presente y futuro. Recuperado el junio de 2014, de www.ewh.ieee.org

IESALC. (2008). Declaración y Plan de Acción de la Conferencia Regional de Educación Superior en América Latina y el Caribe 2008. Recuperado el junio de 2014, de www.iesalc.unesco.org.ve

IESALC. (2014). VINCULAENTORNO. Recuperado el junio de 2014, de http://www.iesalc.unesco.org.ve

IIEP, (. I. (2009). Obtenido de http://www.iiep.unesco.org/es/focus-onhighereducation.html. 
INEI. (junio de 2014a). Instituto Nacional de Estadística e Informática de perú. Recuperado el junio de 2014, de Base de Datos ENAHO - Encuesta Nacional de Hogares: www.inei.gob.pe

INEI, I. N. (mayo de 2014). Evolución de la pobreza Monetaria 2009 - 2013. Informe Técnico. Recuperado el junio de 2014, de www.inei.gob.pe

INEI, I. N. (2010). II Censo Nacional Universitario 2010. Recuperado el junio de 2014, de www.inei.gob.pe

INEI, I. N. (marzo de 2014). Perú: Indicadores de Educación por departamentos 2001 - 2012. Recuperado el junio de 2014, de www.inei.gob.pe

INEI, Instituto Nacional de Estadística e Informática de Perú. (noviembre de 2013). Perú: Evolución de los indicadores de empleo e ingreso por departamento 2004 - 2012. Recuperado el junio de 2014, de www.inei.gob.pe

Knights, D., \& Scarbrough, H. (2010). "In Search of Relevance: Perspectives on the Contribution of Academic-Practitioner Networks". Organization Studies.

Krugmann, P. (20 de marzo de 2014). Seminario Internacional "Nuevos paradigmas en competitividad". Lima. Recuperado el 24 de mayo de 2014, de http://www.esan.edu.pe/conexion

Kuczynski, P., Carranza, L., \& Araoz, M. (23 de mayo de 2014). Simposio del oro y la plata La Minería y su Rol en la Economía del Perú. Recuperado el 24 de mayo de 2014, de http://semanaeconomica.com

Lemaitre, M. J. (2004). INQAAHE principles of good practice. Quality in Higher Education, 10(2).

Loredo, J., Romero, R., \& Inda, P. (2009). Una alternativa de evaluación docente en el posgrado de la Universidad Iberoamericana, ciudad de México. X Congreso Nacional de Investigación Educativa. Veracruz.

Maffioli, F. \&. (2003). Tuning engineering education into the european higher education orchestra. European Journal of the Engineering Education.

Marischio, S., J., R., \& Von Pamel, O. (2000). "El Trabajo Colaborativo por Proyectos en Ambientes Virtuales como Estrategia Formativa Profesional en Ingeniería", $4^{a}$ Jornadas de Educación a Distancia del Mercosur del CREAD/INTA.

Marjoram, T., \& Zhong, Y. (2010). Engineering: issues, challenges and opportunities for development. What engineering is, what engineers do, 24-26.

MEF, M. d. (abril de 2014). Marco Macroeconómico Mutianual 2015 - 2017. Recuperado el junio de 2014, de www.mef.gob.pe 
Memon, J. A., Demirdögen, R. E., \& Chowdhry, B. S. (2009). Achievements, outcomes and proposal for global accreditation of engineering education in developing countries. Procedia Social and Behavorial Sciences , 1, 2557-2561.

Mendieta, C. (2013). Vinculación del postgrado y la formación continua con el entorno productivo y empresarial en Iberoamérica. Desarrollo Indoamericano.

Naidorf, J., Giordana, P., \& Horn, M. (2007). La pertinencia social de la universidad como categoría equívoca. Nomadas (27), 22-33.

Natarajan, R. (2000). The Role of Accreditation in Promoting Quality Assurance of Technical Education. International Journal of Engineering Education.

Ocampo, F. (2010). Quality in engineering education - A Latin American point of view. International leadership colloquium on quality insurance, accreditation and assessment in higher education. Madrid.

Olds, B., Moskal, B., \& Miller, R. (2005). "Assessment in engineering education: Evolution, approaches and collaborations". Journal of Engineering Education, 94, 1, 13-25.

Palma, M., De los Ríos, I., \& Miñán, E. (2011). “Generic competences in engineering field: a comparative study between Latin America and European Union”. Procedia - Social and Behavioral Sciences, 15,

Palomares, D., \& García, A. \&. (2008). Evaluación de las instituciones de educación superior: revisión bibliográfica de sistema de indicadores. Revista española de documentación científica, 31, 2.

Pappas, E., Kampe, S., Hendricks, R., \& Kander, R. (2004). “An Assessment Analysis Methodology and Its Application to an Advanced Engineering Communications Program". Journal of Engineering Education, 233 - 246.

Patton, M.Q. (2002). Qualitative Evaluation and Research Methods, 3rd ed. Thousand Oaks, CA: Sage Publications, 2002.

Payzin, E. (2010). Developments in Engineering Education in Europe, ASME 2010 International Leadership, may 2010 Istanbul.

Phillips, W. M., Peterson, G. D., \& Aberle, K. B. (2000). Quality Assurance for Engineering Education in a Changing World. International Journal Engineering Education., 16, 2, , 97-103.

PROINVERSION, A. d. (2014). Inversiones estratégicas- APP. Recuperado el junio de 2014, de www.proyectosapp.pe

PUCP, P. U. (2009). Guia de autoevaluación de la formación para programas de maestría.

Recuperado el junio de 2014, de www.pucp.edu.pe/dape 
Puerzer, R.; Rooney, D. . (2002). "The Alumni Survey as an Effective Assessment Tool for Small Engineering Programs”. Journal of Engineering Education, 109 - 116.

Rama, C. (2008). El nacimiento de la acreditación internacional. En Primer Congreso Internacional de Evaluación y Acreditación,. Campeche, México.

Rama, C. (2006). La Tercera Reforma de la educación superior en América Latina. Buenos Aires: Fondo de Cultura Económica.

Rama, C. (21-23 de enero de 2010). Seminario de Doctorado. Doctorado en Ciencias de la educación. Escuela de Comando y Estado Mayor del Ejército de Bolivia, Bolivia.

RIACES, R. I. (2004). Glosario Internacional de Evaluación de la Calidad y Acreditación. Madrid.

Salazar, J. (2011). Modelos de aseguramiento de la calidad de la educación superior (Centro Interuniversitario de Desarrollo - CINDA, Proyecto ALFA. Recuperado el 04 de Julio de 2012, de http://www.cinda.cl/proyecto_alfa/htm/documentos.htm

Sánchez, J. (2008). Una propuesta conceptual para diferenciar los programas de postgrado profesionalizantes y orientados a la investigación. Implicaciones para la regulación, el diseño y la implementación de los programas de postgrado. Ciencia y Sociedad. , Vol. XXXIII, 327-341.

Sanyal, B., \& Martin, M. (2007). Garantía de la Calidad y el papel de la Acreditación: Una Visión Global. En Global University Network for Innovation. En La Educación Superior en el mundo 2007: Acreditación para la Garantía de la Calidad, Qué está en juego (págs. 3-17). Barcelona: Mundi Prensa Libros SA.

Scavarda, L. (2010). Engineering for the Sustainable Development. International leadership colloquium on quality insurance, accreditation and assessment in higher education. Madrid.

Smerdon, E. (2000). An Action Agenda for Engineering Curriculum Innovation. En 11th IEEE-USA Biennial Careers Conference. San Jose,California.

Tuning América Latina. (2014). Proyecto Tuning América Latina. Obtenido de http://www.tuningal.org

Tünnermann, C. (1998). "La educación permanente y su impacto en la educación superior". UNESCO, Nuevos Documentos sobre la educación superior, mimeo. Paris.

UDEP, U. d. (2014). Maestría en Ingeniería Civil con mención en Ingeniería Vial - Campus Piura. Recuperado el junio de 2014, de http://udep.edu.pe

UNESCO. (2011). Clasificación Internacional Normalizada de la Educación. Recuperado el 24 de mayo de 2014, de http://www.uis.unesco.org

UNESCO. (2010). Engineering: Issues, Challenges and Opportunities for Development. Francia. 
UNESCO. (1998). La educación superior en el siglo XXI: Visión y acción. Obtenido de http://www.unesco.org/education/educprog/wche/declaration_spa.htm

Unicamp, U. E. (2011). Postgrados en Brasil. Recuperado el junio de 2014, de www.ime.unicamp.br

Universidad de Piura. (2008). Ideario de la Universidad de Piura. Piura, Perú.

Universidad de Piura. (2014b). Maestría en Ingeniería Civil con mención en Ingeniería Vial. Recuperado el junio de 2014, de Malla curricular: www.udep.edu.pe

Universidad de Piura. (2011). Manual de Organización y Funciones. Piura, Perú.

Van Ginkel, H. J., \& Rodrígues Días, M. A. (2007). Retos institucionales y políticos de la acreditación en el ámbito internacional. En Global University Network for Innovation. En La Educación Superior en el mundo 2007: Acreditación para la Garantía de la Calidad, Qué está en juego (págs. 37-57). Barcelona: Mundi Prensa Libros SA.

Varghese, N. (2008). Globalization of higher education and cross-border student mobility. Research papers IIEP.

Veugelers, R., \& Cassiman, B. (2005). R\&D cooperation between firms and universities, some empirical evidence from Belgian manufacturing. International Journal of Industrial Organization, , 23.

World Economic Forum. (2012). “The Global Competitiveness Report 2011-2012”. Yarzábal, L. (2005). Internacionalización de la educación superior: de la cooperación académica al comercio de servicios. . Cuadernos de Investigación en la Educación, (20).

Yong Kim, J. (2013). Una América Latina con oportunidades para todos. Análisis y Opinión de Revista América Economía. 
Anexos 
Anexo 1

Algunos indicadores socio económicos de Latinoamérica, Perú y Piura 


\section{INDICADORES SOCIO ECONÓMICOS DE LATINOAMÉRICA}

Pobreza e indigencia en Latinoamérica, en porcentaje de la población total

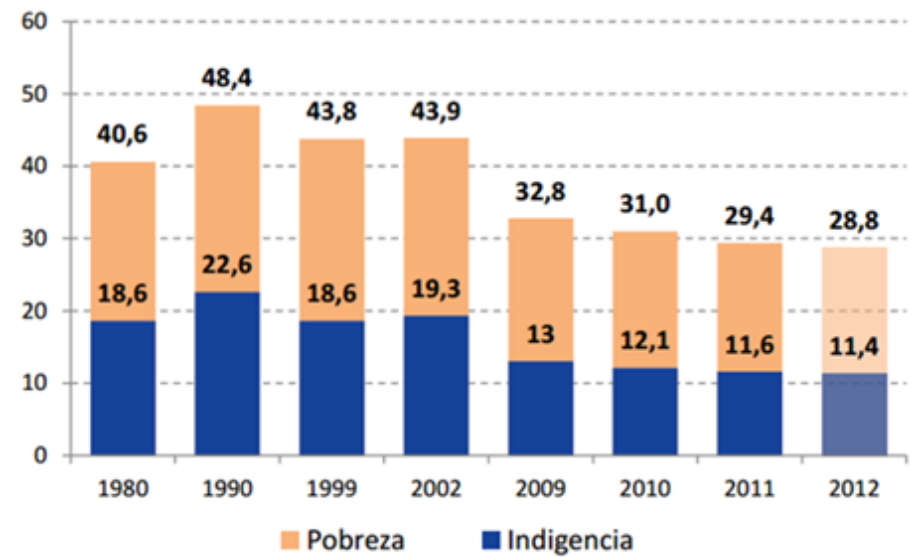

Fuente: (CEPAL, 2013b)

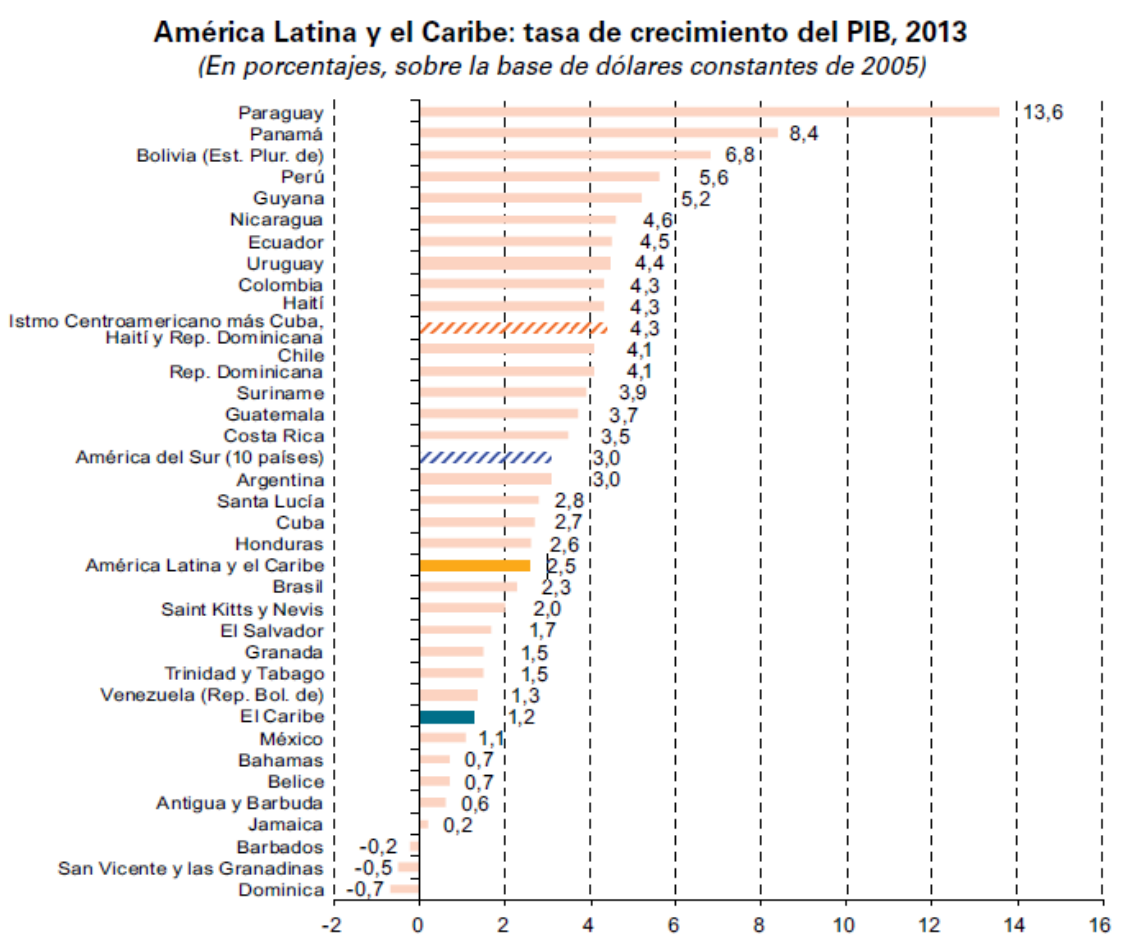

Fuente: (CEPAL, 2014) 
América Latina y el Caribe: producto intemo bruto, 2009-2013

(Tasas anuales de variacion.

\begin{tabular}{|c|c|c|c|c|c|}
\hline & 2009 & 2010 & 2011 & 2012 & $2013=$ \\
\hline América Latina y el Caribe & $-1,6$ & 5,8 & 4,3 & 3,1 & 2,5 \\
\hline América Latina & $-1,5$ & 5,9 & 4,4 & 3,1 & 2,5 \\
\hline Aggentina ${ }^{b}$ & 0,9 & 9,2 & 8,9 & 1,9 & 3,0 \\
\hline Bolivia (Estado Purinacional de) & 3,4 & 4,1 & 5,2 & 5,2 & 6,8 \\
\hline Brasil & $-0,3$ & 7,5 & 2,7 & 1,0 & 2,3 \\
\hline Chile & $-1,0$ & 5,8 & 5,8 & 5,4 & 4,1 \\
\hline Colonbia & 1,7 & 4,0 & 6,6 & 4,2 & 4,3 \\
\hline Costa $\mathrm{F}_{\mathrm{ca}}$ & $-1,0$ & 5,0 & 4,4 & 5,1 & 3,5 \\
\hline Cubs & 1,4 & 2,4 & 2,8 & 3,0 & 2,7 \\
\hline Ecuador & 0,6 & 3,5 & 7,8 & 5,1 & 4,5 \\
\hline BSalvador & $-3,1$ & 1,4 & 2,2 & 1,9 & 1,7 \\
\hline Quaternala & 0,5 & 2,9 & 4,2 & 3,0 & 3,7 \\
\hline Haitl & 2,9 & $-5,4$ & 5,6 & 2,8 & 4,3 \\
\hline Honduras & $-2,4$ & 3,7 & 3,8 & 3,9 & 2,6 \\
\hline Mexico & $-4,7$ & 5,2 & 3,8 & 3,9 & 1,1 \\
\hline Nicaraqua & $-2,2$ & 3,6 & 5,4 & 5,0 & 4,6 \\
\hline Panamab & 4,0 & 5,9 & 10,8 & 10,2 & 8,4 \\
\hline Paraguay & $-4,0$ & 13,1 & 4,3 & $-1,2$ & 13,6 \\
\hline Perób & 1,0 & 8,5 & 6,5 & 6,0 & 5,6 \\
\hline Repoblica Dominicana & 3.5 & 7,8 & 4,5 & 3,9 & 4,1 \\
\hline Lruguay & 2,4 & 8,4 & 7,3 & 3,7 & 4,4 \\
\hline Veneruela (Alepablica Bolivariang de) & $-3,2$ & $-1,5$ & 4,2 & 5,6 & 1,3 \\
\hline ElCaribe & $-3,5$ & 0,1 & 0,5 & 1,2 & 1,2 \\
\hline Antigua y Bartuda & $-12,0$ & $-7,2$ & $-2,0$ & 3,3 & 0,6 \\
\hline Bahartas & $-4,2$ & 1,0 & 1,7 & 1,8 & 0,7 \\
\hline Bartados & $-4,1$ & 0,3 & 0,8 & 0,0 & $-0,2$ \\
\hline Belice & 0,3 & 3,1 & 2,1 & 1,5 & 0,7 \\
\hline Dominica & $-1,1$ & 1,2 & 0,2 & $-1,1$ & $-0,7$ \\
\hline Granada & $-6,6$ & $-0,5$ & 0,8 & $-1,8$ & 1,5 \\
\hline Q.yara & 3,3 & 4,4 & 5,4 & 4,8 & 5,2 \\
\hline Jamaica & $-3,5$ & $-1,5$ & 1,3 & $-0,3$ & 0,2 \\
\hline Saint Kitts y Nevis & $-5,6$ & $-3,2$ & 1,7 & $-1,2$ & 2,0 \\
\hline San Vicante y las Granodinas & $-2,1$ & $-3,3$ & $-0,4$ & 1,6 & $-0,5$ \\
\hline Santa Lucia & $-0,1$ & $-0,7$ & 1,4 & $-1,3$ & 2,8 \\
\hline Suriname & 3,0 & 4,1 & 4,7 & 4,4 & 3,9 \\
\hline Trinidad y Tabago & $-4,4$ & 0,2 & $-1,6$ & 1,5 & 1,5 \\
\hline \multicolumn{6}{|l|}{ Partidas informativas } \\
\hline Centroamerica (3 paises) & 0,8 & 4,8 & 5,1 & 4,7 & 4,3 \\
\hline America del Sur (10 pa'ses) & $-0,2$ & 6,4 & 4,6 & 2,6 & 3,0 \\
\hline
\end{tabular}

Fuente: (CEPAL, 2014) 
América Latina: tasa de variación del PIB y contribución al crecimiento de los componentes de la demanda interna y las exportaciones netas, 2002-2013 ${ }^{\text {a }}$ (En porcentajes, sobre la base de dólares constantes de 2005)

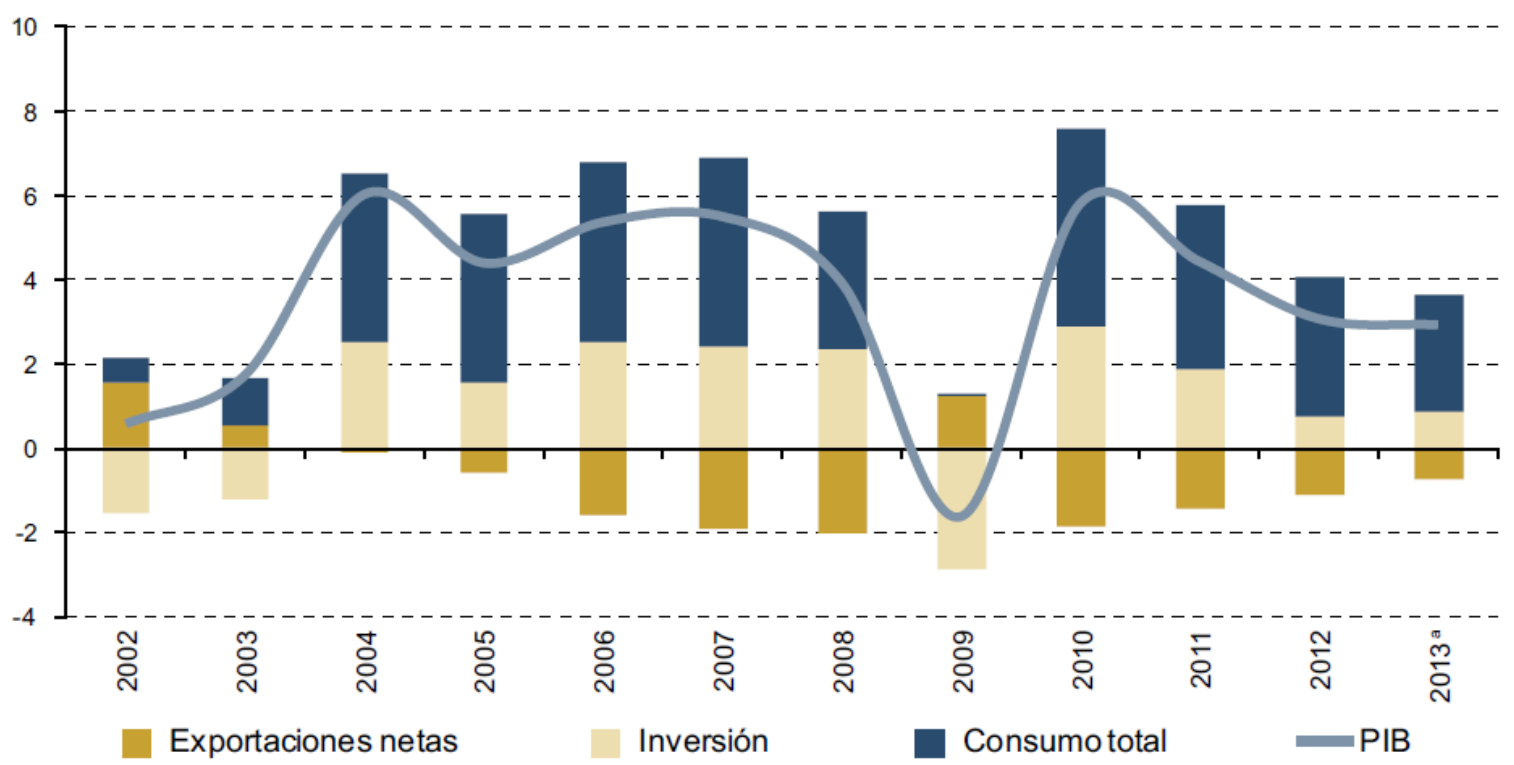

Fuente: (CEPAL, 2013)

AMÉRICA LATINA Y EL CARIBE: INGRESOS DE INVERSIÓN EXTRANJERA DIRECTA POR SUBREGIONES, 1990-2012 (En miles de millones de dólares)

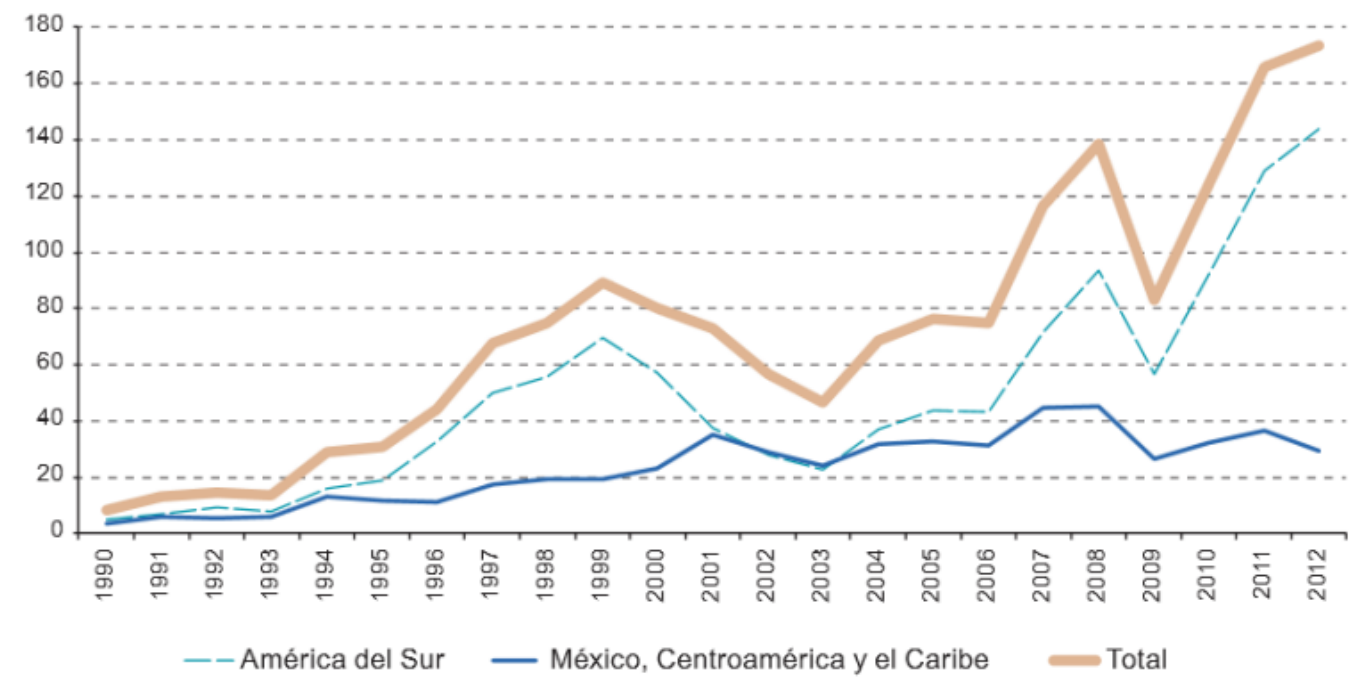

Fuente: (CEPAL, 2013b) 


\section{INDICADORES SOCIO ECONÓMICOS DE PERÚ}

Variación del PIB estimado para 2014 en algunos países de Latinoamérica

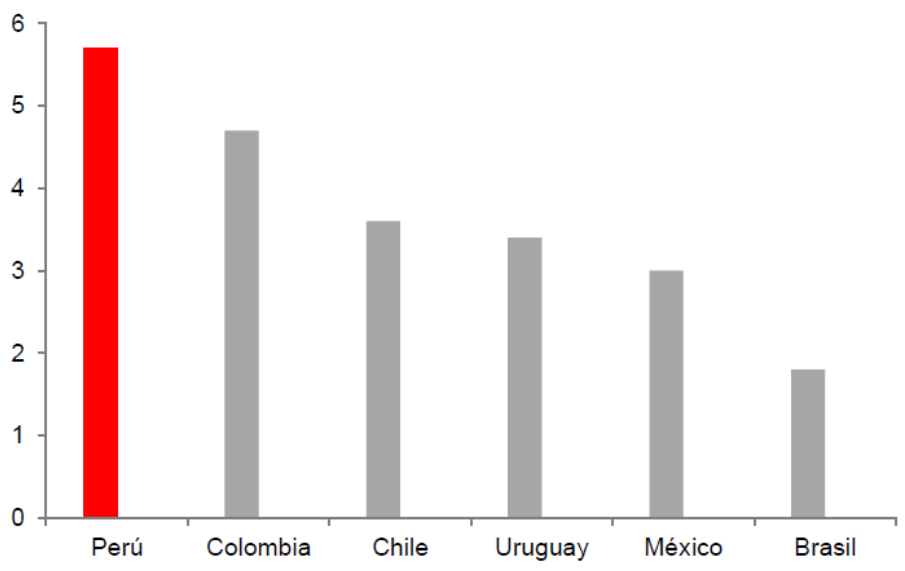

Fuente: (MEF, 2014)

\section{Producto Bruto Interno por Sectores}

\begin{tabular}{|c|c|c|c|c|c|c|c|c|}
\hline & $\begin{array}{l}\text { Ponderación } \\
\text { (Base 2007) }\end{array}$ & 2012 & 2013 & 2014 & 2015 & 2016 & 2017 & $\begin{array}{c}\text { Prom. } \\
2014-2017\end{array}$ \\
\hline Agropecuario & 6,0 & 5,9 & 1,5 & 3,5 & 4,4 & 4,2 & 4,2 & 4,1 \\
\hline Pesca & 0,7 & $-32,2$ & 18,1 & 3,5 & 4,2 & 4,5 & 5,0 & 4,3 \\
\hline Mineria e hidrocarburos & 14,4 & 2,8 & 4,3 & 6,2 & 12,8 & 10,8 & 6,4 & 9,1 \\
\hline Nanuafcura & 16,5 & 1,5 & 4,9 & 4,5 & 4,5 & 4,8 & 4,8 & 4,7 \\
\hline Elecricidad y Agua & 1,7 & 5,8 & 5,5 & 5,7 & 5,8 & 6,0 & 6,0 & 5,9 \\
\hline Constucción & 5,1 & 15,8 & 8,4 & 7,5 & 7,8 & 7,8 & 7,8 & 7,7 \\
\hline Comercio & 10,2 & 7,2 & 5,9 & 6,0 & 6,0 & 6,1 & 6,1 & 6,1 \\
\hline Otos servicios & 37,1 & 7,4 & 6,4 & 6,0 & 6,1 & 6,2 & 6,2 & 6,1 \\
\hline VALOR AGREGADO BRUTO TOTAL & 91,7 & 5,9 & 5,7 & 5,8 & 6,7 & 6,6 & 6,1 & 6,3 \\
\hline Impuestos y derechos de importacion & 8,3 & 6,9 & 4,5 & 4,5 & 4,8 & 4,8 & 4,8 & 4,7 \\
\hline ECONOMIA TOTAL · PBI & 100,0 & 6,0 & 5,6 & 5,7 & 6,5 & 6,5 & 6,0 & 6,2 \\
\hline
\end{tabular}

Fuente: (MEF, 2014)

Perú: Evolución del ingreso real promedio per cápita mensual 2009- 2013 


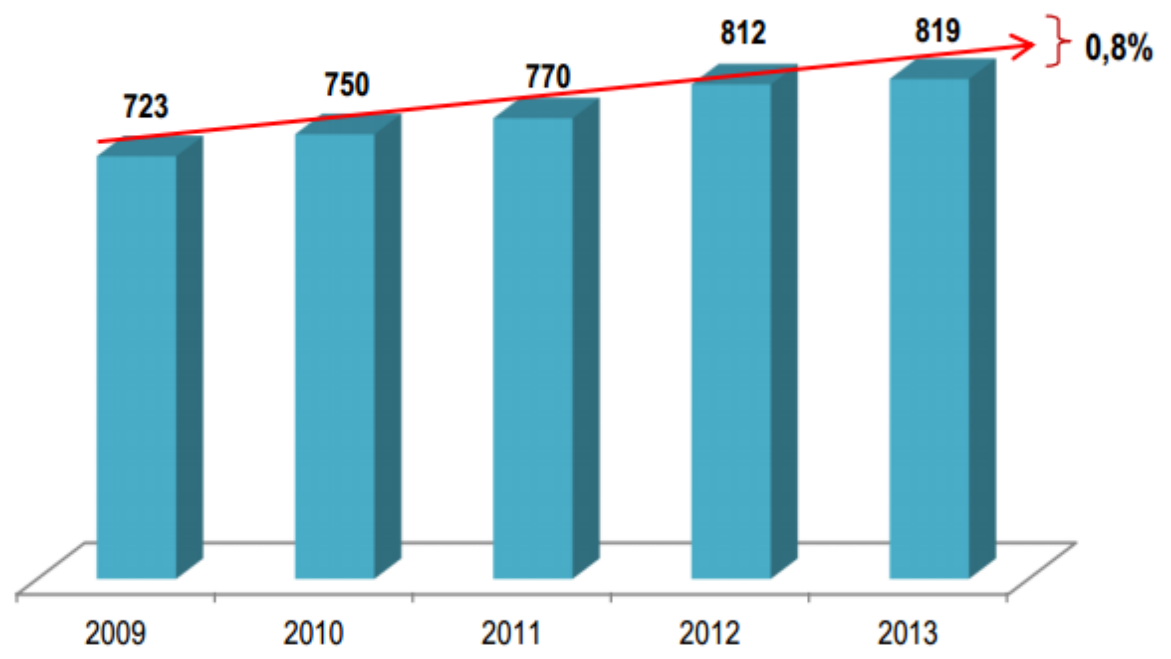

Fuente: Instituto Nacional de Estadistica e Informática - Encuesta Nacional de Hogares 2009 - 2013.

PEA Ocupada a nivel urbano 2005 - 2013 (\%)

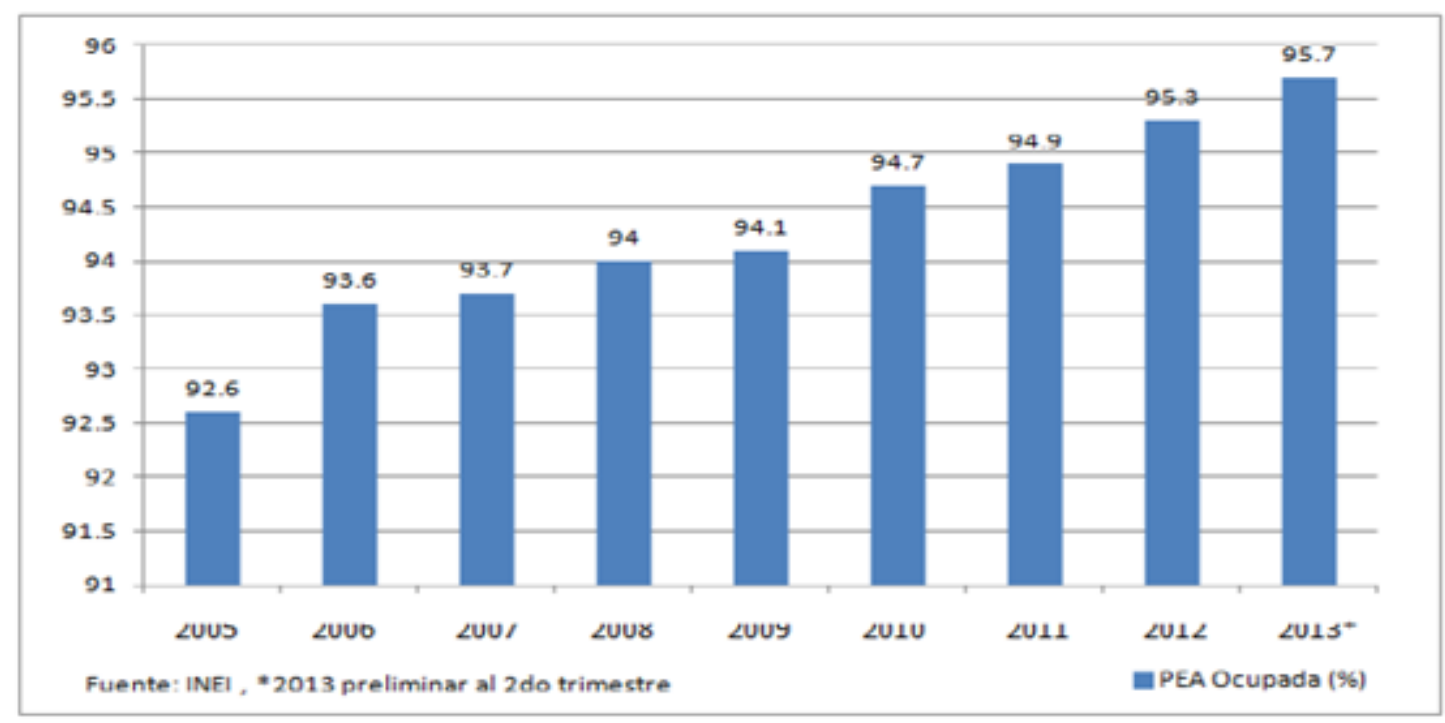


Flujos de Inversión Extranjera Directa al Perú (2000-2012)

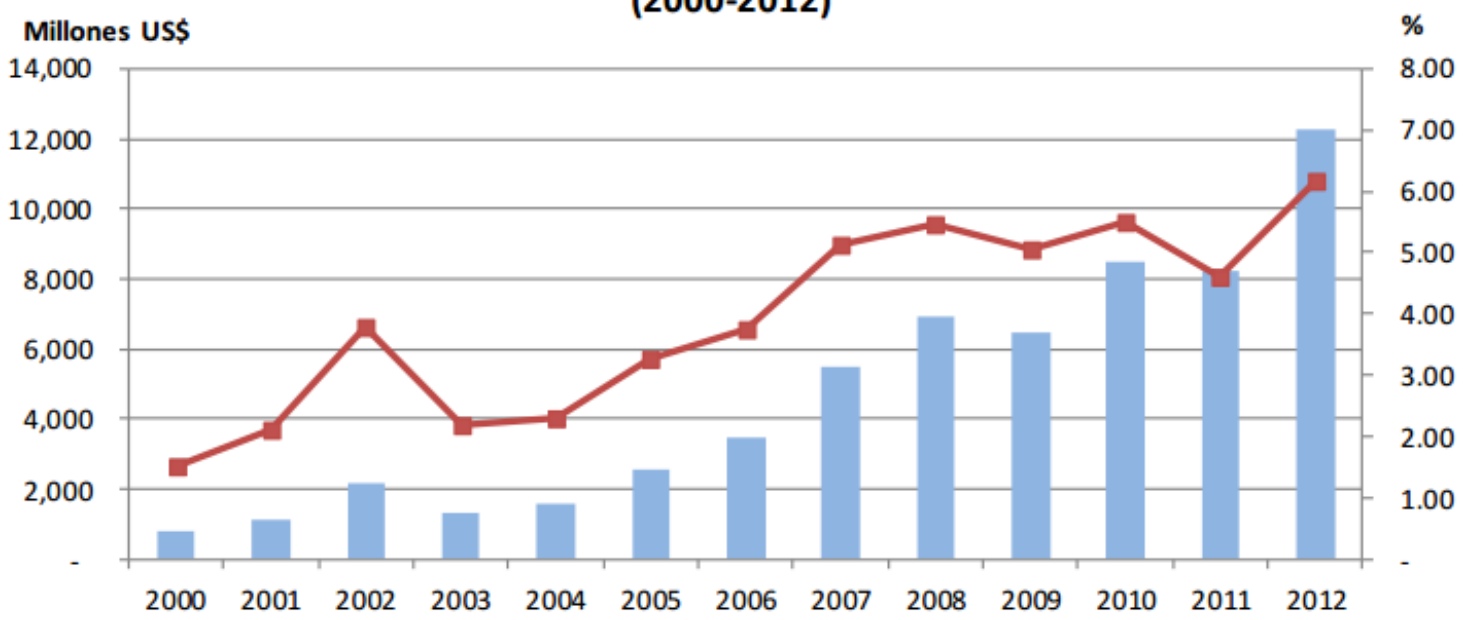

Monto - En \% del PBI (eje derecho)

Deuda pública de Perú y de Latinoamérica (2003 - 2017)

Deuda Pública

(\% del PBI)

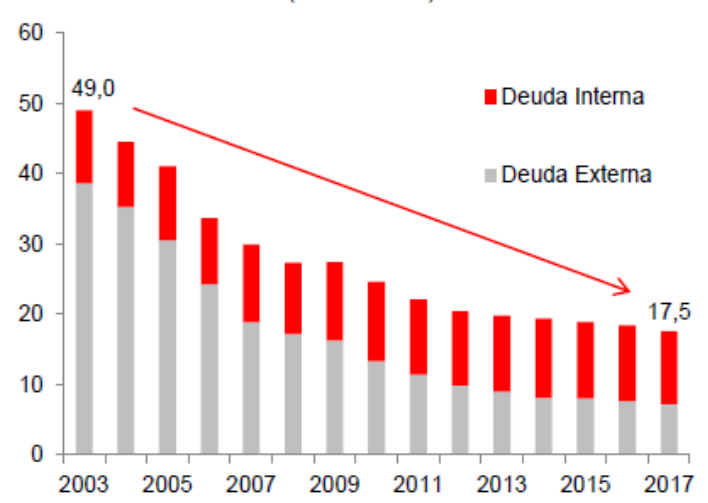

LATAM: Deuda Pública

( $\%$ del PBI)

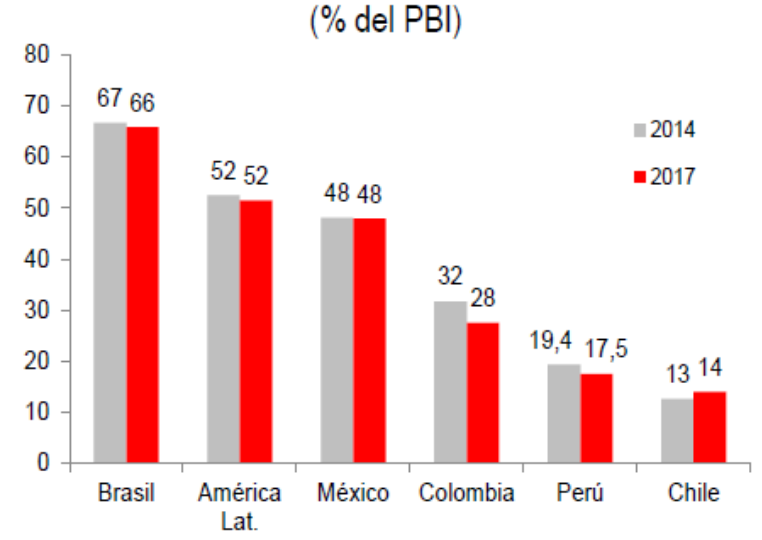

Fuente: (MEF, 2014) 


\section{INDICADORES SOCIO ECONÓMICOS DE PIURA, PERÚ}

Piura. Evolución del PIB per cápita

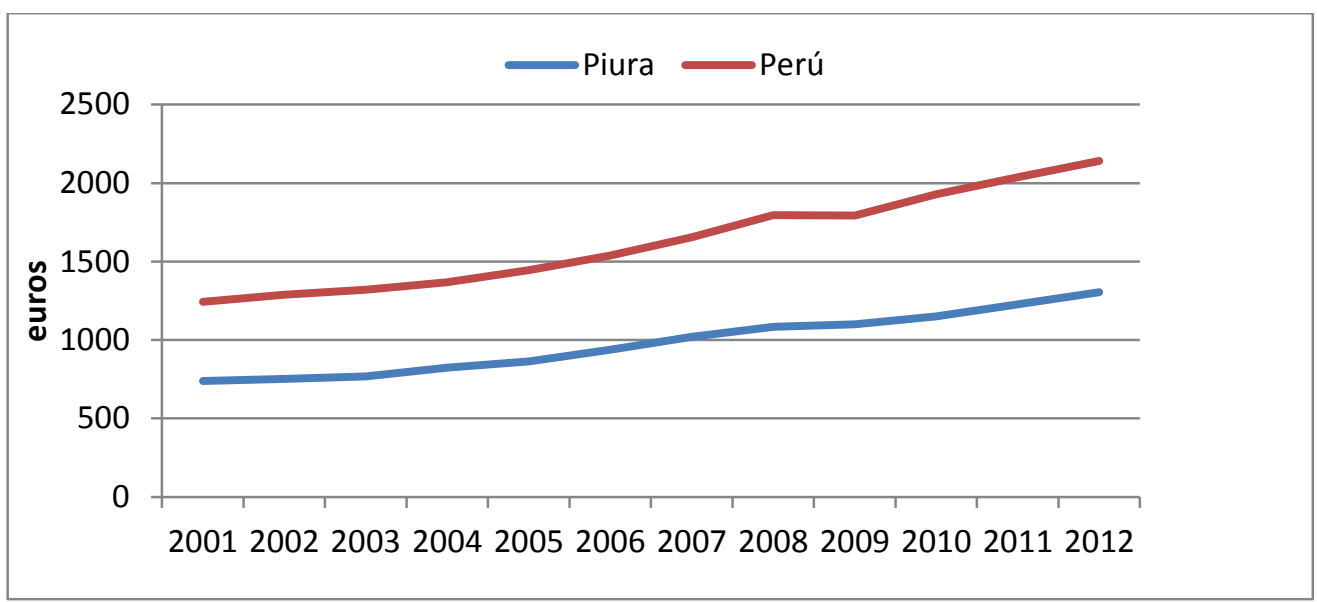

Fuente: Elaboración propia a partir de (INEI, 2014a). Soles constantes de 1994 convertidos s euros

Piura. Contribución de los actividades económicas al valor agregado bruto 2012

\begin{tabular}{clr}
\hline $\mathbf{N}^{\circ}$ & Actividad económica & Porcentaje \\
\hline 1. & Manufactura & $18.8 \%$ \\
2. & Comercio & $17.1 \%$ \\
3. & Construcción & $9.6 \%$ \\
4. & Transportes y comunicaciones & $8.1 \%$ \\
5. & Agricultura, caza y silvicultura & $8.1 \%$ \\
6. & Servicios gubernamentales & $6.0 \%$ \\
7. & Actividad minera & $5.3 \%$ \\
8. & Pesca & $4.9 \%$ \\
9. & Restaurantes y hoteles & $3.8 \%$ \\
10. & Electricidad y agua & $1.6 \%$ \\
11. & Otros servicios & $16.6 \%$ \\
\hline & Total
\end{tabular}

Fuente: Elaboración propia a partir de (INEI, 2014a).

Piura. Evolución PIB - Actividades económicas seleccionadas 


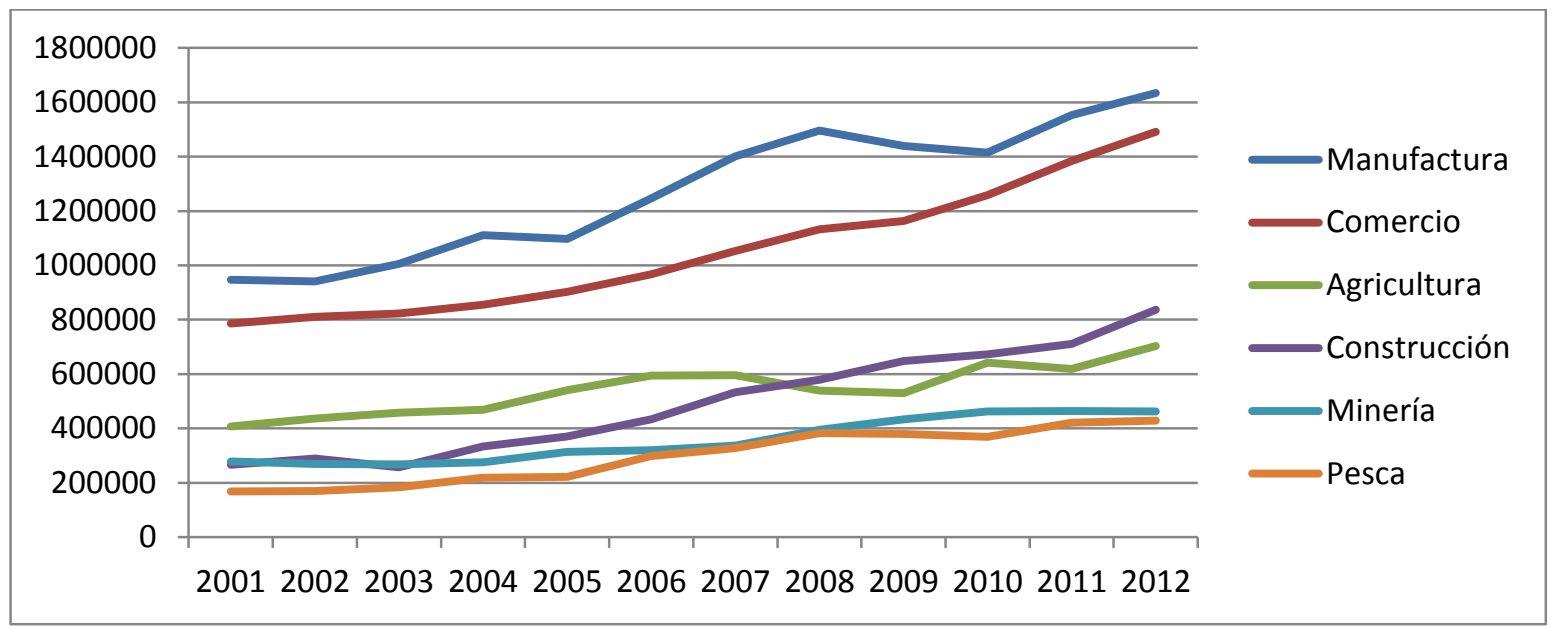

Fuente: Elaboración propia a partir de (INEI, 2014a). Soles constantes de 1994

Piura. Distribución de la PEA ocupada por rama de actividad 2012

\begin{tabular}{lr}
\hline Rama de actividad & \% año $\mathbf{2 0 1 2}$ \\
\hline Agricultura & 27.6 \\
Comercio & 21.0 \\
Manufactura & 8.5 \\
Transportes y comunicaciones & 6.9 \\
Hoteles y restaurantes & 7.1 \\
Construcción & 5.8 \\
Enseñanza & 4.3 \\
Administración Pública, Defensa & 3.5 \\
Inmobiliarias y alquileres & 3.3 \\
Pesca & 1.7 \\
Minería & 1.1 \\
Otros servicios & 9.1 \\
\hline Total & $\mathbf{1 0 0}$
\end{tabular}

Fuente: Elaboración propia a partir de (INEI, Instituto Nacional de Estadística e Informática de Perú, 2013)

Gráfico. Evolución del ingreso promedio mensual proveniente del trabajo Piura 


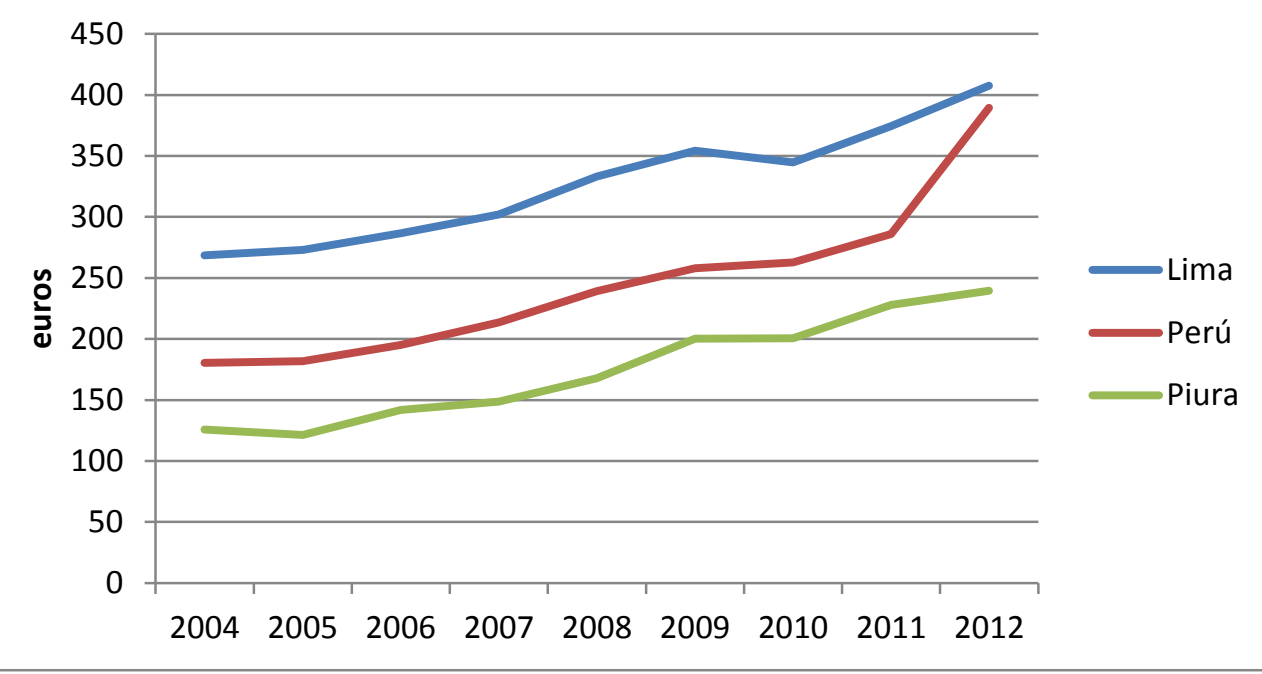

Fuente: Elaboración propia a partir de (INEI, Instituto Nacional de Estadística e Informática de Perú, 2013) 
Principales inversiones privadas en Piura.

\begin{tabular}{clr}
\hline $\mathbf{N}^{\circ}$ & \multicolumn{1}{c}{ Inversión } & \multicolumn{1}{c}{ (millones US\$) } \\
\hline 1. & $\begin{array}{l}\text { Proyecto de modernización de la refinería de Talara, a cargo de } \\
\text { la empresa española Técnicas Reunidas }{ }^{40} .\end{array}$ & 3,500 \\
\hline 2. & $\begin{array}{l}\text { La empresa Cementos Pacasmayo, del grupo Hochschild, inició } \\
\text { la construcción de su nueva planta de cemento }\end{array}$ & 390 \\
\hline 3. & Proyectos Inmobiliarios y centros comerciales & 385 \\
\hline 4. & $\begin{array}{l}\text { La empresa Fosfatos del Pacífico (Fospac) construirá una planta } \\
\text { procesadora de fosfatos.en Bayóvarr }{ }^{42}\end{array}$ & 128 \\
\hline 5. & $\begin{array}{l}\text { Contour Global, propietaria de Energía Eólica S.A., construye la } \\
\text { primera planta de energía eólica del país, con una potencia de 31 }\end{array}$ & 67 \\
& MW. & \\
\hline 6. & $\begin{array}{l}\text { La empresa petrolera Olympic construirá una planta procesadora } \\
\text { de diesel, nafta y asfalto, así como una planta para la producción } \\
\text { de úrea }\end{array}$ & \\
\hline 7. & $\begin{array}{l}\text { Se construyó el tramo Piura - Sullana de la Autopista del Sol, } \\
\text { tramo Piura-Sullana. }\end{array}$ & 28 \\
\hline
\end{tabular}

Fuente: Elaboración propia a partir de Fuente especificada no válida.

Principales inversiones públicas en Piura.

\begin{tabular}{llr}
\hline $\mathbf{N}^{\circ}$ & Inversión & $\begin{array}{r}\text { Monto } \\
\text { (millones } \\
\text { US\$) }\end{array}$ \\
\hline 1. & Proyecto Hidroenergético del Alto Piura & 750 \\
2. & Nuevo Hospital Nuestra Señora de Las Mercedes de Paita & 57 \\
3. & Carretera Piura-Chulucanas & 41 \\
\hline
\end{tabular}

Fuente: Elaboración propia a partir de Fuente especificada no válida.

\footnotetext{
${ }^{40}$ La modernización involucra la construcción de nueve plantas industriales principales y seis auxiliares. Se busca incrementar la capacidad de procesamiento de petróleo desde 65 mil barriles diarios a 95 mil barriles diarios y en la reducción de la contaminación con azufre desde 2 mil partes por millón hasta 50 partes por millón.

${ }^{41}$ La planta tendrá una capacidad de producción de 1,6 millones de toneladas,

${ }^{42}$ Este proyecto es realizado entre las empresas Cementos Pacasmayo, que tiene una participación del 70 por ciento, y la japonesa Mitsubishi, poseedora del 30 por ciento restante.

${ }^{43}$ La planta producirá 200 toneladas diarias de úrea.

44 Inversión total del proyecto
} 
Anexo 2

Algunos indicadores de la educación superior en Latinoamérica y Perú 


\section{INDICADORES DE LA EDUCACIÓN SUPERIOR EN LATINOAMÉRICA}

\section{Matrícula privada}

Participación de la matrícula privada' en el total de la matrícula de educación superior por país, año 2009 (en porcentaje)

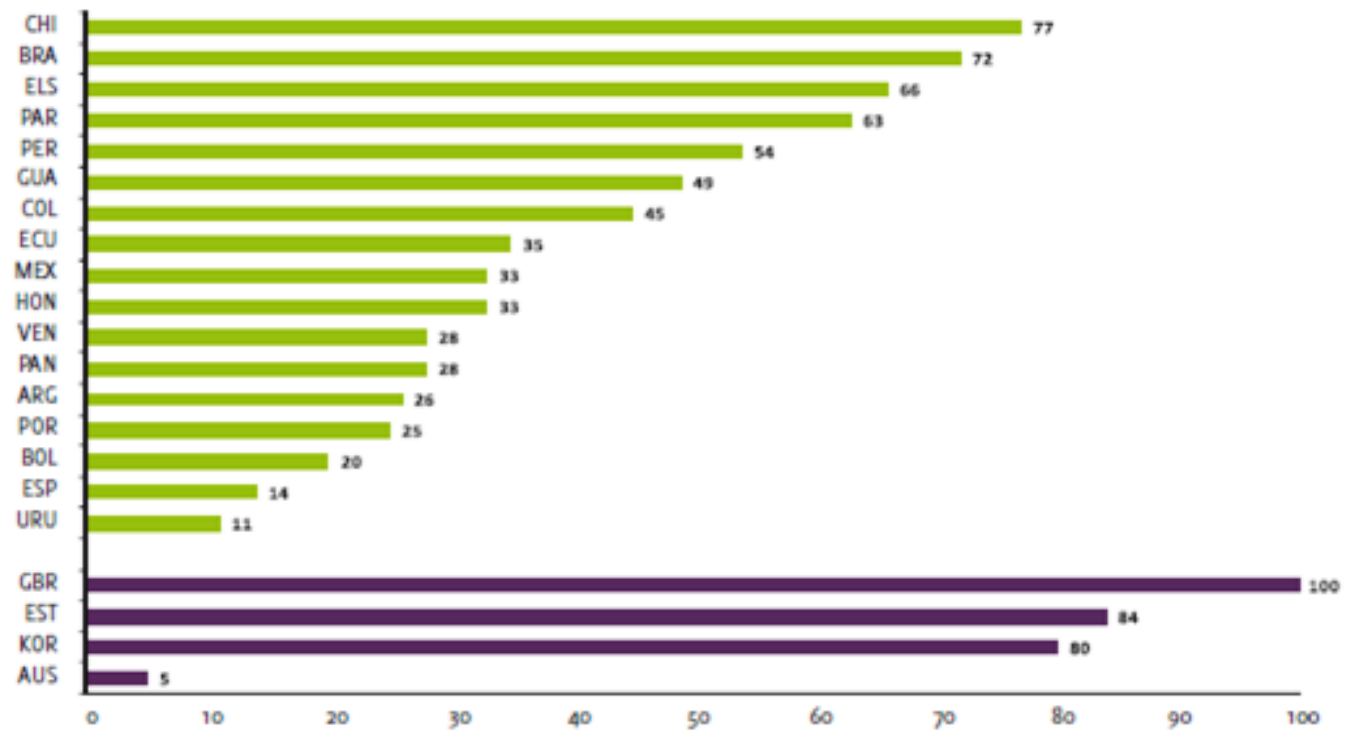

Fuente: Sobre la base de UNESCO, Compendio Mundial de La Educación, 2010.

1: Matricula privada corresponde a aquella registrada en instituciones privadas independientes y dependientes según la clasificación de la OCDE.

Instituciones de educación superior según producción científica, período 2005-2009 (número de instituciones por categoría)

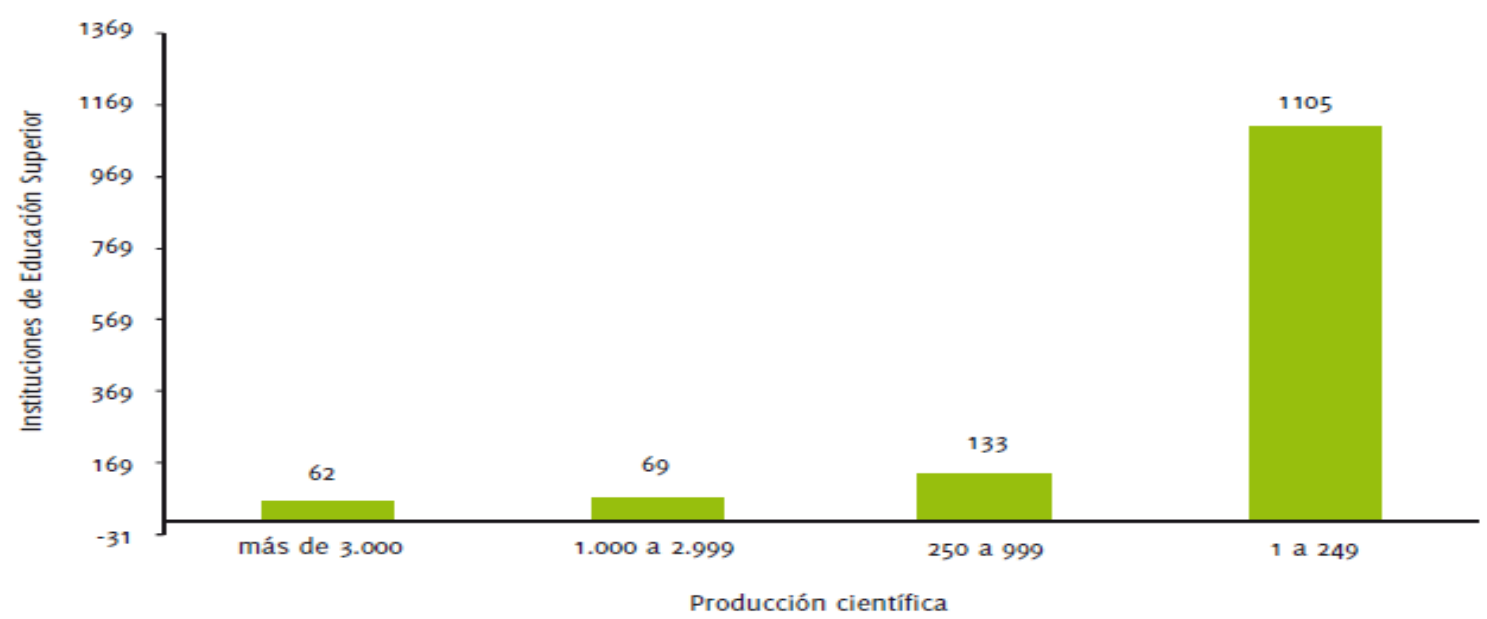

Fuente: Sobre la base de SCImago Institutions Rankings. Ranking Iberoamericano SIR 2011.

Incluye 1.369 instituciones iberoamericanas de enseñanza superior, correspondientes a aquellas que han producido alguna comunicación científica durante el período 2005-2009, indexada en la base de datos Scopus. 
Distribución del gasto en instituciones de educación superior por destino', alrededor de 2008

\begin{tabular}{|c|c|c|c|c|}
\hline míses & Remuneraciones & Otros gastos comientes & Total gasto corriente & Gasto de capital \\
\hline$A R C^{-1}$ & 94.9 & 4,2 & 99,1 & 0,9 \\
\hline BOL & - & - & - & - \\
\hline BRA $^{-1}$ & 74,3 & 20,8 & 95,1 & 49 \\
\hline $\mathrm{CHIl}^{-1}$ & 58,6 & 34,0 & 92,6 & 7,4 \\
\hline $\mathrm{COL}$ & - & - & - & - \\
\hline CRC & - & 100,0 & 100,0 & \\
\hline CUB & 25,6 & 72,9 & 98,5 & 1,5 \\
\hline ECU & - & - & - & - \\
\hline ELS $^{2}$ & 61,4 & 17,7 & 79,1 & 20,9 \\
\hline GUA & - & - & - & - \\
\hline HON & - & - & - & - \\
\hline $\mathrm{MEX}^{-9}$ & 67,1 & 28,2 & 95,2 & 48 \\
\hline NIC & - & - & - & - \\
\hline PAN & 91,8 & - & 91,8 & 8,2 \\
\hline PAR $^{-1}$ & 71,9 & 16,3 & 88,2 & 11,8 \\
\hline PER & 62,0 & 17,0 & 79,0 & 21,0 \\
\hline $\mathrm{RDM}^{-9}$ & 90,5 & - & 90,5 & 9,5 \\
\hline $\mathrm{URU}^{\mathrm{x}}$ & 75,1 & 18,9 & 93,9 & 6,1 \\
\hline VEN & - & - & 97,2 & 2,8 \\
\hline ESP" & 61,8 & 18,6 & 80,4 & 19,6 \\
\hline $\mathrm{POR}^{2}$ & 62,1 & $27,4-2$ & 89.5 & 10,5 \\
\hline AUS $^{-1}$ & 53,9 & 34,8 & 88,7 & 11,3 \\
\hline $\mathrm{CAN}^{2}$ & 58,8 & 33,6 & 92,5 & 2.5 \\
\hline $\mathrm{KOR}^{-1}$ & 45.7 & 38,4 & 84,1 & 15,9 \\
\hline EST & - & - & - & - \\
\hline GBR & - & - & - & - \\
\hline
\end{tabular}

Fuente: Unesco, Compendio Mundial de la Fducación 2010.

httpl/unesdoc.unesco.org/images/0019/001912/191218s.pdf

OECD, Edacation at a Clance 2010: OECD Indicators.

https/www.oecd.org/document/52/0,3746,en_2649_39263238_45897844_1_1_1_1,00.html

n- Los datos se refieren al n años o períodos antes del año o período de referencia

1: Referido solamente a instituciones públicas de educación superior 


\section{INDICADORES DE LA EDUCACIÓN SUPERIOR EN PERÚ}

PERỦ: POBLACION UNIVERSITARIA, POR AÑO CENSAL Y TASA DE CRECIMIENTO ANUAL, SEGÚN TIPO DE UNIVERSIDAD

\begin{tabular}{|c|c|c|c|c|c|}
\hline \multirow{2}{*}{ TIPO DE UNIVERSIDAD } & \multirow{2}{*}{$\begin{array}{l}\text { NÚMERO DE } \\
\text { UNIVERSIDAD }\end{array}$} & \multicolumn{2}{|c|}{ ALUMNOS } & \multirow{2}{*}{$\begin{array}{r}\text { DOCENTES } \\
\text { UNIVERSITARIOS }\end{array}$} & \multirow{2}{*}{$\begin{array}{r}\text { PERSONAL } \\
\text { ADMINISTRATIVOY } \\
\text { DE SERVICIOS }\end{array}$} \\
\hline & & PRE GRADO & POST GRADO & & \\
\hline & \multicolumn{5}{|c|}{ AÑO 2010} \\
\hline TOTAL & 100 & 782970 & 56358 & 59085 & 39017 \\
\hline PÚBLICAS & 35 & 309175 & 24591 & 21434 & 19961 \\
\hline \multirow[t]{2}{*}{ PRIVADAS } & 65 & 473795 & 31767 & 37651 & 19056 \\
\hline & \multicolumn{5}{|c|}{ AÑo 1996} \\
\hline TOTAL & 57 & 335714 & 10818 & 25795 & 16989 \\
\hline PÚBLICAS & 28 & 199943 & 7109 & 16096 & 11708 \\
\hline \multirow[t]{2}{*}{ PRIVADA } & 29 & 135771 & 3709 & 9699 & 5281 \\
\hline & \multicolumn{5}{|c|}{ TASA DE CRECIMIENTO ANUAL PERIODO 1996-2010 } \\
\hline TOTAL & 4,2 & 6,2 & 12,4 & 5,2 & 6,1 \\
\hline PÚBLICAS & 1,6 & 3,1 & 9,2 & 1,4 & 3,9 \\
\hline PRIVADA & 6,0 & 9,3 & 16,5 & 9,1 & 9,6 \\
\hline
\end{tabular}

NOTA: Incluye todas las universidades que vienen funcionando formalmente en el Sistema Universitario Peruano FUENTE: INEI-\|CENSO NACIONAL UNIVERSITARIO, 2010. INEI-ICENSO NACIONALUNIVERSITARIO, 1996.

PERÚ: PORCENTAJE DE DOCENTES UNIVERSITARIOS, POR CONDICIÓN LABORAL, SEGÚN TIPO DE UNIVERSIDAD

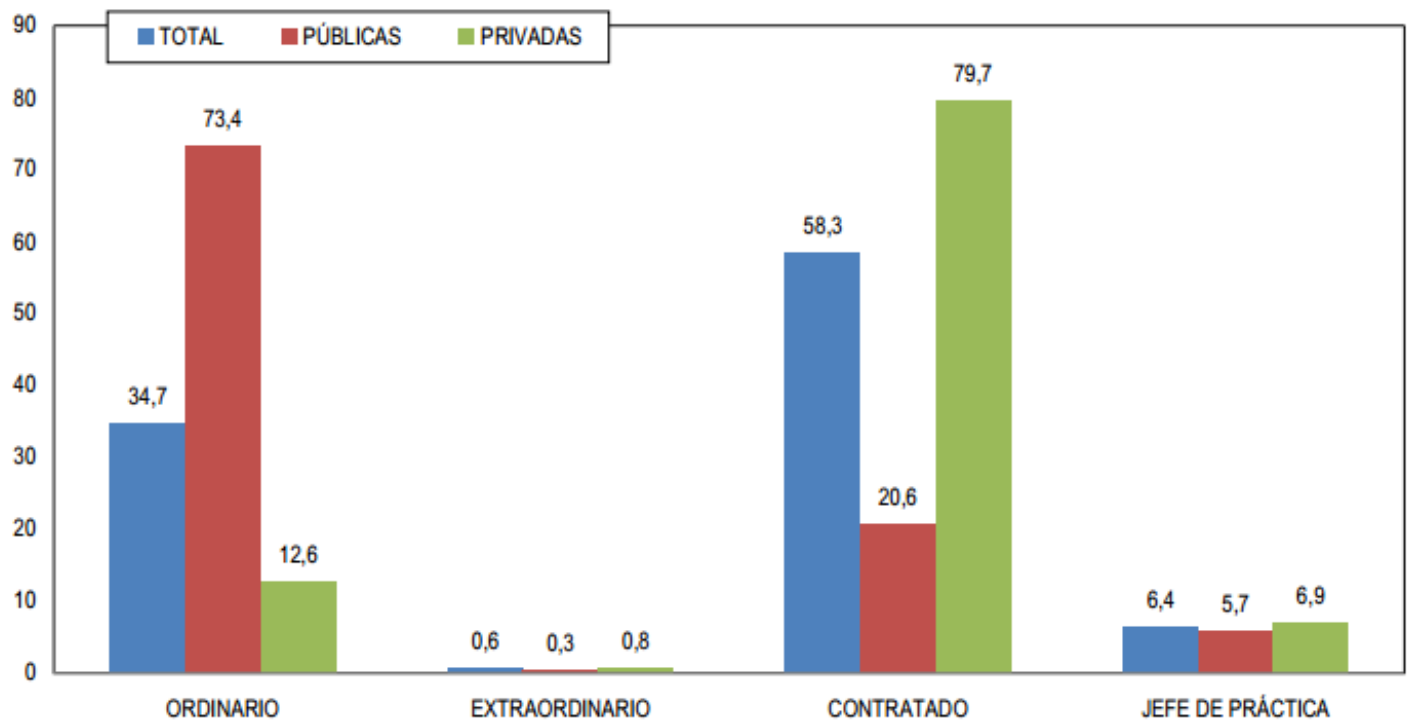

FUENTE: INEI- II CENSO NACIONALUNIVERSITARIO, 2010. 
PERÚ: PROFESIONES O CARRERAS UNIVERSITARIAS DE LAS PERSONAS DE 17 Y MÁS AÑOS DE EDAD, 20072012 (Porcentaje del total de la población de 17 y más años de edad)

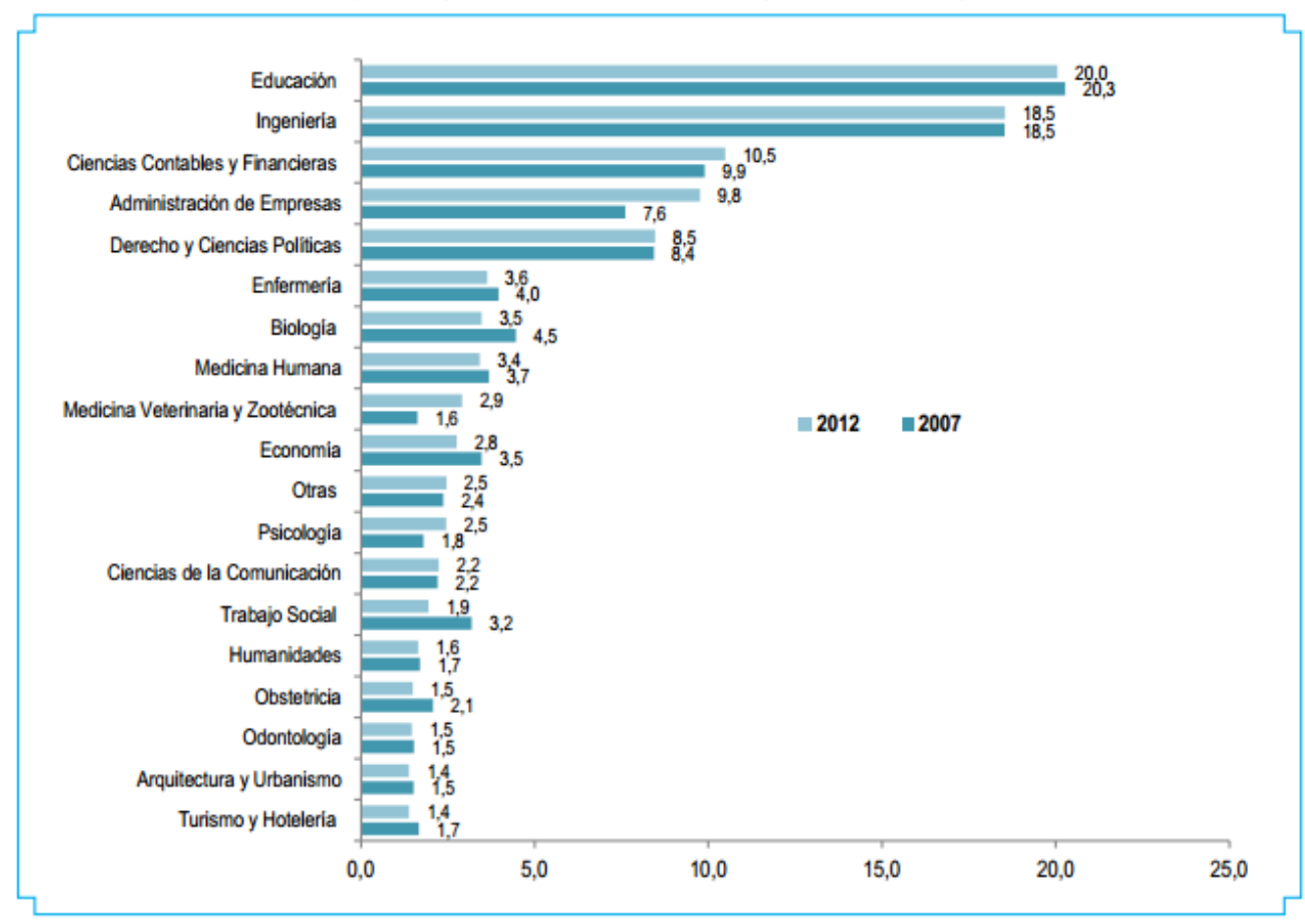

Fuente: Instituto Nacional de Estadistica e Informática - Encuesta Nacional de Hogares.

PERÚ: PORCENTAJE DE ALUMNOS DE POST GRADO, POR GRUPOS DE EDAD

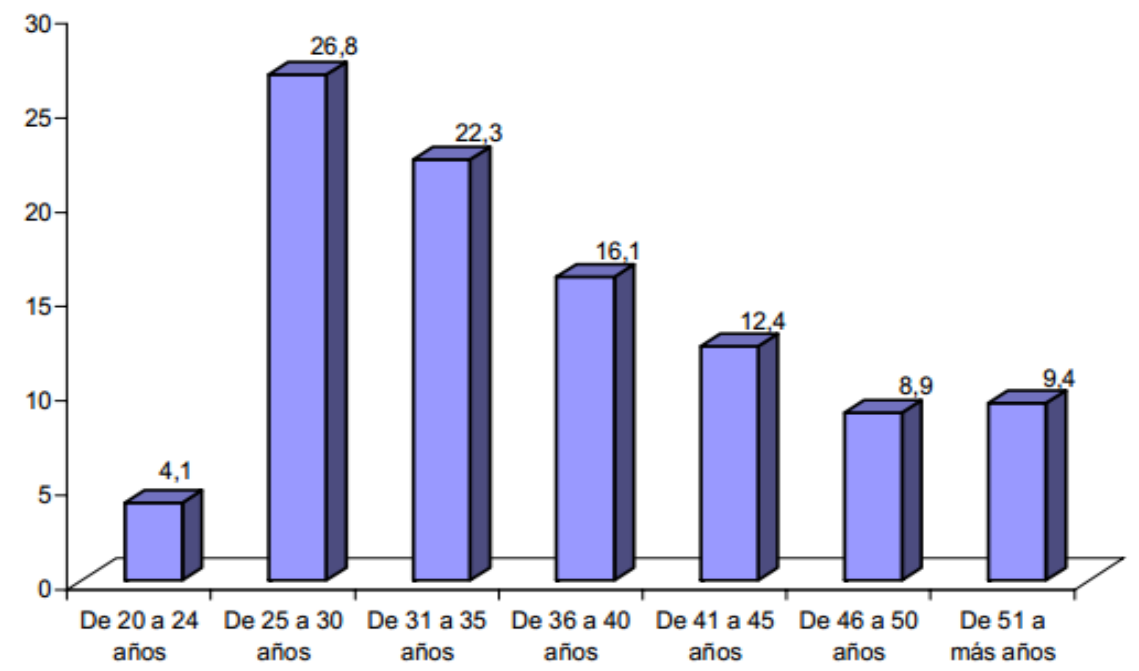

FUENTE: INEI- |I CENSO NACIONALUNIVERSITARIO, 
PERÚ: PORCENTAJE DE ALUMNOS DE POST GRADO, POR LUGAR DE NACIMIENTO, SEGÚN TIPO DE UNIVERSIDAD

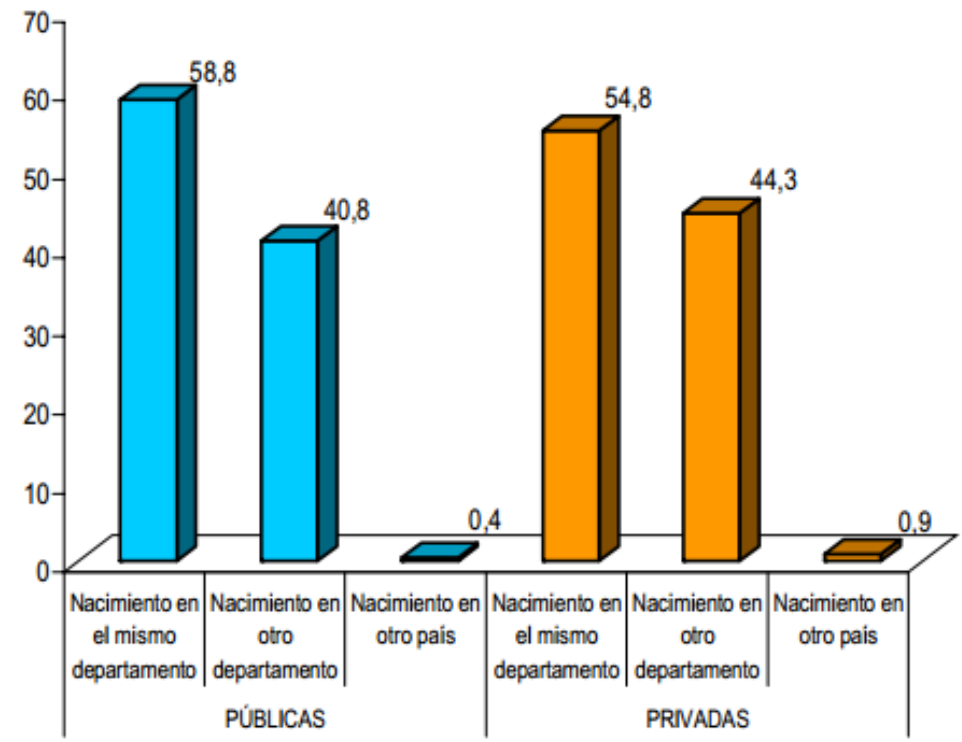

FUENTE: INEI- II CENSO NACIONAL UNIVERSITARIO, 2010.

PERÚ: PROMEDIO DE AÑOS TRANSCURRIDOS ENTRE EL EGRESO DE PRE GRADO Y EL INGRESO A POST GRADO, SEGÚN ESTUDIO DE POST GRADO

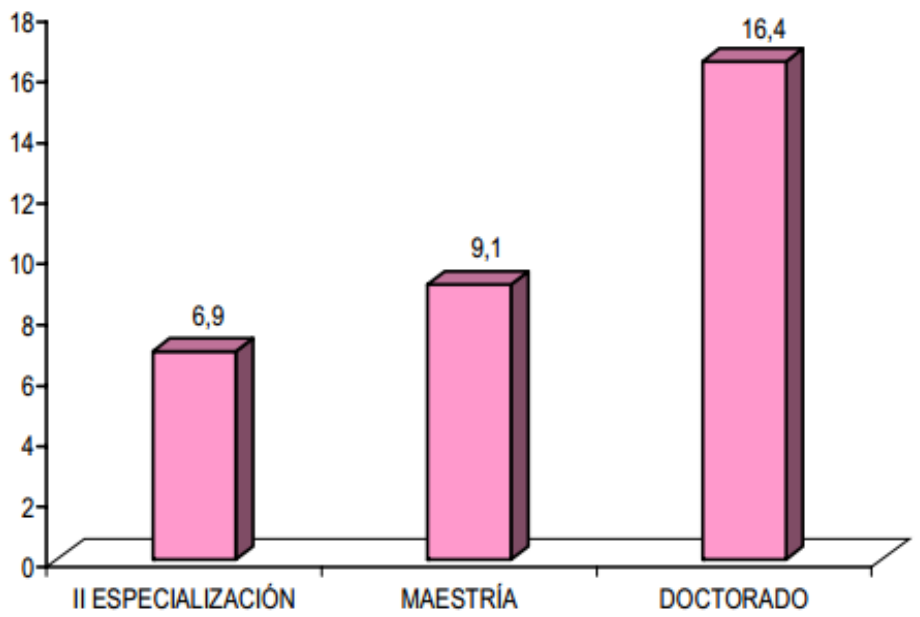

FUENTE: INEI-II CENSO NACIONAL UNIVERSITARIO, 2010. 
Gasto en Ciencia, Tecnología e Innovación, 1999-2012

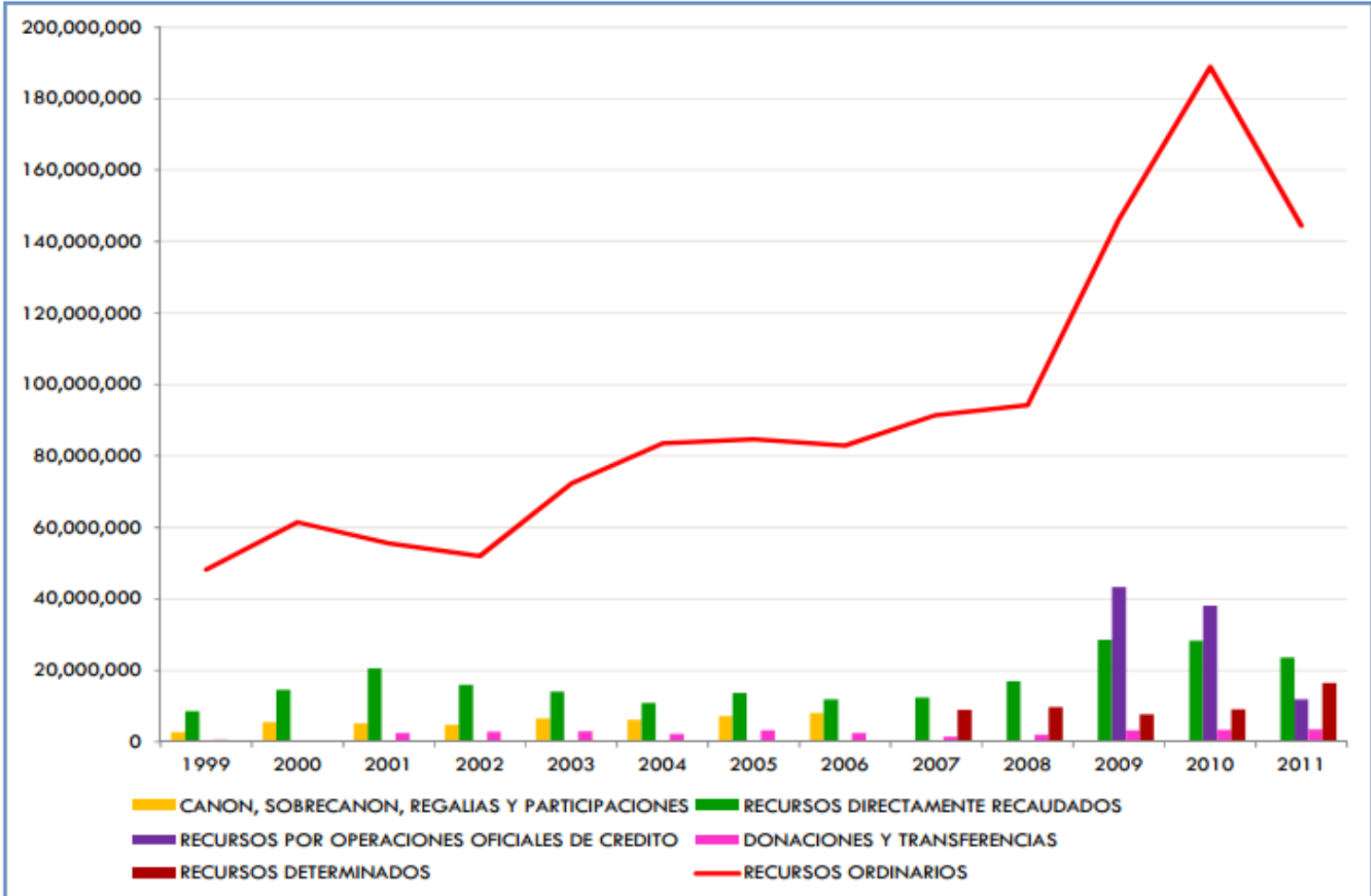

Fuente: Fuente especificada no válida. 
Perú: Inversión en CTI al 2016 en millones de euros

\begin{tabular}{|c|c|c|c|c|}
\hline Instrumento & $\begin{array}{l}\text { Unidad de } \\
\text { medida }\end{array}$ & $\begin{array}{l}\text { Línea } \\
\text { Base }\end{array}$ & $\begin{array}{l}\text { Meta } \\
2016\end{array}$ & $\begin{array}{r}\text { Inversión } \\
\text { acumulada } \\
\text { al } 2016\end{array}$ \\
\hline Financiamiento de investigación & Proyectos & 122 & 1000 & 304.1 \\
\hline $\begin{array}{l}\text { Plataformas conjuntas de } \\
\text { investigación }\end{array}$ & Laboratorios & 0 & 2 & 81.1 \\
\hline $\begin{array}{l}\text { Formación de capital humano } \\
\text { programas }\end{array}$ & Programas & 6 & 40 & 73.0 \\
\hline Parques tecnológicos & $\begin{array}{l}\text { Parques } \\
\text { tecnológicos }\end{array}$ & 0 & 5 & 54.1 \\
\hline Centros de excelencia & Centros & 0 & 10 & 54.1 \\
\hline Formación de capital humano becas & Becarios & 0 & 300 & 36.5 \\
\hline Cuerpo de investigadores del Perú & Investigadores & 0 & 500 & 34.1 \\
\hline Fortalecimiento de cadenas de valor & $\begin{array}{l}\text { Cadenas } \\
\text { fortalecidas }\end{array}$ & 0 & 6 & 27.0 \\
\hline Apoyo a clusters regionales & $\begin{array}{l}\text { Clusters } \\
\text { fortalecidos }\end{array}$ & 0 & 6 & 16.2 \\
\hline Incentivos por investigación & $\begin{array}{l}\text { Subvención } \\
\text { mensual }\end{array}$ & 0 & 1500 & 14.6 \\
\hline $\begin{array}{l}\text { Financiamiento para extensión } \\
\text { tecnológica }\end{array}$ & Proyectos & 0 & 40 & 12.2 \\
\hline $\begin{array}{l}\text { Programa de acceso a bibliotecas } \\
\text { electrónicas }\end{array}$ & Bases de datos & 1 & 4 & 8.6 \\
\hline $\begin{array}{l}\text { Incentivos tributarios + Programa } \\
\text { de compras públicas de base } \\
\text { tecnológica }\end{array}$ & $\begin{array}{l}\text { Normas } \\
\text { diseñadas }\end{array}$ & 1 & 4 & 0.3 \\
\hline
\end{tabular}

Total

Fuente: (CONCYTEC C. N., 2014). Tipo de cambio utilizado 3.7 soles por euro 
CONCYTEC ha definido algunas áreas o sectores prioritarios para focalizar los esfuerzos de desarrollo de la ciencia, la tecnología y la innovación en Perú ${ }^{45}$. Se definieron 5 programas nacionales transversales y 16 clústeres prioritarios.

\section{Programas nacionales de CTI - Perú}

\begin{tabular}{|c|c|c|}
\hline $\mathbf{N}^{\circ}$ & Programa CTI & Componentes \\
\hline 1. & Biotecnología. & $\begin{array}{l}\text { - Seguridad alimentaria y nutrición. } \\
\text { - Valorización de la biodiversidad. } \\
\text { - Salud. }\end{array}$ \\
\hline 2. & Materiales & $\begin{array}{l}\text { - Polímeros naturales y artificiales. } \\
\text { - Metales. } \\
\text { - Materiales cerámicos y minerales no metálicos. } \\
\text { - Nano materiales, materiales compuestos y } \\
\text { semiconductores. }\end{array}$ \\
\hline 3. & $\begin{array}{l}\text { Ciencia y Tecnología } \\
\text { Ambiental }\end{array}$ & $\begin{array}{l}\text { - Cambio climático, riesgos ambientales, conservación y } \\
\text { uso sostenible de los recursos naturales y de la } \\
\text { diversidad biológica. } \\
\text { - Calidad ambiental. }\end{array}$ \\
\hline 4. & $\begin{array}{l}\text { Tecnologías de la } \\
\text { Información y } \\
\text { Comunicación }\end{array}$ & $\begin{array}{l}\text { - Investigación y desarrollo. } \\
\text { - Innovación en la industria nacional de TIC. } \\
\text { - Extensión y transferencia tecnológica a los sectores y a } \\
\text { la sociedad. }\end{array}$ \\
\hline 5. & $\begin{array}{l}\text { Transferencia } \\
\text { Tecnológica para la } \\
\text { Inclusión Social }\end{array}$ & $\begin{array}{l}\text { - Transferencia tecnológica en cultivos y crianzas. } \\
\text { - Transformación agroindustrial. } \\
\text { - Transferencia tecnológica en salud y ambiente. } \\
\text { - Transferencia tecnológica en educación productiva, } \\
\text { organización y gestión. }\end{array}$ \\
\hline
\end{tabular}

Fuente: (CONCYTEC C. N., 2014)

\footnotetext{
${ }^{45}$ Las áreas se priorizaron teniendo en considerando el potencial estratégico de desarrollo, su contribución a la competitividad del país y la mejora del desempeño de las empresas.
} 
Clústeres priorizados por CONCYTEC - Perú para el desarrollo de CTI

\begin{tabular}{l} 
Clúster priorizado \\
\hline 1. Minero Norte y Auxiliar Minero Lima y Arequipa \\
2. Turismo Cultural Cuzco \\
3. Moda Vestir en Lima \\
4. Logística en el Callao \\
5. Pesca: Harina y Aceite de Pescado de la costa \\
6. Pelos Finos Arequipa-Cuzco-Puno \\
7. Construcción en Lima \\
8. Pesca: Pescado Congelado y Conservas de la costa \\
9. Gastronomía \& Food Service en Lima \\
10. Café del Norte \\
11. Software en Lima \\
12. Cárnico en Lima \\
13. Auxiliar Agroalimentario en Lima \\
14. Salud en Lima \\
15. Hortofrutícola en la Costa \\
16. Auxiliar Automotriz en Lima
\end{tabular}

Fuente: (CONCYTEC C. N., 2014) 


\section{Anexo 3}

Instrumentos de recogida de información en el modelo propuesto

Encuestas y guías de entrevista 


\section{ENCUESTA A ESTUDIANTES DE LA MAESTRÍA}

La Universidad está interesada en mejorar la calidad de enseñanza y los servicios de sus programas de postgrado. Para ello, requerimos de unos minutos de su tiempo para responder la siguiente encuesta, según su experiencia adquirida durante el programa de maestría. Agradecemos sinceramente su colaboración.

\section{DATOS GENERALES}

\section{Indique su especialidad:}
a. Mecánica
b. Eléctrica
c. Electrónica
d. Mecánico eléctrica
e. Civil
f. Industrial
g. Industrial y de Sistemas
h. Sistemas o Informática
i. Agrícola o agronómica
j. Petrolera y petroquímica
k. Química
1. Agroindustria
m. Pesquería
n. Minas
o. Geología
p. Otro (especificar):

\section{PERTINENCIA DE LA MAESTRÍA}

A continuación se presentan una serie de afirmaciones. Por favor indique con un aspa X su grado de acuerdo con cada una de ellas, utilizando la siguiente escala:

1. Muy en desacuerdo; 2. En desacuerdo; 3. Ni de acuerdo ni en desacuerdo; 4. De acuerdo; 5. Muy de acuerdo

\begin{tabular}{|l|l|l|l|l|l|}
\cline { 2 - 5 } \multicolumn{1}{c|}{} & 1 & 2 & 3 & 4 & 5 \\
\hline $\begin{array}{l}\text { Los conocimientos adquiridos en la maestría me están } \\
\text { ayudando a un mejor desempeño laboral. }\end{array}$ & & & & & \\
\hline
\end{tabular}


Los temas dictados durante la maestría se relacionan con los temas de mi trabajo o son de mi interés.

Hay correspondencia entre la misión y objetivos de la maestría con su plan de estudios.

La maestría aprovecha las oportunidades locales y nacionales para beneficio de sus estudiantes y docentes.

El plan de estudios de la maestría ayuda a satisfacer necesidades reales de la localidad y del país.

Las asignaturas promueven la transdisciplinariedad y la innovación.

Se utiliza un enfoque de aprendizaje basado en proyectos.

\section{DATOS DEL ENCUESTADO}

\begin{tabular}{|l|l|}
\hline Título de la maestría: & \\
\hline $\begin{array}{l}\text { Año en el que inició la } \\
\text { maestría: }\end{array}$ & \\
\hline Empresa: & \\
\hline Nombres y apellidos: & \\
\hline Email: & \\
\hline Teléfono: & \\
\hline
\end{tabular}

¡Muchas gracias por su tiempo y colaboración! 


\section{ENCUESTA A DOCENTES DE LA MAESTRÍA}

Estimado docente.

La Universidad está buscando generar una experiencia de aprendizaje que le permita mejorar la calidad y pertinencia de sus programas de postgrado. Para ello, requerimos de unos minutos de su tiempo para responder la siguiente encuesta, según su experiencia adquirida durante el programa de maestría donde usted enseña. Agradecemos sinceramente su colaboración.

\section{DATOS DEL DOCENTE}

\begin{tabular}{|c|c|}
\hline \multicolumn{2}{|l|}{$\begin{array}{l}\text { Título de la maestría donde } \\
\text { enseña: }\end{array}$} \\
\hline Nombres y apellidos: & \\
\hline Edad: & \\
\hline Grado máximo obtenido: & \\
\hline Email: & \\
\hline Teléfono: & \\
\hline Procedencia: & $\begin{array}{l}\text { a. De la universidad que imparte la maestría. } \\
\text { b. De otra universidad nacional } \\
\text { c. De otra universidad extranjera } \\
\text { d. No académico nacional o internacional }\end{array}$ \\
\hline Universidad / Empresa: & \\
\hline $\begin{array}{l}\text { Departamento académico / área } \\
\text { de la empresa o institución: }\end{array}$ & \\
\hline $\begin{array}{l}\text { Indique su especialidad (de } \\
\text { pregrado): }\end{array}$ & \\
\hline
\end{tabular}

\section{PERTINENCIA DE LA MAESTRÍA}

A continuación se presentan una serie de afirmaciones. Por favor indique con un aspa X su grado de acuerdo con cada una de ellas, utilizando la siguiente escala:

1. Muy en desacuerdo; 2. En desacuerdo; 3. Ni de acuerdo ni en desacuerdo; 4. De acuerdo;

5. Muy de acuerdo 


\begin{tabular}{|c|c|c|c|c|c|}
\hline & \\
\hline & 1 & 2 & 3 & 4 & 5 \\
\hline \multicolumn{6}{|l|}{$\begin{array}{l}\text { Actualizo los syllabus considerando la opinión de } \\
\text { estudiantes y egresados. }\end{array}$} \\
\hline \multicolumn{6}{|l|}{$\begin{array}{l}\text { He publicado algún paper en ISI, Scopus o Scient Direct } \\
\text { utilizando el nombre de la universidad, en los dos últimos } \\
\text { años. }\end{array}$} \\
\hline \multicolumn{6}{|l|}{$\begin{array}{l}\text { La maestría aprovecha las oportunidades locales y } \\
\text { nacionales para beneficio de sus estudiantes y docentes. }\end{array}$} \\
\hline \multicolumn{6}{|l|}{$\begin{array}{l}\text { Participo en redes o asociaciones científicas y } \\
\text { profesionales. }\end{array}$} \\
\hline \multicolumn{6}{|l|}{ Tengo movilidad académica. } \\
\hline \multicolumn{6}{|l|}{$\begin{array}{l}\text { Actualizo los syllabus incorporando los resultados de mis } \\
\text { investigaciones o los resultados de investigaciones } \\
\text { recientes en el tema. }\end{array}$} \\
\hline \multicolumn{6}{|l|}{$\begin{array}{l}\text { La organización de la universidad facilita la investigación } \\
\text { multidisciplinaria y centrada en problemas. }\end{array}$} \\
\hline \multicolumn{6}{|l|}{$\begin{array}{l}\text { Participo en proyectos de investigación con } \\
\text { financiamiento externo (nacional o internacional). }\end{array}$} \\
\hline \multicolumn{6}{|l|}{$\begin{array}{l}\text { Las asignaturas que dicto promueven la } \\
\text { transdisciplinariedad y la innovación. }\end{array}$} \\
\hline Utilizo un enfoque de aprendizaje basado en proyectos. & & & & & \\
\hline
\end{tabular}


III. COMENTARIOS Y SUGERENCIAS

¡Muchas gracias por su tiempo y colaboración! 


\section{ENCUESTA A EGRESADOS DE LA MAESTRÍA}

La Universidad está interesada en mejorar la calidad de enseñanza y los servicios de sus programas de postgrado. Para ello, requerimos de unos minutos de su tiempo para responder la siguiente encuesta, según su experiencia adquirida durante el programa de maestría que cursó en nuestra casa de estudios. Agradecemos sinceramente su colaboración.

\section{DATOS GENERALES}

1. Año en el que inició la maestría:

2. Año en el que terminó la maestría:

3. Describa el sector al que pertenece su empresa:
a. Minería
b. Petróleo
c. Electricidad
d. Construcción
e. Agroindustria
f. Alimentos y bebidas
g. Pesquería
h. Servicios
i. Manufactura
j. Salud
k. Educación
1. Comercio exterior
m. Acuicultura
n. Otro (especificar):

\section{Indique su área de desempeño:}
a. Mantenimiento
b. Ingeniería
c. Proyectos
d. Producción
e. Gerencia
f. Gestión y control de calidad
g. Logística y Servicios
h. Planeamiento
i. Contabilidad y costos
j. Seguridad y protección
k. Investigación y desarrollo
1. Sistemas
m. Ventas
n. Otro (especificar): 
5. Indique su especialidad:
a. Mecánica
b. Eléctrica
c. Electrónica
d. Mecánico eléctrica
e. Civil
f. Industrial
g. Industrial y de Sistemas
h. Sistemas o Informática
i. Agrícola o agronómica
j. Petrolera y petroquímica
k. Química
1. Agroindustria
m. Pesquería
n. Minas
o. Geología
p. Otro (especificar):

\section{Indique su Universidad de procedencia:}
a. Universidad de Piura (UDEP)
b. Universidad Nacional de Piura (UNP)
c. Universidad Nacional Pedro Ruiz Gallo
d. Universidad Privada Antenor Orrego (UPAO)
e. Universidad Nacional de Ingeniería (UNI)
f. Universidad César Vallejo (UCV)
g. Universidad Católica Santo Toribio de Mogrovejo (USAT)
h. Universidad Alas Peruanas
i. Pontificia Universidad Católica del Perú
j. Universidad San Martín de Porres
k. Universidad Nacional Mayor de San Marcos
1. Otro (especificar): 


\section{CONTENIDO DE LA MAESTRÍA Y SATISFACCION}

A continuación se presentan una serie de afirmaciones. Por favor indique su grado de acuerdo con cada una de ellas, utilizando la siguiente escala: 1. Muy en desacuerdo; 2. En desacuerdo; 3. Ni de acuerdo ni en desacuerdo; 4. De acuerdo; 5. Muy de acuerdo

\begin{tabular}{|c|c|c|c|c|c|}
\hline & 1 & 2 & 3 & 4 & 5 \\
\hline $\begin{array}{l}\text { Los conocimientos adquiridos en la maestría me ayudaron a un } \\
\text { mejor desempeño laboral. }\end{array}$ & & & & & \\
\hline $\begin{array}{l}\text { Los temas dictados durante la maestría se relacionaron con los } \\
\text { temas de mi trabajo o fueron de mi interés. }\end{array}$ & & & & & \\
\hline Funciona el sistema de seguimiento al desempeño de egresados & & & & & \\
\hline $\begin{array}{l}\text { La maestría ayudó a mejorar mi situación laboral (recibir un } \\
\text { aumento de salario, un ascenso u obtener un mejor empleo) }\end{array}$ & & & & & \\
\hline $\begin{array}{l}\text { Hay correspondencia entre la misión y objetivos de la maestría con } \\
\text { el contenido dictado. }\end{array}$ & & & & & \\
\hline $\begin{array}{l}\text { La maestría aprovecha las oportunidades locales y nacionales para } \\
\text { beneficio de sus estudiantes y docentes. }\end{array}$ & & & & & \\
\hline $\begin{array}{l}\text { El plan de estudios de la maestría ayuda a satisfacer necesidades } \\
\text { reales de la localidad y del país. }\end{array}$ & & & & & \\
\hline $\begin{array}{l}\text { Los proyectos de fin de máster tienen aplicación o resuelven } \\
\text { problemas en las empresas }\end{array}$ & & & & & \\
\hline $\begin{array}{l}\text { Las asignaturas promovieron la transdisciplinariedad y la } \\
\text { innovación. }\end{array}$ & & & & & \\
\hline Se utilizó un enfoque de aprendizaje basado en proyectos. & & & & & \\
\hline
\end{tabular}


IV. DATOS DEL ENCUESTADO

\begin{tabular}{|l|l|}
\hline Título de la maestría: & \\
\hline Empresa: & \\
\hline Nombres y apellidos: & \\
\hline Email: & \\
\hline Teléfono: & \\
\hline
\end{tabular}

¡Muchas gracias por su tiempo y colaboración! 


\section{ENCUESTA A EMPLEADORES DE ESTUDIANTES DE LA MAESTRÍA}

La Universidad está interesada en mejorar la calidad de sus programas de postgrado y adecuarlos a las necesidades de la práctica profesional. Para ello, requerimos de unos minutos de su tiempo para responder la siguiente encuesta y de esta forma conocer la opinión de las empresas e instituciones que emplean a nuestros egresados. Agradecemos sinceramente su colaboración.

\section{DATOS GENERALES}

1. Nombre de la empresa o institución:

2. La empresa o institución es:
a. Privada
b. Pública
c. ONG

3. El sector al que pertenece la empresa o institución es:
a. Minería
b. Petróleo
c. Electricidad
d. Construcción
e. Agroindustria
f. Alimentos y bebidas
g. Pesquería
h. Servicios
i. Manufactura
j. Salud
k. Educación
1. Comercio exterior
m. Acuicultura
n. Otro

(especificar):

4. ¿Cuántas personas trabajan en la empresa o institución?
a. De 1 a 50 trabajadores.
b. De 51 a 100 trabajadores.
c. De 101 a 500 trabajadores.
d. Más de 500 trabajadores.

5. Ciudad y País donde está ubicada la empresa:

6. Título de la maestría que siguió el egresado (o que está siguiendo el estudiante): 


\section{PERTINENCIA DE LA MAESTRÍA}

A continuación se presentan una serie de afirmaciones. Por favor indique su grado de acuerdo con cada una de ellas, utilizando la siguiente escala: 1. Muy en desacuerdo; 2. En desacuerdo; 3. Ni de acuerdo ni en desacuerdo; 4. De acuerdo; 5. Muy de acuerdo

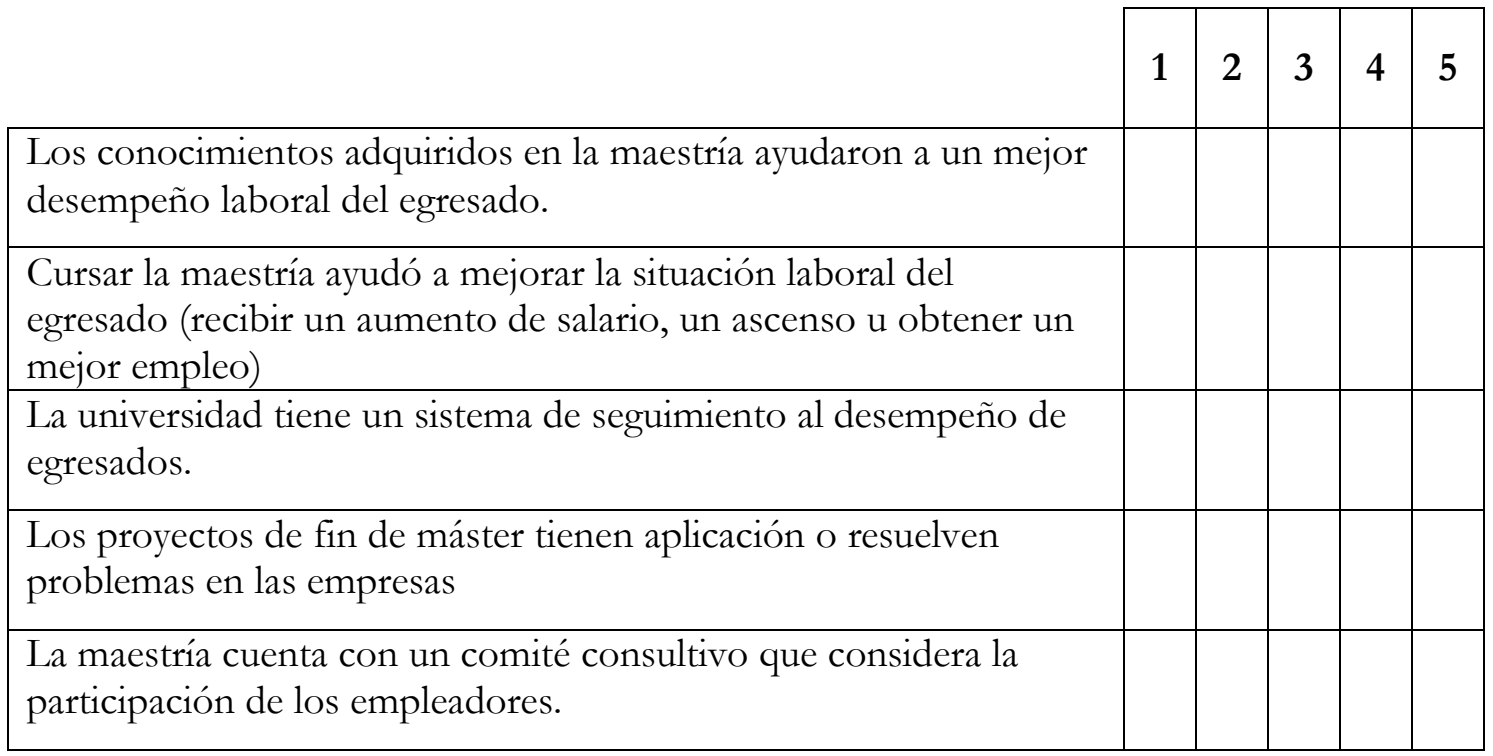

\section{DATOS DEL ENCUESTADO}

\begin{tabular}{|l|l|}
\hline Nombres y apellidos: & \\
\hline Cargo: & \\
\hline Email: & \\
\hline Teléfono: & \\
\hline
\end{tabular}

¡Muchas gracias por su tiempo y colaboración! 


\section{GUÍA DE ENTREVISTA A DIRECTIVOS DE LA MAESTRÍA}

\section{Objetivo:}

Indagar sobre el nivel de pertinencia de la maestría, de acuerdo al modelo de evaluación establecido.

\section{Entrevistado:}

Nombre:

\section{Cargo:}

\section{Fecha y Lugar:}

\section{Instrucciones:}

La guía elaborada tiene forma semiestructurada, en el sentido que se tiene un listado mínimo de preguntas para el entrevistado y el orden de éstas se puede alterar dependiendo del matiz que vaya tomando la entrevista.

\section{Guía de preguntas:}

\begin{tabular}{|c|c|c|}
\hline $\mathbf{N}^{\circ}$ & Pregunta & Check \\
\hline 1. & ¿Funciona un sistema de seguimiento al desempeño de egresados? & \\
\hline 2. & ¿Número de alumnos de la maestría? & \\
\hline 3. & ¿Ratio admitidos/postulantes? & \\
\hline 4. & $\begin{array}{l}\text { ¿La misión, objetivos y estrategias de la maestría son coherentes con la } \\
\text { misión, objetivos y estrategias de la Universidad? }\end{array}$ & \\
\hline 5. & $\begin{array}{l}\text { ¿La gestión de la maestría se desarrolla de acuerdo a las políticas y } \\
\text { procedimientos de trabajo de la Universidad? }\end{array}$ & \\
\hline 6. & $\begin{array}{l}\text { ¿Existe correspondencia entre la misión y objetivos de la maestría con el } \\
\text { plan de estudios? }\end{array}$ & \\
\hline 7. & $\begin{array}{l}\text { ¿La universidad ofrece programas de pregrado o especialización } \\
\text { relacionados con la maestría? }\end{array}$ & \\
\hline 8. & $\begin{array}{l}\text { ¿La maestría aprovecha las oportunidades locales y nacionales para } \\
\text { beneficio de sus estudiantes y docentes? }\end{array}$ & \\
\hline 9. & $\begin{array}{l}¿ \text { El plan de estudios se relaciona con las prioridades de desarrollo local o } \\
\text { nacional? }\end{array}$ & \\
\hline 10. & $\begin{array}{l}\text { ¿Los proyectos de fin de máster tienen aplicación o resuelven problemas } \\
\text { en las empresas? }\end{array}$ & \\
\hline 11. & $\begin{array}{l}\text { ¿Existen relaciones efectivas con programas similares de otras } \\
\text { universidades, empresas, agencias gubernamentales, ONG, entre otros? }\end{array}$ & \\
\hline
\end{tabular}




\begin{tabular}{|c|l|l|}
\hline $\mathbf{N}^{\circ}$ & Pregunta & Check \\
\hline 12. & $\begin{array}{l}\text { ¿La maestría cuenta con un comité consultivo integrado por } \\
\text { representantes de los principales grupos de interés? }\end{array}$ & \\
\hline 13. & $\begin{array}{l}\text { ¿Los docentes participan en redes o asociaciones científicas y } \\
\text { profesionales? }\end{array}$ & \\
\hline 14. & ¿Los docentes poseen movilidad académica? & \\
\hline 15. & $\begin{array}{l}\text { ¿La organización de la universidad facilita la investigación } \\
\text { multidisciplinaria y centrada en problemas? }\end{array}$ & \\
\hline 16. & $\begin{array}{l}\text { ¿Los docentes participan en proyectos de investigación con } \\
\text { financiamiento externo (nacional o internacional)? }\end{array}$ & \\
\hline 17. & ¿Las asignaturas promueven la transdisciplinariedad y la innovación? & \\
\hline 18. & ¿Se utiliza un enfoque de aprendizaje basado en proyectos? & \\
\hline
\end{tabular}




\section{GUÍA DE ENTREVISTA A DIRECTIVOS DE LA UNIVERSIDAD}

\section{Objetivo:}

Indagar sobre el nivel de pertinencia de la maestría, de acuerdo al modelo de evaluación establecido.

\section{Entrevistado:}

Nombre:

Cargo:

\section{Fecha y Lugar:}

\section{Instrucciones:}

La guía elaborada tiene forma semiestructurada, en el sentido que se tiene un listado mínimo de preguntas para el entrevistado y el orden de éstas se puede alterar dependiendo del matiz que vaya tomando la entrevista.

\section{Guía de preguntas:}

\begin{tabular}{|c|c|c|}
\hline $\mathbf{N}^{\circ}$ & Pregunta & Check \\
\hline 1. & ¿Funciona un sistema de seguimiento al desempeño de egresados? & \\
\hline 2. & $\begin{array}{l}\text { ¿La misión, objetivos y estrategias de la maestría son coherentes con la misión, } \\
\text { objetivos y estrategias de la Universidad? }\end{array}$ & \\
\hline 3. & $\begin{array}{l}\text { ¿La gestión de la maestría se desarrolla de acuerdo a las políticas y } \\
\text { procedimientos de trabajo de la Universidad? }\end{array}$ & \\
\hline 4. & $\begin{array}{l}\text { ¿La maestría cuenta con un comité consultivo integrado por representantes de } \\
\text { los principales grupos de interés? }\end{array}$ & \\
\hline 5. & ¿Los docentes participan en redes o asociaciones científicas y profesionales? & \\
\hline 6. & ¿Los docentes poseen movilidad académica? & \\
\hline 7. & $\begin{array}{l}\text { ¿La organización de la universidad facilita la investigación multidisciplinaria y } \\
\text { centrada en problemas? }\end{array}$ & \\
\hline 8. & $\begin{array}{l}\text { ¿Los docentes participan en proyectos de investigación con financiamiento } \\
\text { externo (nacional o internacional)? }\end{array}$ & \\
\hline
\end{tabular}


Anexo 4

Malla curricular - maestría en Ingeniería Civil con mención en Ingeniería Vial, Universidad de Piura 


\section{MALLA CURRICULAR - MAESTRÍA EN INGENIERÍA CIVIL CON MENCIÓN EN INGENIERÍA VIAL, UNIVERSIDAD DE PIURA}

\section{Primer año}

\begin{tabular}{|c|l|}
\hline Ciclo & \multicolumn{1}{|c|}{ Asignatura } \\
\hline $2014-$ I & $\begin{array}{l}\text { Análisis Económico de proyectos de Inversión } \\
\text { Planificación y Gestión de la Infraestructura } \\
\text { Persona, familia y empresa }\end{array}$ \\
\hline $2014-$ II & $\begin{array}{l}\text { Impacto Ambiental del Transporte } \\
\text { Manejo del Sistema de Información Geográfica } \\
\text { Planeamiento del Transporte y sistemas Inteligentes TPTE }\end{array}$ \\
\hline
\end{tabular}

\section{Segundo año}

\begin{tabular}{|c|l|}
\hline \multicolumn{1}{|c|}{ Ciclo } & \multicolumn{1}{c|}{ Asignatura } \\
\hline $2015-$ I & $\begin{array}{l}\text { Confiabilidad y Análisis de riesgo } \\
\text { Fenómeno El Niño, Hidrología e Hidráulica } \\
\text { Geotecnia Vial }\end{array}$ \\
\hline $2015-$ II & $\begin{array}{l}\text { Ingeniería de tránsito y Seguridad Vial } \\
\text { Tecnología de pavimentos } \\
\end{array}$ \\
& Tecnología de la construcción de carreteras \\
\hline
\end{tabular}

